\title{
Supporting Information for \\ Targeted Delivery of mRNA with One-Component Ionizable Amphiphilic Janus Dendrimers
}

Dapeng Zhang, ${ }^{\dagger, \S}$ Elena N. Atochina-Vasserman,,${ }^{\ddagger}$ D Devendra S. Maurya, ${ }^{\dagger}$ Matthew Liu, ${ }^{\dagger}$ Qi Xiao, ${ }^{\dagger}$ Juncheng Lu, ${ }^{\dagger}$ George Lauri, ${ }^{\dagger}$ Nathan Ona, ${ }^{\ddagger}$ Erin K. Reagan,${ }^{\ddagger}$ Houping Ni, ${ }^{\ddagger}$ Drew Weissman,,$* *$ and Virgil Percec $^{\dagger, *}$

$\dagger$ Roy \& Diana Vagelos Laboratories, Department of Chemistry, University of Pennsylvania, Philadelphia, Pennsylvania 19104-6323, United States

*Department of Medicine, Perelman School of Medicine, University of Pennsylvania, Philadelphia, Pennsylvania 19104, United States

*E-mail: dreww@pennmedicine.upenn.edu; percec@sas.upenn.edu 


\section{Table of Contents}

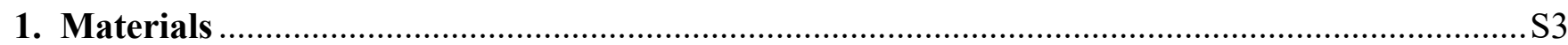

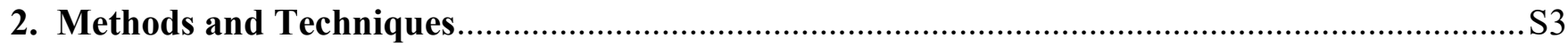

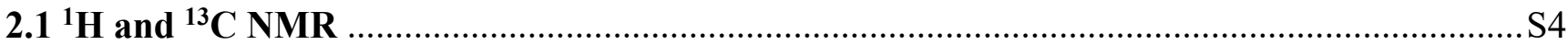

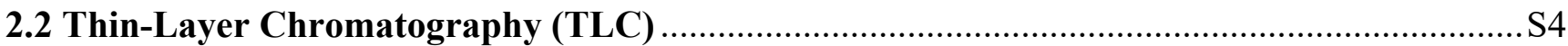

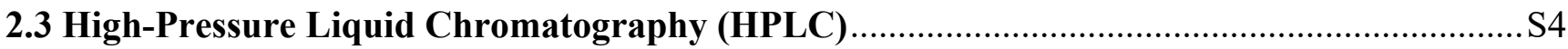

2.4 Matrix Assisted Laser Desorption Ionization-Time of Flight (MALDI-TOF) Mass

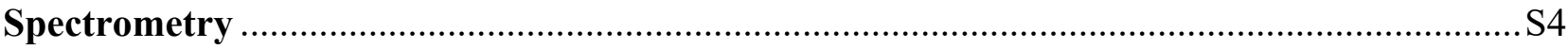

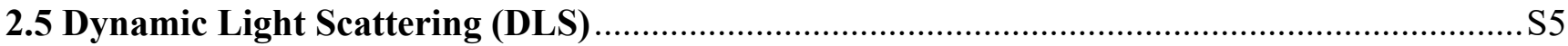

$2.6 \mathrm{pK}_{\mathbf{a}}$ Measurements of Individual IAJD Molecules .........................................................S5

2.7 Formulation of DNPs Obtained by Co-assembly of IAJDs and Luc-mRNA .........................S5

2.8 Luminescence Characterization for In Vitro Transfection Experiments ..............................S5

2.9 Luminescence Characterization for In Vivo Transfection Experiments ..............................S5

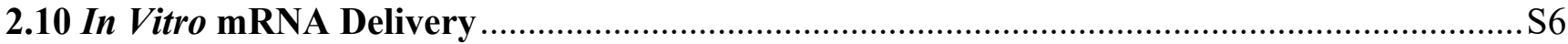

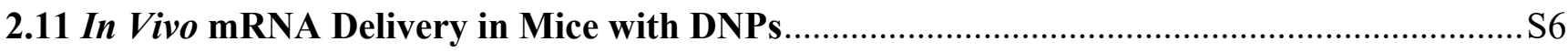

3. Design Principles of the Targeted Delivery of mRNA with One-Component IAJDs ................S7

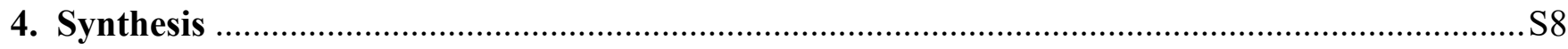

4.1 General Synthesis of IAJDs with Ester Bonds in Hydrophobic Alkyl Chains .......................S8

4.2 Synthesis of Hydrophobic Building Blocks of IAJDs ...................................................

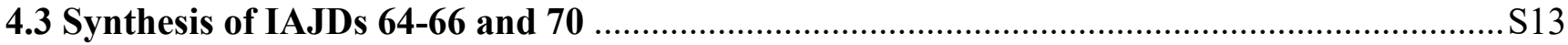

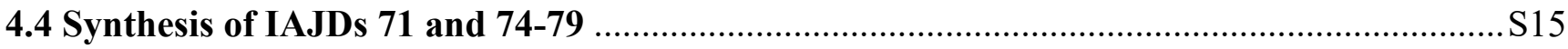

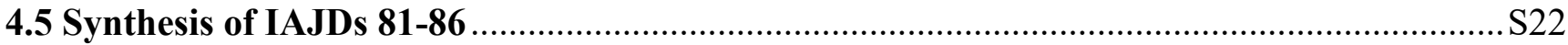

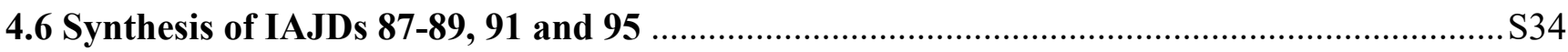

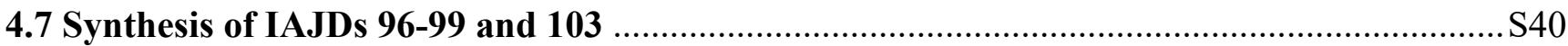

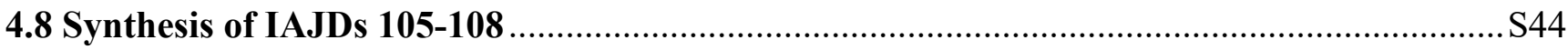

5. Dimensions of DNPs and Luminescence Expression In Vitro ...............................................S54

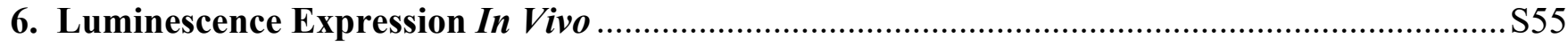

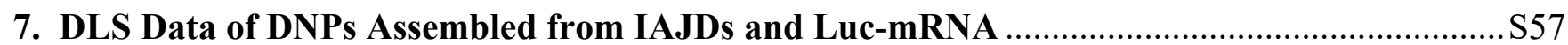

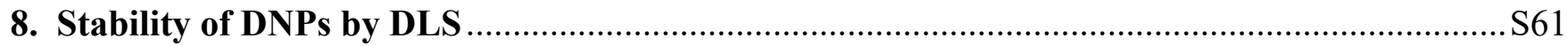

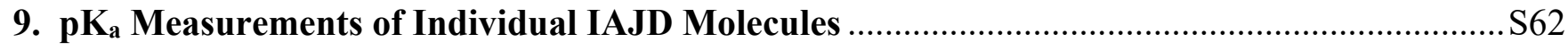

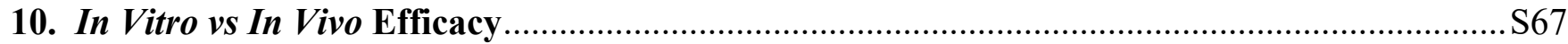

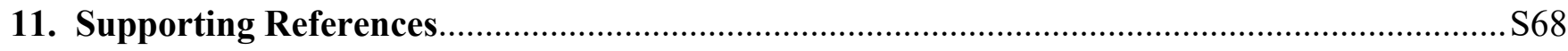




\section{Materials}

3,5-Dihydroxybenzoic acid (Acros, 97\%), 3,4-dihydroxybenzoic acid (Acros, 97\%), 3,4,5trihydroxybenzoic acid (gallic acid, Chem Impex, anhydrous, ACS grade), 1-bromooctane (Aldrich, 99\%), 1-bromononane (Lancaster, 99\%), 1-bromodecane (Acros, 98\%), 1-bromoundecane (Aldrich, 99\%), 1bromododecane (Alfa Aesar, 99\%), 1-bromotetradecane (Acros, 98\%), 1-bromohexadecane (TCI, 96\%), 1-bromooctadecane (Acros, 96\%), (rac)-3-(bromomethyl)heptane (2-ethylhexyl bromide, Aldrich, 95\%), ( rac)-1-bromo-3,7-dimethyloctane (TCI, 93+\%), $\mathrm{LiAlH}_{4}$ (TCI, 95\%), palladium on activated carbon catalyst (Spectrum, $10 \mathrm{wt} \%$ loading), pentaerythritol (Aldrich, 98\%), 4-(dimethylamino)butyric acid hydrochloride (Alfa Aesar, 98\%), 3-bromopropanoic acid (Aldrich, 97\%), 4-bromobutyric acid (Acros, 98\%), 5-bromovaleric acid (Aldrich, 97\%), 1-methylpiperazine (Alfa Aesar, 98\%), 1-(2hydroxyethyl)piperazine (Acros, 99\%), thionyl chloride (Alfa Aesar, 99+\%), triethylamine (TCI, 99\%), other reagents and solvents for chemical synthesis were obtained from commercial sources and were used as received. 4-(Dimethylamino)pyridinium 4-toluenesulfonate (DPTS) was prepared according to a literature procedure. ${ }^{1} \mathrm{CH}_{2} \mathrm{Cl}_{2}$ (DCM) was dried over $\mathrm{CaH}_{2}$ and freshly distilled before use. Acetate buffer $(10 \mathrm{mM})$ was prepared with the following composition: sodium acetate $(0.0023 \mathrm{M})$ and acetic acid $(0.0077$ $\mathrm{M}$ ) in ultra-pure water. Final $\mathrm{pH}$ was adjusted with $0.1 \mathrm{M} \mathrm{NaOH}$ or $0.1 \mathrm{M} \mathrm{HCl}$ solution. Nucleosidemodified mRNA encoding firefly luciferase (Luc-mRNA) was produced as previously described. ${ }^{2}$ Human embryonic kidney (HEK) 293T cells (American Type Culture Collection) were cultured in Dulbecco's modified Eagle's medium (DMEM) supplemented with 10\% inactivated fetal bovine serum (FBS) (Gemini Bio-Products), $2 \mathrm{mM} \mathrm{L-glutamine} \mathrm{and} 100 \mathrm{U} / \mathrm{mL}$ penicillin/streptomycin (Life Technologies). OptiMEM (Gibco), DPBS (Corning), UltraPure DNase/RNase-Free Distilled Water (Invitrogen), Trypan Blue (Sigma-Aldrich), Trypsin-EDTA (0.25\%), (Gibco), Cell Culture Lysis 5X Reagent (Promega), Luciferase Assay System (Promega) and D-luciferin sodium salt (Regis Technologies) were used as received.

\section{Methods and Techniques}

The purity and structural identity of intermediate compounds and final products and was determined by a combination of techniques including thin-layer chromatography (TLC), ${ }^{1} \mathrm{H}$ and ${ }^{13} \mathrm{C} \mathrm{NMR}$, high-pressure liquid chromatography (HPLC), and matrix assisted laser desorption ionization-time of flight (MALDITOF) mass spectrometry. 
2.1 ${ }^{1} \mathrm{H}$ and ${ }^{13} \mathrm{C}$ NMR. ${ }^{1} \mathrm{H}$ and ${ }^{13} \mathrm{C}$ NMR spectra were recorded at $400 \mathrm{MHz}$ and $101 \mathrm{MHz}$, on a Bruker NEO (400 MHz) NMR spectrometer with autosampler, and $500 \mathrm{MHz}$ and $126 \mathrm{MHz}$ respectively, on a Bruker DRX (500 MHz) NMR spectrometer. All NMR spectra were measured at $23{ }^{\circ} \mathrm{C}$ in $\mathrm{CDCl}_{3}$ or $\mathrm{d}_{6}$ acetone. Chemical shifts $(\delta)$ are reported in ppm. The resonance multiplicities in the ${ }^{1} \mathrm{H}$ NMR spectra are described as "s" (singlet), "d" (doublet), "t" (triplet), "m" (multiplet) and "br" (broad resonance). Residual protic solvent of $\mathrm{CDCl}_{3}\left({ }^{1} \mathrm{H}, \delta 7.26 \mathrm{ppm} ;{ }^{13} \mathrm{C}, \delta 77.16 \mathrm{ppm}\right), \mathrm{d}_{6}$-acetone $\left({ }^{1} \mathrm{H}, \delta 2.05 \mathrm{ppm} ;{ }^{13} \mathrm{C}, \delta 29.84\right.$ ppm), and tetramethylsilane (TMS, $\delta 0 \mathrm{ppm}$ ) were used as the internal reference in the ${ }^{1} \mathrm{H}$ and ${ }^{13} \mathrm{C}$ NMR spectra. The absorptions are given in wavenumbers $\left(\mathrm{cm}^{-1}\right)$. NMR spectra were analyzed and exported by MNova 14 or TopSpin 4.07 (Bruker).

2.2 Thin-Layer Chromatography (TLC). Evolution of the reaction was monitored by TLC using silica gel $60 \mathrm{~F}_{254}$ precoated plates (E. Merck) and individual compounds were visualized by UV light with a wavelength of $254 \mathrm{~nm}$ or by staining of the TLC plate with iodine vapor. Purification by flash column chromatography was performed using flash silica gel from Silicycle (60,, $40-63 \mu \mathrm{m})$ with the indicated eluent.

2.3 High-Pressure Liquid Chromatography (HPLC). The determination of the purity of molecules by high-pressure liquid chromatography (HPLC) was carried out using Shimadzu LC-20AD highperformance liquid chromatograph pump, a PE Nelson Analytical 900 Series integration data station, a Shimadzu SPD-10A VP (UV-vis, $\lambda=254 \mathrm{~nm}$ ) and three AM gel columns (a guard column, two $500 \AA$, $10 \mu \mathrm{m}$ columns). THF with $5 \%$ of $\mathrm{NEt}_{3}$ was used as solvent at the oven temperature of $23{ }^{\circ} \mathrm{C}$. Detection was done by UV absorbance at $254 \mathrm{~nm}$ or RI (refractive index) detector.

\subsection{Matrix Assisted Laser Desorption Ionization-Time of Flight (MALDI-TOF) Mass Spectrometry.}

The molar mass of molecules was determined by MALDI-TOF mass spectrometry on a PerSeptive Biosystem-Voyager-DE (Framingham, MA) mass spectrometer equipped with nitrogen laser (337 nm) and operating in linear mode. Internal calibration was performed with Angiotensin II and Bombesin as standards. The sample solution for analysis was prepared by dissolving the sample in THF $(5-10 \mathrm{mg} / \mathrm{mL})$, which was mixed with the THF solution of the matrix (2,5-dihydroxybenzoic acid, $10 \mathrm{mg} / \mathrm{mL}$ ) with a $1 / 5$ $(\mathrm{v} / \mathrm{v})$ ratio. Afterwards, the sample solution (c.a. $0.5 \mu \mathrm{L}$ ) was loaded on the MALDI plate and dried at 23 ${ }^{\circ} \mathrm{C}$. Then the plate was inserted into the vacuum chamber of the instrument. The laser intensity and voltages 
applied for the analysis were adjusted depending on the molar mass and nature of each analyzed compound.

2.5 Dynamic Light Scattering (DLS). DLS for the sizes and polydispersities of DNPs was performed on a Malvern Instruments particle sizer (Zetasizer Nano S, Malvern Instruments, UK) equipped with $4 \mathrm{~mW}$ $\mathrm{He}-\mathrm{Ne}$ laser $633 \mathrm{~nm}$ and avalanche photodiode positioned at $175^{\circ}$ to the beam and temperature-controlled cuvette holder. Instrument parameters were determined automatically along with measurement times. Sample solution $(0.4 \mathrm{~mL})$ was placed in a semi-micro cuvette $(1.6 \mathrm{~mL}$, polystyrene, $10 \times 10 \times 45 \mathrm{~mm}$, manufactured by Greiner Bio-One) and the measurements were performed at $23{ }^{\circ} \mathrm{C}$.

2.6 $\mathrm{pK}_{\mathbf{a}}$ Measurements of Individual IAJD Molecules. IAJD Molecules were first dissolved in ethanol (Sat. with $\mathrm{NaCl}$ ) at a concentration of $1.5 \mathrm{mg} / \mathrm{mL}$ and the solution volume was $3 \mathrm{~mL}$. Then $0.1 \mathrm{M} \mathrm{HCl}$ aqueous solution was added to the above ethanol solution in increments of $7.5 \mu \mathrm{L}$, with the resulting $\mathrm{pH}$ measured using an Thermo Scientific Orion Star A121 meter with Thermo Scientific Orion 8220BNWP $\mathrm{pH}$ probe. $\mathrm{pK}_{\mathrm{a}}$ was calculated using the half equivalence point titration.

2.7 Formulation of DNPs Obtained by Co-assembly of IAJDs and Luc-mRNA. IAJDs were dissolved in ethanol with an initial concentration of $80 \mathrm{mg} / \mathrm{mL}$. Nucleoside-modified mRNA encoding firefly luciferase (Luc-mRNA) was dissolved in UltraPure DNase/RNase-free distilled water with an initial concentration of $4.0 \mathrm{mg} / \mathrm{mL}$. $12.5 \mu \mathrm{L}$ of Luc-mRNA solution was placed into a clean RNAs free eppendorf (1.5 mL) and $463 \mu \mathrm{L}$ acetate buffer (10 mM, pH 4.0) was added. Then, $25 \mu \mathrm{L}$ of IAJD in the ethanol stock solution was rapidly injected into the Luc-mRNA solution in acetate buffer followed by vortex for 5 seconds.

2.8 Luminescence Characterization for In Vitro Transfection Experiments. The determination of luminescence intensity for in vitro Luc-mRNA transfection experiments was performed using a MiniLumat LB 9506 luminometer (Berthold/EG\&G; Wallac).

2.9 Luminescence Characterization for In Vivo Transfection Experiments. Bioluminescence imaging was performed with an IVIS Spectrum imaging system (PerkinElmer, Waltham, MA). Mice were anesthetized with 3\% of isoflurane (Piramal Healthcare Limited) and intraperitoneally (i.p.) administered 
with D-luciferin (Regis Technologies) at a dose of $150 \mathrm{mg} / \mathrm{kg}$ of body weight. Ten minutes post administration of D-luciferin, mice were placed on the imaging platform while being maintained on isoflurane via a nose cone and imaged using an exposure time of 60 seconds. Bioluminescence values were quantified by measuring photon flux (photons/second, $\mathrm{p} / \mathrm{s}$ ) in the region of interest (ROI) on mice where bioluminescence signal emanated using the Living Image Software (PerkinElmer). To quantify luminescent flux, an oval ROI was placed over each organ of interest and analyzed.

2.10 In Vitro mRNA Delivery. For in vitro Luc-mRNA transfection screening experiments, human embryonic kidney $293 \mathrm{~T}$ cells (HEK 293T) were seeded into 96-well plates (20,000 cells/well/200 $\mu \mathrm{L})$ and cultured for $18-20$ hours at $37{ }^{\circ} \mathrm{C}, 5 \% \mathrm{CO}_{2}$ in complete Dulbecco's modified Eagle's medium (DMEM) supplemented with $2 \mathrm{mM}$ L-glutamine (Life Technologies), $100 \mathrm{U} / \mathrm{mL}$ penicillin/streptomycin (Invitrogen) and 10\% fetal bovine serum (FBS, Gemini Bio-Products). Cells were transfected with DNPs with encapsulated naked nucleoside-modified mRNA encoding firefly luciferase (Luc-mRNA) at constant concentration of Luc-mRNA, 125 ng per well. Luc-mRNA complexed with TransIT (TransIT®)-mRNA Transfection Kit, Mirus Bio) or encapsulated in FDA approved MC3-based LNPs were used as positive controls for cell transfection, at the concentration of Luc-mRNA of $125 \mathrm{ng}$ per well, the same as for tested DNPs. After transfection cells were further cultured at $37^{\circ} \mathrm{C}, 5 \% \mathrm{CO}_{2}$ for $18-20$ hours, then medium was aspirated and cells were lysed with luciferase cell culture lysis reagent (30 $\mu \mathrm{L} /$ well) (Promega, Madison, WI). For the determination of the luciferase enzymatic activity as luminescence, $2.5 \mu \mathrm{L}$ of the lysed cells was mixed with $10 \mu \mathrm{L}$ of firefly luciferase assay substrate ((Luciferase assay system, Promega) and luminescence was analyzed by MiniLumat LB9506 luminometer. Transfections were performed in triplicate.

2.11 In Vivo mRNA Delivery in Mice with DNPs. All animals used were in accordance with the guidelines and approval from the Pennsylvania University Institution of Animal Care and Use Committee. Female or male BALB/c mice (6-8 weeks old, from Charles River Laboratories) were anesthetized with isoflurane (Piramal Healthcare Limited) and injected via retro-orbital sinus with $100 \mu \mathrm{L}$ of buffer solution containing DNPs with encapsulated $10 \mu \mathrm{g}$ of Luc-mRNA. At 4-7 hours post injection, mice were i.p. injected with D-Luciferin (150 mg/kg of body weight, Regis Technologies) and imaged on a PerkinElmer IVIS Spectrum CT system (PerkinElmer, Waltham, MA). Tissue luminescence signal was measured on the IVIS imaging system using an exposure time of 60 seconds using medium binning (binning $=8$ ) to 
ensure that the signal obtained was within operative detection range. For IVIS imaging of the organs, mice were sacrificed and heart, lungs, liver, and spleen were immediately collected, and bioluminescence imaging was performed as described above. Image analysis was conducted with the Living Image software (PerkinElmer). Bioluminescence values were quantified by measuring photon flux (photons/s) in the region of interest using Living Image software.

\section{Design Principles of the Targeted Delivery of mRNA with One-Component IAJDs}

a Four-Component Ionizable Lipid Nanoparticle (LNP)
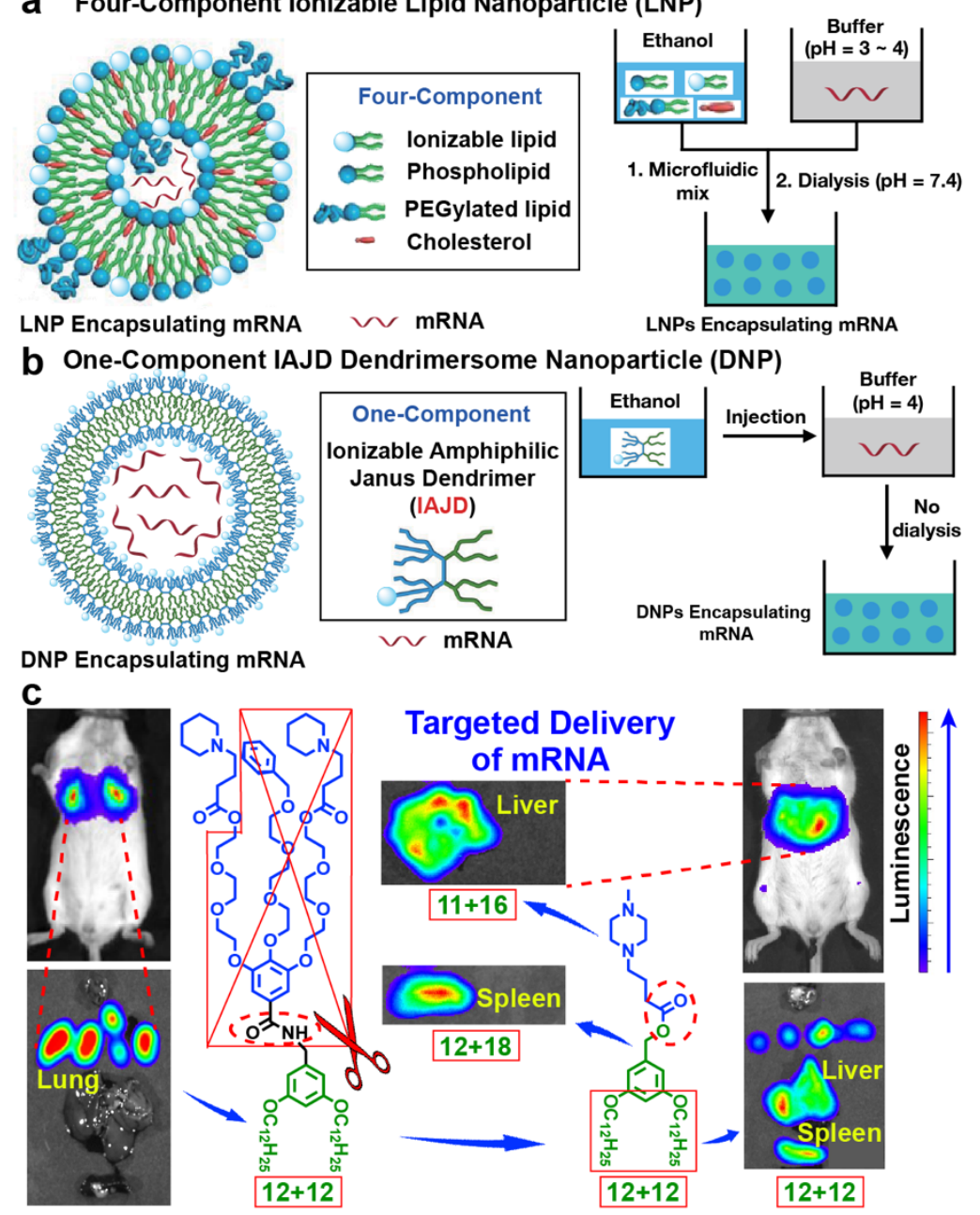

Figure S1. Schematic representation of (a) four-component LNPs for mRNA delivery; ${ }^{6}$ (b) onecomponent DNPs for mRNA delivery; ${ }^{6}$ (c) targeted delivery of mRNA to lungs with amide-linked IAJD and to spleen and liver with ester-linked IAJDs containing different carbon numbers in the hydrophobic alkyl chains. Adapted in part with permission from Ref 6 in SI. Copyright 2021 American Chemical Society. 


\section{Synthesis}

\subsection{General Synthesis of IAJDs with Ester Bonds in Hydrophobic Alkyl Chains}

Scheme S1. Accelerated Synthesis of IAJDs with Ester Bonds in Hydrophobic Alkyl Chains

General Synthesis of IAJDs Containing Alkyl Chains with Ester Bonds: 7 steps
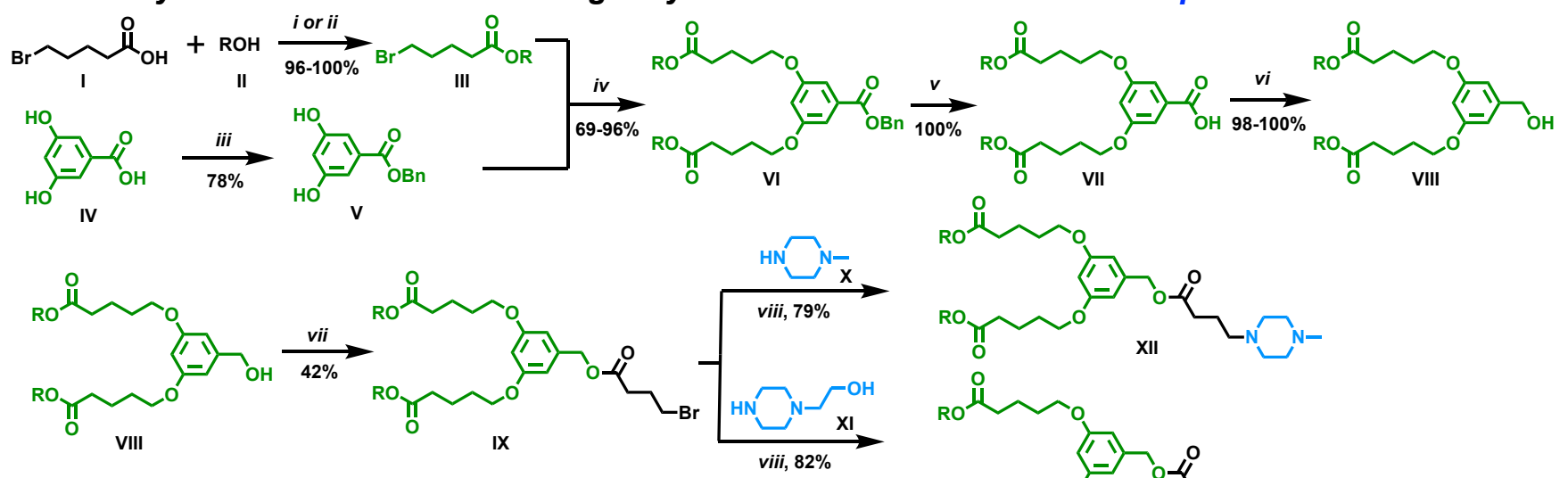

$R=C_{n} H_{2 n+1}$

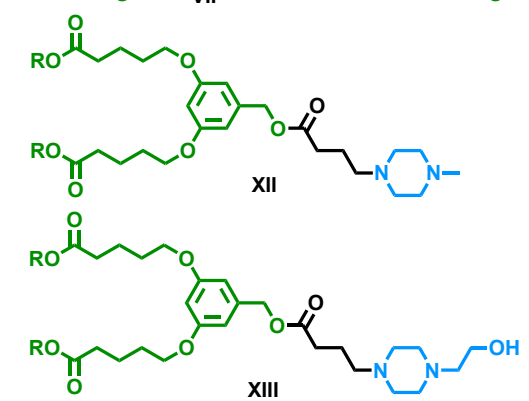

Reagents and Conditions: (i) $\mathrm{SOCl}_{2}$, DMF (cat.), DCM, $23{ }^{\circ} \mathrm{C}, 1 \mathrm{~h}$, then DMAP, $\mathrm{NEt}_{3}, \mathrm{DCM}, 0-23{ }^{\circ} \mathrm{C}$, $2 \mathrm{~h}$; (ii) DCC, DPTS, DCM, $23{ }^{\circ} \mathrm{C}, 12 \mathrm{~h}$; (iii) BnCl, NaHCO $3, \mathrm{DMF}, 40{ }^{\circ} \mathrm{C}, 12 \mathrm{~h}$; (iv) $\mathrm{K}_{2} \mathrm{CO}_{3}, \mathrm{DMF}, 80$ ${ }^{\circ} \mathrm{C}, 5 \mathrm{~h}$; (v) $\mathrm{H}_{2}, \mathrm{Pd} / \mathrm{C}, \mathrm{DCM}, \mathrm{MeOH}, 12 \mathrm{~h}$; (vi) $\mathrm{NaBH}_{4}, \mathrm{I}_{2}$, THF, 0-23 ${ }^{\circ} \mathrm{C}, 2 \mathrm{~h}$; (vii) 4-Bromobutyric acid, $\mathrm{SOCl}_{2}$, DMF (cat.), DCM, $23{ }^{\circ} \mathrm{C}, 1 \mathrm{~h}$, then DMAP, NEt 3 , DCM, 0-23 ${ }^{\circ} \mathrm{C}, 2 \mathrm{~h}$; (viii) $\mathrm{K}_{2} \mathrm{CO}_{3}, \mathrm{MeCN}, 95$ ${ }^{\circ} \mathrm{C}, 3 \mathrm{~h}$. 


\subsection{Synthesis of Hydrophobic Building Blocks of IAJDs}

\section{Scheme S2. Synthesis of Hydrophobic Benzyl Alcohols}
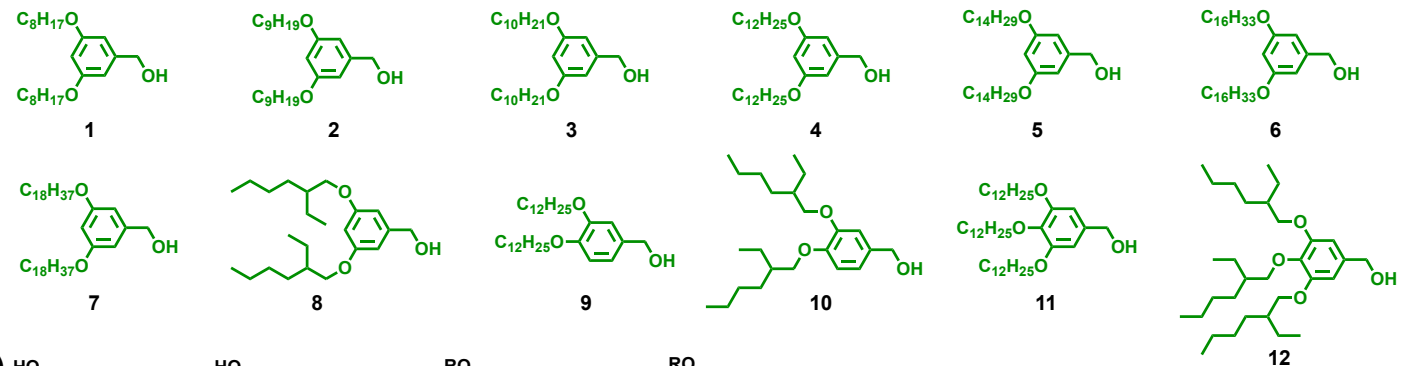

(a) HO

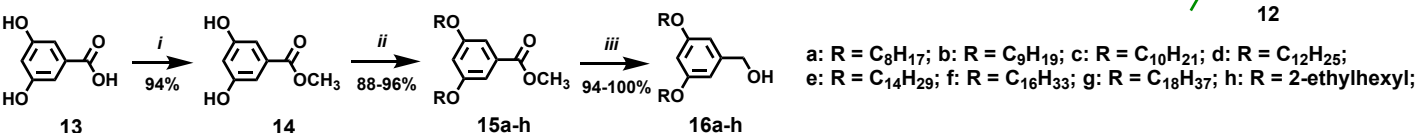

(b) $\mathrm{HO}$

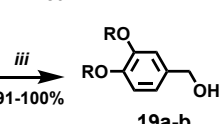

a: $\mathrm{R}=\mathrm{C}_{12} \mathrm{H}_{25} ; \mathrm{b}: \mathrm{R}=$ 2-ethylhexyl;

(c)

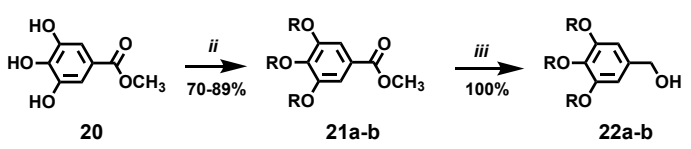

a: $\mathrm{R}=\mathrm{C}_{12} \mathrm{H}_{25} ;$ b: $\mathrm{R}=2$-ethylhexyl;

Reagents and conditions: (i) $\mathrm{H}_{2} \mathrm{SO}_{4}$ (cat.), $\mathrm{MeOH}$, reflux, $2 \mathrm{~h}$; (ii) $\mathrm{RBr}, \mathrm{K}_{2} \mathrm{CO}_{3}$, DMF, $120{ }^{\circ} \mathrm{C}, 2 \mathrm{~h}$; (iii) $\mathrm{LiAlH}_{4}, \mathrm{THF}, 0-23{ }^{\circ} \mathrm{C}, 1 \mathrm{~h}$.

General Synthetic Procedure for Compounds 15a-h, 18a-b, and 21a-b. Compounds 15a-h, 18a-b, and 21a-b were synthesized according to a procedure elaborated and optimized by our laboratory. ${ }^{3}$ Generally, compound 14/17/20 ( 1 equiv) and $\mathrm{K}_{2} \mathrm{CO}_{3}$ (3 equiv for compound 14/17, 4.5 equiv for compound 20) were stirred in dry DMF. $\operatorname{RBr}$ (2.2 equiv for compound 14/17, 3.3 equiv for compound 20) was added, and the mixture was stirred at $120{ }^{\circ} \mathrm{C}$ under $\mathrm{N}_{2}$ atmosphere for $2 \mathrm{~h}$. The reaction mixture was cooled to $23{ }^{\circ} \mathrm{C}$. For compounds 15a-g, 18a and 21a, the reaction mixture was poured into ice/water and the white precipitates were filtered and collected. Then the precipitates were purified by recrystallization from acetone to give the title compound as a white solid. For compounds $15 \mathbf{h}, \mathbf{1 8 b}$ and $\mathbf{2 1 b}$, water was added to the reaction mixture, which was then extracted by DCM for three times. The organic phase was collected and dried over anhydrous $\mathrm{MgSO}_{4}$ and filtered. The filtrate was concentrated and further purified by column chromatography on silica gel with a mobile phase of hexane/EtOAc $=20 / 1(\mathrm{v} / \mathrm{v})$ to afford the title compound as a light-yellow oil. 
General Synthetic Procedure for Compounds 16a-h (1-8), 19a-b (9,10), and 22a-b (11,12). Compounds 16a-h, 19a-b, and 22a-b were synthesized according to a procedure reported by our group. ${ }^{4}$ Generally, compounds 15a-h, 18a-b, and 21a-b (1 equiv) were dissolved in dry THF, which was added dropwise to a slurry of $\mathrm{LiAlH}_{4}$ (1.2 equiv) in dry THF at $0{ }^{\circ} \mathrm{C}$ under $\mathrm{N}_{2}$ atmosphere. The resulted mixture was stirred at $23{ }^{\circ} \mathrm{C}$ for $1 \mathrm{~h}$. The reaction was quenched by the successive addition of water, $15 \% \mathrm{NaOH}$ aqueous solution and water. Then the mixture was filtered and dried over anhydrous $\mathrm{MgSO}_{4}$. Filtration and evaporation of the solvent yielded the title compound as a white solid or light-yellow oil. The synthesis and characterizations of compounds 16d (4), 19a (9) and 22a (11) were reported in the literature. ${ }^{5}$

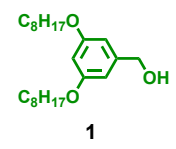

(3,5-Bis(octyloxy)phenyl)methanol (1). From compound 15a (4.50 g, $11.46 \mathrm{mmol})$ and $\mathrm{LiAlH}_{4}(0.52 \mathrm{~g}$, $13.75 \mathrm{mmol})$, compound 1 was obtained as a colorless oil $(4.10 \mathrm{~g}, 98 \%) .{ }^{1} \mathrm{H} \mathrm{NMR}\left(500 \mathrm{MHz}, \mathrm{CDCl}_{3}\right) \delta$ $6.50(\mathrm{~d}, 2 \mathrm{H}, \mathrm{PhH}), 6.38(\mathrm{t}, 1 \mathrm{H}, \mathrm{PhH}), 4.62\left(\mathrm{~d}, 2 \mathrm{H},-\mathrm{CH}_{2} \mathrm{Ph}\right), 3.93\left(\mathrm{t}, 4 \mathrm{H}, 2 \times \mathrm{PhOCH}_{2^{-}}\right), 1.76(\mathrm{~m}, 4 \mathrm{H}$, $\left.2 \times-\mathrm{OCH}_{2} \mathrm{CH}_{2} \mathrm{CH}_{2}\left(\mathrm{CH}_{2}\right)_{4} \mathrm{CH}_{3}\right), 1.44\left(\mathrm{~m}, 4 \mathrm{H}, 2 \times-\mathrm{OCH}_{2} \mathrm{CH}_{2} \mathrm{CH}_{2}\left(\mathrm{CH}_{2}\right)_{4} \mathrm{CH}_{3}\right), 1.29$ (br, $16 \mathrm{H}, 2 \times-$ $\left.\mathrm{OCH}_{2} \mathrm{CH}_{2} \mathrm{CH}_{2}\left(\mathrm{CH}_{2}\right)_{4} \mathrm{CH}_{3}\right), 0.89$ (t, $\left.6 \mathrm{H}, 2 \times-\mathrm{OCH}_{2} \mathrm{CH}_{2} \mathrm{CH}_{2}\left(\mathrm{CH}_{2}\right)_{4} \mathrm{CH}_{3}\right) .{ }^{13} \mathrm{C} \mathrm{NMR}\left(126 \mathrm{MHz}, \mathrm{CDCl}_{3}\right) \delta$ $160.6,143.4,105.2,100.6,68.2,65.4,32.0,29.5,29.5,29.4,29.4,29.3,26.1,22.8,14.2$.

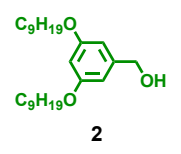

(3,5-Bis(nonyloxy)phenyl)methanol (2). From compound 15b (1.16 g, $2.75 \mathrm{mmol})$ and $\mathrm{LiAlH}_{4}(0.13 \mathrm{~g}$, $3.30 \mathrm{mmol})$, compound 2 was obtained as a colorless oil $(1.08 \mathrm{~g}, 100 \%)$. ${ }^{1} \mathrm{H} \mathrm{NMR}\left(400 \mathrm{MHz}, \mathrm{CDCl}_{3}\right) \delta$ $6.49(\mathrm{~d}, 2 \mathrm{H}, \mathrm{PhH}), 6.37$ (t, $1 \mathrm{H}, \mathrm{PhH}), 4.60$ (s, $\left.2 \mathrm{H},-\mathrm{CH}_{2} \mathrm{Ph}\right), 3.93$ (t, $\left.4 \mathrm{H}, 2 \times \mathrm{PhOCH}_{2}-\right), 1.76(\mathrm{~m}, 4 \mathrm{H}, 2 \times-$ $\left.\mathrm{OCH}_{2} \mathrm{CH}_{2} \mathrm{CH}_{2}\left(\mathrm{CH}_{2}\right)_{5} \mathrm{CH}_{3}\right), \quad 1.44\left(\mathrm{~m}, 4 \mathrm{H}, 2 \times-\mathrm{OCH}_{2} \mathrm{CH}_{2} \mathrm{CH}_{2}\left(\mathrm{CH}_{2}\right)_{5} \mathrm{CH}_{3}\right), 1.28$ (br, $20 \mathrm{H}, 2 \times-$ $\left.\mathrm{OCH}_{2} \mathrm{CH}_{2} \mathrm{CH}_{2}\left(\mathrm{CH}_{2}\right)_{5} \mathrm{CH}_{3}\right), 0.89$ (t, $\left.6 \mathrm{H}, 2 \times-\mathrm{OCH}_{2} \mathrm{CH}_{2} \mathrm{CH}_{2}\left(\mathrm{CH}_{2}\right)_{5} \mathrm{CH}_{3}\right) .{ }^{13} \mathrm{C} \mathrm{NMR}\left(101 \mathrm{MHz}, \mathrm{CDCl}_{3}\right) \delta$ $160.7,143.4,105.2,100.7,68.2,65.5,32.0,29.7,29.5,29.4,26.2,22.8,14.2$.

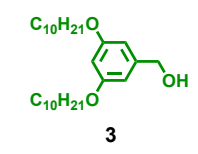

(3,5-bis(decyloxy)phenyl)methanol (3). From compound 15c (3.40 g, $8.08 \mathrm{mmol})$ and $\mathrm{LiAlH}_{4}(0.37 \mathrm{~g}$, $9.70 \mathrm{mmol})$, compound 3 was obtained as a white solid $(3.21 \mathrm{~g}, 94 \%) .{ }^{1} \mathrm{H} \mathrm{NMR}\left(500 \mathrm{MHz}, \mathrm{CDCl}_{3}\right) \delta 6.50$ (d, $2 \mathrm{H}, \mathrm{PhH}), 6.38$ (t, $1 \mathrm{H}, \mathrm{PhH}), 4.62\left(\mathrm{~d}, 2 \mathrm{H},-\mathrm{CH}_{2} \mathrm{Ph}\right), 3.93$ (t, $\left.4 \mathrm{H}, 2 \times \mathrm{PhOCH}_{2}-\right), 1.76(\mathrm{~m}, 4 \mathrm{H}, 2 \times-$ $\left.\mathrm{OCH}_{2} \mathrm{CH}_{2} \mathrm{CH}_{2}\left(\mathrm{CH}_{2}\right)_{6} \mathrm{CH}_{3}\right), \quad 1.44\left(\mathrm{~m}, 4 \mathrm{H}, 2 \times-\mathrm{OCH}_{2} \mathrm{CH}_{2} \mathrm{CH}_{2}\left(\mathrm{CH}_{2}\right)_{6} \mathrm{CH}_{3}\right), \quad 1.27$ (br, $24 \mathrm{H}, 2 \times-$ 
$\left.\mathrm{OCH}_{2} \mathrm{CH}_{2} \mathrm{CH}_{2}\left(\mathrm{CH}_{2}\right)_{6} \mathrm{CH}_{3}\right), 0.88\left(\mathrm{t}, 6 \mathrm{H}, 2 \times-\mathrm{OCH}_{2} \mathrm{CH}_{2} \mathrm{CH}_{2}\left(\mathrm{CH}_{2}\right)_{6} \mathrm{CH}_{3}\right) .{ }^{13} \mathrm{C} \mathrm{NMR}\left(126 \mathrm{MHz}, \mathrm{CDCl}_{3}\right) \delta$ 160.6, 143.3, 105.2, 100.7, 68.2, 65.5, 32.0, 29.7, 29.7, 29.5, 29.5, 29.4, 26.2, 22.8, 14.2. Mp (melting point $)=34^{\circ} \mathrm{C}$.

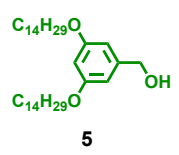

(3,5-Bis(tetradecyloxy)phenyl)methanol (5). From compound 15e (0.50 g, $0.89 \mathrm{mmol})$ and $\mathrm{LiAlH}_{4}(51$ $\mathrm{mg}, 1.34 \mathrm{mmol})$, compound 5 was obtained as a white solid $(0.48 \mathrm{~g}, 100 \%) .{ }^{1} \mathrm{H}$ NMR (400 $\left.\mathrm{MHz}, \mathrm{CDCl}_{3}\right)$ $\delta 6.50(\mathrm{~s}, 2 \mathrm{H}, \mathrm{PhH}), 6.38(\mathrm{~s}, 1 \mathrm{H}, \mathrm{PhH}), 4.62$ (s, $\left.2 \mathrm{H}, \mathrm{PhCH} \mathrm{H}_{2} \mathrm{OH}\right), 3.93\left(\mathrm{t}, 4 \mathrm{H},-\mathrm{CH}_{2} \mathrm{OPh}\right), 3.75(\mathrm{t}, 1 \mathrm{H}$, $\left.\mathrm{CH}_{2} \mathrm{OH}\right), 1.78\left(\mathrm{~m}, 4 \mathrm{H}, \mathrm{PhOCH}_{2} \mathrm{CH}_{2}\left(\mathrm{CH}_{2}\right)_{11} \mathrm{CH}_{3}\right), 1.45\left(\mathrm{~m}, 4 \mathrm{H}, \mathrm{PhOCH}_{2} \mathrm{CH}_{2} \mathrm{CH}_{2}\left(\mathrm{CH}_{2}\right)_{10} \mathrm{CH}_{3}\right), 1.28(\mathrm{br}$, $\left.40 \mathrm{H}, \mathrm{PhOCH}_{2} \mathrm{CH}_{2} \mathrm{CH}_{2}\left(\mathrm{CH}_{2}\right){ }_{10} \mathrm{CH}_{3}\right), 0.90\left(\mathrm{~m}, 6 \mathrm{H}, \mathrm{PhO}\left(\mathrm{CH}_{2}\right)_{13} \mathrm{CH}_{3}\right) .{ }^{13} \mathrm{C} \mathrm{NMR}\left(101 \mathrm{MHz}, \mathrm{CDCl}_{3}\right) \delta$ 160.6, 143.3, 105.2, 100.7, 68.2, 65.5, 32.1, 30.4, 29.8, 29.8, 29.8, 29.8, 29.7, 29.5, 29.5, 29.4, 26.2, 22.8, 14.2. $\mathrm{Mp}=46^{\circ} \mathrm{C}$.

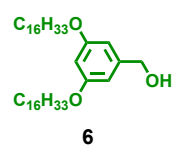

(3,5-Bis(hexadecyloxy)phenyl)methanol (6). From compound $\mathbf{1 5 f}(0.50 \mathrm{~g}, 0.81 \mathrm{mmol})$ and $\mathrm{LiAlH}_{4}(46$ $\mathrm{mg}, 1.22 \mathrm{mmol})$, compound 6 was obtained as a white solid $(0.48 \mathrm{~g}, 100 \%) .{ }^{1} \mathrm{H} \mathrm{NMR}\left(400 \mathrm{MHz}, \mathrm{CDCl}_{3}\right)$ $\delta 6.50(\mathrm{~s}, 2 \mathrm{H}, \mathrm{PhH}), 6.40(\mathrm{~s}, 1 \mathrm{H}, \mathrm{PhH}), 4.64\left(\mathrm{~s}, 2 \mathrm{H}, \mathrm{PhCH}_{2} \mathrm{OH}\right), 3.96\left(\mathrm{t}, 4 \mathrm{H},-\mathrm{CH}_{2} \mathrm{OPh}\right), 3.76(\mathrm{t}, 1 \mathrm{H}$, $\left.\mathrm{CH}_{2} \mathrm{OH}\right), 1.78\left(\mathrm{~m}, 4 \mathrm{H}, \mathrm{PhOCH}_{2} \mathrm{CH}_{2}\left(\mathrm{CH}_{2}\right)_{13} \mathrm{CH}_{3}\right), 1.45\left(\mathrm{~m}, 4 \mathrm{H}, \mathrm{PhOCH}_{2} \mathrm{CH}_{2} \mathrm{CH}_{2}\left(\mathrm{CH}_{2}\right)_{12} \mathrm{CH}_{3}\right), 1.28$ (br, $\left.48 \mathrm{H}, \mathrm{PhOCH}_{2} \mathrm{CH}_{2} \mathrm{CH}_{2}\left(\mathrm{CH}_{2}\right){ }_{12} \mathrm{CH}_{3}\right), 0.90\left(\mathrm{~m}, 6 \mathrm{H}, \mathrm{PhO}\left(\mathrm{CH}_{2}\right)_{15} \mathrm{CH}_{3}\right) .{ }^{13} \mathrm{C} \mathrm{NMR}\left(101 \mathrm{MHz}, \mathrm{CDCl}_{3}\right) \delta$ $160.7,143.3,105.2,100.7,68.2$, 65.6, 32.1, 29.8, 29.8, 29.8, 29.7, 29.5, 29.5, 29.4, 26.2, 22.8, 14.3. Mp $=59{ }^{\circ} \mathrm{C}$.

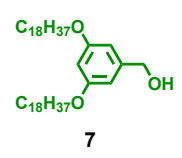

(3,5-Bis(octadecyloxy)phenyl)methanol (7). From compound 15g (0.60 g, $0.89 \mathrm{mmol})$ and $\mathrm{LiAlH}_{4}(68$ mg, $1.78 \mathrm{mmol})$, compound 7 was obtained as a white solid (0.55 g, 96\%). ${ }^{1} \mathrm{H}$ NMR (400 $\left.\mathrm{MHz}, \mathrm{CDCl}_{3}\right)$ $\delta 6.49(\mathrm{~s}, 2 \mathrm{H}, \mathrm{PhH}), 6.37$ (s, $1 \mathrm{H}, \mathrm{PhH}), 4.60$ (s, $\left.2 \mathrm{H}, \mathrm{PhCH}_{2} \mathrm{OH}\right), 3.93$ (t, $\left.4 \mathrm{H},-\mathrm{CH}_{2} \mathrm{OPh}\right), 3.67$ (t, $1 \mathrm{H}$, $\left.\mathrm{CH}_{2} \mathrm{OH}\right), 1.76\left(\mathrm{~m}, 4 \mathrm{H}, \mathrm{PhOCH}_{2} \mathrm{CH}_{2}\left(\mathrm{CH}_{2}\right)_{15} \mathrm{CH}_{3}\right), 1.44$ (m, $\left.4 \mathrm{H}, \mathrm{PhOCH}_{2} \mathrm{CH}_{2} \mathrm{CH}_{2}\left(\mathrm{CH}_{2}\right){ }_{14} \mathrm{CH}_{3}\right), 1.26$ (br, $\left.56 \mathrm{H}, \mathrm{PhOCH}_{2} \mathrm{CH}_{2} \mathrm{CH}_{2}\left(\mathrm{CH}_{2}\right){ }_{14} \mathrm{CH}_{3}\right), 0.89\left(\mathrm{~m}, 6 \mathrm{H}, \mathrm{PhO}\left(\mathrm{CH}_{2}\right){ }_{17} \mathrm{CH}_{3}\right) .{ }^{13} \mathrm{C} \mathrm{NMR}\left(101 \mathrm{MHz}, \mathrm{CDCl}_{3}\right) \delta$ $160.6,143.4,105.2$, 100.7, 68.2, 65.5, 32.1, 30.4, 29.8, 29.8, 29.7, 29.5, 29.5, 29.4, 26.2, 22.8, 14.2. Mp $=69^{\circ} \mathrm{C}$. 


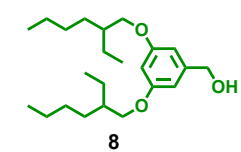

(3,5-Bis((2-ethylhexyl)oxy)phenyl)methanol (8). From compound 15h (4.10 g, $10.44 \mathrm{mmol})$ and $\mathrm{LiAlH}_{4}$ (0.48 g, $12.53 \mathrm{mmol})$, compound 8 was obtained as a light-yellow oil (3.64 g, 96\%). ${ }^{1} \mathrm{H}$ NMR (400 MHz, $\left.\mathrm{CDCl}_{3}\right) \delta 6.51(\mathrm{~d}, 2 \mathrm{H}, \mathrm{PhH}), 6.39(\mathrm{t}, 1 \mathrm{H}, \mathrm{Ph} H), 4.62$ (d, $\left.2 \mathrm{H}, \mathrm{PhCH}_{2} \mathrm{OH}\right), 3.83\left(\mathrm{~m}, 4 \mathrm{H},-\mathrm{CH}_{2} \mathrm{OPh}\right), 1.71$ $\left(\mathrm{m}, 2 \mathrm{H}, \quad \mathrm{PhOCH}_{2} \mathrm{CH}\left(\mathrm{CH}_{2} \mathrm{CH}_{3}\right)-\right), 1.65$ (t, $\left.1 \mathrm{H}, \quad \mathrm{CH}_{2} \mathrm{OH}\right), \quad 1.55-1.24 \quad(\mathrm{~m}, \quad 16 \quad \mathrm{H}$, $\left.\mathrm{PhOCH}_{2} \mathrm{CH}\left(\mathrm{CH}_{2} \mathrm{CH}_{3}\right)\left(\mathrm{CH}_{2} \mathrm{CH}_{2} \mathrm{CH}_{2} \mathrm{CH}_{3}\right)\right), 0.91\left(\mathrm{~m}, 12 \mathrm{H}, \mathrm{PhOCH}_{2} \mathrm{CH}\left(\mathrm{CH}_{2} \mathrm{CH}_{3}\right)\left(\mathrm{CH}_{2} \mathrm{CH}_{2} \mathrm{CH}_{2} \mathrm{CH}_{3}\right)\right) .{ }^{13} \mathrm{C}$ $\mathrm{NMR}\left(101 \mathrm{MHz}, \mathrm{CDCl}_{3}\right) \delta 160.9,143.3,105.1,100.6,70.6,65.5,39.5,30.6,29.2,24.0,23.2,14.2,11.2$.

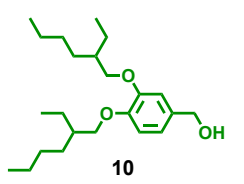

(3,4-Bis((2-ethylhexyl)oxy)phenyl)methanol (10). From compound 18b (2.77 g, $7.10 \mathrm{mmol})$ and $\mathrm{LiAlH}_{4}$ (0.32 g, $8.50 \mathrm{mmol})$, compound 10 was obtained as a colorless oil (2.36 g, 91\%). ${ }^{1} \mathrm{H} \mathrm{NMR}(400 \mathrm{MHz}$, $\left.\mathrm{CDCl}_{3}\right) \delta 6.92(\mathrm{~m}, 1 \mathrm{H}, \mathrm{Ph} H), 6.84(\mathrm{~m}, 2 \mathrm{H}, \mathrm{Ph} H), 4.59\left(\mathrm{~s}, 2 \mathrm{H},-\mathrm{CH}_{2} \mathrm{Ph}\right), 3.87-3.86\left(\mathrm{~m}, 4 \mathrm{H}, 2 \times \mathrm{PhOCH}_{2-}\right.$ ), $\quad 1.78-1.72\left(\mathrm{~m}, \quad 2 \mathrm{H}, \quad 2 \times \mathrm{PhOCH}_{2} \mathrm{CH}\left(\mathrm{CH}_{2} \mathrm{CH}_{3}\right)\left(\mathrm{CH}_{2}\right)_{3} \mathrm{CH}_{3}\right), \quad 1.56-1.26 \quad(\mathrm{~m}, \quad 16 \quad \mathrm{H}$, $\left.2 \times \mathrm{PhOCH}_{2} \mathrm{CH}\left(\mathrm{CH}_{2} \mathrm{CH}_{3}\right)\left(\mathrm{CH}_{2}\right)_{3} \mathrm{CH}_{3}\right), 0.94-0.89\left(\mathrm{~m}, 12 \mathrm{H}, 2 \times \mathrm{PhOCH}_{2} \mathrm{CH}\left(\mathrm{CH}_{2} \mathrm{CH}_{3}\right)\left(\mathrm{CH}_{2}\right)_{3} \mathrm{CH}_{3}\right) .{ }^{13} \mathrm{C}$ NMR $\left(101 \mathrm{MHz}, \mathrm{CDCl}_{3}\right) \delta 149.8,149.2,133.7,119.5,113.7,112.8,71.9,71.7,65.5,39.7,30.7,29.2$, $24.0,24.0,23.2,14.2,11.3$.

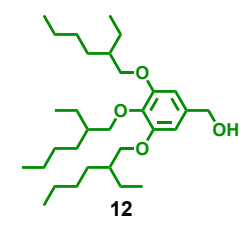

(3,4,5-Tris((2-ethylhexyl)oxy)phenyl)methanol (12). From compound 21b (0.60 g, $1.15 \mathrm{mmol})$ and $\mathrm{LiAlH}_{4}(0.12 \mathrm{~g}, 3.16 \mathrm{mmol})$, compound 12 was obtained as a colorless oil $(0.57 \mathrm{~g}, 100 \%) .{ }^{1} \mathrm{H}$ NMR (400 $\left.\mathrm{MHz}_{2} \mathrm{CDCl}_{3}\right) \delta 6.55(\mathrm{~d}, 2 \mathrm{H}, \mathrm{Ph} H), 4.59\left(\mathrm{~s}, 2 \mathrm{H}, \mathrm{PhCH}_{2} \mathrm{OH}\right), 3.84\left(\mathrm{~m}, 6 \mathrm{H}, 3 \times \mathrm{PhOCH}_{2}-\right), 3.73(\mathrm{t}, 1 \mathrm{H}$, $\left.\mathrm{PhCH}_{2} \mathrm{OH}\right), \quad 1.77\left(\mathrm{~m}, \quad 3 \mathrm{H}, \quad 3 \times \mathrm{PhOCH}_{2} \mathrm{CH}\left(\mathrm{CH}_{2} \mathrm{CH}_{3}\right)\left(\mathrm{CH}_{2}\right)_{3} \mathrm{CH}_{3}\right), \quad 1.58-1.22 \quad(\mathrm{~m}, \quad 24 \quad \mathrm{H}$, $\left.3 \times \mathrm{PhOCH}_{2} \mathrm{CH}\left(\mathrm{CH}_{2} \mathrm{CH}_{3}\right)\left(\mathrm{CH}_{2}\right)_{3} \mathrm{CH}_{3}\right), 0.93\left(\mathrm{~m}, 18 \mathrm{H}, 3 \times \mathrm{PhOCH}_{2} \mathrm{CH}\left(\mathrm{CH}_{2} \mathrm{CH}_{3}\right)\left(\mathrm{CH}_{2}\right)_{3} \mathrm{CH}_{3}\right) .{ }^{13} \mathrm{C} \mathrm{NMR}$ $\left(101 \mathrm{MHz}, \mathrm{CDCl}_{3}\right) \delta 153.6,137.3,136.1,104.7,76.1,71.2,65.7,40.7,39.7,30.6,29.4,29.2,23.9,23.8$, $23.2,23.2,14.2,14.2,11.3,11.3,11.2$. 


\subsection{Synthesis of IAJDs 64-66 and 70}

\section{Scheme S3. Synthesis of IAJDs 64-66 and 70}
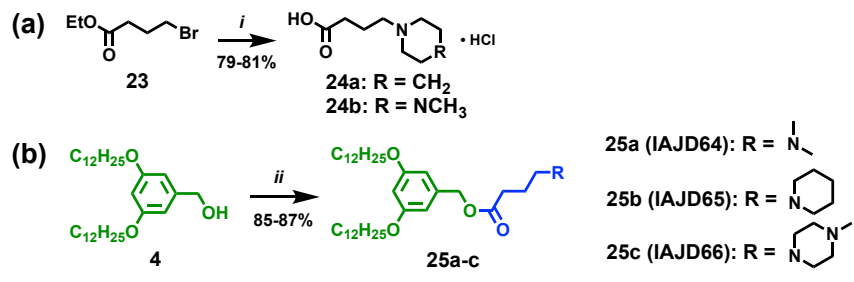

(c)

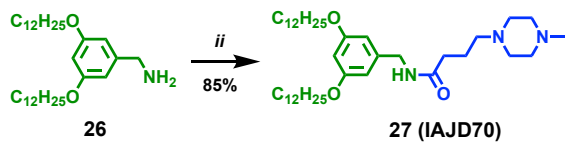

Reagents and conditions: (i) (1) piperidine/1-methylpiperazine, $\mathrm{K}_{2} \mathrm{CO}_{3}, \mathrm{MeCN}$, reflux, $3 \mathrm{~h}$; (2) conc. $\mathrm{HCl} /$ water, reflux, 3 h; (ii) 4-(Dimethylamino)butyric acid hydrochloride/4-(piperidin-1-yl)butanoic acid hydrochloride/4-(4-methylpiperazin-1-yl)butanoic acid hydrochloride, DCC, DCM, $23{ }^{\circ} \mathrm{C}, 12 \mathrm{~h}$.

The synthesis and characterizations of compounds $\mathbf{2 4 a}$ and $\mathbf{2 4 \mathbf { b }}$ were available in the literature. ${ }^{6}$

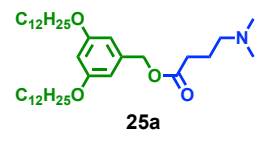

3,5-Bis(dodecyloxy)benzyl 4-(dimethylamino)butanoate (25a, IAJD64). Compound 4 (0.50 g, 1.05 mmol, 1 equiv) and 4-(dimethylamino)butyric acid hydrochloride (0.18 g, $1.05 \mathrm{mmol}, 1$ equiv) were dissolved in $6 \mathrm{~mL}$ dry DCM. $N, N^{\prime}$-Dicyclohexylcarbodiimide (DCC, $0.43 \mathrm{~g}, 2.10 \mathrm{mmol}, 2$ equiv) was added in one portion into the above mixture. The reaction was allowed to stir at $23^{\circ} \mathrm{C}$ for $12 \mathrm{~h}$. Afterwards, urea was removed by filtration, and washed with DCM carefully. The filtrate was concentrated and purified by column chromatography $\left(\mathrm{SiO}_{2}\right)$ with $\mathrm{DCM} / \mathrm{MeOH}=40 / 1,20 / 1$ and $15 / 1$ as the eluent. Then the product was dissolved in DCM $(30 \mathrm{~mL})$, which was washed by $\mathrm{NaHCO}_{3}$ solution $(2 \%, 30 \mathrm{~mL})$. The aqueous phase was extracted by DCM $(30 \mathrm{~mL})$ for another two times. The organic phase was combined and dried over anhydrous $\mathrm{MgSO}_{4}$. Filtration and evaporation of the solvent yielded the title compound as a colorless oil (0.54 g, 87\%). ${ }^{1} \mathrm{H}$ NMR (400 MHz, $\left.\mathrm{CDCl}_{3}\right) \delta 6.46(\mathrm{~d}, 2 \mathrm{H}, \mathrm{Ph} H), 6.39$ (t, $\left.1 \mathrm{H}, \mathrm{Ph} H\right), 5.03$ (s, $\left.2 \mathrm{H},-\mathrm{CH}_{2} \mathrm{Ph}\right), 3.91$ (t, $\left.4 \mathrm{H}, 2 \times \mathrm{PhOCH}_{2}-\right), 2.40$ (t, $\left.2 \mathrm{H},-\mathrm{OCOCH}_{2} \mathrm{CH}_{2} \mathrm{CH}_{2}-\right), 2.27$ (t, $2 \mathrm{H},-$ $\left.\mathrm{OCOCH}_{2} \mathrm{CH}_{2} \mathrm{CH}_{2}-\right), 2.20\left(\mathrm{~s}, 6 \mathrm{H},-\mathrm{OCO}\left(\mathrm{CH}_{2}\right)_{3} \mathrm{~N}\left(\mathrm{CH}_{3}\right)_{2}\right), 1.86-1.70\left(\mathrm{~m}, 6 \mathrm{H},-\mathrm{OCOCH}_{2} \mathrm{CH}_{2} \mathrm{CH}_{2}\right.$ - and $\left.\mathrm{PhOCH}_{2} \mathrm{CH}_{2}\left(\mathrm{CH}_{2}\right)_{9} \mathrm{CH}_{3}\right), \quad 1.44 \quad\left(\mathrm{~m}, \quad 4 \quad \mathrm{H}, \quad \mathrm{PhOCH}_{2} \mathrm{CH}_{2} \mathrm{CH}_{2}\left(\mathrm{CH}_{2}\right)_{8} \mathrm{CH}_{3}\right), 1.26$ (br, $32 \mathrm{H}$, $\left.\mathrm{PhOCH}_{2} \mathrm{CH}_{2} \mathrm{CH}_{2}\left(\mathrm{CH}_{2}\right)_{8} \mathrm{CH}_{3}\right), 0.88$ (t, $\left.6 \mathrm{H}, \mathrm{PhO}\left(\mathrm{CH}_{2}\right)_{11} \mathrm{CH}_{3}\right) .{ }^{13} \mathrm{C} \mathrm{NMR}\left(101 \mathrm{MHz}, \mathrm{CDCl}_{3}\right) \delta$ 173.5, 160.6, $138.2,106.4,101.0,68.2,66.2,59.0,45.5,32.2,32.1,29.8,29.8,29.7,29.7,29.5,29.5,29.4,26.2,23.1$, 
22.8, 14.2. Purity by HPLC: $99+\%$. MALDI-TOF MS $m / z$ of $[\mathrm{M}+\mathrm{H}]^{+}$calculated for $\mathrm{C}_{37} \mathrm{H}_{68} \mathrm{NO}_{4}: 590.5$; Found: 590.7.

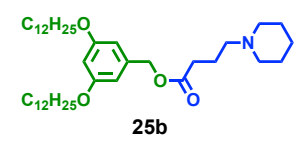

3,5-Bis(dodecyloxy)benzyl 4-(piperidin-1-yl)butanoate (25b, IAJD65). Compound 25b was synthesized from compound 4 ( $0.50 \mathrm{~g}, 1.05 \mathrm{mmol}, 1$ equiv), 4-(piperidin-1-yl)butanoic acid hydrochloride (24a, $0.22 \mathrm{~g}, 1.05 \mathrm{mmol}, 1$ equiv) and DCC ( $0.43 \mathrm{~g}, 2.10 \mathrm{mmol}, 2$ equiv) following a procedure similar to that used for the synthesis of compound 25a. The title compound was obtained as a colorless oil $(0.57 \mathrm{~g}$, 86\%). ${ }^{1} \mathrm{H}$ NMR (400 MHz, $\left.\mathrm{CDCl}_{3}\right) \delta 6.46$ (d, $2 \mathrm{H}, \mathrm{PhH}$ ), 6.39 (t, $1 \mathrm{H}, \mathrm{Ph} H$ ), 5.02 (s, $2 \mathrm{H},-\mathrm{CH}_{2} \mathrm{Ph}$ ), 3.92 (t, $\left.4 \mathrm{H}, 2 \times \mathrm{PhOCH}_{2}-\right), 2.44-2.25$ (m, $\left.8 \mathrm{H}, \mathrm{N}\left(\mathrm{CH}_{2}-\right)_{2} \mathrm{CH}_{2} \mathrm{CH}_{2} \mathrm{CH}_{2} \mathrm{COO}-\right), 1.83$ (m, $2 \mathrm{H},-\mathrm{OCOCH}_{2} \mathrm{CH}_{2} \mathrm{CH}_{2}-$ ), $1.76\left(\mathrm{~m}, 4 \mathrm{H}, \mathrm{PhOCH}_{2} \mathrm{CH}_{2}\left(\mathrm{CH}_{2}\right)_{9} \mathrm{CH}_{3}\right), 1.55\left(\mathrm{~m}, 4 \mathrm{H},-\mathrm{N}\left(\mathrm{CH}_{2} \mathrm{CH}_{2} \mathrm{CH}_{2}\right)_{2}\right), 1.44(\mathrm{~m}, 6 \mathrm{H}$, $\mathrm{PhOCH}_{2} \mathrm{CH}_{2} \mathrm{CH}_{2}\left(\mathrm{CH}_{2}\right)_{8} \mathrm{CH}_{3}$ and $\left.-\mathrm{N}\left(\mathrm{CH}_{2} \mathrm{CH}_{2} \mathrm{CH}_{2}\right)_{2}\right), 1.26$ (br, $\left.32 \mathrm{H}, \mathrm{PhOCH}_{2} \mathrm{CH}_{2} \mathrm{CH}_{2}\left(\mathrm{CH}_{2}\right)_{8} \mathrm{CH}_{3}\right), 0.88$ $\left(\mathrm{t}, 6 \mathrm{H}, \mathrm{PhO}\left(\mathrm{CH}_{2}\right)_{11} \mathrm{CH}_{3}\right) .{ }^{13} \mathrm{C} \mathrm{NMR}\left(101 \mathrm{MHz}, \mathrm{CDCl}_{3}\right) \delta$ 173.6, 160.6, 138.2, 106.5, 101.0, 68.2, 66.2, $58.6,54.7,32.6,32.1,29.8,29.8,29.7,29.7,29.5,29.5,29.4,26.2,26.2,24.6,22.8,22.4,14.3$. Purity by HPLC: 99+\%. MALDI-TOF MS $m / z$ of [M $+\mathrm{H}]^{+}$calculated for $\mathrm{C}_{40} \mathrm{H}_{72} \mathrm{NO}_{4}$ : 630.5; Found: 629.9.

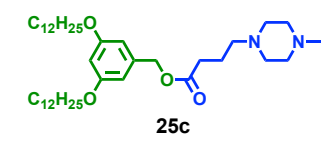

3,5-Bis(dodecyloxy)benzyl 4-(4-methylpiperazin-1-yl)butanoate (25c, IAJD66). Compound 25c was synthesized from compound 4 (0.20 g, $0.42 \mathrm{mmol}, 1$ equiv), 4-(4-methylpiperazin-1-yl)butanoic acid hydrochloride (24b, $94 \mathrm{mg}, 0.42 \mathrm{mmol}, 1$ equiv) and DCC (0.17 g, $0.84 \mathrm{mmol}, 2$ equiv) following a procedure similar to that used for the synthesis of compound 25a. The title compound was obtained as a colorless oil (0.23 g, 85\%). ${ }^{1} \mathrm{H}$ NMR $\left(400 \mathrm{MHz}, \mathrm{CDCl}_{3}\right) \delta 6.45(\mathrm{~d}, 2 \mathrm{H}, \mathrm{Ph} H), 6.38(\mathrm{t}, 1 \mathrm{H}, \mathrm{Ph} H), 5.01(\mathrm{~s}$, $\left.2 \mathrm{H},-\mathrm{CH}_{2} \mathrm{Ph}\right), 3.91\left(\mathrm{t}, 4 \mathrm{H}, 2 \times \mathrm{PhOCH}_{2}-\right), 2.62-2.39\left(\mathrm{~m}, 12 \mathrm{H},-\mathrm{N}\left(\mathrm{CH}_{2} \mathrm{CH}_{2}\right)_{2} \mathrm{~N}-\right.$ and $\left.-\mathrm{OCOCH}_{2} \mathrm{CH}_{2} \mathrm{CH}_{2}-\right)$, $2.26\left(\mathrm{~s}, 3 \mathrm{H},-\mathrm{NCH}_{3}\right), 1.82\left(\mathrm{~m}, 2 \mathrm{H},-\mathrm{OCOCH}_{2} \mathrm{CH}_{2} \mathrm{CH}_{2}-\right), 1.75\left(\mathrm{~m}, 4 \mathrm{H}, \mathrm{PhOCH}_{2} \mathrm{CH}_{2}\left(\mathrm{CH}_{2}\right){ }_{9} \mathrm{CH}_{3}\right), 1.43$ (m, $\left.4 \mathrm{H}, \mathrm{PhOCH}_{2} \mathrm{CH}_{2} \mathrm{CH}_{2}\left(\mathrm{CH}_{2}\right)_{8} \mathrm{CH}_{3}\right), 1.25$ (br, $\left.32 \mathrm{H}, \mathrm{PhOCH}_{2} \mathrm{CH}_{2} \mathrm{CH}_{2}\left(\mathrm{CH}_{2}\right)_{8} \mathrm{CH}_{3}\right), 0.87(\mathrm{t}, 6 \mathrm{H}$, $\left.\mathrm{PhO}\left(\mathrm{CH}_{2}\right)_{11} \mathrm{CH}_{3}\right) .{ }^{13} \mathrm{C} \mathrm{NMR}\left(101 \mathrm{MHz}, \mathrm{CDCl}_{3}\right) \delta 173.4,160.5,138.2,106.5,101.0,68.2,66.3,57.7,55.3$, 53.2, 46.2, 32.4, 32.0, 29.8, 29.8, 29.7, 29.7, 29.5, 29.5, 29.4, 26.2, 22.8, 22.3, 14.2. Purity by HPLC: 99+\%. MALDI-TOF MS $m / z$ of $[\mathrm{M}+\mathrm{H}]^{+}$calculated for $\mathrm{C}_{40} \mathrm{H}_{73} \mathrm{~N}_{2} \mathrm{O}_{4}$ : 645.6; Found: 645.7.

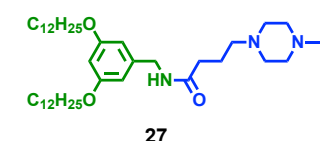


N-(3,5-bis(dodecyloxy)benzyl)-4-(4-methylpiperazin-1-yl)butanamide (27, IAJD70). The synthesis and characterizations of (3,5-bis(dodecyloxy)phenyl)methanamine (26) were reported in the literature. ${ }^{7}$ Compound 26 (0.20 g, 0.42 mmol, 1 equiv) and 4-(4-methylpiperazin-1-yl)butanoic acid hydrochloride (24b, $94 \mathrm{mg}, 0.42 \mathrm{mmol}, 1$ equiv) were dissolved in $6 \mathrm{~mL}$ dry DCM. NEt 3 (3 drops) was added. DCC $(0.17 \mathrm{~g}, 0.84 \mathrm{mmol}, 2$ equiv) was added in one portion into the above mixture. The reaction was allowed to stir at $23{ }^{\circ} \mathrm{C}$ for $12 \mathrm{~h}$. Afterwards, urea was removed by filtration, and washed with DCM carefully. The filtrate was concentrated and purified by column chromatography $\left(\mathrm{SiO}_{2}\right)$ with $\mathrm{DCM} / \mathrm{MeOH}=30 / 1$, $10 / 1,8 / 1$ and $8 / 1$ with $0.1 \%$ TEA as the eluent. Then the product was dissolved in DCM (30 mL), which was washed by $\mathrm{NaHCO}_{3}$ solution $(2 \%, 30 \mathrm{~mL})$. The aqueous phase was extracted by DCM $(30 \mathrm{~mL})$ for another two times. The organic phase was combined and dried over anhydrous $\mathrm{MgSO}_{4}$. Filtration and evaporation of the solvent yielded the title compound as a white solid $(0.23 \mathrm{~g}, 85 \%) .{ }^{1} \mathrm{H} \mathrm{NMR}(400 \mathrm{MHz}$, $\left.\mathrm{CDCl}_{3}\right) \delta 6.89$ (t, $\left.1 \mathrm{H},-\mathrm{CO}-\mathrm{NH}-\right), 6.39$ (d, $\left.2 \mathrm{H}, \mathrm{PhH}\right), 6.34$ (t, $\left.1 \mathrm{H}, \mathrm{Ph} H\right), 4.33$ (d, $\left.2 \mathrm{H},-\mathrm{CH} 2 \mathrm{Ph}\right), 3.89$ (t, 4 $\left.\mathrm{H}, 2 \times \mathrm{PhOCH}_{2}-\right), 2.58-2.00\left(\mathrm{~m}, 15 \mathrm{H},-\mathrm{N}\left(\mathrm{CH}_{2} \mathrm{CH}_{2}\right)_{2} \mathrm{~N}-,-\mathrm{OCOCH}_{2} \mathrm{CH}_{2} \mathrm{CH}_{2}\right.$ - and $\left.-\mathrm{NCH}_{3}\right), 1.81(\mathrm{~m}, 2 \mathrm{H},-$ $\left.\mathrm{OCOCH}_{2} \mathrm{CH}_{2} \mathrm{CH}_{2}-\right), 1.74\left(\mathrm{~m}, 4 \mathrm{H}, \mathrm{PhOCH}_{2} \mathrm{CH}_{2}\left(\mathrm{CH}_{2}\right)_{9} \mathrm{CH}_{3}\right), 1.42\left(\mathrm{~m}, 4 \mathrm{H}, \mathrm{PhOCH}_{2} \mathrm{CH}_{2} \mathrm{CH}_{2}\left(\mathrm{CH}_{2}\right)_{8} \mathrm{CH}_{3}\right)$, 1.25 (br, $\left.32 \mathrm{H}, \mathrm{PhOCH}_{2} \mathrm{CH}_{2} \mathrm{CH}_{2}\left(\mathrm{CH}_{2}\right)_{8} \mathrm{CH}_{3}\right), 0.87$ (t, $\left.6 \mathrm{H}, \mathrm{PhO}\left(\mathrm{CH}_{2}\right)_{11} \mathrm{CH}_{3}\right) .{ }^{13} \mathrm{C} \mathrm{NMR}\left(101 \mathrm{MHz}, \mathrm{CDCl}_{3}\right)$ $\delta 172.8,160.7,140.8,106.5,100.3,68.2,57.5,55.1,53.1,46.1,43.9,35.1,32.0,29.8,29.8,29.7,29.7$, 29.5, 29.5, 29.4, 26.2, 22.8, 22.5, 14.2. Purity by HPLC: 99+\%. MALDI-TOF MS $m / z$ of $[\mathrm{M}+\mathrm{H}]^{+}$ calculated for $\mathrm{C}_{40} \mathrm{H}_{74} \mathrm{~N}_{3} \mathrm{O}_{3}$ : 644.6; Found: 644.1. $\mathrm{Mp}=64{ }^{\circ} \mathrm{C}$.

\subsection{Synthesis of IAJDs 71 and 74-79}

\section{Scheme S4. Synthesis of IAJDs 71 and 74-79}

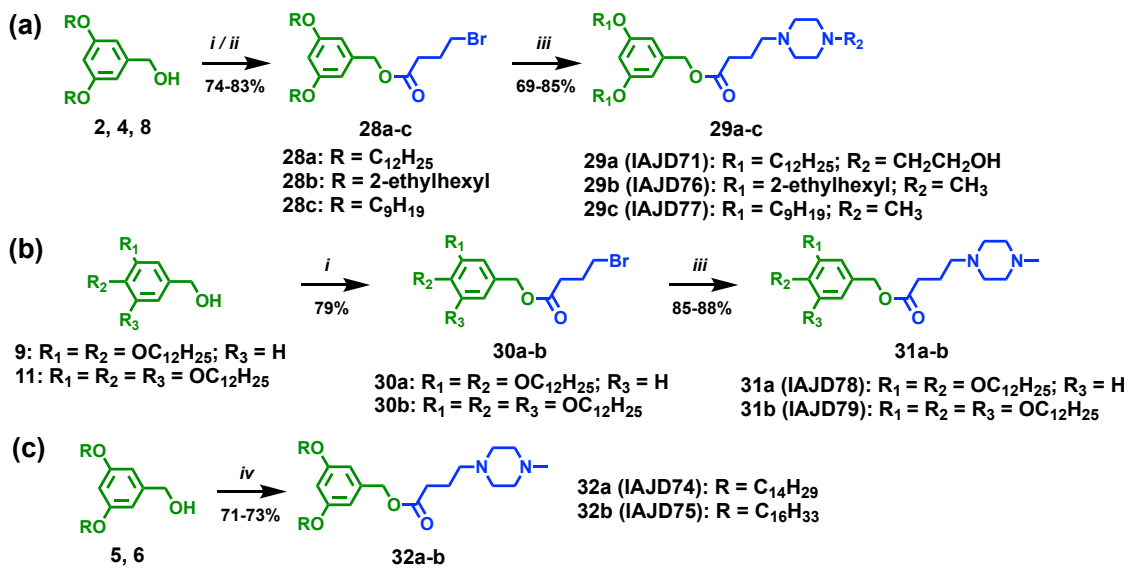

Reagents and conditions: (i) EDC.HCl, DMAP, DCM, $23^{\circ} \mathrm{C}, 12 \mathrm{~h}$; (ii) 4-bromobutyric acid, $\mathrm{SOCl}_{2}$, DMF (cat.), DCM, $23{ }^{\circ} \mathrm{C}, 1 \mathrm{~h}$, then DMAP, NEt 3 , DCM, 0-23 ${ }^{\circ} \mathrm{C}, 2 \mathrm{~h}$; (iii) 1-methylpiperazine/1-(2- 
hydroxyethyl)piperazine, $\mathrm{K}_{2} \mathrm{CO}_{3}, \mathrm{MeCN}, 95{ }^{\circ} \mathrm{C}, 3 \mathrm{~h}$. (iv) 4-(4-methylpiperazin-1-yl)butanoic acid hydrochloride, DCC, DCM, $23{ }^{\circ} \mathrm{C}, 12 \mathrm{~h}$.

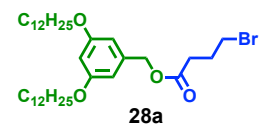

3,5-Bis(dodecyloxy)benzyl 4-bromobutanoate (28a). Compound 4 (0.60 g, 1.26 mmol, 1 equiv), 4bromobutyric acid (0.21 g, $1.26 \mathrm{mmol}, 1$ equiv), EDC.HCl (0.24 g, $1.26 \mathrm{mmol}, 1$ equiv) and DMAP (46 $\mathrm{mg}, 0.38 \mathrm{mmol}, 0.3$ equiv) were dissolved in dry DCM $(6 \mathrm{~mL})$. The reaction mixture was stirred at $23{ }^{\circ} \mathrm{C}$ for $12 \mathrm{~h}$. Afterwards, brine $(30 \mathrm{~mL})$ was added, and the mixture was extracted by DCM (30 $\mathrm{mL})$ for three times. The organic phase was collected, dried over anhydrous $\mathrm{MgSO}_{4}$ and filtered. The filtrate was concentrated and purified by column chromatography $\left(\mathrm{SiO}_{2}\right)$ with hexane/EtOAc $=20 / 1$ as the eluent to give the title compound as a colorless oil (0.62 g, 79\%). ${ }^{1} \mathrm{H} \mathrm{NMR}\left(400 \mathrm{MHz}, \mathrm{CDCl}_{3}\right) \delta 6.47(\mathrm{~d}, 2 \mathrm{H}, \mathrm{PhH})$, $6.40(\mathrm{t}, 1 \mathrm{H}, \mathrm{PhH}), 5.05$ (s, $\left.2 \mathrm{H},-\mathrm{CH}_{2} \mathrm{Ph}\right), 3.93$ (t, $\left.4 \mathrm{H}, 2 \times \mathrm{PhOCH}_{2}-\right), 3.47$ (t, $2 \mathrm{H},-\mathrm{OCOCH}_{2} \mathrm{CH}_{2} \mathrm{CH}_{2} \mathrm{Br}$ ), $2.57\left(\mathrm{t}, 2 \mathrm{H},-\mathrm{OCOCH}_{2} \mathrm{CH}_{2} \mathrm{CH}_{2} \mathrm{Br}\right), 2.20$ (m, $\left.2 \mathrm{H},-\mathrm{OCOCH}_{2} \mathrm{CH}_{2} \mathrm{CH}_{2} \mathrm{Br}\right), 1.76$ (m, $4 \mathrm{H}$, $\left.\mathrm{PhOCH}_{2} \mathrm{CH}_{2}\left(\mathrm{CH}_{2}\right)_{9} \mathrm{CH}_{3}\right), \quad 1.44 \quad\left(\mathrm{~m}, \quad 4 \quad \mathrm{H}, \quad \mathrm{PhOCH}_{2} \mathrm{CH}_{2} \mathrm{CH}_{2}\left(\mathrm{CH}_{2}\right)_{8} \mathrm{CH}_{3}\right), \quad 1.27 \quad$ (br, $32 \mathrm{H}$, $\left.\mathrm{PhOCH}_{2} \mathrm{CH}_{2} \mathrm{CH}_{2}\left(\mathrm{CH}_{2}\right)_{8} \mathrm{CH}_{3}\right), 0.89\left(\mathrm{t}, 6 \mathrm{H}, \mathrm{PhO}\left(\mathrm{CH}_{2}\right){ }_{11} \mathrm{CH}_{3}\right) .{ }^{13} \mathrm{C} \mathrm{NMR}\left(101 \mathrm{MHz}, \mathrm{CDCl}_{3}\right) \delta 172.4,160.6$, $137.9,106.5,101.2,68.2,66.5,32.8,32.6,32.1,29.8,29.8,29.7,29.7,29.5,29.5,29.4,27.9,26.2,22.8$, 14.3 .

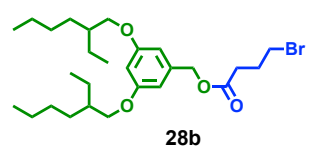

3,5-Bis((2-ethylhexyl)oxy)benzyl 4-bromobutanoate (28b). 4-Bromobutyric acid (0.11 g, $0.63 \mathrm{mmol}$, 1.05 equiv) was dissolved in $5 \mathrm{~mL}$ anhydrous DCM and 1 drop of DMF was added. Thionyl chloride $\left(\mathrm{SOCl}_{2}, 0.14 \mathrm{~g}, 1.20 \mathrm{mmol}, 2\right.$ equiv) was added and the mixture was stirred at $23{ }^{\circ} \mathrm{C}$ for $1 \mathrm{~h}$. Afterwards, DCM and excess $\mathrm{SOCl}_{2}$ was removed under reduced pressure to give the 4-bromobutanoyl chloride. Compound 8 (0.22 g, $0.60 \mathrm{mmol}, 1.0$ equiv), $\mathrm{NEt}_{3}$ (67 mg, $0.66 \mathrm{mmol}, 1.1$ equiv) and DMAP (14 mg, $0.12 \mathrm{mmol}, 0.2$ equiv) were dissolved in $6 \mathrm{~mL}$ anhydrous DCM. To this mixture was added the DCM solution $(3 \mathrm{~mL})$ of above 4-bromobutanoyl chloride dropwise at $0{ }^{\circ} \mathrm{C}$. The mixture was allowed to warm to $23{ }^{\circ} \mathrm{C}$ with stirring during a $2 \mathrm{~h}$ period. Afterwards, water $(30 \mathrm{~mL})$ was added, and the mixture was extracted by DCM (30 mL) for three times. The organic phase was collected, dried over anhydrous $\mathrm{MgSO}_{4}$ and filtered. The filtrate was concentrated and purified by column chromatography $\left(\mathrm{SiO}_{2}\right)$ with hexane/EtOAc $=20 / 1$ as the eluent to give the title compound as a colorless oil $(0.26 \mathrm{~g}, 83 \%)$. ${ }^{1} \mathrm{H}$ NMR $\left(400 \mathrm{MHz} \mathrm{CDCl}_{3}\right) \delta 6.47(\mathrm{~d}, 2 \mathrm{H}, \mathrm{PhH}), 6.41(\mathrm{t}, 1 \mathrm{H}, \mathrm{PhH}), 5.05\left(\mathrm{~s}, 2 \mathrm{H},-\mathrm{CH}_{2} \mathrm{Ph}\right), 3.83-3.81(\mathrm{~m}, 4 \mathrm{H}$, 
2×PhOCH $2_{2}^{-}$), 3.49-3.46 (t, $2 \mathrm{H},-\mathrm{CH}_{2} \mathrm{Br}$ ), 2.59-2.56 (t, $\left.2 \mathrm{H}, \mathrm{BrCH}_{2} \mathrm{CH}_{2} \mathrm{CH}_{2} \mathrm{COO}-\right)$, 2.24-2.17 (m, $2 \mathrm{H}$, $\left.\mathrm{BrCH}_{2} \mathrm{CH}_{2} \mathrm{CH}_{2} \mathrm{COO}-\right)$, 1.73-1.67 (m, $\left.2 \mathrm{H}, 2 \times \mathrm{PhOCH}_{2} \mathrm{CH}\left(\mathrm{CH}_{2} \mathrm{CH}_{3}\right)\left(\mathrm{CH}_{2}\right)_{3} \mathrm{CH}_{3}\right), 1.52-1.30(\mathrm{~m}, 16 \mathrm{H}$, $\left.2 \times \mathrm{PhOCH}_{2} \mathrm{CH}\left(\mathrm{CH}_{2} \mathrm{CH}_{3}\right)\left(\mathrm{CH}_{2}\right)_{3} \mathrm{CH}_{3}\right), 0.94-0.89\left(\mathrm{~m}, 12 \mathrm{H}, 2 \times \mathrm{PhOCH}_{2} \mathrm{CH}\left(\mathrm{CH}_{2} \mathrm{CH}_{3}\right)\left(\mathrm{CH}_{2}\right){ }_{3} \mathrm{CH}_{3}\right) .{ }^{13} \mathrm{C}$ NMR $\left(101 \mathrm{MHz} \mathrm{CDCl}_{3}\right) \delta 172.5,160.8,137.8,106.4,101.1,70.6,66.6,39.5,32.8,32.6,30.7,29.2,27.9$, $24.0,23.2,14.2,11.3$.

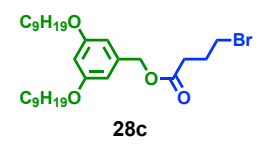

3,5-Bis(nonyloxy)benzyl 4-bromobutanoate (28c). Compound 28c was synthesized from compound 2 (0.50 g, $1.30 \mathrm{mmol})$, 4-bromobutyric acid (0.22 g, $1.30 \mathrm{mmol})$ and $\mathrm{NEt}_{3}(0.14 \mathrm{~g}, 1.43 \mathrm{mmol})$ following a procedure similar to that used for the synthesis of compound $\mathbf{2 8 b}$. The title compound was obtained as a light-yellow oil (0.51 g, 74\%). ${ }^{1} \mathrm{H}$ NMR (400 MHz, $\left.\mathrm{CDCl}_{3}\right) \delta 6.46(\mathrm{~d}, 2 \mathrm{H}, \mathrm{PhH}), 6.40(\mathrm{t}, 1 \mathrm{H}, \mathrm{Ph} H), 5.04$ (s, $\left.2 \mathrm{H},-\mathrm{CH}_{2} \mathrm{Ph}\right), 3.93-3.91\left(\mathrm{t}, 4 \mathrm{H}, 2 \times \mathrm{PhOCH}_{2}-\right), 3.49-3.45$ (t, $\left.2 \mathrm{H},-\mathrm{CH}_{2} \mathrm{Br}\right), 2.58-2.55(\mathrm{t}, 2 \mathrm{H}$, $\left.\mathrm{BrCH}_{2} \mathrm{CH}_{2} \mathrm{CH}_{2} \mathrm{COO}-\right), \quad 2.23-2.17$ (m, $\left.2 \mathrm{H}, \quad \mathrm{BrCH}_{2} \mathrm{CH}_{2} \mathrm{CH}_{2} \mathrm{COO}-\right), \quad 1.80-1.73 \quad$ (m, $4 \mathrm{H}$, $\left.2 \times \mathrm{PhOCH}_{2} \mathrm{CH}_{2}\left(\mathrm{CH}_{2}\right)_{6} \mathrm{CH}_{3}\right), 1.48-1.26\left(\mathrm{~m}, 24 \mathrm{H}, 2 \times \mathrm{PhOCH}_{2} \mathrm{CH}_{2}\left(\mathrm{CH}_{2}\right)_{6} \mathrm{CH}_{3}\right), 0.94-0.89(\mathrm{t}, 6 \mathrm{H}$, $\left.2 \times 2 \times \mathrm{PhOCH}_{2} \mathrm{CH}_{2}\left(\mathrm{CH}_{2}\right)_{6} \mathrm{CH}_{3}\right) .{ }^{13} \mathrm{C} \mathrm{NMR}\left(101 \mathrm{MHz}, \mathrm{CDCl}_{3}\right) \delta 172.5,160.6,138.0,106.5,101.2,68.2$, $66.6,32.8,32.6,32.0,30.5,29.7,29.5,29.4,29.4,27.9,26.2,22.8,14.3$.

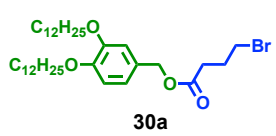

3,4-Bis(dodecyloxy)benzyl 4-bromobutanoate (30a). Compound 30a was synthesized from compound $9(0.50 \mathrm{~g}, 1.05 \mathrm{mmol})$, 4-bromobutyric acid $(0.18 \mathrm{~g}, 1.05 \mathrm{mmol})$ and $\mathrm{NEt}_{3}(0.12 \mathrm{~g}, 1.16 \mathrm{mmol})$ following a procedure similar to that used for the synthesis of compound $\mathbf{2 8 b}$. The title compound was obtained as a white solid $(0.52 \mathrm{~g}, 79 \%) .{ }^{1} \mathrm{H}$ NMR $\left(500 \mathrm{MHz}, \mathrm{CDCl}_{3}\right) \delta 6.92-6.80(\mathrm{~m}, 3 \mathrm{H}, \mathrm{Ph} H), 5.04(\mathrm{~s}, 2 \mathrm{H},-$ $\left.\mathrm{CH}_{2} \mathrm{Ph}\right), 3.99\left(\mathrm{~m}, 4 \mathrm{H}, 2 \times \mathrm{PhOCH}_{2}-\right), 3.45$ (t, $\left.2 \mathrm{H},-\mathrm{OCOCH}_{2} \mathrm{CH}_{2} \mathrm{CH}_{2} \mathrm{Br}\right), 2.53$ (t, $2 \mathrm{H},-$ $\mathrm{OCOCH}_{2} \mathrm{CH}_{2} \mathrm{CH}_{2} \mathrm{Br}$ ), 2.18 (m, $\left.2 \mathrm{H},-\mathrm{OCOCH}_{2} \mathrm{CH}_{2} \mathrm{CH}_{2} \mathrm{Br}\right), 1.81$ (m, $\left.4 \mathrm{H}, \mathrm{PhOCH}_{2} \mathrm{CH}_{2}\left(\mathrm{CH}_{2}\right)_{9} \mathrm{CH}_{3}\right), 1.46$ (m, $\left.4 \mathrm{H}, \mathrm{PhOCH}_{2} \mathrm{CH}_{2} \mathrm{CH}_{2}\left(\mathrm{CH}_{2}\right)_{8} \mathrm{CH}_{3}\right), 1.26$ (br, $\left.32 \mathrm{H}, \mathrm{PhOCH}_{2} \mathrm{CH}_{2} \mathrm{CH}_{2}\left(\mathrm{CH}_{2}\right)_{8} \mathrm{CH}_{3}\right), 0.88(\mathrm{t}, 6 \mathrm{H}$, $\left.\mathrm{PhO}\left(\mathrm{CH}_{2}\right)_{11} \mathrm{CH}_{3}\right) .{ }^{13} \mathrm{C} \mathrm{NMR}\left(126 \mathrm{MHz}, \mathrm{CDCl}_{3}\right) \delta 172.6,149.5,149.3,128.4,121.5,114.4,113.7,69.4$, 69.4, 66.7, 32.8, 32.7, 32.1, 29.8, 29.8, 29.8, 29.6, 29.6, 29.5, 29.4, 29.4, 27.9, 26.2, 26.2, 22.8, 14.3. Mp $=60{ }^{\circ} \mathrm{C}$.

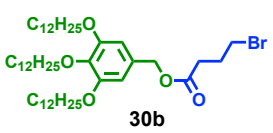


3,4,5-Tris(dodecyloxy)benzyl 4-bromobutanoate (30b). Compound 30b was synthesized from compound 11 (0.50 g, $0.76 \mathrm{mmol})$, 4-bromobutyric acid $(0.13 \mathrm{~g}, 0.76 \mathrm{mmol})$ and $\mathrm{NEt}_{3}(0.12 \mathrm{~g}, 0.84 \mathrm{mmol})$ following a procedure similar to that used for the synthesis of compound $\mathbf{2 8 b}$. The title compound was obtained as a colorless oil (0.48 g, 79\%). ${ }^{1} \mathrm{H}$ NMR (400 MHz, $\left.\mathrm{CDCl}_{3}\right) \delta 6.54(\mathrm{~s}, 2 \mathrm{H}, \mathrm{Ph} H), 5.02(\mathrm{~s}, 2 \mathrm{H}$, $\left.-\mathrm{CH}_{2} \mathrm{Ph}\right), 3.96\left(\mathrm{~m}, 6 \mathrm{H}, 3 \times \mathrm{PhOCH}_{2}-\right), 3.45$ (t, $\left.2 \mathrm{H},-\mathrm{OCOCH}_{2} \mathrm{CH}_{2} \mathrm{CH}_{2} \mathrm{Br}\right), 2.55$ (t, $2 \mathrm{H}$, $\mathrm{OCOCH}_{2} \mathrm{CH}_{2} \mathrm{CH}_{2} \mathrm{Br}$ ), 2.19 (m, $2 \mathrm{H},-\mathrm{OCOCH}_{2} \mathrm{CH}_{2} \mathrm{CH}_{2} \mathrm{Br}$ ), 1.87-1.68 (m, $\left.6 \mathrm{H}, \mathrm{PhOCH}_{2} \mathrm{CH}_{2}\left(\mathrm{CH}_{2}\right){ }_{9} \mathrm{CH}_{3}\right)$, 1.47 (m, $\left.6 \mathrm{H}, \mathrm{PhOCH}_{2} \mathrm{CH}_{2} \mathrm{CH}_{2}\left(\mathrm{CH}_{2}\right)_{8} \mathrm{CH}_{3}\right), 1.27$ (br, $\left.48 \mathrm{H}, \mathrm{PhOCH}_{2} \mathrm{CH}_{2} \mathrm{CH}_{2}\left(\mathrm{CH}_{2}\right)_{8} \mathrm{CH}_{3}\right), 0.88$ (t, $9 \mathrm{H}$, $\left.\mathrm{PhO}\left(\mathrm{CH}_{2}\right){ }_{11} \mathrm{CH}_{3}\right) .{ }^{13} \mathrm{C} \mathrm{NMR}\left(101 \mathrm{MHz}, \mathrm{CDCl}_{3}\right) \delta 172.4,153.3,138.3,130.8,107.0,73.5,69.2,66.9,32.7$, $32.6,32.1,32.0,30.4,29.9,29.8,29.8,29.8,29.8,29.7,29.5,29.5,29.5,27.8,26.2,26.2,22.8,14.2$.

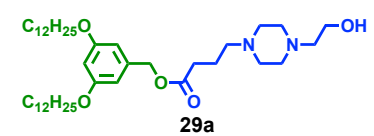

3,5-Bis(dodecyloxy)benzyl 4-(4-(2-hydroxyethyl)piperazin-1-yl)butanoate (29a, IAJD71). Compound 28a (0.24 g, $0.38 \mathrm{mmol}, 1.0$ equiv), 1-(2-hydroxyethyl)piperazine (52 mg, $0.40 \mathrm{mmol}, 1.05$ equiv), $\mathrm{K}_{2} \mathrm{CO}_{3}$ (55 mg, $0.40 \mathrm{mmol}, 1.05$ equiv) were stirred in $\mathrm{MeCN}$ (20 mL). The mixture was heated at reflux $\left(95^{\circ} \mathrm{C}\right)$ for $3 \mathrm{~h}$. The reaction mixture was cooled to $23^{\circ} \mathrm{C}$ and $\mathrm{MeCN}$ was removed under reduced pressure. Then water $(20 \mathrm{~mL})$ was added, and the mixture was extracted by DCM $(20 \mathrm{~mL} \times 3)$. The organic phase was collected, dried over anhydrous $\mathrm{MgSO}_{4}$, filtered and dried to give the crude product. The crude product was purified by column chromatography $\left(\mathrm{SiO}_{2}\right)$ with $\mathrm{DCM} / \mathrm{MeOH}=30 / 1$ and $15 / 1$ as the eluent. Then the obtained product was dissolved in DCM $(20 \mathrm{~mL})$, which was washed by $\mathrm{NaHCO}_{3}$ solution $(2 \%$, $20 \mathrm{~mL})$. The aqueous phase was extracted by DCM $(20 \mathrm{~mL})$ for another two times. The organic phase was combined and dried over anhydrous $\mathrm{MgSO}_{4}$. Filtration and evaporation of the solvent yielded the title compound as a colorless oil (0.22 g, 85\%). ${ }^{1} \mathrm{H}$ NMR (400 MHz, $\left.\mathrm{CDCl}_{3}\right) \delta 6.45(\mathrm{~d}, 2 \mathrm{H}, \mathrm{Ph} H), 6.38(\mathrm{t}, 1$ $\mathrm{H}, \mathrm{PhH}), 5.01\left(\mathrm{~s}, 2 \mathrm{H},-\mathrm{CH}_{2} \mathrm{Ph}\right), 3.91$ (t, $\left.4 \mathrm{H}, 2 \times \mathrm{PhOCH}_{2}-\right), 3.59$ (t, $\left.2 \mathrm{H},-\mathrm{CH}_{2} \mathrm{CH}_{2} \mathrm{OH}\right), 2.75$ (br, $1 \mathrm{H},-$ $\mathrm{CH}_{2} \mathrm{CH}_{2} \mathrm{OH}$ ), 2.60-2.23 (m, $14 \mathrm{H}, \mathrm{N}\left(\mathrm{CH}_{2} \mathrm{CH}_{2}\right)_{2},-\mathrm{OCOCH}_{2} \mathrm{CH}_{2} \mathrm{CH}_{2}$ - and $\left.-\mathrm{CH}_{2} \mathrm{CH}_{2} \mathrm{OH}\right), 1.82(\mathrm{~m}, 2 \mathrm{H}$, $\left.\mathrm{OCOCH}_{2} \mathrm{CH}_{2} \mathrm{CH}_{2-}\right), 1.75\left(\mathrm{~m}, 4 \mathrm{H}, \mathrm{PhOCH}_{2} \mathrm{CH}_{2}\left(\mathrm{CH}_{2}\right)_{9} \mathrm{CH}_{3}\right), 1.43$ (m, $\left.4 \mathrm{H}, \mathrm{PhOCH}_{2} \mathrm{CH}_{2} \mathrm{CH}_{2}\left(\mathrm{CH}_{2}\right)_{8} \mathrm{CH}_{3}\right)$, 1.25 (br, $\left.32 \mathrm{H}, \mathrm{PhOCH}_{2} \mathrm{CH}_{2} \mathrm{CH}_{2}\left(\mathrm{CH}_{2}\right)_{8} \mathrm{CH}_{3}\right), 0.87$ (t, $\left.6 \mathrm{H}, \mathrm{PhO}\left(\mathrm{CH}_{2}\right)_{11} \mathrm{CH}_{3}\right) .{ }^{13} \mathrm{C} \mathrm{NMR}\left(101 \mathrm{MHz}, \mathrm{CDCl}_{3}\right)$ $\delta 173.4,160.5,138.1,106.5,101.0,68.2,66.2,59.4,57.8,57.7,53.3,53.0,32.3,32.0,29.8,29.7,29.7$, 29.7, 29.5, 29.5, 29.4, 26.2, 22.8, 22.3, 14.2. Purity by HPLC: 99+\%. MALDI-TOF MS $m / z$ of $[\mathrm{M}+\mathrm{H}]^{+}$ calculated for $\mathrm{C}_{41} \mathrm{H}_{75} \mathrm{~N}_{2} \mathrm{O}_{5}$ : 675.6; Found: 674.4 . 


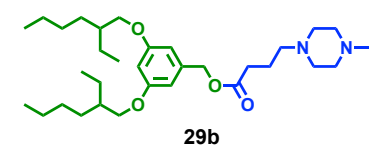

3,5-Bis((2-ethylhexyl)oxy)benzyl 4-(4-methylpiperazin-1-yl)butanoate (29b, IAJD76). Compound 29b was synthesized from compound $\mathbf{2 8 b}(0.26 \mathrm{~g}, 0.50 \mathrm{mmol}), 1$-methylpiperazine (56 $\mathrm{mg}, 0.56 \mathrm{mmol})$ and $\mathrm{K}_{2} \mathrm{CO}_{3}(0.10 \mathrm{~g}, 0.75 \mathrm{mmol})$ following a procedure similar to that used for the synthesis of compound 29a. The title compound was obtained as a colorless oil $(0.19 \mathrm{~g}, 69 \%)$. ${ }^{1} \mathrm{H} \mathrm{NMR}\left(500 \mathrm{MHz}, \mathrm{CDCl}_{3}\right) \delta 6.44$ (d, $2 \mathrm{H}, 2 \times \mathrm{PhH}), 6.38(\mathrm{t}, 1 \mathrm{H}, \mathrm{PhH}), 5.00$ (s, $\left.2 \mathrm{H},-\mathrm{CH}_{2} \mathrm{Ph}\right), 3.82-3.76\left(\mathrm{~m}, 4 \mathrm{H}, 2 \times \mathrm{PhOCH}_{2}-\right), 2.50$ (br, 8 $\left.\mathrm{H}, 2 \times-\mathrm{NCH}_{2} \mathrm{CH}_{2} \mathrm{~N}-\right), 2.40-2.35$ (m, $\left.4 \mathrm{H},-\mathrm{NCH}_{2} \mathrm{CH}_{2} \mathrm{CH}_{2} \mathrm{COO}-\right), 2.31$ (s, $\left.3 \mathrm{H}, \mathrm{NCH}_{3}\right), 1.84-1.80$ (m, $2 \mathrm{H}$, - $\left.\mathrm{NCH}_{2} \mathrm{CH}_{2} \mathrm{CH}_{2} \mathrm{COO}-\right)$, 1.70-1.64 (m, $\left.2 \mathrm{H}, 2 \times \mathrm{PhOCH}_{2} \mathrm{CH}\left(\mathrm{CH}_{2} \mathrm{CH}_{3}\right)\left(\mathrm{CH}_{2}\right)_{3} \mathrm{CH}_{3}\right), 1.51-1.24(\mathrm{~m}, 16 \mathrm{H}$, $\left.2 \times \mathrm{PhOCH}_{2} \mathrm{CH}\left(\mathrm{CH}_{2} \mathrm{CH}_{3}\right)\left(\mathrm{CH}_{2}\right)_{3} \mathrm{CH}_{3}\right), 0.91-0.86\left(\mathrm{~m}, 12 \mathrm{H}, 2 \times \mathrm{PhOCH}_{2} \mathrm{CH}\left(\mathrm{CH}_{2} \mathrm{CH}_{3}\right)\left(\mathrm{CH}_{2}\right)_{3} \mathrm{CH}_{3}\right) .{ }^{13} \mathrm{C}$ $\operatorname{NMR}\left(126 \mathrm{MHz}, \mathrm{CDCl}_{3}\right) \delta 173.3,160.7,138.0,106.4,100.9,70.5,66.3,57.4,54.9,52.6,45.7,39.4,32.2$, 30.6, 29.1, 23.9, 23.1, 22.1, 14.1, 11.2. Purity by HPLC: 99+\%. MALDI-TOF MS m/z of $[\mathrm{M}+\mathrm{H}]^{+}$ calculated for $\mathrm{C}_{32} \mathrm{H}_{57} \mathrm{~N}_{2} \mathrm{O}_{4}$ : 533.4; Found: 533.4.

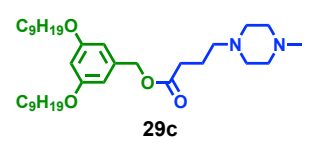

3,5-Bis(nonyloxy)benzyl 4-(4-methylpiperazin-1-yl)butanoate (29c, IAJD77). Compound 29c was synthesized from compound $\mathbf{2 8 c}(0.35 \mathrm{~g}, 0.64 \mathrm{mmol})$, 1-methylpiperazine (70 mg, $0.70 \mathrm{mmol})$ and $\mathrm{K}_{2} \mathrm{CO}_{3}$ (98 $\mathrm{mg}, 0.70 \mathrm{mmol}$ ) following a procedure similar to that used for the synthesis of compound 29a. The title compound was obtained as a light-yellow oil (0.26 g, 72\%). ${ }^{1} \mathrm{H}$ NMR $\left(400 \mathrm{MHz}, \mathrm{CDCl}_{3}\right) \delta 6.44(\mathrm{~d}$, $2 \mathrm{H}, 2 \times \mathrm{PhH}), 6.37(\mathrm{t}, 1 \mathrm{H}, \mathrm{PhH}), 5.01\left(\mathrm{~s}, 2 \mathrm{H},-\mathrm{CH}_{2} \mathrm{Ph}\right), 3.92-3.88$ (t, $\left.4 \mathrm{H}, 2 \times \mathrm{PhOCH}_{2}-\right), 2.42$ (br, $8 \mathrm{H}$, $2 \times-\mathrm{NCH}_{2} \mathrm{CH}_{2} \mathrm{~N}-$ ), 2.40-2.32 (m, $\left.4 \mathrm{H},-\mathrm{NCH}_{2} \mathrm{CH}_{2} \mathrm{CH}_{2} \mathrm{COO}-\right), 2.25$ (s, $3 \mathrm{H}, \mathrm{NCH}_{3}$ ), 1.85-1.79 (m, 2 H, $\left.\mathrm{NCH}_{2} \mathrm{CH}_{2} \mathrm{CH}_{2} \mathrm{COO}-\right), \quad 1.78-1.70 \quad\left(\mathrm{~m}, 4 \mathrm{H}, 2 \times \mathrm{PhOCH}_{2} \mathrm{CH}_{2}\left(\mathrm{CH}_{2}\right)_{6} \mathrm{CH}_{3}\right), \quad 1.46-1.25 \quad(\mathrm{~m}, 24 \mathrm{H}$, $\left.2 \times \mathrm{PhOCH}_{2} \mathrm{CH}_{2}\left(\mathrm{CH}_{2}\right)_{6} \mathrm{CH}_{3}\right), 0.88-0.85\left(\mathrm{~m}, 6 \mathrm{H}, 2 \times \mathrm{PhOCH}_{2} \mathrm{CH}_{2}\left(\mathrm{CH}_{2}\right)_{6} \mathrm{CH}_{3}\right) .{ }^{13} \mathrm{C} \mathrm{NMR}\left(101 \mathrm{MHz}, \mathrm{CDCl}_{3}\right)$ $\delta 173.4,160.5,138.2,106.4,101.0,68.1,66.2,57.6,55.2,53.2,46.1,32.3,31.8,29.8,29.6,29.5,29.4$, 29.3, 26.1, 22.8, 22.3, 14.2. Purity by HPLC: $99+\%$. MALDI-TOF MS m/z of $[\mathrm{M}+\mathrm{H}]^{+}$calculated for $\mathrm{C}_{34} \mathrm{H}_{61} \mathrm{~N}_{2} \mathrm{O}_{4}$ : 561.5; Found: 561.5 .

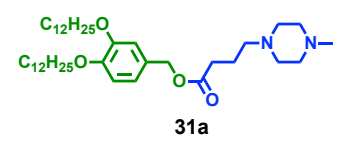

3,4-Bis(dodecyloxy)benzyl 4-(4-methylpiperazin-1-yl)butanoate (31a, IAJD78). Compound 31a was synthesized from compound 30a $(0.40 \mathrm{~g}, 0.64 \mathrm{mmol})$, 1-methylpiperazine (67 mg, $0.67 \mathrm{mmol})$ and $\mathrm{K}_{2} \mathrm{CO}_{3}$ 
(93 $\mathrm{mg}, 0.67 \mathrm{mmol}$ ) following a procedure similar to that used for the synthesis of compound 29a. The title compound was obtained as a viscous white solid $(0.36 \mathrm{~g}, 88 \%) .{ }^{1} \mathrm{H} \mathrm{NMR}\left(400 \mathrm{MHz}, \mathrm{CDCl}_{3}\right) \delta 6.93-$ $6.75(\mathrm{~m}, 3 \mathrm{H}, \mathrm{PhH}), 5.01$ (s, $\left.2 \mathrm{H},-\mathrm{CH}_{2} \mathrm{Ph}\right), 3.97$ (t, $\left.4 \mathrm{H}, 2 \times \mathrm{PhOCH}_{2}-\right), 2.65-2.28\left(\mathrm{~m}, 12 \mathrm{H}, \mathrm{N}\left(\mathrm{CH}_{2} \mathrm{CH}_{2}\right)_{2}\right.$ and $\left.-\mathrm{OCOCH}_{2} \mathrm{CH}_{2} \mathrm{CH}_{2}-\right), 2.26\left(\mathrm{~s}, 3 \mathrm{H},-\mathrm{N}\left(\mathrm{CH}_{2}-\right)_{2} \mathrm{CH}_{3}\right), 1.80\left(\mathrm{~m}, 6 \mathrm{H},-\mathrm{OCOCH}_{2} \mathrm{CH}_{2} \mathrm{CH}_{2}-\right.$ and $\left.\mathrm{PhOCH}_{2} \mathrm{CH}_{2}\left(\mathrm{CH}_{2}\right)_{9} \mathrm{CH}_{3}\right), \quad 1.45$ (m, $\left.4 \quad \mathrm{H}, \quad \mathrm{PhOCH}_{2} \mathrm{CH}_{2} \mathrm{CH}_{2}\left(\mathrm{CH}_{2}\right)_{8} \mathrm{CH}_{3}\right), \quad 1.25 \quad$ (br, $32 \mathrm{H}$,

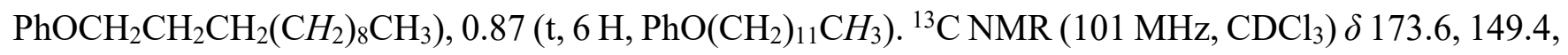
149.3, 128.7, 121.5, 114.5, 113.7, 69.4, 66.4, 57.7, 55.3, 53.2, 46.2, 32.4, 32.1, 29.8, 29.8, 29.8, 29.6, 29.5, 29.5, 29.4, 29.4, 26.2, 26.2, 22.8, 22.3, 14.2. Purity by HPLC: 99+\%. MALDI-TOF MS m/z of [M + H] calculated for $\mathrm{C}_{40} \mathrm{H}_{73} \mathrm{~N}_{2} \mathrm{O}_{4}$ : 645.6; Found: 645.3. $\mathrm{Mp}=33{ }^{\circ} \mathrm{C}$.

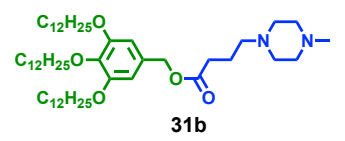

3,4,5-Tris(dodecyloxy)benzyl 4-(4-methylpiperazin-1-yl)butanoate (31b, IAJD79). Compound 31b was synthesized from compound $\mathbf{3 0 b}(0.47 \mathrm{~g}, 0.58 \mathrm{mmol}), 1$-methylpiperazine $(61 \mathrm{mg}, 0.61 \mathrm{mmol})$ and $\mathrm{K}_{2} \mathrm{CO}_{3}(84 \mathrm{mg}, 0.61 \mathrm{mmol})$ following a procedure similar to that used for the synthesis of compound 29a. The title compound was obtained as a light-yellow oil $(0.41 \mathrm{~g}, 85 \%) .{ }^{1} \mathrm{H}$ NMR $\left(400 \mathrm{MHz}, \mathrm{CDCl}_{3}\right) \delta 6.52$ (s, $2 \mathrm{H}, \mathrm{PhH}), 4.99$ (s, $\left.2 \mathrm{H},-\mathrm{CH}_{2} \mathrm{Ph}\right), 3.94\left(\mathrm{~m}, 6 \mathrm{H}, 3 \times \mathrm{PhOCH}_{2}-\right), 2.68-2.29\left(\mathrm{~m}, 12 \mathrm{H}, \mathrm{N}\left(\mathrm{CH}_{2} \mathrm{CH}_{2}\right)_{2}\right.$ and $\left.\mathrm{OCOCH}_{2} \mathrm{CH}_{2} \mathrm{CH}_{2-}\right), 2.26\left(\mathrm{~s}, 3 \mathrm{H},-\mathrm{N}\left(\mathrm{CH}_{2}\right)_{2} \mathrm{CH}_{3}\right), 1.78\left(\mathrm{~m}, 8 \mathrm{H}, \quad-\mathrm{OCOCH}_{2} \mathrm{CH}_{2} \mathrm{CH}_{2-}\right.$ and $\left.\mathrm{PhOCH}_{2} \mathrm{CH}_{2}\left(\mathrm{CH}_{2}\right)_{9} \mathrm{CH}_{3}\right), \quad 1.45 \quad\left(\mathrm{~m}, \quad 6 \quad \mathrm{H}, \quad \mathrm{PhOCH}_{2} \mathrm{CH}_{2} \mathrm{CH}_{2}\left(\mathrm{CH}_{2}\right)_{8} \mathrm{CH}_{3}\right), \quad 1.25 \quad$ (br, $48 \quad \mathrm{H}$,

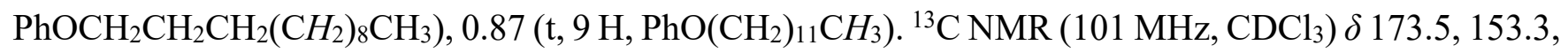
138.3, 131.0, 107.1, 73.5, 69.2, 66.7, 57.7, 55.3, 53.2, 46.2, 32.4, 32.1, 32.0, 30.5, 29.9, 29.8, 29.8, 29.8, 29.8, 29.7, 29.5, 29.5, 29.5, 26.2, 26.2, 22.8, 22.3, 14.2. Purity by HPLC: 99+\%. MALDI-TOF MS $m / z$ of $[\mathrm{M}+\mathrm{H}]^{+}$calculated for $\mathrm{C}_{52} \mathrm{H}_{97} \mathrm{~N}_{2} \mathrm{O}_{5}: 829.7$; Found: 830.2.

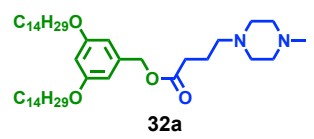

3,5-Bis(tetradecyloxy)benzyl 4-(4-methylpiperazin-1-yl)butanoate (32a, IAJD74). Compound 5 (0.24 g, 0.45 mmol, 1 equiv) and 4-(4-methylpiperazin-1-yl)butanoic acid hydrochloride (24b, $0.10 \mathrm{~g}, 0.45$ mmol, 1 equiv) were dissolved in 6 mL dry DCM. NEt 3 (3 drops) was added. DCC (0.19 g, 0.90 mmol, 2 equiv) was added in one portion into the above mixture. The reaction was allowed to stir at $23{ }^{\circ} \mathrm{C}$ for 12 h. Afterwards, urea was removed by filtration, and washed with DCM carefully. The filtrate was concentrated and purified by column chromatography $\left(\mathrm{SiO}_{2}\right)$ with $\mathrm{DCM} / \mathrm{MeOH}=40 / 1,20 / 1$ and 15/1 as the eluent. Then the product was dissolved in DCM $(20 \mathrm{~mL})$, which was washed by $\mathrm{NaHCO}_{3}$ solution 
$(2 \%, 20 \mathrm{~mL})$. The aqueous phase was extracted by DCM $(20 \mathrm{~mL})$ for another two times. The organic phase was combined and dried over anhydrous $\mathrm{MgSO}_{4}$. Filtration and evaporation of the solvent yielded the title compound as a light-yellow oil (0.22 g, 71\%). ${ }^{1} \mathrm{H}$ NMR (400 MHz, $\left.\mathrm{CDCl}_{3}\right) \delta 6.48(\mathrm{~d}, 2 \mathrm{H}, \mathrm{Ph} H)$, $6.42(\mathrm{t}, 1 \mathrm{H}, \mathrm{PhH}), 5.00$ (s, $2 \mathrm{H}, \mathrm{PhCH}_{2}$ ), 3.90 (t, $4 \mathrm{H}, 2 \times \mathrm{PhOCH}_{2}$ ) , 2.75-2.28 (m, $12 \mathrm{H},-\mathrm{NCH}_{2} \mathrm{CH}_{2} \mathrm{~N}-$ and $\left.-\mathrm{NCH}_{2} \mathrm{CH}_{2} \mathrm{CH}_{2} \mathrm{COO}-\right), 2.26\left(\mathrm{~s}, 3 \mathrm{H},-\mathrm{NCH}_{3}\right), 1.82\left(\mathrm{~m}, 2 \mathrm{H},-\mathrm{OCOCH}_{2} \mathrm{CH}_{2} \mathrm{CH}_{2}-\right), 1.75(\mathrm{~m}, 4 \mathrm{H}$, $\left.\mathrm{PhOCH}_{2} \mathrm{CH}_{2}\left(\mathrm{CH}_{2}\right)_{11} \mathrm{CH}_{3}\right), \quad 1.43\left(\mathrm{~m}, \quad 4 \quad \mathrm{H}, \quad \mathrm{PhOCH}_{2} \mathrm{CH}_{2} \mathrm{CH}_{2}\left(\mathrm{CH}_{2}\right)_{10} \mathrm{CH}_{3}\right), \quad 1.26 \quad$ (br, $40 \quad \mathrm{H}$, $\left.\mathrm{PhOCH}_{2} \mathrm{CH}_{2} \mathrm{CH}_{2}\left(\mathrm{CH}_{2}\right)_{10} \mathrm{CH}_{3}\right), 0.89\left(\mathrm{~m}, 6 \mathrm{H}, \mathrm{PhO}\left(\mathrm{CH}_{2}\right){ }_{13} \mathrm{CH}_{3}\right) .{ }^{13} \mathrm{C} \mathrm{NMR}\left(101 \mathrm{MHz}, \mathrm{CDCl}_{3}\right) \delta 173.4$, $160.5,138.2,106.5,101.0,68.2,66.3,57.7,55.3,53.2,46.2,32.4,32.0,29.7,29.7,29.5,29.5,29.4,26.2$, 22.8, 22.3, 14.2. Purity by HPLC: $99+\%$. MALDI-TOF MS $m / z$ of $[\mathrm{M}+\mathrm{H}]^{+}$calculated for $\mathrm{C}_{44} \mathrm{H}_{80} \mathrm{~N}_{2} \mathrm{O}_{4}$ : 701.6; Found: 700.8 .

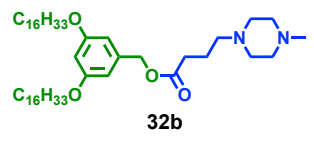

3,5-Bis(hexadecyloxy)benzyl 4-(4-methylpiperazin-1-yl)butanoate (32b, IAJD75). Compound 32b was synthesized from compound 6 (0.27 g, 0.45 mmol, 1 equiv), 4-(4-methylpiperazin-1-yl)butanoic acid hydrochloride (24b, $0.10 \mathrm{~g}, 0.45 \mathrm{mmol}, 1$ equiv) and DCC (0.19 g, $0.90 \mathrm{mmol}, 2$ equiv) following a procedure similar to that used for the synthesis of compound 32a. The title compound was obtained as a light-yellow oil (0.25 g, 73\%). ${ }^{1} \mathrm{H}$ NMR (400 MHz, $\left.\mathrm{CDCl}_{3}\right) \delta 6.48(\mathrm{~d}, 1 \mathrm{H}, \mathrm{Ph} H), 6.47(\mathrm{t}, 1 \mathrm{H}, \mathrm{PhH}), 6.42$ $(\mathrm{s}, 1 \mathrm{H}, \mathrm{PhH}), 5.02\left(\mathrm{~s}, 2 \mathrm{H}, \mathrm{PhCH}_{2^{-}}\right), 3.91\left(\mathrm{t}, 4 \mathrm{H}, 2 \times \mathrm{PhOCH}_{2^{-}}\right), 2.74-2.28$ (m, $15 \mathrm{H},-\mathrm{NCH}_{2} \mathrm{CH}_{2} \mathrm{~N}-$, $\mathrm{NCH}_{2} \mathrm{CH}_{2} \mathrm{CH}_{2} \mathrm{COO}-$ and $\left.-\mathrm{NCH}_{3}\right), 1.83$ (m, $2 \mathrm{H}, \quad-\mathrm{OCOCH}_{2} \mathrm{CH}_{2} \mathrm{CH}_{2}$ ), 1.75 (m, $4 \mathrm{H}$, $\left.\mathrm{PhOCH}_{2} \mathrm{CH}_{2}\left(\mathrm{CH}_{2}\right)_{13} \mathrm{CH}_{3}\right), \quad 1.43$ (m, $\left.4 \mathrm{H}, \quad \mathrm{PhOCH}_{2} \mathrm{CH}_{2} \mathrm{CH}_{2}\left(\mathrm{CH}_{2}\right)_{12} \mathrm{CH}_{3}\right), \quad 1.25$ (br, $48 \mathrm{H}$, $\left.\mathrm{PhOCH}_{2} \mathrm{CH}_{2} \mathrm{CH}_{2}\left(\mathrm{CH}_{2}\right)_{12} \mathrm{CH}_{3}\right), 0.87\left(\mathrm{~m}, 6 \mathrm{H}, \mathrm{PhO}\left(\mathrm{CH}_{2}\right){ }_{15} \mathrm{CH}_{3}\right) .{ }^{13} \mathrm{C} \mathrm{NMR}\left(101 \mathrm{MHz}, \mathrm{CDCl}_{3}\right) \delta 173.4$, $160.5,138.2$, 106.5, 101.0, 68.2, 66.2, 57.7, 55.3, 53.2, 46.2, 32.4, 32.0, 29.8, 29.7, 29.7, 29.5, 29.5, 29.4, 26.2, 22.8, 22.3, 14.2. Purity by HPLC: 99+\%. MALDI-TOF MS $m / z$ of $[\mathrm{M}+\mathrm{H}]^{+}$calculated for $\mathrm{C}_{48} \mathrm{H}_{88} \mathrm{~N}_{2} \mathrm{O}_{4}$ : 757.7; Found: 757.2. 


\subsection{Synthesis of IAJDs 81-86}

\section{Scheme S5. Synthesis of IAJDs 81-86}

(a)
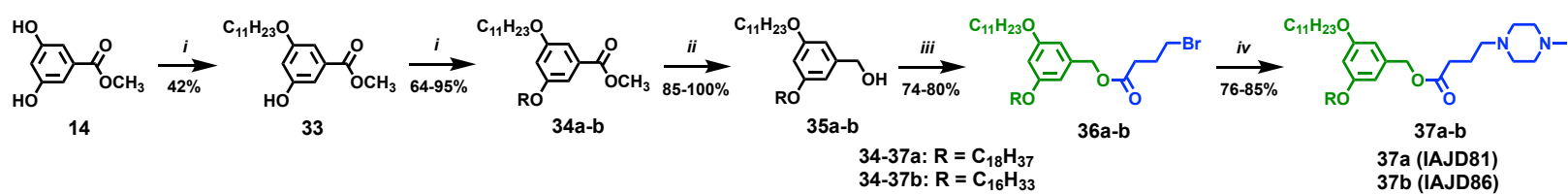

(b)
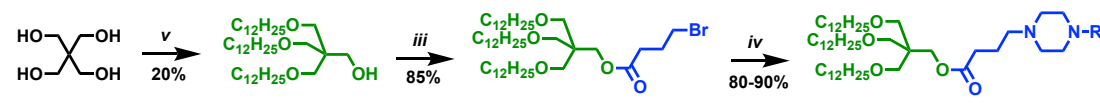

41a (IAJD82): $\mathrm{R}=\mathrm{CH}_{3}$ 41b (IAJD83): $\mathrm{R}=\mathrm{CH}_{2} \mathrm{CH}_{2} \mathrm{OH}$

38

39

40

41a-b

(c)

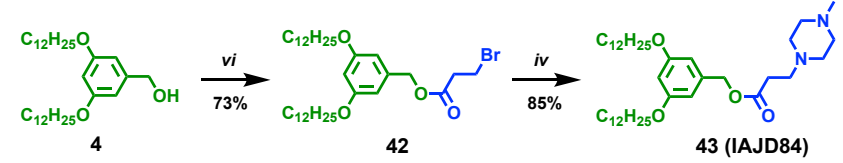

(d)
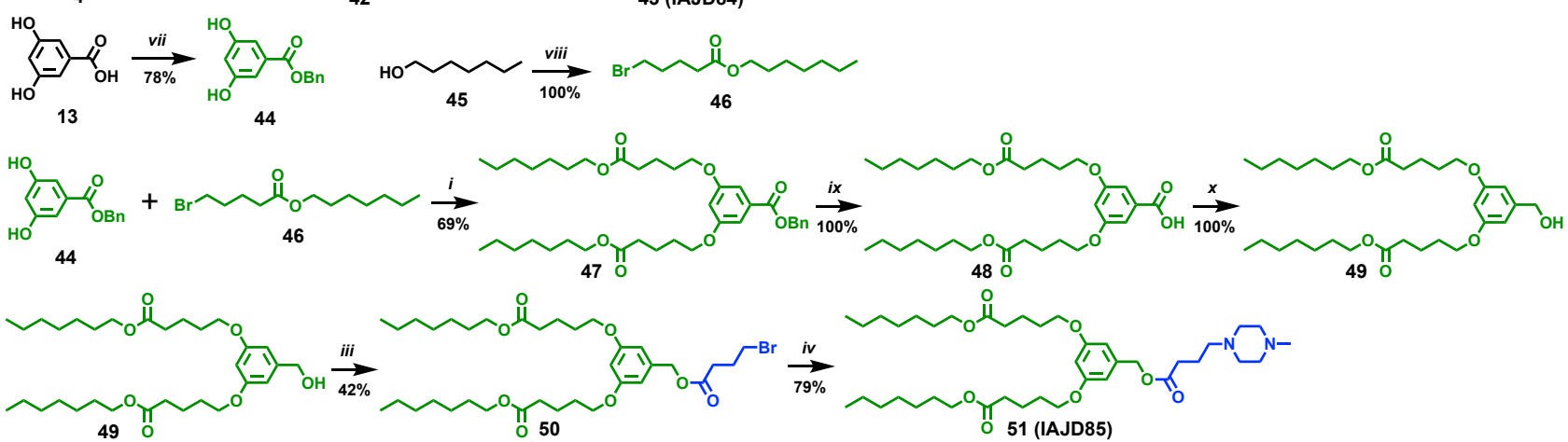

Reagents and conditions: (i) $\mathrm{RBr}, \mathrm{K}_{2} \mathrm{CO}_{3}$, DMF, $60{ }^{\circ} \mathrm{C}, 6 \mathrm{~h}$; (ii) $\mathrm{LiAlH}_{4}$, THF, 0-23 ${ }^{\circ} \mathrm{C}, 1 \mathrm{~h}$; (iii) 4bromobutyric acid, $\mathrm{SOCl}_{2}$, DMF (cat.), DCM, $23{ }^{\circ} \mathrm{C}, 1 \mathrm{~h}$, then DMAP, NEt 3 , DCM, 0-23 ${ }^{\circ} \mathrm{C}, 2 \mathrm{~h}$; (iv) 1methylpiperazine/1-(2-hydroxyethyl)piperazine, $\mathrm{K}_{2} \mathrm{CO}_{3}, \mathrm{MeCN}, 95{ }^{\circ} \mathrm{C}, 3 \mathrm{~h} ;(v) \mathrm{C}_{12} \mathrm{H}_{25} \mathrm{Br}, 50 \% \mathrm{NaOH}$, $\mathrm{TBABr}$ (cat.), $80{ }^{\circ} \mathrm{C}, 5 \mathrm{~h}$; (vi) 3-bromopropanoic acid, $\mathrm{SOCl}_{2}$, DMF (cat.), DCM, $23^{\circ} \mathrm{C}, 1 \mathrm{~h}$, then $\mathrm{NEt}_{3}$, DCM, 0-23 ${ }^{\circ} \mathrm{C}, 2 \mathrm{~h}$; (vii) $\mathrm{BnCl}, \mathrm{NaHCO}_{3}, \mathrm{DMF}, 40{ }^{\circ} \mathrm{C}, 12 \mathrm{~h}$; (viii) 5-bromovaleric acid, $\mathrm{SOCl}_{2}, \mathrm{DMF}$ (cat.), DCM, $23{ }^{\circ} \mathrm{C}, 1 \mathrm{~h}$, then DMAP, NEt 3 , DCM, 0-23 ${ }^{\circ} \mathrm{C}, 2 \mathrm{~h}$; (ix) $\mathrm{H}_{2}, \mathrm{Pd} / \mathrm{C}, \mathrm{DCM}, \mathrm{MeOH}, 12 \mathrm{~h} ;(x)$ $\mathrm{NaBH}_{4}, \mathrm{I}_{2}, \mathrm{THF}, 0-2{ }^{\circ} \mathrm{C}, 2 \mathrm{~h}$.

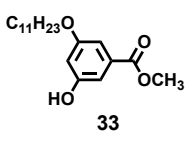

Methyl 3-hydroxy-5-(undecyloxy)benzoate (33). Methyl 3,5-dihydroxybenzoate (14, 5.00 g, 29.7 mmol, 1.2 equiv), 1-bromoundecane (5.83 g, $24.8 \mathrm{mmol}, 1$ equiv), and $\mathrm{K}_{2} \mathrm{CO}_{3}$ (3.42 $\mathrm{g}, 24.8 \mathrm{mmol}, 1$ equiv) were stirred in DMF $(50 \mathrm{~mL})$. The mixture was stirred at $60{ }^{\circ} \mathrm{C}$ under $\mathrm{N}_{2}$ atmosphere for $6 \mathrm{~h}$. The reaction mixture was cooled to $23^{\circ} \mathrm{C}$ and DMF was removed under reduced pressure. Then water $(30 \mathrm{~mL})$ was added, and the mixture was extracted by DCM $(30 \mathrm{~mL} \times 3)$. The organic phase was dried over anhydrous $\mathrm{MgSO}_{4}$ and filtered. The filtrate was concentrated and purified by column chromatography 
$\left(\mathrm{SiO}_{2}\right)$ with hexane/EtOAc $=10 / 1$ as the eluent to give the title compound as a white solid $(3.31 \mathrm{~g}, 42 \%)$. ${ }^{1} \mathrm{H} \mathrm{NMR}\left(400 \mathrm{MHz}, \mathrm{CDCl}_{3}\right) \delta 7.15(\mathrm{br}, 2 \mathrm{H}, \mathrm{Ph} H), 6.61$ (s, $\left.1 \mathrm{H}, \mathrm{PhH}\right), 5.73(\mathrm{~s}, 1 \mathrm{H}, \mathrm{PhOH}), 3.95$ (t, $2 \mathrm{H}$, $\left.\mathrm{PhOCH}_{2}-\right), 3.90$ (s, $\left.3 \mathrm{H}, \mathrm{PhCOOCH}_{3}\right), 1.77\left(\mathrm{~m}, 2 \mathrm{H}, \mathrm{PhOCH}_{2} \mathrm{CH}_{2}\left(\mathrm{CH}_{2}\right)_{8} \mathrm{CH}_{3}\right), 1.44(\mathrm{~m}, 2 \mathrm{H}$, $\left.\mathrm{PhOCH}_{2} \mathrm{CH}_{2} \mathrm{CH}_{2}\left(\mathrm{CH}_{2}\right)_{7} \mathrm{CH}_{3}\right), \quad 1.27$ (br, $\left.14 \quad \mathrm{H}, \quad \mathrm{PhOCH}_{2} \mathrm{CH}_{2} \mathrm{CH}_{2}\left(\mathrm{CH}_{2}\right)_{7} \mathrm{CH}_{3}\right), \quad 0.89 \quad$ (t, $3 \mathrm{H}$, $\left.\mathrm{PhO}\left(\mathrm{CH}_{2}\right)_{10} \mathrm{CH}_{3}\right) .{ }^{13} \mathrm{C} \mathrm{NMR}\left(101 \mathrm{MHz}, \mathrm{CDCl}_{3}\right) \delta 167.2$ 160.6, 157.0, 132.0, 109.2, 108.0, 107.2, 68.5, $52.5,32.1,29.8,29.7,29.7,29.5,29.5,29.3,26.1,22.9,14.3 . \mathrm{Mp}=87^{\circ} \mathrm{C}$.

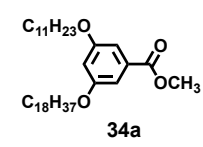

Methyl 3-(octadecyloxy)-5-(undecyloxy)benzoate (34a). Compound 34a was synthesized from compound 33 (1.0 g, 3.10 mmol, 1 equiv), 1-bromooctadecane (1.24 g, 3.72 mmol, 1.2 equiv), and $\mathrm{K}_{2} \mathrm{CO}_{3}$ ( $1.28 \mathrm{~g}, 9.30 \mathrm{mmol}, 3$ equiv) following a procedure similar to that used for the synthesis of compound 33. The title compound was obtained as a white solid (1.69 g, 95\%). ${ }^{1} \mathrm{H}$ NMR (400 MHz, $\left.\mathrm{CDCl}_{3}\right) \delta 7.15$ (br, $2 \mathrm{H}, \mathrm{Ph} H), 6.63(\mathrm{~s}, 1 \mathrm{H}, \mathrm{Ph} H), 3.96\left(\mathrm{t}, 4 \mathrm{H}, \mathrm{PhOCH}_{2^{-}}\right), 3.89$ (s, $\left.3 \mathrm{H}, \mathrm{PhCOOCH}_{3}\right), 1.77(\mathrm{~m}, 4 \mathrm{H}$, $\mathrm{PhOCH}_{2} \mathrm{CH}_{2}\left(\mathrm{CH}_{2}\right)_{15} \mathrm{CH}_{3}$ and $\left.\mathrm{PhOCH}_{2} \mathrm{CH}_{2}\left(\mathrm{CH}_{2}\right)_{8} \mathrm{CH}_{3}\right), 1.44\left(\mathrm{~m}, 4 \mathrm{H}, \mathrm{PhOCH}_{2} \mathrm{CH}_{2} \mathrm{CH}_{2}\left(\mathrm{CH}_{2}\right)_{14} \mathrm{CH}_{3}\right.$ and $\left.\mathrm{PhOCH}_{2} \mathrm{CH}_{2} \mathrm{CH}_{2}\left(\mathrm{CH}_{2}\right)_{7} \mathrm{CH}_{3}\right), \quad 1.26$ (br, $42 \quad \mathrm{H}, \quad \mathrm{PhOCH}_{2} \mathrm{CH}_{2} \mathrm{CH}_{2}\left(\mathrm{CH}_{2}\right)_{14} \mathrm{CH}_{3} \quad$ and $\left.\mathrm{PhOCH}_{2} \mathrm{CH}_{2} \mathrm{CH}_{2}\left(\mathrm{CH}_{2}\right)_{7} \mathrm{CH}_{3}\right), 0.88\left(\mathrm{t}, 6 \mathrm{H}, \mathrm{PhO}\left(\mathrm{CH}_{2}\right){ }_{17} \mathrm{CH}_{3}\right.$ and $\left.\mathrm{PhO}\left(\mathrm{CH}_{2}\right)_{10} \mathrm{CH}_{3}\right) .{ }^{13} \mathrm{C} \mathrm{NMR}(101 \mathrm{MHz}$, $\left.\mathrm{CDCl}_{3}\right) \delta 167.0,160.2,131.8,107.6,106.6,68.3,52.2,31.9,29.7,29.7,29.6,29.6,29.4,29.4,29.2,26.0$, 22.7, 14.1. $\mathrm{Mp}=65^{\circ} \mathrm{C}$.

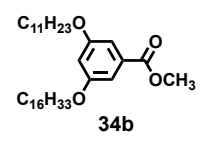

Methyl 3-(hexadecyloxy)-5-(undecyloxy)benzoate (34b). Compound 34b was synthesized from compound 33 (0.50 g, $1.55 \mathrm{mmol}, 1$ equiv), 1-bromohexadecane (0.52 g, $1.71 \mathrm{mmol}, 1.1$ equiv), and $\mathrm{K}_{2} \mathrm{CO}_{3}(0.64 \mathrm{~g}, 4.65 \mathrm{mmol}, 3$ equiv) following a procedure similar to that used for the synthesis of compound 33. The title compound was obtained as a white solid (0.54 g, 64\%). ${ }^{1} \mathrm{H}$ NMR (400 MHz, $\left.\mathrm{CDCl}_{3}\right) \delta 7.16(\mathrm{br}, 2 \mathrm{H}, \mathrm{Ph} H), 6.63(\mathrm{~s}, 1 \mathrm{H}, \mathrm{Ph} H), 3.96$ (t, $\left.4 \mathrm{H}, \mathrm{PhOCH}_{2}-\right), 3.89$ (s, $\left.3 \mathrm{H}, \mathrm{PhCOOCH}_{3}\right), 1.77$ $\left(\mathrm{m}, 4 \mathrm{H}, \quad \mathrm{PhOCH}_{2} \mathrm{CH}_{2}\left(\mathrm{CH}_{2}\right)_{13} \mathrm{CH}_{3}\right.$ and $\left.\mathrm{PhOCH}_{2} \mathrm{CH}_{2}\left(\mathrm{CH}_{2}\right)_{8} \mathrm{CH}_{3}\right), \quad 1.45 \quad(\mathrm{~m}, \quad 4 \quad \mathrm{H}$, $\mathrm{PhOCH}_{2} \mathrm{CH}_{2} \mathrm{CH}_{2}\left(\mathrm{CH}_{2}\right)_{12} \mathrm{CH}_{3} \quad$ and $\left.\mathrm{PhOCH}_{2} \mathrm{CH}_{2} \mathrm{CH}_{2}\left(\mathrm{CH}_{2}\right)_{7} \mathrm{CH}_{3}\right), \quad 1.26 \quad$ (br, $38 \quad \mathrm{H}$,

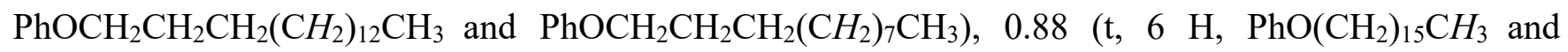
$\left.\mathrm{PhO}\left(\mathrm{CH}_{2}\right)_{10} \mathrm{CH}_{3}\right) .{ }^{13} \mathrm{C} \mathrm{NMR}\left(101 \mathrm{MHz}, \mathrm{CDCl}_{3}\right) \delta 167.1,160.3,131.9,107.7,106.7,68.4,52.3,32.1,32.0$, $29.8,29.8,29.7,29.7,29.7,29.5,29.5,29.3,26.1,22.8,14.3 . \mathrm{Mp}=62{ }^{\circ} \mathrm{C}$. 


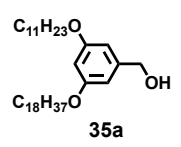

(3-(Octadecyloxy)-5-(undecyloxy)phenyl)methanol (35a). Compound 34a (1.0 g, 1.74 mmol, 1 equiv) was dissolved in $5 \mathrm{~mL}$ dry THF, which was added dropwise to a slurry of $\mathrm{LiAlH}_{4}(0.10 \mathrm{~g}, 2.61 \mathrm{mmol}, 1.5$ equiv) in dry $\mathrm{THF}(5 \mathrm{~mL})$ at $0{ }^{\circ} \mathrm{C}$ under $\mathrm{N}_{2}$ atmosphere. The resulted mixture was stirred at $23{ }^{\circ} \mathrm{C}$ for $1 \mathrm{~h}$. The reaction was quenched by the successive addition of water $(0.3 \mathrm{~mL}), 15 \% \mathrm{NaOH}$ aqueous solution $(0.3 \mathrm{~mL})$ and water $(1.5 \mathrm{~mL})$. Then the mixture was filtered to remove white precipitates and the filtrate was dried over anhydrous $\mathrm{MgSO}_{4}$. Filtration and evaporation of the solvent yielded the title compound as a white solid (0.95 g, 100\%). ${ }^{1} \mathrm{H}$ NMR (400 MHz, $\left.\mathrm{CDCl}_{3}\right) \delta 6.50(\mathrm{~s}, 2 \mathrm{H}, \mathrm{Ph} H), 6.38(\mathrm{~s}, 1 \mathrm{H}, \mathrm{Ph} H), 4.60$ (s, $\left.2 \mathrm{H}, \mathrm{PhCH}_{2} \mathrm{OH}\right), 3.93$ (t, $4 \mathrm{H}, \mathrm{PhOCH}_{2}$ ), 3.65 (t, $\left.1 \mathrm{H}, \mathrm{CH}_{2} \mathrm{OH}\right), 1.76\left(\mathrm{~m}, 4 \mathrm{H}, \mathrm{PhOCH}_{2} \mathrm{CH}_{2}\left(\mathrm{CH}_{2}\right)_{15} \mathrm{CH}_{3}\right.$ and $\left.\mathrm{PhOCH}_{2} \mathrm{CH}_{2}\left(\mathrm{CH}_{2}\right)_{8} \mathrm{CH}_{3}\right), \quad 1.55 \quad\left(\mathrm{~m}, \quad 4 \quad \mathrm{H}, \quad \mathrm{PhOCH}_{2} \mathrm{CH}_{2} \mathrm{CH}_{2}\left(\mathrm{CH}_{2}\right)_{14} \mathrm{CH}_{3}\right.$ and $\left.\mathrm{PhOCH}_{2} \mathrm{CH}_{2} \mathrm{CH}_{2}\left(\mathrm{CH}_{2}\right)_{7} \mathrm{CH}_{3}\right), \quad 1.27$ (br, $42 \quad \mathrm{H}, \quad \mathrm{PhOCH}_{2} \mathrm{CH}_{2} \mathrm{CH}_{2}\left(\mathrm{CH}_{2}\right)_{14} \mathrm{CH}_{3} \quad$ and $\left.\mathrm{PhOCH}_{2} \mathrm{CH}_{2} \mathrm{CH}_{2}\left(\mathrm{CH}_{2}\right)_{7} \mathrm{CH}_{3}\right), 0.89\left(\mathrm{~m}, 6 \mathrm{H}, \mathrm{PhO}\left(\mathrm{CH}_{2}\right){ }_{17} \mathrm{CH}_{3}\right.$ and $\left.\mathrm{PhO}\left(\mathrm{CH}_{2}\right){ }_{10} \mathrm{CH}_{3}\right) .{ }^{13} \mathrm{C} \mathrm{NMR}(101 \mathrm{MHz}$, $\left.\mathrm{CDCl}_{3}\right) \delta 160.6,143.3,105.2,100.6,68.2,65.5,32.1,32.1,29.8,29.8,29.7,29.5,29.5,29.5,29.4,26.2$, 22.8, 14.2. $\mathrm{Mp}=51^{\circ} \mathrm{C}$.

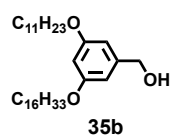

(3-(Hexadecyloxy)-5-(undecyloxy)phenyl)methanol (35b). Compound 35b was synthesized from compound 34b (0.50 g, $0.91 \mathrm{mmol}, 1$ equiv) and $\mathrm{LiAlH}_{4}(52 \mathrm{mg}, 1.37 \mathrm{mmol}, 1.5$ equiv) following a procedure similar to that used for the synthesis of compound 35a. The title compound was obtained as a white solid (0.40 g, 85\%). ${ }^{1} \mathrm{H}$ NMR (400 MHz, $\left.\mathrm{CDCl}_{3}\right) \delta 6.49$ (s, $\left.2 \mathrm{H}, \mathrm{Ph} H\right), 6.38(\mathrm{~s}, 1 \mathrm{H}, \mathrm{Ph} H), 4.61(\mathrm{~d}$, $\left.2 \mathrm{H}, \mathrm{PhCH}_{2} \mathrm{OH}\right), 3.93$ (t, $\left.4 \mathrm{H}, \mathrm{PhOCH}_{2}-\right), 3.63$ (t, $\left.1 \mathrm{H}, \mathrm{CH}_{2} \mathrm{OH}\right), 1.76$ (m, $4 \mathrm{H}, \mathrm{PhOCH}_{2} \mathrm{CH}_{2}\left(\mathrm{CH}_{2}\right)_{13} \mathrm{CH}_{3}$ and $\left.\mathrm{PhOCH}_{2} \mathrm{CH}_{2}\left(\mathrm{CH}_{2}\right)_{8} \mathrm{CH}_{3}\right), \quad 1.55 \quad\left(\mathrm{~m}, \quad 4 \quad \mathrm{H}, \quad \mathrm{PhOCH}_{2} \mathrm{CH}_{2} \mathrm{CH}_{2}\left(\mathrm{CH}_{2}\right)_{12} \mathrm{CH}_{3} \quad\right.$ and $\left.\mathrm{PhOCH}_{2} \mathrm{CH}_{2} \mathrm{CH}_{2}\left(\mathrm{CH}_{2}\right)_{7} \mathrm{CH}_{3}\right), \quad 1.26 \quad$ (br, $38 \quad \mathrm{H}, \quad \mathrm{PhOCH}_{2} \mathrm{CH}_{2} \mathrm{CH}_{2}\left(\mathrm{CH}_{2}\right)_{12} \mathrm{CH}_{3} \quad$ and $\left.\mathrm{PhOCH}_{2} \mathrm{CH}_{2} \mathrm{CH}_{2}\left(\mathrm{CH}_{2}\right)_{7} \mathrm{CH}_{3}\right), 0.89\left(\mathrm{~m}, 6 \mathrm{H}, \mathrm{PhO}\left(\mathrm{CH}_{2}\right){ }_{15} \mathrm{CH}_{3}\right.$ and $\left.\mathrm{PhO}\left(\mathrm{CH}_{2}\right){ }_{10} \mathrm{CH}_{3}\right) .{ }^{13} \mathrm{C} \mathrm{NMR}(101 \mathrm{MHz}$, $\left.\mathrm{CDCl}_{3}\right) \delta 160.8,143.4,105.2,100.7,68.1,65.5,31.9,29.7,29.7,29.6,29.4,29.4,29.3,26.1,22.7,14.1$. $\mathrm{Mp}=39{ }^{\circ} \mathrm{C}$.

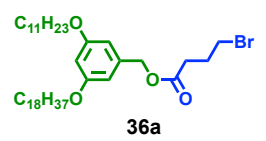


3-(Octadecyloxy)-5-(undecyloxy)benzyl 4-bromobutanoate (36a). 4-Bromobutyric acid (0.10 g, 0.60 mmol, 1.0 equiv) was dissolved in $5 \mathrm{~mL}$ anhydrous DCM and 1 drop of DMF was added. $\mathrm{SOCl}_{2}(0.14 \mathrm{~g}$, $1.20 \mathrm{mmol}, 2$ equiv) was added and the mixture was stirred at $23{ }^{\circ} \mathrm{C}$ for $1 \mathrm{~h}$. Afterwards, DCM and excess $\mathrm{SOCl}_{2}$ was removed under reduced pressure to give the 4-bromobutanoyl chloride. Compound $35 \mathbf{a}(0.35$ g, 0.60 mmol, 1 equiv) and $\mathrm{NEt}_{3}(0.12 \mathrm{~g}, 1.20 \mathrm{mmol}, 2$ equiv) were dissolved in $6 \mathrm{~mL}$ anhydrous DCM. Then DMAP (15 mg, $0.12 \mathrm{mmol}, 0.2$ equiv) was added. To this mixture was added the DCM solution (3 $\mathrm{mL}$ ) of above 4-bromobutanoyl chloride dropwise at $0{ }^{\circ} \mathrm{C}$. The mixture was allowed to warm to $23{ }^{\circ} \mathrm{C}$ with stirring during a $2 \mathrm{~h}$ period. Afterwards, water $(30 \mathrm{~mL})$ was added, and the mixture was extracted by $\operatorname{DCM}(30 \mathrm{~mL})$ for three times. The organic phase was collected, dried over anhydrous $\mathrm{MgSO}_{4}$ and filtered. The filtrate was concentrated and purified by column chromatography $\left(\mathrm{SiO}_{2}\right)$ with hexane/EtOAc $=20 / 1$ as the eluent to give the title compound as a colorless oil $(0.31 \mathrm{~g}, 74 \%) .{ }^{1} \mathrm{H}$ NMR $\left(400 \mathrm{MHz}, \mathrm{CDCl}_{3}\right) \delta$ 6.47 (br, $2 \mathrm{H}, \mathrm{PhH}), 6.41$ (s, $1 \mathrm{H}, \mathrm{PhH}), 5.05$ (s, $2 \mathrm{H}, \mathrm{PhCH}_{2^{-}}$), 3.93 (t, $4 \mathrm{H}, \mathrm{PhOCH}_{2}-$ ), 3.47 (t, $2 \mathrm{H}$, $\mathrm{OCOCH}_{2} \mathrm{CH}_{2} \mathrm{CH}_{2} \mathrm{Br}$ ), 2.57 (t, $\left.2 \mathrm{H},-\mathrm{OCOCH}_{2} \mathrm{CH}_{2} \mathrm{CH}_{2} \mathrm{Br}\right), 2.20$ (m, $\left.2 \mathrm{H},-\mathrm{OCOCH}_{2} \mathrm{CH}_{2} \mathrm{CH}_{2} \mathrm{Br}\right), 1.75$ (m, $4 \mathrm{H}, \mathrm{PhOCH}_{2} \mathrm{CH}_{2}\left(\mathrm{CH}_{2}\right)_{15} \mathrm{CH}_{3}$ and $\left.\mathrm{PhOCH}_{2} \mathrm{CH}_{2}\left(\mathrm{CH}_{2}\right)_{8} \mathrm{CH}_{3}\right), 1.44\left(\mathrm{~m}, 4 \mathrm{H}, \mathrm{PhOCH}_{2} \mathrm{CH}_{2} \mathrm{CH}_{2}\left(\mathrm{CH}_{2}\right)_{14} \mathrm{CH}_{3}\right.$ and $\left.\mathrm{PhOCH}_{2} \mathrm{CH}_{2} \mathrm{CH}_{2}\left(\mathrm{CH}_{2}\right)_{7} \mathrm{CH}_{3}\right), \quad 1.27$ (br, $42 \quad \mathrm{H}, \quad \mathrm{PhOCH}_{2} \mathrm{CH}_{2} \mathrm{CH}_{2}\left(\mathrm{CH}_{2}\right)_{14} \mathrm{CH}_{3}$ and $\left.\mathrm{PhOCH}_{2} \mathrm{CH}_{2} \mathrm{CH}_{2}\left(\mathrm{CH}_{2}\right)_{7} \mathrm{CH}_{3}\right), 0.89\left(\mathrm{~m}, 6 \mathrm{H}, \mathrm{PhO}\left(\mathrm{CH}_{2}\right)_{17} \mathrm{CH}_{3}\right.$ and $\left.\mathrm{PhO}\left(\mathrm{CH}_{2}\right){ }_{10} \mathrm{CH}_{3}\right) .{ }^{13} \mathrm{C} \mathrm{NMR}(101 \mathrm{MHz}$, $\left.\mathrm{CDCl}_{3}\right) \delta 172.3,160.6,137.9,106.4,101.1,68.2,66.5,32.7,32.5,32.0,32.0,29.8,29.8,29.7,29.7,29.5$, 29.5, 29.4, 29.3, 27.8, 26.2, 22.8 .

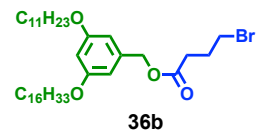

3-(Hexadecyloxy)-5-(undecyloxy)benzyl 4-bromobutanoate (36b). Compound 36b was synthesized from compound $35 \mathrm{~b}$ ( $0.37 \mathrm{~g}, 0.60 \mathrm{mmol}, 1$ equiv), 4-bromobutyric acid ( $0.10 \mathrm{~g}, 0.60 \mathrm{mmol}, 1.0$ equiv), $\mathrm{NEt}_{3}(0.12 \mathrm{~g}, 1.20 \mathrm{mmol}, 2$ equiv) and DMAP (15 mg, $0.12 \mathrm{mmol}, 0.2$ equiv) following a procedure similar to that used for the synthesis of compound 36a. The title compound was obtained as a colorless oil (0.33 g, 80\%). ${ }^{1} \mathrm{H}$ NMR (400 MHz, $\left.\mathrm{CDCl}_{3}\right) \delta 6.46(\mathrm{~d}, 2 \mathrm{H}, \mathrm{PhH}), 6.40(\mathrm{t}, 1 \mathrm{H}, \mathrm{PhH}), 5.03(\mathrm{~s}, 2 \mathrm{H}$, $\mathrm{PhCH}_{2-}$ ), 3.92 (t, $\left.4 \mathrm{H}, \mathrm{PhOCH}_{2}-\right), 3.45$ (t, $2 \mathrm{H},-\mathrm{OCOCH}_{2} \mathrm{CH}_{2} \mathrm{CH}_{2} \mathrm{Br}$ ), 2.55 (t, $2 \mathrm{H},-\mathrm{OCOCH}_{2} \mathrm{CH}_{2} \mathrm{CH}_{2} \mathrm{Br}$ ), $2.18\left(\mathrm{~m}, \quad 2 \mathrm{H}, \quad-\mathrm{OCOCH}_{2} \mathrm{CH}_{2} \mathrm{CH}_{2} \mathrm{Br}\right), \quad 1.76 \quad\left(\mathrm{~m}, \quad 4 \quad \mathrm{H}, \quad \mathrm{PhOCH}_{2} \mathrm{CH}_{2}\left(\mathrm{CH}_{2}\right)_{13} \mathrm{CH}_{3}\right.$ and $\left.\mathrm{PhOCH}_{2} \mathrm{CH}_{2}\left(\mathrm{CH}_{2}\right)_{8} \mathrm{CH}_{3}\right), 1.44$ (m, $4 \mathrm{H}, \mathrm{PhOCH}_{2} \mathrm{CH}_{2} \mathrm{CH}_{2}\left(\mathrm{CH}_{2}\right)_{12} \mathrm{CH}_{3}$ and $\left.\mathrm{PhOCH}_{2} \mathrm{CH}_{2} \mathrm{CH}_{2}\left(\mathrm{CH}_{2}\right)_{7} \mathrm{CH}_{3}\right)$, 1.27 (br, $38 \mathrm{H}, \mathrm{PhOCH}_{2} \mathrm{CH}_{2} \mathrm{CH}_{2}\left(\mathrm{CH}_{2}\right)_{12} \mathrm{CH}_{3}$ and $\left.\mathrm{PhOCH}_{2} \mathrm{CH}_{2} \mathrm{CH}_{2}\left(\mathrm{CH}_{2}\right)_{7} \mathrm{CH}_{3}\right), 0.88$ (m, $6 \mathrm{H}$, $\mathrm{PhO}\left(\mathrm{CH}_{2}\right){ }_{15} \mathrm{CH}_{3}$ and $\left.\mathrm{PhO}\left(\mathrm{CH}_{2}\right){ }_{10} \mathrm{CH}_{3}\right) .{ }^{13} \mathrm{C} \mathrm{NMR}\left(101 \mathrm{MHz}, \mathrm{CDCl}_{3}\right) \delta 172.3,160.6,137.9,106.4,101.1$, 68.1, 66.4, 32.6, 32.5, 32.0, 32.0, 29.8, 29.8, 29.7, 29.7, 29.5, 29.5, 29.5, 29.4, 27.8, 26.2, 22.8. 


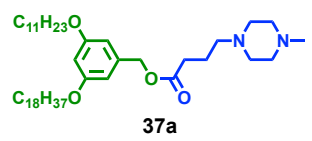

\section{3-(Octadecyloxy)-5-(undecyloxy)benzyl 4-(4-methylpiperazin-1-yl)butanoate (37a, IAJD81).}

Compound 36a (0.24 g, $0.35 \mathrm{mmol}, 1$ equiv), 1-methylpiperazine ( $37 \mathrm{mg}, 0.36 \mathrm{mmol}, 1.05$ equiv), $\mathrm{K}_{2} \mathrm{CO}_{3}$ (53 mg, $0.38 \mathrm{mmol}, 1.1$ equiv) were stirred in $\mathrm{MeCN}(20 \mathrm{~mL})$. The mixture was heated at reflux $\left(95^{\circ} \mathrm{C}\right)$ for $3 \mathrm{~h}$. The reaction mixture was cooled to $23^{\circ} \mathrm{C}$ and $\mathrm{MeCN}$ was removed under reduced pressure. Then water $(20 \mathrm{~mL})$ was added, and the mixture was extracted by DCM $(20 \mathrm{~mL} \times 3)$. The organic phase was collected, dried over anhydrous $\mathrm{MgSO}_{4}$, filtered and dried to give the crude product. The crude product was purified by column chromatography $\left(\mathrm{SiO}_{2}\right)$ with $\mathrm{DCM} / \mathrm{MeOH}=30 / 1$ and $15 / 1$ as the eluent. Then the obtained product was dissolved in DCM $(20 \mathrm{~mL})$, which was washed by $\mathrm{NaHCO}_{3}$ solution $(2 \%, 20$ $\mathrm{mL})$. The aqueous phase was extracted by DCM $(20 \mathrm{~mL})$ for another two times. The organic phase was combined and dried over anhydrous $\mathrm{MgSO}_{4}$. Filtration and evaporation of the solvent yielded the title compound as a light-yellow oil (0.21 g, 85\%). ${ }^{1} \mathrm{H}$ NMR (400 MHz, $\left.\mathrm{CDCl}_{3}\right) \delta 6.44(\mathrm{~d}, 2 \mathrm{H}, \mathrm{Ph} H), 6.37(\mathrm{t}$, $1 \mathrm{H}, \mathrm{PhH}), 5.01\left(\mathrm{~s}, 2 \mathrm{H}, \mathrm{PhCH}_{2^{-}}\right), 3.90\left(\mathrm{t}, 4 \mathrm{H}, \mathrm{PhOCH}_{2^{-}}\right), 2.74-2.28\left(\mathrm{~m}, 15 \mathrm{H},-\mathrm{NCH}_{2} \mathrm{CH}_{2} \mathrm{~N}-\right.$, $\mathrm{NCH}_{2} \mathrm{CH}_{2} \mathrm{CH}_{2} \mathrm{COO}-$ and $\left.-\mathrm{NCH}_{3}\right), 1.82$ (m, $2 \mathrm{H}, \quad-\mathrm{OCOCH}_{2} \mathrm{CH}_{2} \mathrm{CH}_{2}$ ), 1.73 (m, $4 \mathrm{H}$, $\mathrm{PhOCH}_{2} \mathrm{CH}_{2}\left(\mathrm{CH}_{2}\right)_{15} \mathrm{CH}_{3}$ and $\left.\mathrm{PhOCH}_{2} \mathrm{CH}_{2}\left(\mathrm{CH}_{2}\right)_{8} \mathrm{CH}_{3}\right), 1.42\left(\mathrm{~m}, 4 \mathrm{H}, \mathrm{PhOCH}_{2} \mathrm{CH}_{2} \mathrm{CH}_{2}\left(\mathrm{CH}_{2}\right)_{14} \mathrm{CH}_{3}\right.$ and $\left.\mathrm{PhOCH}_{2} \mathrm{CH}_{2} \mathrm{CH}_{2}\left(\mathrm{CH}_{2}\right)_{7} \mathrm{CH}_{3}\right), \quad 1.24$ (br, $42 \quad \mathrm{H}, \quad \mathrm{PhOCH}_{2} \mathrm{CH}_{2} \mathrm{CH}_{2}\left(\mathrm{CH}_{2}\right)_{14} \mathrm{CH}_{3} \quad$ and $\left.\mathrm{PhOCH}_{2} \mathrm{CH}_{2} \mathrm{CH}_{2}\left(\mathrm{CH}_{2}\right)_{7} \mathrm{CH}_{3}\right), 0.86\left(\mathrm{~m}, 6 \mathrm{H}, \mathrm{PhO}\left(\mathrm{CH}_{2}\right){ }_{17} \mathrm{CH}_{3}\right.$ and $\left.\mathrm{PhO}\left(\mathrm{CH}_{2}\right){ }_{10} \mathrm{CH}_{3}\right) .{ }^{13} \mathrm{C} \mathrm{NMR}(101 \mathrm{MHz}$, $\left.\mathrm{CDCl}_{3}\right) \delta 173.3,160.5,138.1,106.4,100.9,68.1,66.2,57.5,55.0,52.8,45.8,32.3,32.0,32.0,29.8,29.7$, 29.7, 29.5, 29.4, 29.4, 29.3, 26.1, 22.8, 22.1, 14.2. Purity by HPLC: 99+\%. MALDI-TOF MS $m / z$ of [M $+\mathrm{H}]^{+}$calculated for $\mathrm{C}_{45} \mathrm{H}_{82} \mathrm{~N}_{2} \mathrm{O}_{4}$ : 715.6; Found: 715.3.

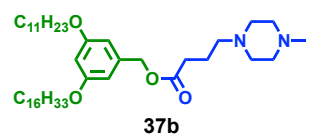

3-(Hexadecyloxy)-5-(undecyloxy)benzyl 4-(4-methylpiperazin-1-yl)butanoate (37b, IAJD86). Compound 37b was synthesized from compound $\mathbf{3 6 b}$ ( $0.33 \mathrm{~g}, 0.49 \mathrm{mmol}, 1$ equiv), 1-methylpiperazine (52 mg, $0.52 \mathrm{mmol}, 1.05$ equiv) and $\mathrm{K}_{2} \mathrm{CO}_{3}(74 \mathrm{mg}, 0.53 \mathrm{mmol}, 1.1$ equiv) following a procedure similar to that used for the synthesis of compound 37a. The title compound was obtained as a light-yellow oil (0.31 g, 76\%). ${ }^{1} \mathrm{H}$ NMR (400 MHz, $\left.\mathrm{CDCl}_{3}\right) \delta 6.45$ (d, $\left.2 \mathrm{H}, \mathrm{PhH}\right), 6.39$ (t, $\left.1 \mathrm{H}, \mathrm{Ph} H\right), 5.29\left(\mathrm{~s}, 2 \mathrm{H}, \mathrm{PhCH}_{2^{-}}\right.$ ), 3.91 (t, $\left.4 \mathrm{H}, \mathrm{PhOCH}_{2}-\right)$, 2.76-2.29 (m, $15 \mathrm{H},-\mathrm{NCH}_{2} \mathrm{CH}_{2} \mathrm{~N}-,-\mathrm{NCH}_{2} \mathrm{CH}_{2} \mathrm{CH}_{2} \mathrm{COO}-$ and $\left.-\mathrm{NCH}_{3}\right), 1.85$ (m, $\left.2 \mathrm{H},-\mathrm{OCOCH}_{2} \mathrm{CH}_{2} \mathrm{CH}_{2}-\right), 1.75\left(\mathrm{~m}, 4 \mathrm{H}, \mathrm{PhOCH}_{2} \mathrm{CH}_{2}\left(\mathrm{CH}_{2}\right)_{13} \mathrm{CH}_{3}\right.$ and $\left.\mathrm{PhOCH}_{2} \mathrm{CH}_{2}\left(\mathrm{CH}_{2}\right)_{8} \mathrm{CH}_{3}\right), 1.45(\mathrm{~m}$,

$4 \mathrm{H}, \quad \mathrm{PhOCH}_{2} \mathrm{CH}_{2} \mathrm{CH}_{2}\left(\mathrm{CH}_{2}\right)_{12} \mathrm{CH}_{3}$ and $\left.\mathrm{PhOCH}_{2} \mathrm{CH}_{2} \mathrm{CH}_{2}\left(\mathrm{CH}_{2}\right)_{7} \mathrm{CH}_{3}\right), \quad 1.26 \quad$ (br, $38 \mathrm{H}$, 


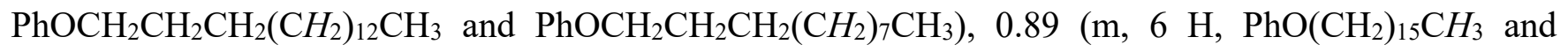
$\left.\mathrm{PhO}\left(\mathrm{CH}_{2}\right)_{10} \mathrm{CH}_{3}\right) .{ }^{13} \mathrm{C} \mathrm{NMR}\left(101 \mathrm{MHz}, \mathrm{CDCl}_{3}\right) \delta 173.2,160.4,138.0,106.3,100.8,68.0,66.1,57.4,54.9$, 52.6, 45.7, 32.2 , 31.9, 31.9, 29.7, 29.7, 29.6, 29.6, 29.4, 29.4, 29.3, 29.2, 26.0, 22.7, 22.0, 14.1. Purity by HPLC: $99+\%$. MALDI-TOF MS $m / z$ of $[\mathrm{M}+\mathrm{H}]^{+}$calculated for $\mathrm{C}_{43} \mathrm{H}_{78} \mathrm{~N}_{2} \mathrm{O}_{4}$ : 687.6; Found: 687.2 .

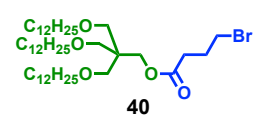

3-(Dodecyloxy)-2,2-bis((dodecyloxy)methyl)propyl 4-bromobutanoate (40). The synthesis and characterizations of 3-(dodecyloxy)-2,2-bis((dodecyloxy)methyl)propan-1-ol (39) were reported in the literature..$^{5}$ 4-Bromobutyric acid ( $0.15 \mathrm{~g}, 0.86 \mathrm{mmol}, 1.1$ equiv) was dissolved in $5 \mathrm{~mL}$ anhydrous DCM and 1 drop of DMF was added. $\mathrm{SOCl}_{2}(0.19 \mathrm{~g}, 1.56 \mathrm{mmol}, 2$ equiv) was added and the mixture was stirred at $23{ }^{\circ} \mathrm{C}$ for $1 \mathrm{~h}$. Afterwards, DCM and excess $\mathrm{SOCl}_{2}$ was removed under reduced pressure to give the 4bromobutanoyl chloride. Compound 39 (0.50 g, 0.78 mmol, 1.0 equiv) and $\mathrm{NEt}_{3}$ (87 mg, 0.86 mmol, 1.1 equiv) were dissolved in $6 \mathrm{~mL}$ anhydrous DCM. To this mixture was added the DCM solution $(3 \mathrm{~mL})$ of above 4-bromobutanoyl chloride dropwise at $0{ }^{\circ} \mathrm{C}$. The mixture was allowed to warm to $23{ }^{\circ} \mathrm{C}$ with stirring during a $2 \mathrm{~h}$ period. Afterwards, water $(20 \mathrm{~mL})$ was added, and the mixture was extracted by DCM (20 $\mathrm{mL}$ ) for three times. The organic phase was collected, dried over anhydrous $\mathrm{MgSO}_{4}$ and filtered. The filtrate was concentrated and purified by column chromatography $\left(\mathrm{SiO}_{2}\right)$ with hexane/EtOAc $=40 / 1$ as the eluent to give the title compound as a colorless oil $(0.48 \mathrm{~g}, 85 \%)$. ${ }^{1} \mathrm{H}$ NMR $\left(500 \mathrm{MHz}, \mathrm{CDCl}_{3}\right) \delta 4.15$ (s, $\left.2 \mathrm{H},-\mathrm{CH}_{2} \mathrm{COO}\right), 3.49$ (t, $\left.2 \mathrm{H},-\mathrm{OCOCH}_{2} \mathrm{CH}_{2} \mathrm{CH}_{2} \mathrm{Br}\right), 3.43-3.32\left(\mathrm{~m}, 12 \mathrm{H},-\mathrm{CH}_{2} \mathrm{OCH}_{2}\left(\mathrm{CH}_{2}\right){ }_{10} \mathrm{CH}_{3}\right)$, 2.52 (t, $\left.2 \mathrm{H},-\mathrm{OCOCH}_{2} \mathrm{CH}_{2} \mathrm{CH}_{2} \mathrm{Br}\right), 2.19$ (m, $2 \mathrm{H},-\mathrm{CH}_{2} \mathrm{OCOCH}_{2} \mathrm{CH}_{2} \mathrm{CH}_{2} \mathrm{Br}$ ), 1.60-1.49 (m, $12 \mathrm{H}, 3 \times-$ $\left.\mathrm{OCH}_{2} \mathrm{CH}_{2} \mathrm{CH}_{2}\left(\mathrm{CH}_{2}\right)_{8} \mathrm{CH}_{3}\right), 1.29$ (br, $\left.48 \mathrm{H}, 3 \times-\mathrm{OCH}_{2} \mathrm{CH}_{2} \mathrm{CH}_{2}\left(\mathrm{CH}_{2}\right)_{8} \mathrm{CH}_{3}\right), \quad 0.91 \quad(\mathrm{~m}, 9 \mathrm{H}, 3 \times-$ $\left.\mathrm{O}\left(\mathrm{CH}_{2}\right)_{11} \mathrm{CH}_{3}\right) .{ }^{13} \mathrm{C} \mathrm{NMR}\left(126 \mathrm{MHz}, \mathrm{CDCl}_{3}\right) \delta 172.3,71.6,69.5,64.4,44.4,32.7,32.5,32.0,29.7,29.7$, $29.7,29.6,29.5,29.4,27.9,26.2,22.7,14.1$.

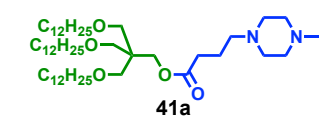

3-(Dodecyloxy)-2,2-bis((dodecyloxy)methyl)propyl 4-(4-methylpiperazin-1-yl)butanoate (41a, IAJD82). Compound 40 (0.15 g, $0.19 \mathrm{mmol}, 1$ equiv), 1-methylpiperazine (26 mg, $0.20 \mathrm{mmol}, 1.05$ equiv), $\mathrm{K}_{2} \mathrm{CO}_{3}$ (26 mg, $0.20 \mathrm{mmol}, 1.05$ equiv) were stirred in $\mathrm{MeCN}$ (15 mL). The mixture was heated at reflux $\left(95^{\circ} \mathrm{C}\right)$ for $3 \mathrm{~h}$. The reaction mixture was cooled to $23{ }^{\circ} \mathrm{C}$ and $\mathrm{MeCN}$ was removed under reduced pressure. Then water $(20 \mathrm{~mL})$ was added, and the mixture was extracted by DCM $(20 \mathrm{~mL} \times 3)$. The organic phase was collected, dried over anhydrous $\mathrm{MgSO}_{4}$, filtered and dried to give the crude product. The crude 
product was purified by column chromatography $\left(\mathrm{SiO}_{2}\right)$ with $\mathrm{DCM} / \mathrm{MeOH}=30 / 1$ and $20 / 1$ as the eluent. Then the obtained product was dissolved in DCM $(20 \mathrm{~mL})$, which was washed by $\mathrm{NaHCO}_{3}$ solution $(2 \%$, $20 \mathrm{~mL})$. The aqueous phase was extracted by DCM $(20 \mathrm{~mL})$ for another two times. The organic phase was combined and dried over anhydrous $\mathrm{MgSO}_{4}$. Filtration and evaporation of the solvent yielded the title compound as a light-yellow oil ( $0.13 \mathrm{~g}, 80 \%) .{ }^{1} \mathrm{H} \mathrm{NMR}\left(400 \mathrm{MHz}, \mathrm{CDCl}_{3}\right) \delta 4.13$ (s, $2 \mathrm{H},-\mathrm{CH}_{2} \mathrm{OCO}$ ), $3.38\left(\mathrm{~m}, 12 \mathrm{H},-\mathrm{CH}_{2} \mathrm{OCH}_{2}\left(\mathrm{CH}_{2}\right)_{10} \mathrm{CH}_{3}\right), 2.54\left(\mathrm{br}, 7 \mathrm{H},-\mathrm{N}\left(\mathrm{CH}_{2} \mathrm{CH}_{2}\right)_{2} \mathrm{NCH}_{3}\right.$ and $\left.-\mathrm{OCOCH}_{2} \mathrm{CH}_{2} \mathrm{CH}_{2}\right), 2.46-$ $2.28\left(\mathrm{~m}, 8 \mathrm{H},-\mathrm{N}\left(\mathrm{CH}_{2} \mathrm{CH}_{2}\right)_{2} \mathrm{NCH}_{3}\right), 1.83\left(\mathrm{~m}, 2 \mathrm{H},-\mathrm{OCOCH}_{2} \mathrm{CH}_{2} \mathrm{CH}_{2}\right), 1.62-1.48(\mathrm{~m}, 6 \mathrm{H}, 3 \times-$ $\left.\mathrm{OCH}_{2} \mathrm{CH}_{2}\left(\mathrm{CH}_{2}\right)_{9} \mathrm{CH}_{3}\right), \quad 1.29$ (br, $\left.54 \mathrm{H}, \quad 3 \times-\mathrm{OCH}_{2} \mathrm{CH}_{2}\left(\mathrm{CH}_{2}\right)_{9} \mathrm{CH}_{3}\right), \quad 0.99-0.86$ (m, $9 \mathrm{H}, 3 \times-$ $\left.\mathrm{O}\left(\mathrm{CH}_{2}\right)_{11} \mathrm{CH}_{3}\right) .{ }^{13} \mathrm{C} \mathrm{NMR}\left(101 \mathrm{MHz}, \mathrm{CDCl}_{3}\right) \delta 173.2,71.6,69.5,64.1,57.5,54.9,52.7,45.8,44.5,32.2$, $31.9,29.7,29.7,29.6,29.5,29.4,26.2,22.7,22.1,14.1$. Purity by HPLC: $99+\%$. MALDI-TOF MS $m / z$ of $[\mathrm{M}+\mathrm{H}]^{+}$calculated for $\mathrm{C}_{50} \mathrm{H}_{101} \mathrm{~N}_{2} \mathrm{O}_{5}: 809.8$; Found: 808.5.

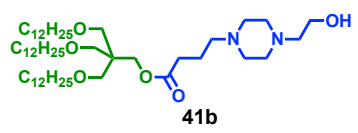

3-(Dodecyloxy)-2,2-bis((dodecyloxy)methyl)propyl 4-(4-(2-hydroxyethyl)piperazin-1-yl)butanoate (41b, IAJD83). Compound 41b was synthesized from compound 40 (0.19 g, 0.24 mmol, 1 equiv), 1-(2hydroxyethyl)piperazine ( $33 \mathrm{mg}, 0.25 \mathrm{mmol}, 1.05$ equiv) and $\mathrm{K}_{2} \mathrm{CO}_{3}(33 \mathrm{mg}, 0.25 \mathrm{mmol}, 1.05$ equiv) following a procedure similar to that used for the synthesis of compound 41a. The title compound was obtained as a light-yellow oil ( $0.18 \mathrm{~g}, 90 \%) .{ }^{1} \mathrm{H}$ NMR (400 MHz, $\left.\mathrm{CDCl}_{3}\right) \delta 4.12$ (s, $2 \mathrm{H},-\mathrm{CH}_{2} \mathrm{OCO}$ ), 3.64 (t, $\left.2 \mathrm{H},-\mathrm{NCH}_{2} \mathrm{CH} \mathrm{H}_{2} \mathrm{OH}\right), 3.37\left(\mathrm{~m}, 12 \mathrm{H}, 3 \times-\mathrm{CH}_{2} \mathrm{OCH}_{2}\left(\mathrm{CH}_{2}\right)_{10} \mathrm{CH}_{3}\right), 3.08$ (s, $1 \mathrm{H},-\mathrm{NCH}_{2} \mathrm{CH}_{2} \mathrm{OH}$ ), 2.67$2.48\left(\mathrm{~m}, 10 \mathrm{H},-\mathrm{N}\left(\mathrm{CH}_{2} \mathrm{CH}_{2}\right)_{2} \mathrm{NCH}_{2} \mathrm{CH}_{2} \mathrm{OH}\right), 2.38\left(\mathrm{~m}, 4 \mathrm{H},-\mathrm{COOCH}_{2} \mathrm{CH}_{2} \mathrm{CH}_{2}\right), 1.83(\mathrm{~m}, 2 \mathrm{H},-$ $\left.\mathrm{OCOCH}_{2} \mathrm{CH}_{2} \mathrm{CH}_{2}\right), \quad 1.58-1.46\left(\mathrm{~m}, \quad 6 \quad \mathrm{H}, \quad 3 \times-\mathrm{OCH}_{2} \mathrm{CH}_{2}\left(\mathrm{CH}_{2}\right)_{9} \mathrm{CH}_{3}\right), \quad 1.29 \quad($ br, $54 \quad \mathrm{H}, \quad 3 \times-$ $\left.\mathrm{OCH}_{2} \mathrm{CH}_{2}\left(\mathrm{CH}_{2}\right)_{9} \mathrm{CH}_{3}\right), 0.90$ (t, $\left.9 \mathrm{H}, 3 \times-\mathrm{O}\left(\mathrm{CH}_{2}\right)_{11} \mathrm{CH}_{3}\right) .{ }^{13} \mathrm{C} \mathrm{NMR}\left(101 \mathrm{MHz}, \mathrm{CDCl}_{3}\right) \delta$ 173.2, 77.2, 71.6, 69.5, 64.1, 59.3, 57.6, 57.6, 52.9, 52.8, 44.5, 32.2, 31.9, 29.7, 29.7, 29.7, 29.6, 29.5, 29.4, 26.2, 22.7, 22.1, 14.1. Purity by HPLC: $99+\%$. MALDI-TOF MS $m / z$ of $[\mathrm{M}+\mathrm{H}]^{+}$calculated for $\mathrm{C}_{51} \mathrm{H}_{103} \mathrm{~N}_{2} \mathrm{O}_{6}: 839.8$; Found: 838.3 .

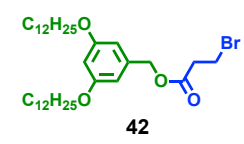

3,5-Bis(dodecyloxy)benzyl 3-bromopropanoate (42). 3-Bromopropanoic acid (0.16 g, 1.05 mmol, 1.0 equiv) was dissolved in $5 \mathrm{~mL}$ anhydrous DCM and 1 drop of DMF was added. $\mathrm{SOCl}_{2}(0.25 \mathrm{~g}, 2.10 \mathrm{mmol}$, 2.0 equiv) was added and the mixture was stirred at $23{ }^{\circ} \mathrm{C}$ for $1 \mathrm{~h}$. Afterwards, DCM and excess $\mathrm{SOCl}_{2}$ was removed under reduced pressure to give the 3-bromopropanoyl chloride. Compound 4 ( $0.50 \mathrm{~g}, 1.05$ 
mmol, 1.0 equiv) and $\mathrm{NEt}_{3}(0.12 \mathrm{~g}, 1.16 \mathrm{mmol}, 1.1$ equiv) were dissolved in $6 \mathrm{~mL}$ anhydrous DCM. To this mixture was added the DCM solution $\left(3 \mathrm{~mL}\right.$ ) of above 3 -bromopropanoyl chloride dropwise at $0{ }^{\circ} \mathrm{C}$. The mixture was allowed to warm to $23{ }^{\circ} \mathrm{C}$ with stirring during a $2 \mathrm{~h}$ period. Afterwards, water $(30 \mathrm{~mL})$ was added, and the mixture was extracted by DCM $(30 \mathrm{~mL})$ for three times. The organic phase was collected, dried over anhydrous $\mathrm{MgSO}_{4}$ and filtered. The filtrate was concentrated and purified by column chromatography $\left(\mathrm{SiO}_{2}\right)$ with hexane/EtOAc $=20 / 1$ as the eluent to give the title compound as a colorless oil (0.47 g, 73\%). ${ }^{1} \mathrm{H}$ NMR (400 MHz, $\left.\mathrm{CDCl}_{3}\right) \delta 6.53-6.36\left(\mathrm{~m}, 5 \mathrm{H}, \mathrm{PhH}\right.$ and $\left.-\mathrm{OCOCH}_{2} \mathrm{CH}_{2} \mathrm{Br}\right), 6.18(\mathrm{~m}$, $\left.1 \mathrm{H},-\mathrm{OCOCH}_{2} \mathrm{CH}_{2} \mathrm{Br}\right), 5.85\left(\mathrm{~m}, 1 \mathrm{H},-\mathrm{OCOCH}_{2} \mathrm{CH}_{2} \mathrm{Br}\right), 5.12(\mathrm{~s}, 2 \mathrm{H},-\mathrm{CH} 2 \mathrm{Ph}), 3.93\left(\mathrm{t}, 4 \mathrm{H}, 2 \times \mathrm{PhOCH}_{2}-\right.$ ), 1.77 (m, $\left.4 \mathrm{H}, \mathrm{PhOCH}_{2} \mathrm{CH}_{2}\left(\mathrm{CH}_{2}\right)_{9} \mathrm{CH}_{3}\right), 1.45$ (m, $\left.4 \mathrm{H}, \mathrm{PhOCH}_{2} \mathrm{CH}_{2} \mathrm{CH}_{2}\left(\mathrm{CH}_{2}\right)_{8} \mathrm{CH}_{3}\right), 1.27$ (br, $32 \mathrm{H}$,

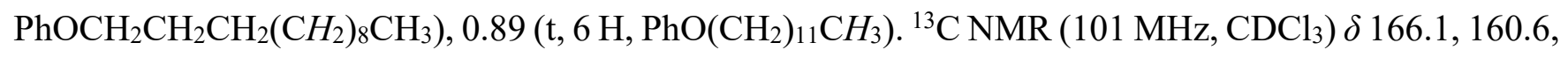
138.0, 131.2, 128.5, 106.5, 101.1, 68.2, 66.4, 32.1, 29.8, 29.8, 29.7, 29.7, 29.5, 29.5, 29.4, 26.2, 22.8, 14.2.

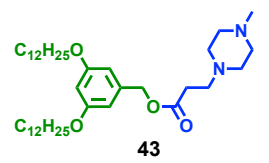

3,5-Bis(dodecyloxy)benzyl 3-(4-methylpiperazin-1-yl)propanoate (43, IAJD84). Compound 42 (0.26 g, $0.43 \mathrm{mmol}, 1$ equiv), 1-methylpiperazine (45 mg, $0.45 \mathrm{mmol}, 1.05$ equiv), $\mathrm{K}_{2} \mathrm{CO}_{3}$ (62 mg, $0.45 \mathrm{mmol}$, 1.05 equiv) were stirred in $\mathrm{MeCN}(15 \mathrm{~mL})$. The mixture was heated at reflux $\left(95^{\circ} \mathrm{C}\right)$ for $3 \mathrm{~h}$. The reaction mixture was cooled to $23{ }^{\circ} \mathrm{C}$ and $\mathrm{MeCN}$ was removed under reduced pressure. Then water $(20 \mathrm{~mL})$ was added, and the mixture was extracted by DCM $(20 \mathrm{~mL} \times 3)$. The organic phase was collected, dried over anhydrous $\mathrm{MgSO}_{4}$, filtered and dried to give the crude product. The crude product was purified by column chromatography $\left(\mathrm{SiO}_{2}\right)$ with $\mathrm{DCM} / \mathrm{MeOH}=40 / 1,20 / 1$ and $15 / 1$ as the eluent. Then the obtained product was dissolved in DCM (20 mL), which was washed by $\mathrm{NaHCO}_{3}$ solution $(2 \%, 20 \mathrm{~mL})$. The aqueous phase was extracted by DCM $(20 \mathrm{~mL})$ for another two times. The organic phase was combined and dried over anhydrous $\mathrm{MgSO}_{4}$. Filtration and evaporation of the solvent yielded the title compound as a light-yellow oil (0.23 g, 85\%). ${ }^{1} \mathrm{H}$ NMR (400 MHz, $\left.\mathrm{CDCl}_{3}\right) \delta 6.45$ (d, $\left.2 \mathrm{H}, \mathrm{PhH}\right), 6.38(\mathrm{t}, 1 \mathrm{H}, \mathrm{PhH}), 5.03(\mathrm{~s}, 2 \mathrm{H},-$ $\left.\mathrm{CH}_{2} \mathrm{Ph}\right), 3.91\left(\mathrm{t}, 4 \mathrm{H}, 2 \times \mathrm{PhOCH}_{2}-\right), 2.71\left(\mathrm{t}, 2 \mathrm{H},-\mathrm{OCOCH}_{2} \mathrm{CH}_{2}-\right), 2.63-2.29\left(\mathrm{~m}, 10 \mathrm{H}, \mathrm{N}\left(\mathrm{CH}_{2} \mathrm{CH}_{2}\right)_{2}\right.$ and $\left.-\mathrm{OCOCH}_{2} \mathrm{CH}_{2-}\right), 2.26\left(\mathrm{~s}, 3 \mathrm{H},-\mathrm{N}\left(\mathrm{CH}_{2}-\right)_{2} \mathrm{CH}_{3}\right), 1.75\left(\mathrm{~m}, 4 \mathrm{H}, \mathrm{PhOCH}_{2} \mathrm{CH}_{2}\left(\mathrm{CH}_{2}\right)_{9} \mathrm{CH}_{3}\right), 1.43(\mathrm{~m}, 4 \mathrm{H}$, $\left.\mathrm{PhOCH}_{2} \mathrm{CH}_{2} \mathrm{CH}_{2}\left(\mathrm{CH}_{2}\right)_{8} \mathrm{CH}_{3}\right), \quad 1.26$ (br, $\left.32 \quad \mathrm{H}, \quad \mathrm{PhOCH}_{2} \mathrm{CH}_{2} \mathrm{CH}_{2}\left(\mathrm{CH}_{2}\right)_{8} \mathrm{CH}_{3}\right), \quad 0.87 \quad$ (t, $6 \quad \mathrm{H}$, $\left.\mathrm{PhO}\left(\mathrm{CH}_{2}\right)_{11} \mathrm{CH}_{3}\right) .{ }^{13} \mathrm{C} \mathrm{NMR}\left(101 \mathrm{MHz}, \mathrm{CDCl}_{3}\right) \delta 172.4,160.6,138.1,106.5,101.0,68.2,66.3,55.2,53.6$, 53.0, 46.1, 32.5, 32.0, 29.8, 29.8, 29.7, 29.7, 29.5, 29.5, 29.4, 26.2, 22.8, 14.2. Purity by HPLC: 99+\%. MALDI-TOF MS $m / z$ of $[\mathrm{M}+\mathrm{H}]^{+}$calculated for $\mathrm{C}_{39} \mathrm{H}_{71} \mathrm{~N}_{2} \mathrm{O}_{4}$ : 631.5; Found: 632.0. 


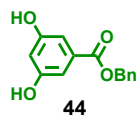

Benzyl 3,5-dihydroxybenzoate (44). The synthesis of compound 44 was adapted from literature procedure. ${ }^{8}$ 3,5-Dihydroxyl benzoic acid (13, $\left.5.0 \mathrm{~g}, 32.4 \mathrm{mmol}\right)$, benzyl chloride $(6.1 \mathrm{~g}, 48.5 \mathrm{mmol})$ and $\mathrm{NaHCO}_{3}(3.3 \mathrm{~g}, 38.9 \mathrm{mmol})$ were mixed with $\mathrm{DMF}(60 \mathrm{~mL})$, and allowed to stir at $40{ }^{\circ} \mathrm{C}$ for $12 \mathrm{~h}$. After the reaction mixture was cooled to $23{ }^{\circ} \mathrm{C}$, DCM $(350 \mathrm{~mL})$ and saturated $\mathrm{NH}_{4} \mathrm{Cl}$ aqueous solution $(350$ $\mathrm{mL})$ was added. The mixture was extracted with DCM $(100 \mathrm{~mL})$ for 3 times. The organic extract was dried over anhydrous $\mathrm{MgSO}_{4}$, filtered and dried to give the crude product. The crude product was further purified by column chromatography $\left(\mathrm{SiO}_{2}\right)$ with a mobile phase of hexane/EtOAc $=3 / 2(\mathrm{v} / \mathrm{v})$ to yield the title compound as a white solid (6.2 g, 78\%). ${ }^{1} \mathrm{H}$ NMR (500 MHz, $\mathrm{d}_{6}$-acetone) $\delta 8.59$ (s, $\left.2 \mathrm{H}, 2 \times-\mathrm{OH}\right)$, 7.49-7.33 (m, $5 \mathrm{H}, 5 \times \mathrm{Ph} H), 7.07(\mathrm{~d}, 2 \mathrm{H}, 2 \times \mathrm{PhH}), 6.61(\mathrm{t}, 1 \mathrm{H}, \mathrm{Ph} H), 5.32\left(\mathrm{~s}, 2 \mathrm{H},-\mathrm{CH}_{2} \mathrm{Ph}\right) .{ }^{13} \mathrm{C} \mathrm{NMR}$ $\left(126 \mathrm{MHz}, \mathrm{d}_{6}\right.$-acetone) $\delta 166.5,159.5,137.4,133.1,129.4,128.9,108.7,108.1,67.0 . \mathrm{Mp}=97^{\circ} \mathrm{C}$.

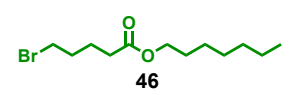

Heptyl 5-bromopentanoate (46). To a solution of 5-bromovaleric acid (5.00 g, $27.6 \mathrm{mmol})$ in dry DCM $(20 \mathrm{~mL})$ was added 1 drop of DMF, followed by the dropwise addition of $\mathrm{SOCl}_{2}(6.57 \mathrm{~g}, 55.2 \mathrm{mmol})$. The reaction mixture was stirred at $23{ }^{\circ} \mathrm{C}$ for $30 \mathrm{~min}$, then $\mathrm{DCM}$ and excess $\mathrm{SOCl}_{2}$ was removed under reduced pressure. The obtained acyl chloride was dissolved in dry DCM (10 mL) and added dropwise into a solution of 1-heptanol $(3.55 \mathrm{~g}, 30.4 \mathrm{mmol})$ and $\mathrm{NEt}_{3}(3.07 \mathrm{~g}, 30.4 \mathrm{mmol})$ in dry DCM $(20 \mathrm{~mL})$ at $0{ }^{\circ} \mathrm{C}$. After the mixture was stirred at $23{ }^{\circ} \mathrm{C}$ for $12 \mathrm{~h}$, water $(50 \mathrm{~mL})$ was added, and the mixture was extracted by DCM $(50 \mathrm{~mL} \times 3)$. The organic phase was dried over anhydrous $\mathrm{MgSO}_{4}$ and filtered. The filtrate was concentrated and purified by column chromatography $\left(\mathrm{SiO}_{2}\right)$ with hexane/EtOAc $=10 / 1$ as the eluent to give the title compound as a colorless oil (7.70 g, 100\%). ${ }^{1} \mathrm{H}$ NMR $\left(500 \mathrm{MHz}, \mathrm{CDCl}_{3}\right) \delta 4.05-4.03(\mathrm{t}, 2$ $\mathrm{H},-\mathrm{COOCH}_{2}-$ ), 3.43-3.40 (t, $2 \mathrm{H},-\mathrm{CH}_{2} \mathrm{Br}$ ), 2.35-2.32 (t, $\left.2 \mathrm{H},-\mathrm{CH}_{2} \mathrm{COO}-\right)$, 1.94-1.87 (m, 2 H, $\mathrm{CH}_{2}$ ), 1.82-1.74 (m, 2 H, CH$), 1.64-1.61\left(\mathrm{~m}, 2 \mathrm{H}, \mathrm{CH}_{2}\right), 1.32-1.24\left(\mathrm{~m}, 8 \mathrm{H}, 4 \times \mathrm{CH}_{2}\right), 0.90-0.87\left(\mathrm{t}, 3 \mathrm{H}, \mathrm{CH}_{3}\right)$. ${ }^{1} \mathrm{H}$ NMR $\left(126 \mathrm{MHz}, \mathrm{CDCl}_{3}\right) \delta 173.1,64.6,33.3,32.9,32.0,31.7,28.9,28.6,25.9,23.5,22.6,14.0$.

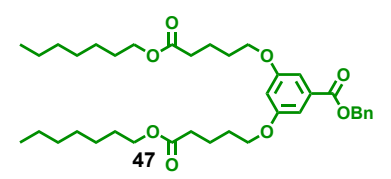

Diheptyl 5,5'-((5-((benzyloxy)carbonyl)-1,3-phenylene)bis(oxy))dipentanoate (47). Compound 44 (0.39 g, $1.58 \mathrm{mmol}$ ), compound 46 (1.10 g, $4.00 \mathrm{mmol})$, and $\mathrm{K}_{2} \mathrm{CO}_{3}(1.30 \mathrm{~g}, 9.50 \mathrm{mmol})$ were stirred in DMF $(25 \mathrm{~mL})$. The mixture was stirred at $60{ }^{\circ} \mathrm{C}$ under $\mathrm{N}_{2}$ atmosphere for $6 \mathrm{~h}$. The reaction mixture was 
cooled to $23{ }^{\circ} \mathrm{C}$ and DMF was removed under reduced pressure. Then water $(30 \mathrm{~mL})$ was added, and the mixture was extracted by DCM $(30 \mathrm{~mL} \times 3)$. The organic phase was dried over anhydrous $\mathrm{MgSO}_{4}$ and filtered. The filtrate was concentrated and purified by column chromatography $\left(\mathrm{SiO}_{2}\right)$ with hexane/EtOAc $=20 / 1$ as the eluent to give the title compound as a colorless oil $(0.70 \mathrm{~g}, 69 \%) .{ }^{1} \mathrm{H} \mathrm{NMR}(500 \mathrm{MHz}$, $\left.\mathrm{CDCl}_{3}\right) \delta 7.45-7.34(\mathrm{~m}, 5 \mathrm{H}, 5 \times \mathrm{Ph} H), 7.18(\mathrm{~d}, 2 \mathrm{H}, 2 \times \mathrm{Ph} H), 6.62(\mathrm{t}, 1 \mathrm{H}, \mathrm{Ph} H), 5.34\left(\mathrm{~s}, 2 \mathrm{H},-\mathrm{CH}_{2} \mathrm{Ph}\right)$, 4.07-4.05 (t, $\left.4 \mathrm{H}, 2 \times-\mathrm{OCH}_{2}-\right), 3.99-3.96\left(\mathrm{t}, 4 \mathrm{H}, 2 \times-\mathrm{OCH}_{2}-\right), 2.39-2.36\left(\mathrm{~m}, 8 \mathrm{H}, 4 \times-\mathrm{CH}_{2}-\right), 1.63-1.60(\mathrm{~m}$, $\left.4 \mathrm{H}, 2 \times \mathrm{CH}_{2}\right), 1.33-1.28\left(\mathrm{~m}, 16 \mathrm{H}, 8 \times \mathrm{CH}_{2}\right), 0.89-0.86\left(\mathrm{~m}, 6 \mathrm{H}, 2 \times \mathrm{CH}_{3}\right) .{ }^{13} \mathrm{C} \mathrm{NMR}\left(126 \mathrm{MHz}, \mathrm{CDCl}_{3}\right) \delta$ 173.6, 166.3, 160.1, 136.1, 132.0, 128.7, 128.3, 128.3, 108.0, 106.5, 67.8, 66.9, 64.7, 34.0, 31.8, 29.0, $28.7,28.7,26.0,22.7,21.7,14.2$.

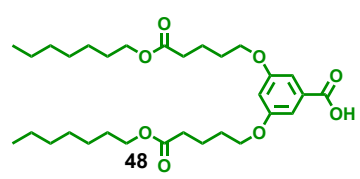

3,5-Bis((5-(heptyloxy)-5-oxopentyl)oxy)benzoic acid (48). Compound 47 (0.70 g, $1.09 \mathrm{mmol})$ was dissolved in 1:2 MeOH:DCM (30 mL). Then Pd/C (50 mg, $7 \mathrm{wt} \%)$ was added and the flask was evacuated and filled with hydrogen for three times. The mixture was stirred at $23{ }^{\circ} \mathrm{C}$ for $12 \mathrm{~h}$ under hydrogen atmosphere. The reaction mixture was filtered through Celite and the filter cake was washed with DCM. Evaporation of the solvent yielded the title compound as a colorless oil $(0.60 \mathrm{~g}, 100 \%)$. ${ }^{1} \mathrm{H}$ NMR $(500$ $\left.\mathrm{MHz}_{2} \mathrm{CDCl}_{3}\right) \delta 9.30(\mathrm{br}, 1 \mathrm{H}, \mathrm{COOH}), 7.23(\mathrm{~d}, 2 \mathrm{H}, 2 \times \mathrm{Ph} H), 6.67(\mathrm{~d}, 2 \mathrm{H}, 2 \times \mathrm{PhH}), 4.09-4.06(\mathrm{t}, 4 \mathrm{H}, 2 \times-$ $\left.\mathrm{OCH}_{2-}\right), 4.00\left(\mathrm{~m}, 4 \mathrm{H}, 2 \times-\mathrm{OCH}_{2-}\right), 2.41\left(\mathrm{~m}, 4 \mathrm{H}, 2 \times-\mathrm{CH}_{2}-\right), 1.83\left(\mathrm{~m}, 8 \mathrm{H}, 4 \times-\mathrm{CH}_{2-}\right), 1.65-1.61(\mathrm{~m}, 4 \mathrm{H}$, $\left.2 \times \mathrm{CH}_{2}\right), 1.38-1.28\left(\mathrm{~m}, 16 \mathrm{H}, 8 \times \mathrm{CH}_{2}\right), 0.89-0.87\left(\mathrm{~m}, 6 \mathrm{H}, 2 \times \mathrm{CH}_{3}\right) .{ }^{13} \mathrm{C} \mathrm{NMR}\left(126 \mathrm{MHz}, \mathrm{CDCl}_{3}\right) \delta 173.7$, $171.5,160.1,131.2,108.2,107.4,67.8,64.7,34.0,31.8,29.0,28.7,28.6,25.9,22.6,21.7,14.1$.

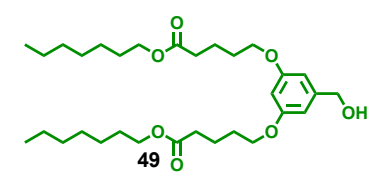

Diheptyl 5,5'-((5-(hydroxymethyl)-1,3-phenylene)bis(oxy))dipentanoate (49). The synthesis of compound 49 was adapted from literature procedure. ${ }^{9}$ To a solution of compound 48 (0.60 g, $\left.1.09 \mathrm{mmol}\right)$ in $30 \mathrm{~mL}$ THF was added $\mathrm{NaBH}_{4}(0.10 \mathrm{~g}, 2.75 \mathrm{mmol})$. The reaction mixture was stirred at $23{ }^{\circ} \mathrm{C}$ for 30 min under $\mathrm{N}_{2}$ until no more gas was generated. A solution of iodine $(0.34 \mathrm{~g}, 1.32 \mathrm{mmol})$ in THF $(10 \mathrm{~mL})$ was added dropwise into the reaction mixture under $\mathrm{N}_{2}$ in $20 \mathrm{~min}$ at $0{ }^{\circ} \mathrm{C}$. After stirring at $0{ }^{\circ} \mathrm{C}$ for $30 \mathrm{~min}$, the reaction was returned to $23{ }^{\circ} \mathrm{C}$ and stirred for $1.5 \mathrm{~h}$. The reaction was quenched with $\mathrm{HCl}(2 \mathrm{M})$ solution $(10 \mathrm{~mL})$ until no more gas was generated, and then saturated $\mathrm{NaHCO}_{3}$ aqueous solution was added until $\mathrm{pH}=7$. The mixture was extracted by DCM $(50 \mathrm{~mL} \times 3)$. The organic phase was dried over 
anhydrous $\mathrm{MgSO}_{4}$ and filtered. The alcohol as the product (0.59 $\left.\mathrm{g}, 100 \%\right)$ was obtained by concentrating the filtrate as colorless oil without further purification. ${ }^{1} \mathrm{H} \mathrm{NMR}\left(500 \mathrm{MHz}, \mathrm{CDCl}_{3}\right) \delta 6.47(\mathrm{~d}, 2 \mathrm{H}$, $2 \times \mathrm{Ph} H), 6.32(\mathrm{t}, 1 \mathrm{H}, \mathrm{PhH}), 4.58\left(\mathrm{~s}, 2 \mathrm{H},-\mathrm{CH}_{2} \mathrm{Ph}\right), 4.05-4.02\left(\mathrm{~m}, 4 \mathrm{H}, 2 \times \mathrm{OCH}_{2}\right), 3.92\left(\mathrm{~m}, 4 \mathrm{H}, 2 \times \mathrm{OCH}_{2}\right)$, $2.35\left(\mathrm{~m}, 4 \mathrm{H}, 2 \times \mathrm{CH}_{2}\right), 1.78\left(\mathrm{~m}, 8 \mathrm{H}, 4 \times \mathrm{CH}_{2}\right), 1.64-1.58\left(\mathrm{~m}, 4 \mathrm{H}, 2 \times \mathrm{CH}_{2}\right), 1.30-1.26\left(\mathrm{~m}, 16 \mathrm{H}, 8 \times \mathrm{CH}_{2}\right)$, 0.87-0.85 (m, $\left.6 \mathrm{H}, 2 \times \mathrm{CH}_{3}\right) .{ }^{13} \mathrm{C} \mathrm{NMR}\left(126 \mathrm{MHz} \mathrm{CDCl}_{3}\right) \delta 173.7,160.3,143.5,105.1,100.5,67.5,64.7$, $34.0,31.8,29.0,28.7,28.7,25.9,22.6,21.7,14.1$.

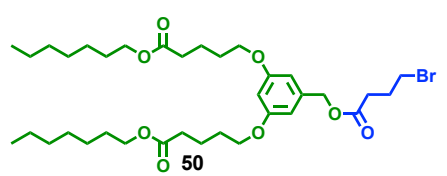

Diheptyl 5,5'-((5-(((4-bromobutanoyl)oxy)methyl)-1,3-phenylene)bis(oxy))dipentanoate (50). 4Bromobutyric acid (0.22 g, $1.30 \mathrm{mmol}, 1.2$ equiv) was dissolved in $5 \mathrm{~mL}$ anhydrous DCM and 1 drop of DMF was added. $\mathrm{SOCl}_{2}\left(0.26 \mathrm{~g}, 2.20 \mathrm{mmol}, 2.0\right.$ equiv) was added and the mixture was stirred at $23{ }^{\circ} \mathrm{C}$ for $1 \mathrm{~h}$. Afterwards, DCM and excess $\mathrm{SOCl}_{2}$ was removed under reduced pressure to give the 4bromobutanoyl chloride. Compound 49 (0.59 g, 1.10 mmol, 1.0 equiv) and $\mathrm{NEt}_{3}$ (0.13 g, 1.30 mmol, 1.2 equiv) were dissolved in $6 \mathrm{~mL}$ anhydrous DCM. Then DMAP (24 mg, $0.20 \mathrm{mmol}, 0.2$ equiv) was added. To this mixture was added the DCM solution $(3 \mathrm{~mL})$ of above 4-bromobutanoyl chloride dropwise at 0 ${ }^{\circ} \mathrm{C}$. The mixture was allowed to warm to $23{ }^{\circ} \mathrm{C}$ with stirring during a $2 \mathrm{~h}$ period. Afterwards, water $(20$ $\mathrm{mL})$ was added, and the mixture was extracted by DCM $(20 \mathrm{~mL})$ for three times. The organic phase was collected, dried over anhydrous $\mathrm{MgSO}_{4}$ and filtered. The filtrate was concentrated and purified by column chromatography $\left(\mathrm{SiO}_{2}\right)$ with hexane/EtOAc $=10 / 1$ as the eluent to give the title compound as a colorless oil (0.32 g, 42\%). ${ }^{1} \mathrm{H}$ NMR (500 MHz, $\left.\mathrm{CDCl}_{3}\right) \delta 6.45$ (d, $\left.2 \mathrm{H}, 2 \times \mathrm{PhH}\right), 6.37$ (t, $\left.1 \mathrm{H}, \mathrm{PhH}\right), 5.02$ (s, $2 \mathrm{H}$, $\left.\mathrm{CH}_{2} \mathrm{Ph}\right), 4.07-4.04$ (t, $\left.4 \mathrm{H}, 2 \times \mathrm{OCH}_{2}\right), 3.93\left(\mathrm{~m}, 4 \mathrm{H}, 2 \times \mathrm{OCH}_{2}\right), 3.47-3.44\left(\mathrm{t}, 2 \mathrm{H},-\mathrm{CH}_{2} \mathrm{Br}\right), 2.57-2.54(\mathrm{t}$, $\left.2 \mathrm{H}, \mathrm{CH}_{2}\right), 2.38-2.35\left(\mathrm{~m}, 4 \mathrm{H}, 2 \times \mathrm{CH}_{2}\right), 2.20-2.17\left(\mathrm{~m}, 2 \mathrm{H}, \mathrm{CH}_{2}\right), 1.81-1.78\left(\mathrm{~m}, 8 \mathrm{H}, 4 \times \mathrm{CH}_{2}\right), 1.63-1.58$ $\left(\mathrm{m}, 4 \mathrm{H}, 2 \times \mathrm{CH}_{2}\right), 1.32-1.25\left(\mathrm{~m}, 16 \mathrm{H}, 8 \times \mathrm{CH}_{2}\right), 0.88-0.85\left(\mathrm{~m}, 6 \mathrm{H}, 2 \times \mathrm{CH}_{3}\right) .{ }^{13} \mathrm{C} \mathrm{NMR}\left(126 \mathrm{MHz}, \mathrm{CDCl}_{3}\right)$ $\delta 173.6,172.4,160.4,138.0,106.5,101.1,67.5,66.4,64.6,34.0,32.7,32.5,31.8,29.0,28.7,27.8,26.0$, $22.7,21.7,14.2$.

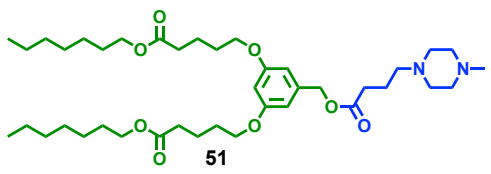

Diheptyl 5,5'-((5-(((4-(4-methylpiperazin-1-yl)butanoyl)oxy)methyl)-1,3-phenylene)bis(oxy)) dipentanoate (51, IAJD85). Compound 50 (0.32 g, 0.47 mmol, 1 equiv), 1-methylpiperazine (50 mg, $0.50 \mathrm{mmol}, 1.05$ equiv), $\mathrm{K}_{2} \mathrm{CO}_{3}$ (69 mg, $0.50 \mathrm{mmol}, 1.05$ equiv) were stirred in $\mathrm{MeCN}(15 \mathrm{~mL}) . \mathrm{The}$ 
mixture was heated at reflux $\left(95^{\circ} \mathrm{C}\right)$ for $3 \mathrm{~h}$. The reaction mixture was cooled to $23{ }^{\circ} \mathrm{C}$ and $\mathrm{MeCN}$ was removed under reduced pressure. Then water $(20 \mathrm{~mL})$ was added, and the mixture was extracted by DCM $(20 \mathrm{~mL} \times 3)$. The organic phase was collected, dried over anhydrous $\mathrm{MgSO}_{4}$, filtered and dried to give the crude product. The crude product was purified by column chromatography $\left(\mathrm{SiO}_{2}\right)$ with $\mathrm{DCM} / \mathrm{MeOH}=$ 40/1, 20/1 and 10/1 as the eluent. Then the obtained product was dissolved in DCM (20 mL), which was washed by $\mathrm{NaHCO}_{3}$ solution $(2 \%, 20 \mathrm{~mL})$. The aqueous phase was extracted by DCM $(20 \mathrm{~mL})$ for another two times. The organic phase was combined and dried over anhydrous $\mathrm{MgSO}_{4}$. Filtration and evaporation of the solvent yielded the title compound as a colorless oil $(0.28 \mathrm{~g}, 79 \%) .{ }^{1} \mathrm{H} \mathrm{NMR}\left(500 \mathrm{MHz}, \mathrm{CDCl}_{3}\right) \delta$ $6.42(\mathrm{~d}, 2 \mathrm{H}, 2 \times \mathrm{PhH}), 6.33(\mathrm{t}, 1 \mathrm{H}, \mathrm{PhH}), 4.98\left(\mathrm{~s}, 2 \mathrm{H},-\mathrm{CH}_{2} \mathrm{Ph}\right), 4.04-4.01\left(\mathrm{~m}, 4 \mathrm{H}, 2 \times-\mathrm{OCH}_{2}-\right), 3.90(\mathrm{~m}$, $\left.4 \mathrm{H}, 2 \times-\mathrm{OCH}_{2}-\right), 2.50$ (br, $\left.8 \mathrm{H}, 2 \times-\mathrm{NCH}_{2} \mathrm{CH}_{2} \mathrm{~N}-\right), 2.38-2.33\left(\mathrm{~m}, 8 \mathrm{H}, 4 \times \mathrm{CH}_{2}\right), 2.31\left(\mathrm{~s}, 3 \mathrm{H}, \mathrm{NCH}_{3}\right), 1.82-$ $1.77\left(\mathrm{~m}, 10 \mathrm{H}, 5 \times \mathrm{CH}_{2}\right), 1.59-1.55\left(\mathrm{~m}, 4 \mathrm{H}, 2 \times \mathrm{CH}_{2}\right), 1.29-1.24\left(\mathrm{~m}, 16 \mathrm{H}, 8 \times \mathrm{CH}_{2}\right), 0.85-0.83(\mathrm{~m}, 6 \mathrm{H}$, $\left.2 \times \mathrm{CH}_{3}\right) .{ }^{13} \mathrm{C} \mathrm{NMR}\left(126 \mathrm{MHz}, \mathrm{CDCl}_{3}\right) \delta 173.5,173.2,160.3,138.2,106.5,100.9,67.5,66.1,64.6,57.4$, 54.8, 52.5, 45.6, 34.0, 32.2, 31.7, 28.9, 28.7, 25.9, 22.6, 22.0, 21.7, 14.1. Purity by HPLC: 99+\%. MALDITOF MS $m / z$ of $[\mathrm{M}+\mathrm{H}]^{+}$calculated for $\mathrm{C}_{48} \mathrm{H}_{69} \mathrm{~N}_{2} \mathrm{O}_{8}: 705.5$; Found: 704.9 . 


\subsection{Synthesis of IAJDs 87-89, 91 and 95}

\section{Scheme S6. Synthesis of IAJDs 87-89, 91 and 95}

(a)

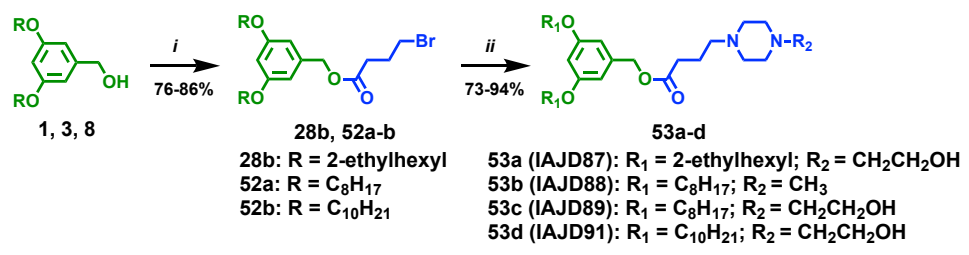

(b)
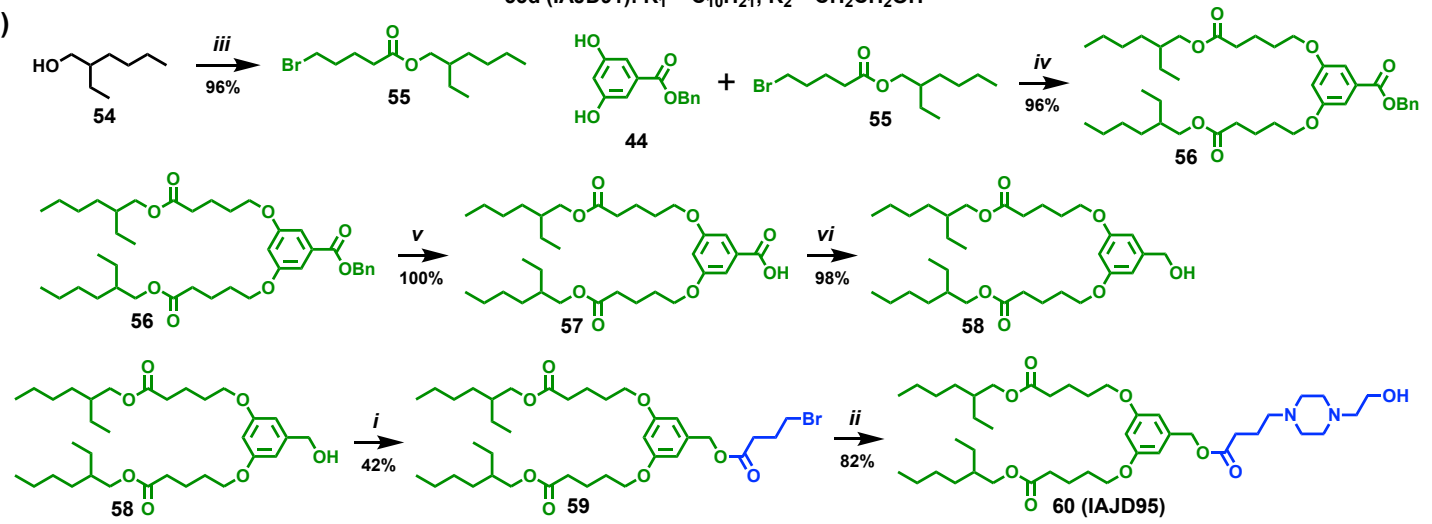

Reagents and conditions: (i) 4-Bromobutyric acid, $\mathrm{SOCl}_{2}, \mathrm{DMF}$ (cat.), DCM, $23{ }^{\circ} \mathrm{C}, 1 \mathrm{~h}$, then DMAP, $\mathrm{NEt}_{3}, \mathrm{DCM}, 0-23{ }^{\circ} \mathrm{C}, 2 \mathrm{~h}$; (ii) 1-methylpiperazine/1-(2-hydroxyethyl)piperazine, $\mathrm{K}_{2} \mathrm{CO}_{3}, \mathrm{MeCN}^{\circ} 95^{\circ} \mathrm{C}$, 3 h; (iii) 5-bromovaleric acid, DCC, DPTS, DCM, $23{ }^{\circ} \mathrm{C}, 12 \mathrm{~h}$; (iv) $\mathrm{K}_{2} \mathrm{CO}_{3}$, DMF, $60{ }^{\circ} \mathrm{C}, 6 \mathrm{~h}$; (v) $\mathrm{H}_{2}, \mathrm{Pd} / \mathrm{C}$, DCM, MeOH, 12 h; (vi) $\mathrm{NaBH}_{4}, \mathrm{I}_{2}$, THF, 0-23 ${ }^{\circ} \mathrm{C}, 2 \mathrm{~h}$.

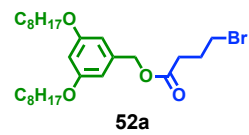

3,5-Bis(octyloxy)benzyl 4-bromobutanoate (52a). 4-Bromobutyric acid (0.45 g, $2.70 \mathrm{mmol}, 1.0$ equiv) was dissolved in $6 \mathrm{~mL}$ anhydrous DCM and 1 drop of DMF was added. $\mathrm{SOCl}_{2}(0.64 \mathrm{~g}, 5.40 \mathrm{mmol}, 2.0$ equiv) was added and the mixture was stirred at $23{ }^{\circ} \mathrm{C}$ for $1 \mathrm{~h}$. Afterwards, DCM and excess $\mathrm{SOCl}_{2} \mathrm{Was}$ removed under reduced pressure to give the 4-bromobutanoyl chloride. Compound 1 (1.00 g, $2.70 \mathrm{mmol}$, 1.0 equiv) and $\mathrm{NEt}_{3}(0.30 \mathrm{~g}, 3.00 \mathrm{mmol}, 1.1$ equiv) were dissolved in $10 \mathrm{~mL}$ anhydrous DCM. To this mixture was added the DCM solution $(5 \mathrm{~mL})$ of above 4-bromobutanoyl chloride dropwise at $0{ }^{\circ} \mathrm{C}$. The mixture was allowed to warm to $23{ }^{\circ} \mathrm{C}$ with stirring during a $2 \mathrm{~h}$ period. Afterwards, water $(30 \mathrm{~mL}) \mathrm{was}$ added, and the mixture was extracted by DCM $(30 \mathrm{~mL})$ for three times. The organic phase was collected, dried over anhydrous $\mathrm{MgSO}_{4}$ and filtered. The filtrate was concentrated and purified by column chromatography $\left(\mathrm{SiO}_{2}\right)$ with hexane/EtOAc $=20 / 1$ as the eluent to give the title compound as a lightyellow oil (1.22 g, 86\%). ${ }^{1} \mathrm{H}$ NMR $\left(400 \mathrm{MHz}, \mathrm{CDCl}_{3}\right) \delta 6.47(\mathrm{~d}, 2 \mathrm{H}, 2 \times \mathrm{Ph} H), 6.40(\mathrm{t}, 1 \mathrm{H}, \mathrm{Ph} H), 5.04(\mathrm{~s}$, $\left.2 \mathrm{H},-\mathrm{CH}_{2} \mathrm{Ph}\right), 3.94-3.91\left(\mathrm{t}, 4 \mathrm{H}, 2 \times \mathrm{PhOCH}_{2}-\right), 3.48-3.45\left(\mathrm{t}, 2 \mathrm{H},-\mathrm{CH}_{2} \mathrm{Br}\right), 2.58-2.55(\mathrm{t}, 2 \mathrm{H}$, 
$\left.\mathrm{BrCH}_{2} \mathrm{CH}_{2} \mathrm{CH}_{2} \mathrm{COO}-\right)$, 2.23-2.16 (m, $\left.2 \mathrm{H}, \quad \mathrm{BrCH}_{2} \mathrm{CH}_{2} \mathrm{CH}_{2} \mathrm{COO}-\right), \quad 1.80-1.73 \quad$ (m, $4 \quad \mathrm{H}$, $\left.2 \times \mathrm{PhOCH}_{2} \mathrm{CH}_{2}\left(\mathrm{CH}_{2}\right)_{5} \mathrm{CH}_{3}\right), \quad 1.48-1.28\left(\mathrm{~m}, 20 \mathrm{H}, 2 \times \mathrm{PhOCH}_{2} \mathrm{CH}_{2}\left(\mathrm{CH}_{2}\right)_{5} \mathrm{CH}_{3}\right), 0.90-0.87(\mathrm{t}, 6 \mathrm{H}$, $\left.2 \times \mathrm{PhOCH}_{2} \mathrm{CH}_{2}\left(\mathrm{CH}_{2}\right)_{5} \mathrm{CH}_{3}\right) .{ }^{13} \mathrm{C} \mathrm{NMR}\left(101 \mathrm{MHz}, \mathrm{CDCl}_{3}\right) \delta 172.5,160.6,138.0,106.5,101.2,68.2,66.6$, $32.8,32.6,32.0,29.5,29.4,27.9,26.2,22.8,14.2$.

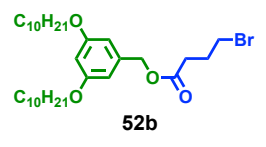

3,5-Bis(decyloxy)benzyl 4-bromobutanoate (52b). Compound 52b was synthesized from compound 3 (1.00 g, $2.38 \mathrm{mmol}, 1.0$ equiv), 4-bromobutyric acid (0.40 g, $2.38 \mathrm{mmol}, 1.0$ equiv) and $\mathrm{NEt}_{3}$ (0.27 g, 2.62 mmol, 1.1 equiv) following a procedure similar to that used for the synthesis of compound 52a. The title compound was obtained as a light-yellow oil (1.02 g, 76\%). ${ }^{1} \mathrm{H} \mathrm{NMR}\left(400 \mathrm{MHz}, \mathrm{CDCl}_{3}\right) \delta 6.47(\mathrm{~d}, 2 \mathrm{H}$, $\mathrm{Ph} H), 6.41(\mathrm{t}, 1 \mathrm{H}, \mathrm{Ph} H), 5.05\left(\mathrm{~s}, 2 \mathrm{H},-\mathrm{CH}_{2} \mathrm{Ph}\right), 3.93\left(\mathrm{t}, 4 \mathrm{H}, 2 \times \mathrm{PhOCH}_{2}-\right), 3.47(\mathrm{t}, 2 \mathrm{H},-$ $\mathrm{OCOCH}_{2} \mathrm{CH}_{2} \mathrm{CH}_{2} \mathrm{Br}$ ), 2.57 (t, $2 \mathrm{H},-\mathrm{OCOCH}_{2} \mathrm{CH}_{2} \mathrm{CH}_{2} \mathrm{Br}$ ), 2.20 (m, $\left.2 \mathrm{H},-\mathrm{OCOCH}_{2} \mathrm{CH}_{2} \mathrm{CH}_{2} \mathrm{Br}\right), 1.77$ (m, $\left.4 \mathrm{H}, \mathrm{PhOCH}_{2} \mathrm{CH}_{2}\left(\mathrm{CH}_{2}\right)_{7} \mathrm{CH}_{3}\right), 1.45$ (m, $\left.4 \mathrm{H}, \mathrm{PhOCH}_{2} \mathrm{CH}_{2} \mathrm{CH}_{2}\left(\mathrm{CH}_{2}\right)_{6} \mathrm{CH}_{3}\right), 1.28$ (br, $24 \mathrm{H}$, $\left.\mathrm{PhOCH}_{2} \mathrm{CH}_{2} \mathrm{CH}_{2}\left(\mathrm{CH}_{2}\right)_{6} \mathrm{CH}_{3}\right), 0.89$ (t, $\left.6 \mathrm{H}, \mathrm{PhO}\left(\mathrm{CH}_{2}\right)_{9} \mathrm{CH}_{3}\right) .{ }^{13} \mathrm{C} \mathrm{NMR}\left(101 \mathrm{MHz}, \mathrm{CDCl}_{3}\right) \delta 172.4,160.6$, $137.9,106.5,101.1,68.2,66.5,32.7,32.6,32.0,29.7,29.7,29.5,29.5,29.4,27.9,26.2,22.8,14.2$.

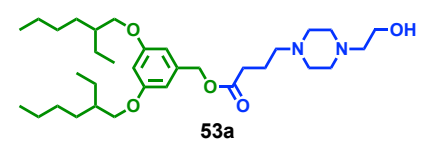

3,5-Bis((2-ethylhexyl)oxy)benzyl 4-(4-(2-hydroxyethyl)piperazin-1-yl)butanoate (53a, IAJD87). Compound 28b (0.30 g, $0.58 \mathrm{mmol}, 1.0$ equiv), 1-(2-hydroxyethyl)piperazine (79 mg, $0.61 \mathrm{mmol}, 1.05$ equiv), $\mathrm{K}_{2} \mathrm{CO}_{3}$ (84 mg, $0.61 \mathrm{mmol}, 1.05$ equiv) were stirred in $\mathrm{MeCN}$ (20 mL). The mixture was heated at reflux $\left(95^{\circ} \mathrm{C}\right)$ for $3 \mathrm{~h}$. The reaction mixture was cooled to $23^{\circ} \mathrm{C}$ and $\mathrm{MeCN}$ was removed under reduced pressure. Then water $(20 \mathrm{~mL})$ was added, and the mixture was extracted by DCM $(20 \mathrm{~mL} \times 3)$. The organic phase was collected, dried over anhydrous $\mathrm{MgSO}_{4}$, filtered and dried to give the crude product. The crude product was purified by column chromatography $\left(\mathrm{SiO}_{2}\right)$ with $\mathrm{DCM} / \mathrm{MeOH}=40 / 1$ and $15 / 1$ as the eluent. Then the obtained product was dissolved in DCM $(20 \mathrm{~mL})$, which was washed by $\mathrm{NaHCO}_{3}$ solution $(2 \%$, $20 \mathrm{~mL})$. The aqueous phase was extracted by DCM $(20 \mathrm{~mL})$ for another two times. The organic phase was combined and dried over anhydrous $\mathrm{MgSO}_{4}$. Filtration and evaporation of the solvent yielded the title compound as a light-yellow oil (0.31 g, 94\%). ${ }^{1} \mathrm{H}$ NMR (400 MHz, $\left.\mathrm{CDCl}_{3}\right) \delta 6.46(\mathrm{~d}, 2 \mathrm{H}, \mathrm{Ph} H), 6.40(\mathrm{t}$, $1 \mathrm{H}, \mathrm{PhH}), 5.02\left(\mathrm{~s}, 2 \mathrm{H},-\mathrm{CH}_{2} \mathrm{Ph}\right), 3.80\left(\mathrm{~m}, 4 \mathrm{H}, 2 \times \mathrm{PhOCH}_{2}-\right), 3.59$ (t, $\left.2 \mathrm{H},-\mathrm{CH}_{2} \mathrm{CH}_{2} \mathrm{OH}\right), 2.85$ (br, $1 \mathrm{H},-$ $\left.\mathrm{CH}_{2} \mathrm{CH}_{2} \mathrm{OH}\right), 2.67-2.20\left(\mathrm{~m}, 14 \mathrm{H}, \mathrm{N}\left(\mathrm{CH}_{2} \mathrm{CH}_{2}\right)_{2},-\mathrm{OCOCH}_{2} \mathrm{CH}_{2} \mathrm{CH}_{2}\right.$ - and $\left.-\mathrm{CH}_{2} \mathrm{CH}_{2} \mathrm{OH}\right), 1.82(\mathrm{~m}, 2 \mathrm{H}$, $\left.\mathrm{OCOCH}_{2} \mathrm{CH}_{2} \mathrm{CH}_{2-}\right), \quad 1.69 \quad\left(\mathrm{~m}, 2 \mathrm{H}, \quad \mathrm{PhOCH}_{2} \mathrm{CH}\left(\mathrm{CH}_{2} \mathrm{CH}_{3}\right)-\right), \quad 1.56-1.21 \quad(\mathrm{~m}, \quad 16 \quad \mathrm{H}$, 
$\left.\mathrm{PhOCH}_{2} \mathrm{CH}\left(\mathrm{CH}_{2} \mathrm{CH}_{3}\right)\left(\mathrm{CH}_{2}\right)_{3} \mathrm{CH}_{3}\right), 0.90\left(\mathrm{~m}, 12 \mathrm{H}, \mathrm{PhOCH}_{2} \mathrm{CH}\left(\mathrm{CH}_{2} \mathrm{CH}_{3}\right)\left(\mathrm{CH}_{2}\right)_{3} \mathrm{CH}_{3}\right) .{ }^{13} \mathrm{C} \mathrm{NMR}(101$ $\left.\mathrm{MHz}, \mathrm{CDCl}_{3}\right) \delta 173.4,160.8,138.1,106.4,101.0,70.5,66.3,59.4,59.3,57.8,57.7,53.3,53.0,39.5,32.3$, 30.6, 29.2, 24.0, 23.1, 22.3, 14.2, 11.2. Purity by HPLC: 99+\%. MALDI-TOF MS $m / z$ of $[\mathrm{M}+\mathrm{H}]^{+}$ calculated for $\mathrm{C}_{33} \mathrm{H}_{59} \mathrm{~N}_{2} \mathrm{O}_{5}$ : 563.4; Found: 563.2.

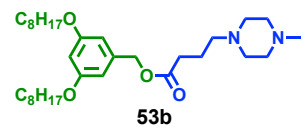

3,5-Bis(octyloxy)benzyl 4-(4-methylpiperazin-1-yl)butanoate (53b, IAJD88). Compound 53b was synthesized from compound 52a $(0.30 \mathrm{~g}, 0.58 \mathrm{mmol}, 1$ equiv), 1-methylpiperazine (61 $\mathrm{mg}, 0.61 \mathrm{mmol}$, 1.05 equiv) and $\mathrm{K}_{2} \mathrm{CO}_{3}(85 \mathrm{mg}, 0.61 \mathrm{mmol}, 1.05$ equiv) following a procedure similar to that used for the synthesis of compound 53a. The title compound was obtained as a light-yellow oil (0.23 g, 74\%). ${ }^{1} \mathrm{H}$ NMR $\left(400 \mathrm{MHz}, \mathrm{CDCl}_{3}\right) \delta 6.46(\mathrm{~d}, 2 \mathrm{H}, 2 \times \mathrm{PhH}), 6.39(\mathrm{t}, 1 \mathrm{H}, \mathrm{PhH}), 5.02\left(\mathrm{~s}, 2 \mathrm{H},-\mathrm{CH}_{2} \mathrm{Ph}\right), 3.92(\mathrm{t}, 4 \mathrm{H}$, $2 \times \mathrm{PhOCH}_{2}$ ), 2.43 (br, $8 \mathrm{H}, 2 \times-\mathrm{NCH}_{2} \mathrm{CH}_{2} \mathrm{~N}-$ ), 2.41-2.34 (m, $\left.4 \mathrm{H},-\mathrm{NCH}_{2} \mathrm{CH}_{2} \mathrm{CH}_{2} \mathrm{COO}-\right), 2.27$ (s, $3 \mathrm{H}$, $\mathrm{NCH}_{3}$ ), 1.86-1.81 (m, $\left.2 \mathrm{H},-\mathrm{NCH}_{2} \mathrm{CH}_{2} \mathrm{CH}_{2} \mathrm{COO}-\right)$, 1.79-1.72 (m, $\left.4 \mathrm{H}, 2 \times \mathrm{PhOCH}_{2} \mathrm{CH}_{2}\left(\mathrm{CH}_{2}\right)_{5} \mathrm{CH}_{3}\right), 1.48-$ $1.25\left(\mathrm{~m}, 20 \mathrm{H}, 2 \times \mathrm{PhOCH}_{2} \mathrm{CH}_{2}\left(\mathrm{CH}_{2}\right)_{5} \mathrm{CH}_{3}\right), 0.90-0.87\left(\mathrm{~m}, 6 \mathrm{H}, 2 \times \mathrm{PhOCH}_{2} \mathrm{CH}_{2}\left(\mathrm{CH}_{2}\right)_{5} \mathrm{CH}_{3}\right) .{ }^{13} \mathrm{C} \mathrm{NMR}$ $\left(101 \mathrm{MHz}, \mathrm{CDCl}_{3}\right) \delta 173.5,160.6,138.2,106.5,101.0,68.2,66.3,57.7,55.3,53.2,46.2,32.4,32.0,29.5$, 29.4, 26.2, 22.8, 22.3, 14.2. Purity by HPLC: 99+\%. MALDI-TOF MS $m / z$ of $[\mathrm{M}+\mathrm{H}]^{+}$calculated for $\mathrm{C}_{32} \mathrm{H}_{57} \mathrm{~N}_{2} \mathrm{O}_{4}$ : 533.4; Found: 532.3.

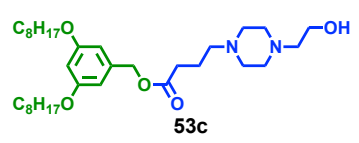

3,5-Bis(octyloxy)benzyl 4-(4-(2-hydroxyethyl)piperazin-1-yl)butanoate (53c, IAJD89). Compound 53c was synthesized from compound 52a ( $0.30 \mathrm{~g}, 0.58 \mathrm{mmol}, 1$ equiv), 1-(2-hydroxyethyl)piperazine (82 $\mathrm{mg}, 0.61 \mathrm{mmol}, 1.05$ equiv) and $\mathrm{K}_{2} \mathrm{CO}_{3}(85 \mathrm{mg}, 0.61 \mathrm{mmol}, 1.05$ equiv) following a procedure similar to that used for the synthesis of compound 53a. The title compound was obtained as a light-yellow oil $(0.24$ g, 73\%). ${ }^{1} \mathrm{H} \mathrm{NMR}\left(400 \mathrm{MHz}, \mathrm{CDCl}_{3}\right) \delta 6.46(\mathrm{~d}, 2 \mathrm{H}, 2 \times \mathrm{PhH}), 6.39(\mathrm{t}, 1 \mathrm{H}, \mathrm{Ph} H), 5.03\left(\mathrm{~s}, 2 \mathrm{H},-\mathrm{CH}_{2} \mathrm{Ph}\right)$, 3.92 (t, $\left.4 \mathrm{H}, 2 \times \mathrm{PhOCH}_{2}-\right), 3.60$ (t, $\left.2 \mathrm{H}, \mathrm{CH}_{2} \mathrm{OH}\right), 2.54-2.34$ (br, $14 \mathrm{H}, 2 \times-\mathrm{NCH}_{2} \mathrm{CH}_{2} \mathrm{~N}-, \mathrm{CH}_{2} \mathrm{CH}_{2} \mathrm{OH}$ and $\left.-\mathrm{NCH}_{2} \mathrm{CH}_{2} \mathrm{CH}_{2} \mathrm{COO}-\right), \quad 1.87-1.81 \quad\left(\mathrm{~m}, 2 \quad \mathrm{H}, \quad-\mathrm{NCH}_{2} \mathrm{CH}_{2} \mathrm{CH}_{2} \mathrm{COO}-\right), \quad 1.79-1.72 \quad(\mathrm{~m}, 4 \quad \mathrm{H}$, $\left.2 \times \mathrm{PhOCH}_{2} \mathrm{CH}_{2}\left(\mathrm{CH}_{2}\right)_{5} \mathrm{CH}_{3}\right)$, 1.47-1.25 (m, $\left.20 \mathrm{H}, 2 \times \mathrm{PhOCH}_{2} \mathrm{CH}_{2}\left(\mathrm{CH}_{2}\right)_{5} \mathrm{CH}_{3}\right), 0.90-0.87(\mathrm{~m}, 6 \mathrm{H}$,

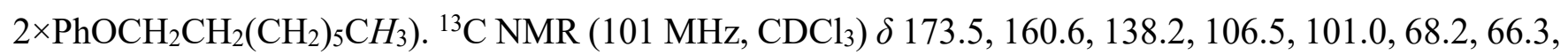
59.3, 57.8, 57.7, 53.3, 53.0, 32.4, 32.0, 29.5, 29.4, 26.2, 22.8, 22.3, 14.2. Purity by HPLC: 99+\%. MALDITOF MS $m / z$ of $[\mathrm{M}+\mathrm{H}]^{+}$calculated for $\mathrm{C}_{33} \mathrm{H}_{59} \mathrm{~N}_{2} \mathrm{O}_{5}$ : 563.4; Found: 562.5 . 


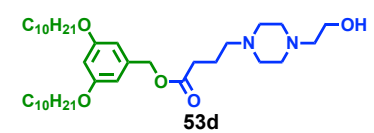

3,5-Bis(decyloxy)benzyl 4-(4-(2-hydroxyethyl)piperazin-1-yl)butanoate (53d, IAJD91). Compound 53d was synthesized from compound 52b ( $0.30 \mathrm{~g}, 0.53 \mathrm{mmol}, 1$ equiv), 1-(2-hydroxyethyl)piperazine (73 $\mathrm{mg}, 0.56 \mathrm{mmol}, 1.05$ equiv) and $\mathrm{K}_{2} \mathrm{CO}_{3}(77 \mathrm{mg}, 0.56 \mathrm{mmol}, 1.05$ equiv) following a procedure similar to that used for the synthesis of compound 53a. The title compound was obtained as a colorless oil $(0.31 \mathrm{~g}$, 94\%). ${ }^{1} \mathrm{H}$ NMR (400 MHz, $\left.\mathrm{CDCl}_{3}\right) \delta 6.45$ (d, $2 \mathrm{H}, \mathrm{Ph} H$ ), 6.38 (t, $1 \mathrm{H}, \mathrm{Ph} H$ ), 5.02 (s, $2 \mathrm{H},-\mathrm{CH}_{2} \mathrm{Ph}$ ), 3.91 (t, $\left.4 \mathrm{H}, 2 \times \mathrm{PhOCH}_{2}-\right), 3.59$ (t, $\left.2 \mathrm{H},-\mathrm{CH}_{2} \mathrm{CH}_{2} \mathrm{OH}\right), 2.74\left(\mathrm{br}, 1 \mathrm{H},-\mathrm{CH}_{2} \mathrm{CH}_{2} \mathrm{OH}\right), 2.62-2.22(\mathrm{~m}, 14 \mathrm{H}$, $\mathrm{N}\left(\mathrm{CH}_{2} \mathrm{CH}_{2}\right)_{2},-\mathrm{OCOCH}_{2} \mathrm{CH}_{2} \mathrm{CH}_{2}$ - and $\left.-\mathrm{CH}_{2} \mathrm{CH}_{2} \mathrm{OH}\right), 1.82\left(\mathrm{~m}, 2 \mathrm{H},-\mathrm{OCOCH}_{2} \mathrm{CH}_{2} \mathrm{CH}_{2}-\right), 1.75(\mathrm{~m}, 4 \mathrm{H}$, $\left.\mathrm{PhOCH}_{2} \mathrm{CH}_{2}\left(\mathrm{CH}_{2}\right)_{7} \mathrm{CH}_{3}\right), \quad 1.43\left(\mathrm{~m}, \quad 4 \quad \mathrm{H}, \quad \mathrm{PhOCH}_{2} \mathrm{CH}_{2} \mathrm{CH}_{2}\left(\mathrm{CH}_{2}\right)_{8} \mathrm{CH}_{3}\right), \quad 1.26$ (br, $24 \mathrm{H}$, $\left.\mathrm{PhOCH}_{2} \mathrm{CH}_{2} \mathrm{CH}_{2}\left(\mathrm{CH}_{2}\right)_{6} \mathrm{CH}_{3}\right), 0.87$ (t, $\left.6 \mathrm{H}, \mathrm{PhO}\left(\mathrm{CH}_{2}\right)_{9} \mathrm{CH}_{3}\right) .{ }^{13} \mathrm{C} \mathrm{NMR}\left(101 \mathrm{MHz}, \mathrm{CDCl}_{3}\right) \delta 173.4,160.5$, 138.2, 106.5, 101.0, 68.2, 66.3, 59.4, 57.8, 57.7, 53.3, 53.0, 32.3, 32.0, 29.7, 29.7, 29.5, 29.4, 29.4, 26.2, 22.8, 22.3, 14.2. Purity by HPLC: 99+\%. MALDI-TOF MS $m / z$ of $[\mathrm{M}+\mathrm{H}]^{+}$calculated for $\mathrm{C}_{37} \mathrm{H}_{67} \mathrm{~N}_{2} \mathrm{O}_{5}$ : 619.5; Found: 619.1.

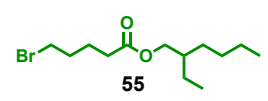

2-Ethylhexyl 5-bromopentanoate (55). To a DCM (10 mL) solution of 2-ethylhexanol (54, $2.00 \mathrm{~g}, 11.1$ mmol), 5-bromovaleric acid (1.44 g, $11.1 \mathrm{mmol})$ and DPTS (3.60 g, $12.2 \mathrm{mmol})$, was added DCC (4.58 g, $22.2 \mathrm{mmol}$ ). The mixture was allowed to stir at $23{ }^{\circ} \mathrm{C}$ for $12 \mathrm{~h}$. The precipitate was filtered, and the filtrate was concentrated to dryness. The crude product was further purified by column chromatography with a mobile phase of hexane/DCM $=1 / 1$ to yield the title compound as a colorless oil $(3.13 \mathrm{~g}, 96 \%) .{ }^{1} \mathrm{H}$ NMR (500 MHz, $\left.\mathrm{CDCl}_{3}\right) \delta 3.98-3.40$ (m, $2 \mathrm{H},-\mathrm{COOCH}_{2}-$ ), 3.42-3.40 (t, $2 \mathrm{H},-\mathrm{CH} \mathrm{H}_{2} \mathrm{Br}$ ), 2.36-2.33 (t, 2 $\left.\mathrm{H},-\mathrm{CH}_{2} \mathrm{COO}-\right), 1.92-1.87$ (m, $2 \mathrm{H}, \mathrm{CH}_{2}$ ), $1.81-1.75$ (m, $\left.2 \mathrm{H}, \mathrm{CH}_{2}\right), 1.57-1.55$ (m, $\left.1 \mathrm{H}, \mathrm{CH}\right), 1.38-1.28$ (m, $\left.8 \mathrm{H}, 4 \times \mathrm{CH}_{2}\right), 0.90-0.87\left(\mathrm{t}, 6 \mathrm{H}, 2 \times \mathrm{CH}_{3}\right) .{ }^{13} \mathrm{C} \mathrm{NMR}\left(126 \mathrm{MHz}, \mathrm{CDCl}_{3}\right) \delta 173.2,66.8,38.6,33.3,32.9$, $31.9,30.3,28.8,23.7,23.5,22.9,14.0,10.9$.

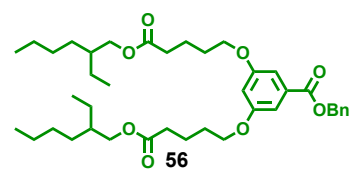

Bis(2-ethylhexyl) 5,5'-((5-((benzyloxy)carbonyl)-1,3-phenylene)bis(oxy))dipentanoate (56). Benzyl 3,5-hydroxyl benzoate (44, $0.78 \mathrm{~g}, 3.21 \mathrm{mmol})$, compound 55 (2.00 g, $6.75 \mathrm{mmol})$ and $\mathrm{K}_{2} \mathrm{CO}_{3}(2.66 \mathrm{~g}$, $19.3 \mathrm{mmol})$ were stirred in DMF $(20 \mathrm{~mL})$. The mixture was stirred at $60{ }^{\circ} \mathrm{C}$ under $\mathrm{N}_{2}$ atmosphere for $6 \mathrm{~h}$. The reaction mixture was cooled to $23^{\circ} \mathrm{C}$ and DMF was removed under reduced pressure. Then water (30 
$\mathrm{mL})$ was added, and the mixture was extracted by DCM $(30 \mathrm{~mL} \times 3)$. The organic phase was dried over anhydrous $\mathrm{MgSO}_{4}$ and filtered. The filtrate was concentrated and purified by column chromatography $\left(\mathrm{SiO}_{2}\right)$ with DCM as the eluent to give the title compound as a colorless oil $(2.95 \mathrm{~g}, 96 \%) .{ }^{1} \mathrm{H}$ NMR $(500$ $\left.\mathrm{MHz} \mathrm{CDCl}_{3}\right) \delta$ 7.44-7.34 (m, $\left.5 \mathrm{H}, 5 \times \mathrm{PhH}\right), 7.18(\mathrm{~d}, 2 \mathrm{H}, 2 \times \mathrm{Ph} H), 6.66(\mathrm{t}, 1 \mathrm{H}, \mathrm{Ph} H), 5.34(\mathrm{~s}, 2 \mathrm{H},-$ $\mathrm{CH}_{2} \mathrm{Ph}$ ), 4.00-3.97 (m, $\left.8 \mathrm{H}, 4 \times-\mathrm{OCH}_{2}-\right), 2.40-2.37$ (m, $\left.4 \mathrm{H}, 2 \times-\mathrm{CH}_{2} \mathrm{COO}-\right), 1.82-1.81$ (m, $\left.8 \mathrm{H}, 4 \times \mathrm{CH}_{2}\right)$, 1.59-1.55 (m, $2 \mathrm{H}, 2 \times \mathrm{CH}), 1.38-1.28\left(\mathrm{~m}, 16 \mathrm{H}, 8 \times \mathrm{CH}_{2}\right), 0.90-0.87\left(\mathrm{t}, 12 \mathrm{H}, 4 \times \mathrm{CH}_{3}\right) .{ }^{13} \mathrm{C} \mathrm{NMR}(126$ $\left.\mathrm{MHz}_{2} \mathrm{CDCl}_{3}\right) \delta 173.7,166.4,160.1,136.1,132.0,128.7,128.4,128.3,108.0,106.6,67.8,66.9,38.9,34.1$, $30.5,29.0,28.7,23.9,23.1,21.8,14.2,11.1$.

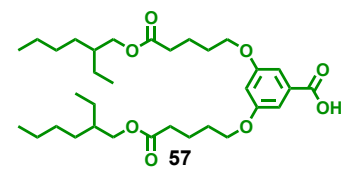

3,5-Bis((5-((2-ethylhexyl)oxy)-5-oxopentyl)oxy)benzoic acid (57). Compound 56 (2.13 g, 3.18 mmol) was dissolved in 1:2 MeOH:DCM (45 mL). Then Pd/C (0.21 g, $10 \mathrm{wt} \%)$ was added and the flask was evacuated and filled with hydrogen for three times. The mixture was stirred at $23{ }^{\circ} \mathrm{C}$ for $12 \mathrm{~h}$ under hydrogen atmosphere. The reaction mixture was filtered through Celite and the filter cake was washed with DCM. Evaporation of the solvent yielded the title compound as a colorless oil (1.84 g, 100\%). ${ }^{1} \mathrm{H}$ NMR $\left(500 \mathrm{MHz}, \mathrm{CDCl}_{3}\right) \delta 7.21(\mathrm{~d}, 2 \mathrm{H}, 2 \times \mathrm{Ph} H), 6.65(\mathrm{~d}, 2 \mathrm{H}, 2 \times \mathrm{Ph} H), 4.00-3.98\left(\mathrm{~m}, 8 \mathrm{H}, 4 \times-\mathrm{OCH}_{2}-\right)$, 2.40-2.38 (m, 4 H, 2×-CH $\left.\mathrm{C}_{2} \mathrm{COO}-\right)$, 1.83-1.82 (m, $\left.8 \mathrm{H}, 4 \times \mathrm{CH}_{2}\right), 1.58-1.55$ (m, $\left.2 \mathrm{H}, 2 \times \mathrm{CH}\right), 1.38-1.28(\mathrm{~m}$, $\left.16 \mathrm{H}, 8 \times \mathrm{CH}_{2}\right), 0.90-0.87\left(\mathrm{t}, 12 \mathrm{H}, 4 \times \mathrm{CH}_{3}\right) .{ }^{13} \mathrm{C} \mathrm{NMR}\left(126 \mathrm{MHz}, \mathrm{CDCl}_{3}\right) \delta 173.8,171.2,160.1,131.3$, $108.3,107.4,67.8,67.0,38.9,34.1,30.5,29.0,28.7,23.9,23.1,21.8,14.2,11.1$.

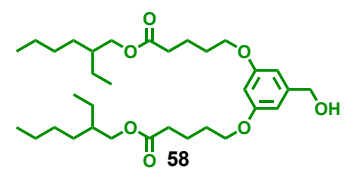

Bis(2-ethylhexyl) 5,5'-((5-(hydroxymethyl)-1,3-phenylene)bis(oxy))dipentanoate (58). To a solution of compound 57 (1.78 g, $3.08 \mathrm{mmol})$ in $50 \mathrm{~mL}$ THF was added $\mathrm{NaBH}_{4}(0.35 \mathrm{~g}, 9.23 \mathrm{mmol})$. The reaction mixture was stirred at $23{ }^{\circ} \mathrm{C}$ for 30 min under $\mathrm{N}_{2}$ until no more gas was generated. A solution of iodine (1.02 g, $4.00 \mathrm{mmol})$ in THF $(20 \mathrm{~mL})$ was added dropwise into the reaction mixture under $\mathrm{N}_{2}$ in 20 min at $0{ }^{\circ} \mathrm{C}$. After stirring at $0{ }^{\circ} \mathrm{C}$ for $30 \mathrm{~min}$, the reaction was returned to $23{ }^{\circ} \mathrm{C}$ and stirred for $1.5 \mathrm{~h}$. The reaction was quenched with $\mathrm{HCl}(2 \mathrm{M})$ solution $(10 \mathrm{~mL})$ until no more gas was generated, and then saturated $\mathrm{NaHCO}_{3}$ aqueous solution was added until $\mathrm{pH}=7$. The mixture was extracted by DCM $(50 \mathrm{~mL} \times 3)$. The organic phase was dried over anhydrous $\mathrm{MgSO}_{4}$ and filtered. The alcohol as the product (1.70 g, 98\%) was obtained by concentrating the filtrate as colorless oil without further purification. ${ }^{1} \mathrm{H} \mathrm{NMR}(500 \mathrm{MHz}$, 
$\left.\mathrm{CDCl}_{3}\right) \delta 6.50(\mathrm{~d}, 2 \mathrm{H}, 2 \times \mathrm{Ph} H), 6.34(\mathrm{t}, 1 \mathrm{H}, \mathrm{Ph} H), 4.60\left(\mathrm{~s}, 2 \mathrm{H},-\mathrm{CH}_{2} \mathrm{Ph}\right), 3.99-3.97\left(\mathrm{~m}, 4 \mathrm{H}, 2 \times \mathrm{OCH}_{2}\right)$, 3.95-3.94 (m, $\left.4 \mathrm{H}, 2 \times \mathrm{OCH}_{2}\right), 2.37\left(\mathrm{~m}, 4 \mathrm{H}, 2 \times \mathrm{CH}_{2}\right), 1.80\left(\mathrm{~m}, 8 \mathrm{H}, 4 \times \mathrm{CH}_{2}\right), 1.57-1.52(\mathrm{~m}, 2 \mathrm{H}, 2 \times \mathrm{CH})$, 1.37-1.28 (m, $\left.16 \mathrm{H}, 8 \times \mathrm{CH}_{2}\right), 0.90-0.87\left(\mathrm{t}, 12 \mathrm{H}, 4 \times \mathrm{CH}_{3}\right) .{ }^{13} \mathrm{C} \mathrm{NMR}\left(126 \mathrm{MHz}, \mathrm{CDCl}_{3}\right) \delta 173.8,160.4$, $105.2,100.6,67.5,66.9,65.4,38.8,34.1,30.5,29.0,28.8,23.9,23.1,21.8,14.2,11.1$.

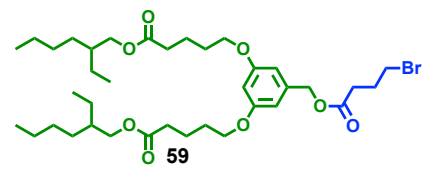

Compound 59. Compound 59 was synthesized from compound 58 (1.70 g, 3.0 mmol), 4-bromobutyric acid $(0.60 \mathrm{~g}, 3.6 \mathrm{mmol})$ and $\mathrm{NEt}_{3}(0.36 \mathrm{~g}, 3.6 \mathrm{mmol})$ following a procedure similar to that used for the synthesis of compound 52a. Besides, DMAP ( $24 \mathrm{mg}, 0.2 \mathrm{mmol}$ ) was added together with $\mathrm{NEt}_{3}$ to perform the esterification. The title compound was obtained as a colorless oil $(0.90 \mathrm{~g}, 42 \%) .{ }^{1} \mathrm{H} \mathrm{NMR}(500 \mathrm{MHz}$, $\left.\mathrm{CDCl}_{3}\right) \delta 6.45(\mathrm{~d}, 2 \mathrm{H}, 2 \times \mathrm{Ph} H), 6.37(\mathrm{t}, 1 \mathrm{H}, \mathrm{PhH}), 5.02\left(\mathrm{~s}, 2 \mathrm{H},-\mathrm{CH}_{2} \mathrm{Ph}\right), 3.99-3.97\left(\mathrm{t}, 4 \mathrm{H}, 2 \times \mathrm{OCH}_{2}\right)$, $3.93\left(\mathrm{~m}, 4 \mathrm{H}, 2 \times \mathrm{OCH}_{2}\right), 3.47-3.44(\mathrm{~m}, 2 \mathrm{H},-\mathrm{CH} 2 \mathrm{Br}), 2.57-2.50\left(\mathrm{t}, 2 \mathrm{H}, \mathrm{CH}_{2}\right), 2.37\left(\mathrm{~m}, 4 \mathrm{H}, 2 \times \mathrm{CH}_{2}\right)$, 2.20-2.15 (m, $\left.2 \mathrm{H}, \mathrm{CH}_{2}\right), 1.80\left(\mathrm{~m}, 8 \mathrm{H}, 4 \times \mathrm{CH}_{2}\right), 1.57-1.53(\mathrm{~m}, 2 \mathrm{H}, 2 \times \mathrm{CH}), 1.37-1.31\left(\mathrm{~m}, 16 \mathrm{H}, 8 \times \mathrm{CH}_{2}\right)$, 0.89-0.86 (t, $\left.12 \mathrm{H}, 4 \times \mathrm{CH}_{3}\right) .{ }^{13} \mathrm{C} \mathrm{NMR}\left(126 \mathrm{MHz}, \mathrm{CDCl}_{3}\right) \delta 173.7,172.4,160.4,138.0,106.5,101.1,67.5$, $66.9,66.4,38.8,34.1,32.7,32.5,30.5,29.0,28.8,27.8,23.9,23.1,21.8,14.1,11.1$.

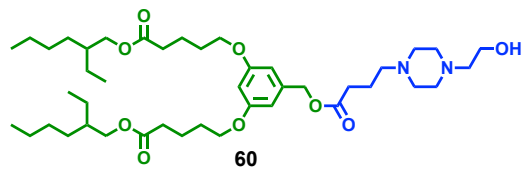

Compound 60 (IAJD95). Compound 60 was synthesized from compound 59 (0.45 g, 0.63 mmol, 1.0 equiv), 1-(2-hydroxyethyl)piperazine ( $90 \mathrm{mg}, 0.69 \mathrm{mmol}, 1.1$ equiv) and $\mathrm{K}_{2} \mathrm{CO}_{3}$ (95 mg, $0.69 \mathrm{mmol}, 1.1$ equiv) following a procedure similar to that used for the synthesis of compound 53a. The title compound was obtained as a colorless oil $(0.38 \mathrm{~g}, 82 \%)$. ${ }^{1} \mathrm{H}$ NMR $\left(500 \mathrm{MHz}, \mathrm{CDCl}_{3}\right) \delta 6.44(\mathrm{~d}, 2 \mathrm{H}, 2 \times \mathrm{Ph} H), 6.36$ (t, $1 \mathrm{H}, \mathrm{PhH}), 5.00$ (s, $\left.2 \mathrm{H},-\mathrm{CH}_{2} \mathrm{Ph}\right), 3.98-3.97$ (m, $\left.4 \mathrm{H}, 2 \times-\mathrm{OCH}_{2}-\right), 3.92\left(\mathrm{~m}, 4 \mathrm{H}, 2 \times-\mathrm{OCH}_{2}-\right), 3.63-3.61$ (t, $\left.2 \mathrm{H}, \mathrm{CH}_{2} \mathrm{OH}\right), 3.30$ (br, $\left.1 \mathrm{H}, \mathrm{CH}_{2} \mathrm{OH}\right), 2.57-2.49$ (br, $10 \mathrm{H}, 2 \times-\mathrm{NCH}_{2} \mathrm{CH}_{2} \mathrm{~N}-$ and $-\mathrm{CH}_{2} \mathrm{CH}_{2} \mathrm{OH}$ ), 2.40$2.35\left(\mathrm{~m}, 8 \mathrm{H}, 4 \times \mathrm{CH}_{2}\right), 1.84-1.79\left(\mathrm{~m}, 10 \mathrm{H}, 5 \times \mathrm{CH}_{2}\right), 1.56-1.53(\mathrm{~m}, 2 \mathrm{H}, 2 \times \mathrm{CH}), 1.37-1.26(\mathrm{~m}, 16 \mathrm{H}$, $\left.8 \times \mathrm{CH}_{2}\right), 0.88-0.85\left(\mathrm{t}, 12 \mathrm{H}, 4 \times \mathrm{CH}_{3}\right) .{ }^{13} \mathrm{C} \mathrm{NMR}\left(126 \mathrm{MHz}, \mathrm{CDCl}_{3}\right) \delta 173.7,173.3,160.3,138.2,106.6$, $100.9,67.5,66.9,66.2,59.5,57.7,57.5,52.9,52.8,38.8,34.0,32.2,30.5,29.0,28.8,23.9,23.0,22.1$, 21.7, 14.1, 11.1. Purity by HPLC: $99+\%$. MALDI-TOF MS $m / z$ of $[\mathrm{M}+\mathrm{H}]^{+}$calculated for $\mathrm{C}_{43} \mathrm{H}_{75} \mathrm{~N}_{2} \mathrm{O}_{9}$ : 763.5; Found: 763.1. 


\subsection{Synthesis of IAJDs 96-99 and 103}

\section{Scheme S7. Synthesis of IAJDs 96-99 and 103}

(a)
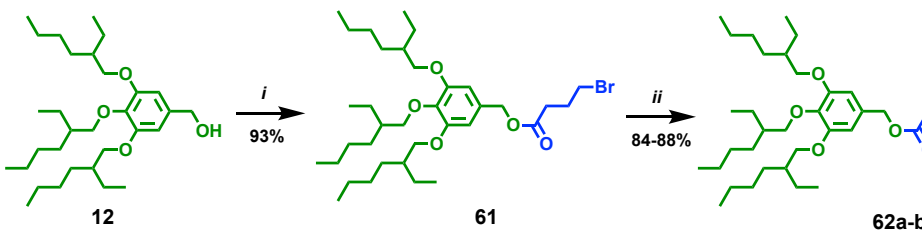

(b)
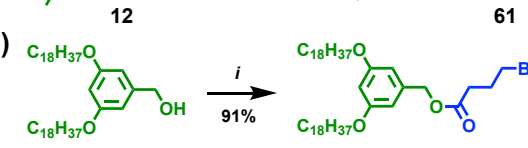

$62 \mathrm{a}-\mathrm{b}$

62a (IAJD96): $\mathrm{R}=\mathrm{CH}_{3}$
62b (IAJD97): $\mathrm{R}=\mathrm{CH}_{2} \mathrm{CH}_{2} \mathrm{OH}$

(c)

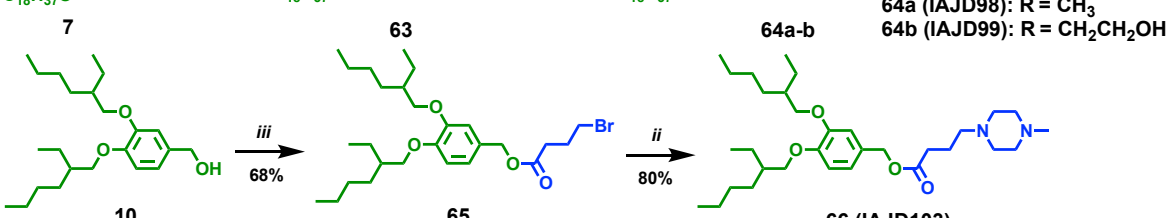

10

65

66 (IAJD103)

Reagents and conditions: (i) 4-Bromobutyric acid, $\mathrm{SOCl}_{2}$, DMF (cat.), DCM, $23{ }^{\circ} \mathrm{C}, 1 \mathrm{~h}$, then DMAP, $\mathrm{NEt}_{3}$, DCM, 0-23 ${ }^{\circ} \mathrm{C}, 2 \mathrm{~h}$; (ii) 1-methylpiperazine/1-(2-hydroxyethyl)piperazine, $\mathrm{K}_{2} \mathrm{CO}_{3}, \mathrm{MeCN}, 95^{\circ} \mathrm{C}$, $3 \mathrm{~h}$; (iii) DCC, DPTS, DCM, $23^{\circ} \mathrm{C}, 12 \mathrm{~h}$.

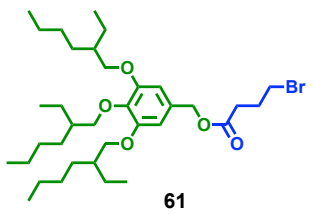

3,4,5-Tris((2-ethylhexyl)oxy)benzyl 4-bromobutanoate (61). 4-Bromobutyric acid (0.33 g, $1.95 \mathrm{mmol}$, 1.1 equiv) was dissolved in $6 \mathrm{~mL}$ anhydrous DCM and 1 drop of DMF was added. $\mathrm{SOCl}_{2}(0.42 \mathrm{~g}, 3.54$ mmol, 2.0 equiv) was added and the mixture was stirred at $23{ }^{\circ} \mathrm{C}$ for $1 \mathrm{~h}$. Afterwards, DCM and excess $\mathrm{SOCl}_{2}$ was removed under reduced pressure to give the 4-bromobutanoyl chloride. Compound 12 (0.87 g, $1.77 \mathrm{mmol}, 1.0$ equiv) and $\mathrm{NEt}_{3}(0.27 \mathrm{~g}, 2.66 \mathrm{mmol}, 1.5$ equiv) were dissolved in $6 \mathrm{~mL}$ anhydrous DCM. To this mixture was added the DCM solution $(4 \mathrm{~mL})$ of above 4-bromobutanoyl chloride dropwise at $0{ }^{\circ} \mathrm{C}$. The mixture was allowed to warm to $23{ }^{\circ} \mathrm{C}$ with stirring during a $2 \mathrm{~h}$ period. Afterwards, water $(20 \mathrm{~mL})$ was added, and the mixture was extracted by DCM $(20 \mathrm{~mL})$ for three times. The organic phase was collected, dried over anhydrous $\mathrm{MgSO}_{4}$ and filtered. The filtrate was concentrated and purified by column chromatography $\left(\mathrm{SiO}_{2}\right)$ with hexane/EtOAc $=20 / 1$ as the eluent to give the title compound as a colorless oil (1.06 g, 93\%). ${ }^{1} \mathrm{H}$ NMR (400 MHz, $\left.\mathrm{CDCl}_{3}\right) \delta 6.53\left(\mathrm{~s}, 2 \mathrm{H}, \mathrm{Ph} H\right.$ ), $5.03\left(\mathrm{~s}, 2 \mathrm{H},-\mathrm{CH}_{2} \mathrm{Ph}\right.$ ), 3.84 (m, $\left.6 \mathrm{H}, 3 \times \mathrm{PhOCH}_{2}-\right), 3.47$ (t, $2 \mathrm{H},-\mathrm{CH}_{2} \mathrm{Br}$ ), 2.57 (t, $\left.2 \mathrm{H}, \mathrm{BrCH}_{2} \mathrm{CH}_{2} \mathrm{CH}_{2} \mathrm{COO}-\right), 2.20$ (m, $2 \mathrm{H}$, $\left.\mathrm{BrCH}_{2} \mathrm{CH}_{2} \mathrm{CH}_{2} \mathrm{COO}-\right), \quad 1.82-1.64\left(\mathrm{~m}, 3 \mathrm{H}, \quad 3 \times \mathrm{PhOCH}_{2} \mathrm{CH}\left(\mathrm{CH}_{2} \mathrm{CH}_{3}\right)-\right), \quad 1.64-1.21 \quad(\mathrm{~m}, 24 \mathrm{H}$, $\left.3 \times \mathrm{PhOCH}_{2} \mathrm{CH}\left(\mathrm{CH}_{2} \mathrm{CH}_{3}\right)\left(\mathrm{CH}_{2}\right)_{3} \mathrm{CH}_{3}\right), 1.00-0.80\left(\mathrm{~m}, 18 \mathrm{H}, 3 \times \mathrm{PhOCH}_{2} \mathrm{CH}\left(\mathrm{CH}_{2} \mathrm{CH}_{3}\right)\left(\mathrm{CH}_{2}\right)_{3} \mathrm{CH}_{3}\right) .{ }^{13} \mathrm{C}$ 
$\operatorname{NMR}\left(101 \mathrm{MHz}, \mathrm{CDCl}_{3}\right) \delta 172.5,153.6,138.2,130.7,106.4,76.1,71.3,67.0,66.9,40.7,39.8,32.8,32.6$, $30.6,29.5,29.5,29.4,29.2,27.9,23.9,23.8,23.3,23.2,14.3,14.2,11.3,11.3,11.3,11.3$.

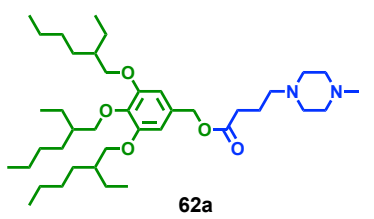

3,4,5-Tris((2-ethylhexyl)oxy)benzyl 4-(4-methylpiperazin-1-yl)butanoate (62a, IAJD96). Compound 61 (0.30 g, $0.47 \mathrm{mmol}, 1.0$ equiv), 1-methylpiperazine (49 mg, $0.49 \mathrm{mmol}, 1.05$ equiv), $\mathrm{K}_{2} \mathrm{CO}_{3}$ (68 mg, $0.49 \mathrm{mmol}, 1.05$ equiv) were stirred in $\mathrm{MeCN}(20 \mathrm{~mL})$. The mixture was heated at reflux $\left(95^{\circ} \mathrm{C}\right)$ for $3 \mathrm{~h}$. The reaction mixture was cooled to $23{ }^{\circ} \mathrm{C}$ and $\mathrm{MeCN}$ was removed under reduced pressure. Then water $(20 \mathrm{~mL})$ was added, and the mixture was extracted by DCM $(20 \mathrm{~mL} \times 3)$. The organic phase was collected, dried over anhydrous $\mathrm{MgSO}_{4}$, filtered and dried to give the crude product. The crude product was purified by column chromatography $\left(\mathrm{SiO}_{2}\right)$ with $\mathrm{DCM} / \mathrm{MeOH}=40 / 1$ and $15 / 1$ as the eluent. Then the obtained product was dissolved in DCM $(20 \mathrm{~mL})$, which was washed by $\mathrm{NaHCO}_{3}$ solution $(2 \%, 20 \mathrm{~mL})$. The aqueous phase was extracted by DCM $(20 \mathrm{~mL})$ for another two times. The organic phase was combined and dried over anhydrous $\mathrm{MgSO}_{4}$. Filtration and evaporation of the solvent yielded the title compound as a light-yellow oil (0.26 g, 84\%). ${ }^{1} \mathrm{H}$ NMR (400 MHz, $\left.\mathrm{CDCl}_{3}\right) \delta 6.52(\mathrm{~s}, 2 \mathrm{H}, \mathrm{PhH}), 5.00$ (s, $\left.2 \mathrm{H},-\mathrm{CH}_{2} \mathrm{Ph}\right)$, $3.82\left(\mathrm{~m}, 6 \mathrm{H}, 3 \times \mathrm{PhOCH}_{2}-\right), 2.72-2.28\left(\mathrm{~m}, 12 \mathrm{H}, \mathrm{N}\left(\mathrm{CH}_{2} \mathrm{CH}_{2}\right)_{2}\right.$ and $\left.-\mathrm{OCOCH}_{2} \mathrm{CH}_{2} \mathrm{CH}_{2}-\right), 2.26(\mathrm{~s}, 3 \mathrm{H}$, $\left.\mathrm{NCH}_{3}\right), 1.82\left(\mathrm{~m}, 2 \mathrm{H},-\mathrm{OCOCH}_{2} \mathrm{CH}_{2} \mathrm{CH}_{2}-\right), 1.77-1.63\left(\mathrm{~m}, 3 \mathrm{H}, 3 \times \mathrm{PhOCH}_{2} \mathrm{CH}\left(\mathrm{CH}_{2} \mathrm{CH}_{3}\right)-\right), 1.63-1.20(\mathrm{~m}$, $\left.24 \mathrm{H}, 3 \times \mathrm{PhOCH}_{2} \mathrm{CH}\left(\mathrm{CH}_{2} \mathrm{CH}_{3}\right)\left(\mathrm{CH}_{2}\right)_{3} \mathrm{CH}_{3}\right), 0.99-0.80\left(\mathrm{~m}, 18 \mathrm{H}, 3 \times \mathrm{PhOCH}_{2} \mathrm{CH}\left(\mathrm{CH}_{2} \mathrm{CH}_{3}\right)\left(\mathrm{CH}_{2}\right)_{3} \mathrm{CH}_{3}\right)$. ${ }^{13} \mathrm{C}$ NMR $\left(101 \mathrm{MHz}, \mathrm{CDCl}_{3}\right) \delta 173.5,153.5,138.1,130.9,106.4,76.0,71.3,66.8,57.7,55.3,53.2,46.2$, 40.7, 39.7, 32.4, 30.6, 30.6, 29.4, 29.4, 29.4, 29.2, 23.9, 23.8, 23.3, 23.2, 22.3, 14.3, 14.2, 11.3, 11.3, 11.3, 11.2. Purity by HPLC: $99+\%$. MALDI-TOF MS $m / z$ of $[\mathrm{M}+\mathrm{H}]^{+}$calculated for $\mathrm{C}_{40} \mathrm{H}_{73} \mathrm{~N}_{2} \mathrm{O}_{5}$ : 661.5; Found: 661.8 .

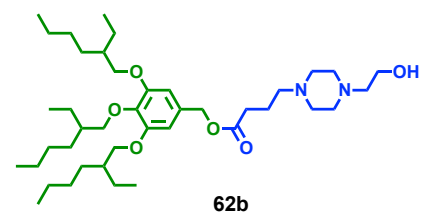

3,4,5-Tris((2-ethylhexyl)oxy)benzyl 4-(4-(2-hydroxyethyl)piperazin-1-yl)butanoate (62b, IAJD97). Compound 62b was synthesized from compound 61 (0.30 g, 0.47 mmol, 1.0 equiv), 1-(2hydroxyethyl)piperazine (64 mg, $0.49 \mathrm{mmol}, 1.05$ equiv) and $\mathrm{K}_{2} \mathrm{CO}_{3}$ (68 mg, $0.49 \mathrm{mmol}$, 1.05 equiv) following a procedure similar to that used for the synthesis of compound 62a. The title compound was 
obtained as a light-yellow oil (0.28 g, 88\%). ${ }^{1} \mathrm{H}$ NMR $\left(400 \mathrm{MHz}, \mathrm{CDCl}_{3}\right) \delta 6.52(\mathrm{~s}, 2 \mathrm{H}, \mathrm{PhH}), 5.00(\mathrm{~s}, 2$ $\left.\mathrm{H},-\mathrm{CH}_{2} \mathrm{Ph}\right), 3.82\left(\mathrm{~m}, 6 \mathrm{H}, 3 \times \mathrm{PhOCH}_{2}-\right), 3.58$ (t, $\left.2 \mathrm{H},-\mathrm{CH}_{2} \mathrm{CH}_{2} \mathrm{OH}\right), 2.78$ (br, $\left.1 \mathrm{H},-\mathrm{CH}_{2} \mathrm{CH}_{2} \mathrm{OH}\right), 2.64-$ $2.21\left(\mathrm{~m}, 14 \mathrm{H}, \mathrm{N}\left(\mathrm{CH}_{2} \mathrm{CH}_{2}\right)_{2},-\mathrm{OCOCH}_{2} \mathrm{CH}_{2} \mathrm{CH}_{2}\right.$ - and $\left.-\mathrm{CH}_{2} \mathrm{CH}_{2} \mathrm{OH}\right), 1.82\left(\mathrm{~m}, 2 \mathrm{H},-\mathrm{OCOCH}_{2} \mathrm{CH}_{2} \mathrm{CH}_{2}-\right)$, 1.77-1.63 (m, $\left.3 \mathrm{H}, 3 \times \mathrm{PhOCH}_{2} \mathrm{CH}\left(\mathrm{CH}_{2} \mathrm{CH}_{3}\right)-\right), 1.63-1.20\left(\mathrm{~m}, 24 \mathrm{H}, 3 \times \mathrm{PhOCH}_{2} \mathrm{CH}\left(\mathrm{CH}_{2} \mathrm{CH}_{3}\right)\left(\mathrm{CH}_{2}\right)_{3} \mathrm{CH}_{3}\right)$, 0.99-0.78 (m, $\left.18 \mathrm{H}, 3 \times \mathrm{PhOCH}_{2} \mathrm{CH}\left(\mathrm{CH}_{2} \mathrm{CH}_{3}\right)\left(\mathrm{CH}_{2}\right)_{3} \mathrm{CH}_{3}\right) .{ }^{13} \mathrm{C} \mathrm{NMR}\left(101 \mathrm{MHz}, \mathrm{CDCl}_{3}\right) \delta 173.5,153.5$, 138.1, 130.9, 106.4, 76.0, 71.3, 66.8, 59.4, 57.8, 57.7, 53.2, 53.0, 40.7, 39.7, 32.4, 30.6, 30.6, 29.4, 29.4, 29.4, 29.2, 23.9, 23.8, 23.2, 23.2, 22.3, 14.2, 14.2, 11.3, 11.3, 11.3, 11.2. Purity by HPLC: 99+\%. MALDITOF MS $m / z$ of $[\mathrm{M}+\mathrm{H}]^{+}$calculated for $\mathrm{C}_{41} \mathrm{H}_{75} \mathrm{~N}_{2} \mathrm{O}_{6}$ : 691.6; Found: 691.1.

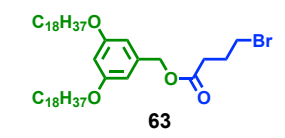

3,5-Bis(octadecyloxy)benzyl 4-bromobutanoate (63). Compound 63 was synthesized from compound 7 (0.85 g, 1.32 mmol, 1.0 equiv), 4-bromobutyric acid (0.24 g, 1.45 mmol, 1.1 equiv) and $\mathrm{NEt}_{3}(0.15 \mathrm{~g}$ $1.45 \mathrm{mmol}, 1.1$ equiv) following a procedure similar to that used for the synthesis of compound 61. Besides, DMAP (32 mg, 0.26 mmol, 0.2 equiv) was added together with $\mathrm{NEt}_{3}$ to perform the esterification. The title compound was obtained as a colorless oil $(0.94 \mathrm{~g}, 91 \%) .{ }^{1} \mathrm{H}$ NMR $\left(400 \mathrm{MHz}, \mathrm{CDCl}_{3}\right) \delta 6.47$ (d, $2 \mathrm{H}, \mathrm{PhH}), 6.41(\mathrm{t}, 1 \mathrm{H}, \mathrm{PhH}), 5.05\left(\mathrm{~s}, 2 \mathrm{H}, \mathrm{PhCH}_{2} \mathrm{O}-\right), 3.93\left(\mathrm{t}, 4 \mathrm{H},-\mathrm{CH}_{2} \mathrm{OPh}\right), 3.47(\mathrm{t}, 2 \mathrm{H},-$ $\mathrm{OCOCH}_{2} \mathrm{CH}_{2} \mathrm{CH}_{2} \mathrm{Br}$ ), 2.57 (t, $2 \mathrm{H},-\mathrm{OCOCH}_{2} \mathrm{CH}_{2} \mathrm{CH}_{2} \mathrm{Br}$ ), 2.20 (m, $2 \mathrm{H},-\mathrm{OCOCH}_{2} \mathrm{CH}_{2} \mathrm{CH}_{2} \mathrm{Br}$ ), 1.75 (m, $\left.4 \mathrm{H}, \mathrm{PhOCH}_{2} \mathrm{CH}_{2}\left(\mathrm{CH}_{2}\right)_{15} \mathrm{CH}_{3}\right), 1.44$ (m, $\left.4 \mathrm{H}, \mathrm{PhOCH}_{2} \mathrm{CH}_{2} \mathrm{CH}_{2}\left(\mathrm{CH}_{2}\right)_{14} \mathrm{CH}_{3}\right), 1.26$ (br, $56 \mathrm{H}$, $\left.\mathrm{PhOCH}_{2} \mathrm{CH}_{2} \mathrm{CH}_{2}\left(\mathrm{CH}_{2}\right)_{14} \mathrm{CH}_{3}\right), 0.88\left(\mathrm{~m}, 6 \mathrm{H}, \mathrm{PhO}\left(\mathrm{CH}_{2}\right){ }_{17} \mathrm{CH}_{3}\right) .{ }^{13} \mathrm{C} \mathrm{NMR}\left(101 \mathrm{MHz}, \mathrm{CDCl}_{3}\right) \delta 172.9$, $160.7,160.6,137.9$, 106.7, 106.5, 101.2, 68.2, 66.6, 32.8, 32.6, 32.1, 29.9, 29.8, 29.7, 29.6, 29.5, 29.4, $27.9,26.2,22.8,14.3$.

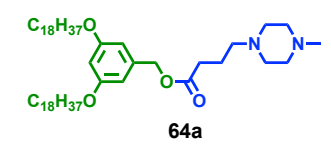

3,5-Bis(octadecyloxy)benzyl 4-(4-methylpiperazin-1-yl)butanoate (64a, IAJD98). Compound 64a was synthesized from compound $63(0.30 \mathrm{~g}, 0.38 \mathrm{mmol}, 1.0$ equiv), 1-methylpiperazine (41 mg, 0.40 mmol, 1.05 equiv) and $\mathrm{K}_{2} \mathrm{CO}_{3}(58 \mathrm{mg}, 0.42 \mathrm{mmol}, 1.1$ equiv) following a procedure similar to that used for the synthesis of compound 62a. The title compound was obtained as a light-yellow oil $(0.27 \mathrm{~g}, 88 \%)$. ${ }^{1} \mathrm{H}$ NMR (400 MHz, $\left.\mathrm{CDCl}_{3}\right) \delta 6.46$ (d, $\left.2 \mathrm{H}, \mathrm{Ph} H\right), 6.40$ (t, $\left.1 \mathrm{H}, \mathrm{Ph} H\right), 5.03$ (s, 2 H, PhCH $\mathrm{H}_{2}$ ), 3.92 (t, 4 $\left.\mathrm{H},-\mathrm{CH}_{2} \mathrm{OPh}\right), 2.72-2.28\left(\mathrm{~m}, 15 \mathrm{H}, \mathrm{N}\left(\mathrm{CH}_{2} \mathrm{CH}_{2}\right)_{2},-\mathrm{OCOCH}_{2} \mathrm{CH}_{2} \mathrm{CH}_{2}-\right.$ and $\left.\mathrm{NCH}_{3}\right), 1.82(\mathrm{~m}, 2 \mathrm{H},-$ $\left.\mathrm{OCOCH}_{2} \mathrm{CH}_{2} \mathrm{CH}_{2}-\right), \quad 1.75 \quad\left(\mathrm{~m}, \quad 4 \quad \mathrm{H}, \quad \mathrm{PhOCH}_{2} \mathrm{CH}_{2}\left(\mathrm{CH}_{2}\right)_{15} \mathrm{CH}_{3}\right), \quad 1.43 \quad(\mathrm{~m}, \quad 4 \quad \mathrm{H}$, $\left.\mathrm{PhOCH}_{2} \mathrm{CH}_{2} \mathrm{CH}_{2}\left(\mathrm{CH}_{2}\right)_{14} \mathrm{CH}_{3}\right), \quad 1.26$ (br, $\left.56 \mathrm{H}, \quad \mathrm{PhOCH}_{2} \mathrm{CH}_{2} \mathrm{CH}_{2}\left(\mathrm{CH}_{2}\right)_{14} \mathrm{CH}_{3}\right), \quad 0.87 \quad(\mathrm{~m}, \quad 6 \mathrm{H}$, 
$\left.\mathrm{PhO}\left(\mathrm{CH}_{2}\right)_{17} \mathrm{CH}_{3}\right) .{ }^{13} \mathrm{C} \mathrm{NMR}\left(101 \mathrm{MHz}, \mathrm{CDCl}_{3}\right) \delta 173.3,160.4,138.1,106.4,100.9,68.1,66.2,57.5,55.1$, 53.0, 46.0, 32.2, 31.9, 29.7, 29.6, 29.6, 29.4, 29.4, 29.3, 26.1, 22.7, 22.1, 14.1. Purity by HPLC: 99+\%. MALDI-TOF MS $m / z$ of $[\mathrm{M}+\mathrm{H}]^{+}$calculated for $\mathrm{C}_{52} \mathrm{H}_{96} \mathrm{~N}_{2} \mathrm{O}_{4}$ : 813.7; Found: 813.5.

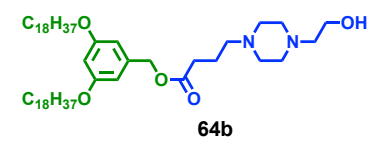

\section{3,5-Bis(octadecyloxy)benzyl 4-(4-(2-hydroxyethyl)piperazin-1-yl)butanoate (64b, IAJD99).}

Compound 64b was synthesized from compound 63 (0.30 g, 0.38 mmol, 1.0 equiv), 1-(2hydroxyethyl)piperazine (53 mg, $0.40 \mathrm{mmol}, 1.05$ equiv) and $\mathrm{K}_{2} \mathrm{CO}_{3}$ (58 $\mathrm{mg}, 0.42 \mathrm{mmol}, 1.1$ equiv) following a procedure similar to that used for the synthesis of compound 62a. The title compound was obtained as a light-yellow oil (0.24 g, 75\%). ${ }^{1} \mathrm{H}$ NMR (400 MHz, $\left.\mathrm{CDCl}_{3}\right) \delta 6.46(\mathrm{~d}, 2 \mathrm{H}, \mathrm{PhH}), 6.39(\mathrm{t}, 1$ $\mathrm{H}, \mathrm{PhH}), 5.03$ (s, $\left.2 \mathrm{H}, \mathrm{PhCH}_{2} \mathrm{O}-\right), 3.92$ (t, $\left.4 \mathrm{H},-\mathrm{CH}_{2} \mathrm{OPh}\right), 3.63$ (t, $\left.2 \mathrm{H},-\mathrm{NCH}_{2} \mathrm{CH}_{2} \mathrm{OH}\right), 2.75$ (br, $1 \mathrm{H},-$ $\left.\mathrm{CH}_{2} \mathrm{CH}_{2} \mathrm{OH}\right), 2.65-2.20\left(\mathrm{~m}, 14 \mathrm{H}, \mathrm{N}\left(\mathrm{CH}_{2} \mathrm{CH}_{2}\right)_{2},-\mathrm{OCOCH}_{2} \mathrm{CH}_{2} \mathrm{CH}_{2}\right.$ - and $\left.-\mathrm{CH}_{2} \mathrm{CH}_{2} \mathrm{OH}\right), 1.84(\mathrm{~m}, 2 \mathrm{H},-$ $\left.\mathrm{OCOCH}_{2} \mathrm{CH}_{2} \mathrm{CH}_{2-}\right), \quad 1.76 \quad\left(\mathrm{~m}, \quad 4 \quad \mathrm{H}, \quad \mathrm{PhOCH}_{2} \mathrm{CH}_{2}\left(\mathrm{CH}_{2}\right)_{15} \mathrm{CH}_{3}\right), \quad 1.43 \quad(\mathrm{~m}, \quad 4 \quad \mathrm{H}$, $\left.\mathrm{PhOCH}_{2} \mathrm{CH}_{2} \mathrm{CH}_{2}\left(\mathrm{CH}_{2}\right)_{14} \mathrm{CH}_{3}\right), \quad 1.26$ (br, $\left.56 \mathrm{H}, \quad \mathrm{PhOCH}_{2} \mathrm{CH}_{2} \mathrm{CH}_{2}\left(\mathrm{CH}_{2}\right)_{14} \mathrm{CH}_{3}\right), \quad 0.88 \quad$ (m, $6 \mathrm{H}$, $\left.\mathrm{PhO}\left(\mathrm{CH}_{2}\right)_{17} \mathrm{CH}_{3}\right) .{ }^{13} \mathrm{C} \mathrm{NMR}\left(101 \mathrm{MHz}, \mathrm{CDCl}_{3}\right) \delta 173.4,160.6,138.1,106.5,101.0,68.2,66.3,59.5,57.7$, 57.6, 52.9, 32.3, 32.0, 29.8, 29.7, 29.7, 29.5, 29.5, 29.4, 26.2, 22.8, 22.1, 14.2. Purity by HPLC: 99+\%. MALDI-TOF MS $m / z$ of $[\mathrm{M}+\mathrm{H}]^{+}$calculated for $\mathrm{C}_{53} \mathrm{H}_{98} \mathrm{~N}_{2} \mathrm{O}_{5}$ : 843.8; Found: 843.4.

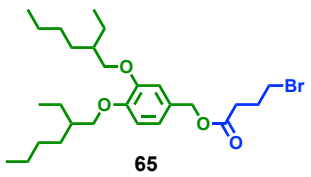

3,4-Bis((2-ethylhexyl)oxy)benzyl 4-bromobutanoate (65). To a DCM (10 mL) solution of compound 10 (0.60 g, $1.65 \mathrm{mmol})$, 4-bromobutyric acid (0.28 g, $1.65 \mathrm{mmo})$ and DPTS (0.53 g, $1.81 \mathrm{mmol})$, was added DCC $(0.68 \mathrm{~g}, 3.30 \mathrm{mmol})$. The mixture was allowed to stir at $23{ }^{\circ} \mathrm{C}$ for $12 \mathrm{~h}$. The precipitate was filtered, and the filtrate was concentrated to dryness. The crude product was further purified by column chromatography with a mobile phase of hexane/DCM $=1 / 1$ to yield the title compound as a colorless oil (0.58 g, 68\%). ${ }^{1} \mathrm{H}$ NMR (500 MHz, $\left.\mathrm{CDCl}_{3}\right) \delta 6.91-6.83(\mathrm{~m}, 3 \mathrm{H}, 3 \times \mathrm{Ph} H), 5.05\left(\mathrm{~s}, 2 \mathrm{H},-\mathrm{CH}_{2} \mathrm{Ph}\right), 3.90-$ 3.83 (m, 4 H, 2× $\mathrm{PhOCH}_{2}-$ ), 3.47-3.45 (t, $2 \mathrm{H},-\mathrm{CH}_{2} \mathrm{Br}$ ), 2.55-2.53 (t, $2 \mathrm{H}, \mathrm{BrCH}_{2} \mathrm{CH}_{2} \mathrm{CH}_{2} \mathrm{COO}-$ ), 2.21$2.16\left(\mathrm{~m}, 2 \mathrm{H}, \mathrm{BrCH}_{2} \mathrm{CH}_{2} \mathrm{CH}_{2} \mathrm{COO}-\right)$, 1.77-1.73 (m, $\left.2 \mathrm{H}, 2 \times \mathrm{PhOCH}_{2} \mathrm{CH}\left(\mathrm{CH}_{2} \mathrm{CH}_{3}\right)\left(\mathrm{CH}_{2}\right)_{3} \mathrm{CH}_{3}\right), 1.57-1.32$ $\left(\mathrm{m}, \quad 16 \mathrm{H}, \quad 2 \times \mathrm{PhOCH}_{2} \mathrm{CH}\left(\mathrm{CH}_{2} \mathrm{CH}_{3}\right)\left(\mathrm{CH}_{2}\right)_{3} \mathrm{CH}_{3}\right), \quad 0.96-0.89 \quad(\mathrm{~m}, \quad 12 \quad \mathrm{H}$, $\left.2 \times \mathrm{PhOCH}_{2} \mathrm{CH}\left(\mathrm{CH}_{2} \mathrm{CH}_{3}\right)\left(\mathrm{CH}_{2}\right)_{3} \mathrm{CH}_{3}\right) .{ }^{13} \mathrm{C} \mathrm{NMR}\left(126 \mathrm{MHz}, \mathrm{CDCl}_{3}\right) \delta 172.6,149.8,149.6,128.2,121.4$, $114.1,113.3,71.7,66.8,39.7,39.6,32.8,32.7,30.7,29.3,27.9,24.0,23.2,14.2,11.3,11.3$. 


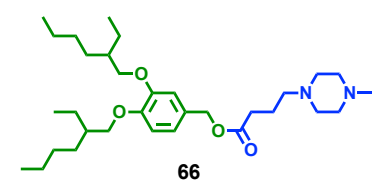

3,4-Bis((2-ethylhexyl)oxy)benzyl 4-(4-methylpiperazin-1-yl)butanoate (66, IAJD103). Compound 66 was synthesized from compound 65 ( $0.54 \mathrm{~g}, 1.05 \mathrm{mmol}, 1.0$ equiv), 1-methylpiperazine ( $0.12 \mathrm{~g}, 1.16$ mmol, 1.1 equiv) and $\mathrm{K}_{2} \mathrm{CO}_{3}(0.16 \mathrm{~g}, 1.16 \mathrm{mmol}, 1.1$ equiv) following a procedure similar to that used for the synthesis of compound 62a. The title compound was obtained as a colorless oil $(0.45 \mathrm{~g}, 80 \%) .{ }^{1} \mathrm{H}$ NMR $\left(500 \mathrm{MHz}, \mathrm{CDCl}_{3}\right) \delta 6.87-6.81(\mathrm{~m}, 3 \mathrm{H}, 3 \times \mathrm{Ph} H), 5.01\left(\mathrm{~s}, 2 \mathrm{H},-\mathrm{CH}_{2} \mathrm{Ph}\right), 3.87-3.81(\mathrm{~m}, 4 \mathrm{H}$, $\left.2 \times \mathrm{PhOCH}_{2}-\right), 2.47$ (br, $\left.8 \mathrm{H},-\mathrm{N}\left(\mathrm{CH}_{2} \mathrm{CH}_{2}\right)_{2} \mathrm{~N}-\right), 2.37-2.33$ (m, $\left.4 \mathrm{H},-\mathrm{NCH}_{2} \mathrm{CH}_{2} \mathrm{CH}_{2} \mathrm{COO}-\right), 2.29$ (s, $3 \mathrm{H}$, $\left.\mathrm{NCH}_{3}\right), \quad 1.84-1.78 \quad\left(\mathrm{~m}, \quad 2 \quad \mathrm{H}, \quad-\mathrm{NCH}_{2} \mathrm{CH}_{2} \mathrm{CH}_{2} \mathrm{COO}-\right), \quad 1.75-1.71 \quad(\mathrm{~m}, 22 \mathrm{H}$, $\left.2 \times \mathrm{PhOCH}_{2} \mathrm{CH}\left(\mathrm{CH}_{2} \mathrm{CH}_{3}\right)\left(\mathrm{CH}_{2}\right)_{3} \mathrm{CH}_{3}\right), 1.55-1.29\left(\mathrm{~m}, 16 \mathrm{H}, 2 \times \mathrm{PhOCH}_{2} \mathrm{CH}\left(\mathrm{CH}_{2} \mathrm{CH}_{3}\right)\left(\mathrm{CH}_{2}\right)_{3} \mathrm{CH}_{3}\right), 0.93-$ $0.87\left(\mathrm{~m}, 12 \mathrm{H}, 2 \times \mathrm{PhOCH}_{2} \mathrm{CH}\left(\mathrm{CH}_{2} \mathrm{CH}_{3}\right)\left(\mathrm{CH}_{2}\right)_{3} \mathrm{CH}_{3}\right) .{ }^{13} \mathrm{C} \mathrm{NMR}\left(126 \mathrm{MHz}, \mathrm{CDCl}_{3}\right) \delta$ 173.5, 149.7, 149.6, 128.4, 121.3, 114.1, 113.3, 71.7, 66.5, 57.6, 55.1, 52.9, 46.0, 39.7, 39.6, 32.4, 30.7, 29.2, 29.2, 24.0, 23.2, 22.2, 14.2, 11.3, 11.3. Purity by HPLC: $99+\%$. MALDI-TOF MS $m / z$ of $[\mathrm{M}+\mathrm{H}]^{+}$calculated for $\mathrm{C}_{32} \mathrm{H}_{57} \mathrm{~N}_{2} \mathrm{O}_{4}$ : 533.4; Found: 533.4.

\subsection{Synthesis of IAJDs 105-108}

Scheme S8. Synthesis of IAJDs 105-108

(a)
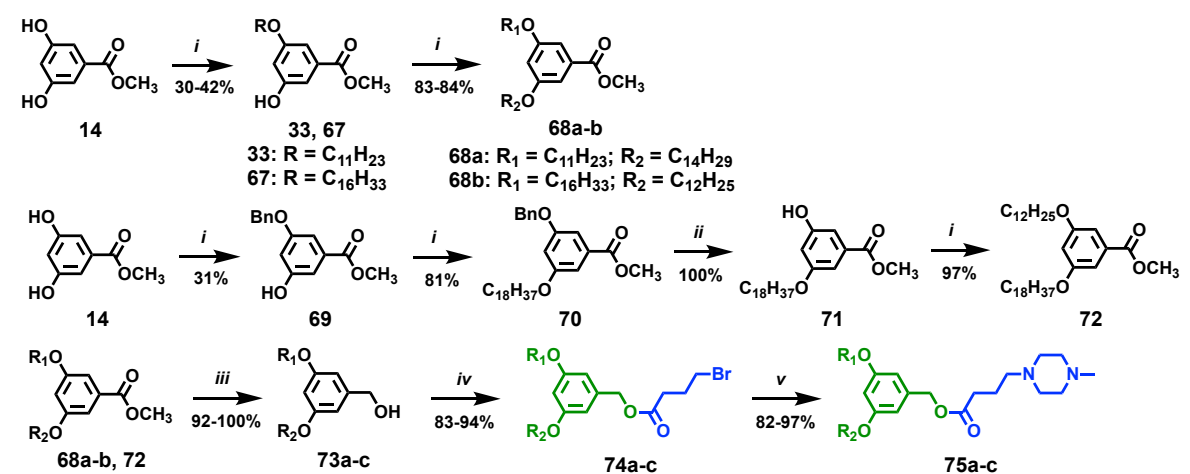

74a-c
73-75a: $R_{1}=C_{11} \mathrm{H}_{23} ; R_{2}=C_{14} \mathrm{H}_{29}$
73-75b: $R_{1}=C_{16} \mathrm{H}_{33} ; R_{2}=C_{12} \mathrm{H}_{25}$

73-75c: $R_{1}=C_{12} \mathrm{H}_{25} ; R_{2}=\mathrm{C}_{18} \mathrm{H}_{37}$

(b)

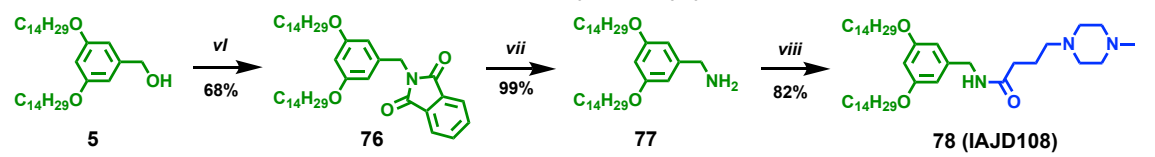

Reagents and conditions: (i) $\mathrm{RBr}, \mathrm{K}_{2} \mathrm{CO}_{3}$, DMF, $60^{\circ} \mathrm{C}, 6 \mathrm{~h}$; (ii) $\mathrm{H}_{2}$, $\mathrm{Pd} / \mathrm{C}, \mathrm{DCM}, \mathrm{MeOH}, 12 \mathrm{~h}$; (iii) $\mathrm{LiAlH}_{4}$, THF, 0-23 ${ }^{\circ} \mathrm{C}, 1 \mathrm{~h}$; (iv) DCC, DPTS, DCM, $23{ }^{\circ} \mathrm{C}, 12 \mathrm{~h}$; (v) 1-methylpiperazine, $\mathrm{K}_{2} \mathrm{CO}_{3}, \mathrm{MeCN}$, 
$95^{\circ} \mathrm{C}, 3 \mathrm{~h}$; (vi) $\mathrm{SOCl}_{2}$, DMF (cat.), DCM, $23{ }^{\circ} \mathrm{C}, 0.5 \mathrm{~h}$, then potassium phthalimide, DMF, $80{ }^{\circ} \mathrm{C}, 1 \mathrm{~h}$; (vii) Hydrazine monohydrate, EtOH, reflux, 2 h; (viii) DCC, DCM, $23{ }^{\circ} \mathrm{C}, 12 \mathrm{~h}$.

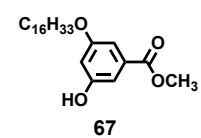

Methyl 3-(hexadecyloxy)-5-hydroxybenzoate (67). Methyl 3,5-dihydroxybenzoate (14, 2.62 g, 15.6 mmol, 1 equiv), 1-bromohexadecane (10.0 g, 32.7 mmol, 2.1 equiv), and $\mathrm{K}_{2} \mathrm{CO}_{3}$ (8.61 g, 62.4 mmol, 4 equiv) were stirred in DMF $(50 \mathrm{~mL})$. The mixture was stirred at $60{ }^{\circ} \mathrm{C}$ under $\mathrm{N}_{2}$ atmosphere for $6 \mathrm{~h}$. The reaction mixture was cooled to $23^{\circ} \mathrm{C}$ and DMF was removed under reduced pressure. Then water $(30 \mathrm{~mL})$ was added, and the mixture was extracted by DCM $(30 \mathrm{~mL} \times 3)$. The organic phase was dried over anhydrous $\mathrm{MgSO}_{4}$ and filtered. The filtrate was concentrated and purified by column chromatography $\left(\mathrm{SiO}_{2}\right)$ with hexane/EtOAc $=10 / 1$ as the eluent to give the title compound as a white solid $(1.86 \mathrm{~g}, 30 \%)$. ${ }^{1} \mathrm{H}$ NMR (400 MHz, $\left.\mathrm{CDCl}_{3}\right) \delta 7.13$ (br, $2 \mathrm{H}, \mathrm{Ph} H$ ), 6.60 (s, $1 \mathrm{H}, \mathrm{Ph} H$ ), 5.47 (s, $1 \mathrm{H}, \mathrm{PhOH}$ ), 3.97 (t, $2 \mathrm{H}$, $\left.\mathrm{PhOCH}_{2}-\right), 3.90\left(\mathrm{~s}, 3 \mathrm{H}, \mathrm{PhCOOCH}_{3}\right), 1.77\left(\mathrm{~m}, 2 \mathrm{H}, \mathrm{PhOCH}_{2} \mathrm{CH}_{2}\left(\mathrm{CH}_{2}\right)_{13} \mathrm{CH}_{3}\right), 1.62(\mathrm{~m}, 2 \mathrm{H}$, $\left.\mathrm{PhOCH}_{2} \mathrm{CH}_{2} \mathrm{CH}_{2}\left(\mathrm{CH}_{2}\right)_{12} \mathrm{CH}_{3}\right), 1.26$ (br, $\left.24 \mathrm{H}, \quad \mathrm{PhOCH}_{2} \mathrm{CH}_{2} \mathrm{CH}_{2}\left(\mathrm{CH}_{2}\right)_{12} \mathrm{CH}_{3}\right), 0.88$ (t, $3 \mathrm{H}$, $\left.\mathrm{PhO}\left(\mathrm{CH}_{2}\right)_{15} \mathrm{CH}_{3}\right) .{ }^{13} \mathrm{C}$ NMR (101 MHz, $\left.\mathrm{CDCl}_{3}\right) \delta 167.3$ 160.4, 157.0, 143.8, 109.1, 107.9, 107.2, 68.5, $60.6,52.4,32.1,29.8,29.8,29.8,29.8,29.7,29.7,29.7,29.5,29.5,29.3,26.1,22.8,14.3 . \mathrm{Mp}=92{ }^{\circ} \mathrm{C}$.

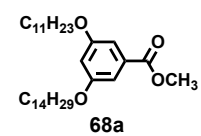

Methyl 3-(tetradecyloxy)-5-(undecyloxy)benzoate (68a). Compound 68a was synthesized from compound 33 ( $0.45 \mathrm{~g}, 1.39 \mathrm{mmol}, 1.0$ equiv), 1-bromotetradecane ( $0.41 \mathrm{~g}, 1.46 \mathrm{mmol}, 1.05$ equiv), and $\mathrm{K}_{2} \mathrm{CO}_{3}(0.58 \mathrm{~g}, 4.17 \mathrm{mmol}, 3$ equiv) following a procedure similar to that used for the synthesis of compound 67 . The title compound was obtained as a white solid $(0.60 \mathrm{~g}, 83 \%) .{ }^{1} \mathrm{H}$ NMR (500 MHz, $\left.\mathrm{CDCl}_{3}\right) \delta 7.16\left(\mathrm{~d}, 2 \mathrm{H}, \mathrm{Ph} H\right.$ ), 6.63 (t, $1 \mathrm{H}, \mathrm{Ph} H$ ), 3.98-3.95 (m, $\left.4 \mathrm{H}, \mathrm{PhOCH}_{2^{-}}\right), 3.89$ (s, $3 \mathrm{H}, \mathrm{PhCOOCH}_{3}$ ), 1.80-1.74 (m, $4 \mathrm{H}, \mathrm{PhOCH}_{2} \mathrm{CH}_{2} \mathrm{CH}_{2}\left(\mathrm{CH}_{2}\right)_{7} \mathrm{CH}_{3}$ and $\left.\mathrm{PhOCH}_{2} \mathrm{CH}_{2} \mathrm{CH}_{2}\left(\mathrm{CH}_{2}\right)_{10} \mathrm{CH}_{3}\right), 1.46-1.43(\mathrm{~m}, 4 \mathrm{H}$, $\mathrm{PhOCH}_{2} \mathrm{CH}_{2} \mathrm{CH}_{2}\left(\mathrm{CH}_{2}\right)_{7} \mathrm{CH}_{3}$ and $\left.\mathrm{PhOCH}_{2} \mathrm{CH}_{2} \mathrm{CH}_{2}\left(\mathrm{CH}_{2}\right)_{10} \mathrm{CH}_{3}\right)$, 1.34-1.26 (m, $34 \quad \mathrm{H}$, $\mathrm{PhOCH}_{2} \mathrm{CH}_{2} \mathrm{CH}_{2}\left(\mathrm{CH}_{2}\right)_{7} \mathrm{CH}_{3}$ and $\left.\mathrm{PhOCH}_{2} \mathrm{CH}_{2} \mathrm{CH}_{2}\left(\mathrm{CH}_{2}\right)_{10} \mathrm{CH}_{3}\right), 0.89-0.87$ (m, $6 \mathrm{H}, \mathrm{PhO}\left(\mathrm{CH}_{2}\right)_{10} \mathrm{CH}_{3}$ and $\left.\mathrm{PhO}\left(\mathrm{CH}_{2}\right)_{13} \mathrm{CH}_{3}\right) .{ }^{13} \mathrm{C} \mathrm{NMR}\left(126 \mathrm{MHz}, \mathrm{CDCl}_{3}\right) \delta$ 167.1, 160.3, 131.9, 107.7, 106.7, 68.4, 52.3, 32.1, 32.1, $29.8,29.8,29.8,29.8,29.7,29.5,29.5,29.3,26.2,22.8,14.3 . \mathrm{Mp}=36^{\circ} \mathrm{C}$.

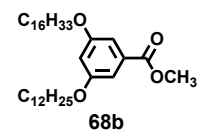


Methyl 3-(dodecyloxy)-5-(hexadecyloxy)benzoate (68b). Compound 68b was synthesized from compound 67 ( $0.30 \mathrm{~g}, 0.76 \mathrm{mmol}, 1.0$ equiv), 1-bromododecane (0.20 g, $0.80 \mathrm{mmol}, 1.05$ equiv), and $\mathrm{K}_{2} \mathrm{CO}_{3}(0.21 \mathrm{~g}, 1.53 \mathrm{mmol}, 2$ equiv) following a procedure similar to that used for the synthesis of compound 67. The title compound was obtained as a white solid $(0.36 \mathrm{~g}, 84 \%)$. ${ }^{1} \mathrm{H} \mathrm{NMR}(400 \mathrm{MHz}$, $\left.\mathrm{CDCl}_{3}\right) \delta 6.49(\mathrm{~d}, 2 \mathrm{H}, \mathrm{Ph} H), 6.43(\mathrm{t}, 1 \mathrm{H}, \mathrm{Ph} H), 3.99$ (t, $\left.4 \mathrm{H}, \mathrm{PhOCH}_{2}-\right), 3.92$ (s, $\left.3 \mathrm{H}, \mathrm{PhCOOCH}_{3}\right), 1.79$ $\left(\mathrm{m}, 4 \mathrm{H}, \quad \mathrm{PhOCH}_{2} \mathrm{CH}_{2}\left(\mathrm{CH}_{2}\right)_{9} \mathrm{CH}_{3}\right.$ and $\left.\mathrm{PhOCH}_{2} \mathrm{CH}_{2}\left(\mathrm{CH}_{2}\right)_{13} \mathrm{CH}_{3}\right), \quad 1.50-1.19 \quad(\mathrm{~m}, \quad 44 \mathrm{H}$, $\mathrm{PhOCH}_{2} \mathrm{CH}_{2}\left(\mathrm{CH}_{2}\right)_{9} \mathrm{CH}_{3}$ and $\left.\mathrm{PhOCH}_{2} \mathrm{CH}_{2}\left(\mathrm{CH}_{2}\right)_{13} \mathrm{CH}_{3}\right), \quad 0.90 \quad\left(\mathrm{t}, \quad 6 \quad \mathrm{H}, \quad \mathrm{PhO}\left(\mathrm{CH}_{2}\right)_{11} \mathrm{CH}_{3}\right.$ and $\left.\mathrm{PhO}\left(\mathrm{CH}_{2}\right){ }_{15} \mathrm{CH}_{3}\right) .{ }^{13} \mathrm{C} \mathrm{NMR}\left(101 \mathrm{MHz}, \mathrm{CDCl}_{3}\right) \delta$ 167.0, 160.2, 131.8, 107.6, 106.6, 77.2, 71.52, 69.8, $68.3,52.2,31.9,31.9,29.7,29.7,29.65,29.6,29.6,29.5,29.4,29.2,26.2,26.0,22.7,14.1 . \mathrm{Mp}=61{ }^{\circ} \mathrm{C}$.

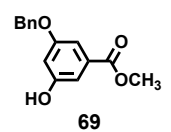

Methyl 3-(benzyloxy)-5-hydroxybenzoate (69). Compound 69 was synthesized from compound 14 (10.00 g, 59.5 mmol, 1.0 equiv), benzyl chloride ( $8.30 \mathrm{~g}, 65.4 \mathrm{mmol}, 1.1$ equiv), and $\mathrm{K}_{2} \mathrm{CO}_{3}$ (9.06 g, 65.4 mmol, 1.1 equiv) following a procedure similar to that used for the synthesis of compound 67. The title compound was obtained as a white solid (4.80 g, 31\%). ${ }^{1} \mathrm{H}$ NMR (400 MHz, $\left.\mathrm{CDCl}_{3}\right) \delta 7.46-7.34(\mathrm{~m}, 5$ $\mathrm{H}, \mathrm{Ph} H), 7.28$ (s, $1 \mathrm{H}, \mathrm{PhH}), 7.17$ (s, $1 \mathrm{H}, \mathrm{PhH}), 6.71$ (s, $1 \mathrm{H}, \mathrm{PhH}), 5.10$ (s, $\left.2 \mathrm{H}, \mathrm{PhCH}_{2} \mathrm{O}-\right), 3.93$ (s, $3 \mathrm{H}$, $\left.\mathrm{PhCOOCH}_{3}\right) .{ }^{13} \mathrm{C} \mathrm{NMR}\left(101 \mathrm{MHz}, \mathrm{CDCl}_{3}\right) \delta 167.6,160.0,157.2,136.5,131.8,128.7,128.2,127.7$, 109.8, 108.0, 107.7, 70.3, 52.6. $\mathrm{Mp}=96^{\circ} \mathrm{C}$.

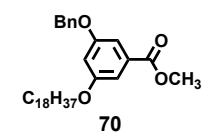

Methyl 3-(benzyloxy)-5-(octadecyloxy)benzoate (70). Compound 70 was synthesized from compound 69 (2.00 g, 7.74 mmol, 1.0 equiv), 1-bromooctadecane ( $2.70 \mathrm{~g}, 8.13 \mathrm{mmol}, 1.05$ equiv), and $\mathrm{K}_{2} \mathrm{CO}_{3}(2.14$ g, $15.50 \mathrm{mmol}, 2.0$ equiv) following a procedure similar to that used for the synthesis of compound 67. The title compound was obtained as a white solid (3.20 g, 81\%). ${ }^{1} \mathrm{H}$ NMR (400 MHz, $\left.\mathrm{CDCl}_{3}\right) \delta 7.45-7.32$ (m, $5 \mathrm{H}, \mathrm{PhH}), 7.27$ (s, $1 \mathrm{H}, \mathrm{Ph} H), 7.20$ (s, $1 \mathrm{H}, \mathrm{Ph} H), 6.73$ (s, $1 \mathrm{H}, \mathrm{Ph} H), 5.11$ (s, $2 \mathrm{H}, \mathrm{PhCH} \mathrm{O}_{2}$ ), 3.983.95 (t, $2 \mathrm{H}, \mathrm{PhOCH}_{2-}$ ), 3.93 (s, $\left.3 \mathrm{H}, \mathrm{PhCOOCH}_{3}\right), 1.81-1.74$ (m, $\left.2 \mathrm{H}, \mathrm{PhOCH}_{2} \mathrm{CH}_{2} \mathrm{CH}_{2}\left(\mathrm{CH}_{2}\right){ }_{14} \mathrm{CH}_{3}\right)$, 1.45-1.43 (m, $\left.2 \mathrm{H}, \mathrm{PhOCH}_{2} \mathrm{CH}_{2} \mathrm{CH}_{2}\left(\mathrm{CH}_{2}\right)_{14} \mathrm{CH}_{3}\right), 1.27$ (m, $\left.28 \mathrm{H}, \mathrm{PhOCH}_{2} \mathrm{CH}_{2} \mathrm{CH}_{2}\left(\mathrm{CH}_{2}\right){ }_{14} \mathrm{CH}_{3}\right), 0.90-$ 0.87 (t, $\left.3 \mathrm{H}, \mathrm{PhO}\left(\mathrm{CH}_{2}\right){ }_{17} \mathrm{CH}_{3}\right) .{ }^{13} \mathrm{C} \mathrm{NMR}\left(101 \mathrm{MHz}, \mathrm{CDCl}_{3}\right) \delta 167.0,160.3,159.9,136.7,132.1,128.7$, 128.2, 127.7, 108.3, 107.9, 107.0, 70.4, 68.5, 52.3, 32.1, 29.8, 29.8, 29.7, 29.7, 29.5, 29.3, 26.1, 22.8, 14.3. $\mathrm{Mp}=65^{\circ} \mathrm{C}$. 


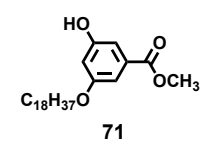

Methyl 3-hydroxy-5-(octadecyloxy)benzoate (71). Compound 70 (3.20 g, 6.26 mmol) was dissolved in the mixture of DCM $(50 \mathrm{~mL})$ and methanol $(10 \mathrm{~mL})$. Then $\mathrm{Pd} / \mathrm{C}(0.20 \mathrm{~g}, 6 \mathrm{wt} \%)$ was added and the flask was evacuated and filled with hydrogen for three times. The mixture was stirred at $23{ }^{\circ} \mathrm{C}$ for $12 \mathrm{~h}$ under hydrogen atmosphere. The reaction mixture was filtered through Celite and the filter cake was washed with DCM. Evaporation of the solvent yielded the title compound as a white solid $(2.63 \mathrm{~g}, 100 \%) .{ }^{1} \mathrm{H}$ NMR (500 MHz, d6-acetone+ $\left.\mathrm{CDCl}_{3}\right) \delta 8.55$ (br, $\left.1 \mathrm{H}, \mathrm{PhOH}\right), 7.05(\mathrm{dd}, 1 \mathrm{H}, \mathrm{Ph} H), 7.00(\mathrm{dd}, 1 \mathrm{H}, \mathrm{Ph} H)$, $6.58(\mathrm{dd}, 1 \mathrm{H}, \mathrm{Ph} H), 3.94\left(\mathrm{t}, 2 \mathrm{H}, \mathrm{PhOCH}_{2}-\right), 3.82\left(\mathrm{~s}, 3 \mathrm{H}, \mathrm{PhCOOCH}_{3}\right), 1.76-1.73(\mathrm{~m}, 2 \mathrm{H}$, $\left.\mathrm{PhOCH}_{2} \mathrm{CH}_{2} \mathrm{CH}_{2}\left(\mathrm{CH}_{2}\right)_{14} \mathrm{CH}_{3}\right), \quad 1.44$ (m, $\left.2 \mathrm{H}, \quad \mathrm{PhOCH}_{2} \mathrm{CH}_{2} \mathrm{CH}_{2}\left(\mathrm{CH}_{2}\right)_{14} \mathrm{CH}_{3}\right), \quad 1.25$ (br, $28 \mathrm{H}$, $\left.\mathrm{PhOCH}_{2} \mathrm{CH}_{2} \mathrm{CH}_{2}\left(\mathrm{CH}_{2}\right)_{14} \mathrm{CH}_{3}\right), \quad 0.86-0.84$ (t, $\left.3 \mathrm{H}, \quad \mathrm{PhO}\left(\mathrm{CH}_{2}\right)_{17} \mathrm{CH}_{3}\right)$. ${ }^{13} \mathrm{C} \quad \mathrm{NMR}\left(126 \mathrm{MHz}, \mathrm{d}_{6^{-}}\right.$ acetone $\left.+\mathrm{CDCl}_{3}\right) \delta 166.9,160.9,158.9,132.5,109.3,107.1,107.0,68.4,52.1,32.3,30.1,29.8,29.7,29.6$, 29.6, 26.4, 23.0, 14.2. $\mathrm{Mp}=99^{\circ} \mathrm{C}$.

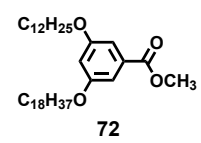

Methyl 3-(dodecyloxy)-5-(octadecyloxy)benzoate (72). Compound 72 was synthesized from compound 71 (0.53 g, 1.26 mmol, 1.0 equiv), 1-bromododecane (0.33 g, $1.32 \mathrm{mmol}, 1.05$ equiv), and $\mathrm{K}_{2} \mathrm{CO}_{3}(0.35$ $\mathrm{g}, 2.52 \mathrm{mmol}, 2.0$ equiv) following a procedure similar to that used for the synthesis of compound 67 . The title compound was obtained as a white solid $(0.72 \mathrm{~g}, 97 \%) .{ }^{1} \mathrm{H} \mathrm{NMR}\left(500 \mathrm{MHz}, \mathrm{CDCl}_{3}\right) \delta 7.16(\mathrm{~d}, 2 \mathrm{H}$, $\mathrm{Ph} H$ ), 6.63 (t, $1 \mathrm{H}, \mathrm{Ph} H), 3.98-3.95$ (m, 4 H, PhOCH $2_{2}$ ), 3.89 (s, $\left.3 \mathrm{H}, \mathrm{PhCOOCH}_{3}\right), 1.79-1.74(\mathrm{~m}, 4 \mathrm{H}$, $\mathrm{PhOCH}_{2} \mathrm{CH}_{2} \mathrm{CH}_{2}\left(\mathrm{CH}_{2}\right)_{8} \mathrm{CH}_{3}$ and $\left.\mathrm{PhOCH}_{2} \mathrm{CH}_{2} \mathrm{CH}_{2}\left(\mathrm{CH}_{2}\right)_{14} \mathrm{CH}_{3}\right), \quad 1.47-1.41 \quad(\mathrm{~m}, \quad 4 \quad \mathrm{H}$, $\mathrm{PhOCH}_{2} \mathrm{CH}_{2} \mathrm{CH}_{2}\left(\mathrm{CH}_{2}\right)_{8} \mathrm{CH}_{3} \quad$ and $\left.\mathrm{PhOCH}_{2} \mathrm{CH}_{2} \mathrm{CH}_{2}\left(\mathrm{CH}_{2}\right)_{14} \mathrm{CH}_{3}\right), \quad 1.26 \quad(\mathrm{~m}, \quad 44 \quad \mathrm{H}$, $\mathrm{PhOCH}_{2} \mathrm{CH}_{2} \mathrm{CH}_{2}\left(\mathrm{CH}_{2}\right)_{8} \mathrm{CH}_{3} \quad$ and $\left.\mathrm{PhOCH}_{2} \mathrm{CH}_{2} \mathrm{CH}_{2}\left(\mathrm{CH}_{2}\right)_{14} \mathrm{CH}_{3}\right), \quad 0.89-0.87 \quad$ (t, $6 \quad \mathrm{H}$,

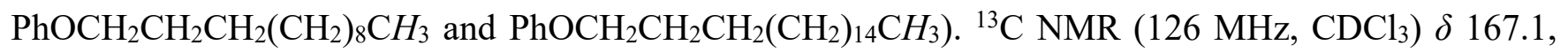
$160.3,131.9$, 107.7, 106.7, 68.4, 52.3, 32.1, 29.9, 29.8, 29.8, 29.8, 29.7, 29.5, 29.3, 26.2, 22.8, 14.3. Mp $=64^{\circ} \mathrm{C}$.

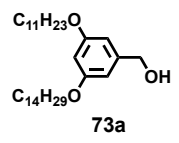

(3-(Tetradecyloxy)-5-(undecyloxy)phenyl)methanol (73a). Compound 68a (0.59 g, 1.14 mmol, 1.0 equiv) was dissolved in $5 \mathrm{~mL}$ dry THF, which was added dropwise to a slurry of $\mathrm{LiAlH}_{4}(44 \mathrm{mg}, 1.14$ 
mmol, 1.0 equiv) in dry THF $(5 \mathrm{~mL})$ at $0{ }^{\circ} \mathrm{C}$ under $\mathrm{N}_{2}$ atmosphere. The resulted mixture was stirred at 23 ${ }^{\circ} \mathrm{C}$ for $1 \mathrm{~h}$. The reaction was quenched by the successive addition of water $(0.3 \mathrm{~mL}), 15 \% \mathrm{NaOH}$ aqueous solution $(0.3 \mathrm{~mL})$ and water $(1.5 \mathrm{~mL})$. Then the mixture was filtered to remove white precipitates and the filtrate was dried over anhydrous $\mathrm{MgSO}_{4}$. Filtration and evaporation of the solvent yielded the title compound as a colorless oil (0.55 g, 98\%). ${ }^{1} \mathrm{H}$ NMR $\left(500 \mathrm{MHz}, \mathrm{CDCl}_{3}\right) \delta 6.49$ (d, $\left.2 \mathrm{H}, \mathrm{Ph} H\right), 6.37$ (t, 1 $\mathrm{H}, \mathrm{Ph} H), 4.60\left(\mathrm{~s}, 2 \mathrm{H}, \mathrm{PhCH}_{2} \mathrm{OH}\right), 3.94-3.91\left(\mathrm{~m}, 4 \mathrm{H}, \mathrm{PhOCH}_{2^{-}}\right), 1.77-1.75(\mathrm{~m}, 4 \mathrm{H}$, $\mathrm{PhOCH}_{2} \mathrm{CH}_{2} \mathrm{CH}_{2}\left(\mathrm{CH}_{2}\right)_{7} \mathrm{CH}_{3}$ and $\left.\mathrm{PhOCH}_{2} \mathrm{CH}_{2} \mathrm{CH}_{2}\left(\mathrm{CH}_{2}\right)_{10} \mathrm{CH}_{3}\right), \quad 1.45-1.42 \quad(\mathrm{~m}, \quad 4 \quad \mathrm{H}$, $\mathrm{PhOCH}_{2} \mathrm{CH}_{2} \mathrm{CH}_{2}\left(\mathrm{CH}_{2}\right)_{7} \mathrm{CH}_{3}$ and $\left.\mathrm{PhOCH}_{2} \mathrm{CH}_{2} \mathrm{CH}_{2}\left(\mathrm{CH}_{2}\right)_{10} \mathrm{CH}_{3}\right), \quad 1.30-1.27 \quad$ (m, $34 \quad \mathrm{H}$, $\mathrm{PhOCH}_{2} \mathrm{CH}_{2} \mathrm{CH}_{2}\left(\mathrm{CH}_{2}\right)_{7} \mathrm{CH}_{3}$ and $\left.\mathrm{PhOCH}_{2} \mathrm{CH}_{2} \mathrm{CH}_{2}\left(\mathrm{CH}_{2}\right)_{10} \mathrm{CH}_{3}\right), \quad 0.90-0.87$ (t, $6 \quad \mathrm{H}$, $\mathrm{PhOCH}_{2} \mathrm{CH}_{2} \mathrm{CH}_{2}\left(\mathrm{CH}_{2}\right)_{7} \mathrm{CH}_{3}$ and $\left.\mathrm{PhOCH}_{2} \mathrm{CH}_{2} \mathrm{CH}_{2}\left(\mathrm{CH}_{2}\right)_{10} \mathrm{CH}_{3}\right) .{ }^{13} \mathrm{C}$ NMR (126 MHz, $\left.\mathrm{CDCl}_{3}\right) \delta$ 160.6, 143.3, 105.2, 100.7, 68.2, 65.5, 32.1, 29.8, 29.8, 29.7, 29.5, 29.5, 29.5, 29.4, 26.2, 22.8, 14.3 .

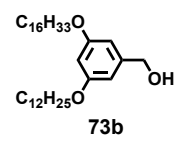

(3-(Dodecyloxy)-5-(hexadecyloxy)phenyl)methanol (73b). Compound 73b was synthesized from compound $68 \mathrm{~b}$ ( $0.32 \mathrm{~g}, 0.57 \mathrm{mmol}, 1.0$ equiv) and $\mathrm{LiAlH}_{4}(22 \mathrm{mg}, 0.57 \mathrm{mmol}, 1.0$ equiv) following a procedure similar to that used for the synthesis of compound 73a. The title compound was obtained as a white solid (0.30 g, 100\%). ${ }^{1} \mathrm{H}$ NMR (400 MHz, $\left.\mathrm{CDCl}_{3}\right) \delta 6.52$ (d, $\left.2 \mathrm{H}, \mathrm{Ph} H\right), 6.40(\mathrm{t}, 1 \mathrm{H}, \mathrm{Ph} H), 4.63(\mathrm{~s}$, $\left.2 \mathrm{H}, \mathrm{PhCH}_{2} \mathrm{OH}\right), 3.95$ (t, $\left.4 \mathrm{H}, \mathrm{PhOCH}_{2}-\right), 1.79$ (m, $4 \mathrm{H}, \mathrm{PhOCH}_{2} \mathrm{CH}_{2}\left(\mathrm{CH}_{2}\right)_{9} \mathrm{CH}_{3}$ and $\left.\mathrm{PhOCH}_{2} \mathrm{CH}_{2}\left(\mathrm{CH}_{2}\right)_{13} \mathrm{CH}_{3}\right), 1.64-1.17$ (m, $44 \mathrm{H}, \mathrm{PhOCH}_{2} \mathrm{CH}_{2}\left(\mathrm{CH}_{2}\right)_{9} \mathrm{CH}_{3}$ and $\mathrm{PhOCH}_{2} \mathrm{CH}_{2}\left(\mathrm{CH}_{2}\right)_{13} \mathrm{CH}_{3}$ ), $0.91\left(\mathrm{t}, 6 \mathrm{H}, \mathrm{PhO}\left(\mathrm{CH}_{2}\right){ }_{11} \mathrm{CH}_{3}\right.$ and $\left.\mathrm{PhO}\left(\mathrm{CH}_{2}\right)_{15} \mathrm{CH}_{3}\right) .{ }^{13} \mathrm{C} \mathrm{NMR}\left(101 \mathrm{MHz}, \mathrm{CDCl}_{3}\right) \delta$ 160.5, 143.2, 105.1, $100.6,68.1,65.4,32.0,29.7,29.7,29.7,29.6,29.6,29.4,29.4,29.3,26.1,22.7,14.1 . \mathrm{Mp}=43^{\circ} \mathrm{C}$.

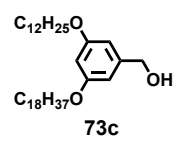

(3-(Dodecyloxy)-5-(octadecyloxy)phenyl)methanol (73c). Compound 73c was synthesized from compound 72 (0.72 g, $1.22 \mathrm{mmol}, 1.0$ equiv) and $\mathrm{LiAlH}_{4}(47 \mathrm{mg}, 1.22 \mathrm{mmol}, 1.0$ equiv) following a procedure similar to that used for the synthesis of compound 73a. The title compound was obtained as a colorless oil (0.63 g, 92\%). ${ }^{1} \mathrm{H}$ NMR (500 MHz, $\left.\mathrm{CDCl}_{3}\right) \delta 6.50$ (d, $\left.2 \mathrm{H}, \mathrm{Ph} H\right), 6.38(\mathrm{t}, 1 \mathrm{H}, \mathrm{Ph} H), 4.61(\mathrm{~s}$, $2 \mathrm{H}, \mathrm{PhCH}_{2} \mathrm{OH}$ ), 3.95-3.92 (m, $\left.4 \mathrm{H}, \mathrm{PhOCH}_{2}-\right), 1.79-1.73$ (m, $4 \mathrm{H}, \mathrm{PhOCH}_{2} \mathrm{CH}_{2} \mathrm{CH}_{2}\left(\mathrm{CH}_{2}\right)_{14} \mathrm{CH}_{3}$ and $\left.\mathrm{PhOCH}_{2} \mathrm{CH}_{2} \mathrm{CH}_{2}\left(\mathrm{CH}_{2}\right)_{8} \mathrm{CH}_{3}\right), \quad 1.47-1.38 \quad\left(\mathrm{~m}, \quad 4 \quad \mathrm{H}, \quad \mathrm{PhOCH}_{2} \mathrm{CH}_{2} \mathrm{CH}_{2}\left(\mathrm{CH}_{2}\right)_{14} \mathrm{CH}_{3} \quad\right.$ and $\left.\mathrm{PhOCH}_{2} \mathrm{CH}_{2} \mathrm{CH}_{2}\left(\mathrm{CH}_{2}\right)_{8} \mathrm{CH}_{3}\right), \quad 1.26 \quad\left(\mathrm{~m}, \quad 44 \quad \mathrm{H}, \quad \mathrm{PhOCH}_{2} \mathrm{CH}_{2} \mathrm{CH}_{2}\left(\mathrm{CH}_{2}\right)_{14} \mathrm{CH}_{3} \quad\right.$ and $\left.\mathrm{PhOCH}_{2} \mathrm{CH}_{2} \mathrm{CH}_{2}\left(\mathrm{CH}_{2}\right)_{8} \mathrm{CH}_{3}\right), 0.90-0.87$ (t, $6 \mathrm{H}, \mathrm{PhO}\left(\mathrm{CH}_{2}\right)_{17} \mathrm{CH}_{3}$ and $\left.\mathrm{PhO}\left(\mathrm{CH}_{2}\right)_{11} \mathrm{CH}_{3}\right) .{ }^{13} \mathrm{C} \mathrm{NMR}(126$ 
$\left.\mathrm{MHz}, \mathrm{CDCl}_{3}\right) \delta 160.7,143.3,105.2,100.7,68.2,65.6,32.1,29.9,29.8,29.8,29.8,29.7,29.5,29.5,29.4$, $26.2,22.8,14.3$.

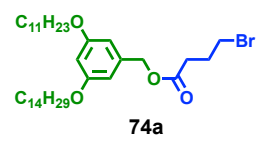

3-(Tetradecyloxy)-5-(undecyloxy)benzyl 4-bromobutanoate (74a). To a DCM (10 mL) solution of compound 73a ( $0.53 \mathrm{~g}, 1.08 \mathrm{mmol}, 1.0$ equiv), 4-bromobutyric acid ( $0.20 \mathrm{~g}, 1.19 \mathrm{mmol}, 1.1$ equiv) and DPTS ( $0.35 \mathrm{~g}, 1.19 \mathrm{mmol}, 1.1$ equiv), was added DCC ( $0.45 \mathrm{~g}, 2.16 \mathrm{mmol}, 2.0$ equiv). The mixture was allowed to stir at $23{ }^{\circ} \mathrm{C}$ for $12 \mathrm{~h}$. The precipitate was filtered, and the filtrate was concentrated to dryness. The crude product was further purified by column chromatography with a mobile phase of hexane/DCM $=1 / 1$ to yield the title compound as a colorless oil $(0.61 \mathrm{~g}, 88 \%) .{ }^{1} \mathrm{H}$ NMR $\left(500 \mathrm{MHz}, \mathrm{CDCl}_{3}\right) \delta 6.47(\mathrm{~d}$, $2 \mathrm{H}, \mathrm{Ph} H$ ), 6.41 (t, $1 \mathrm{H}, \mathrm{Ph} H$ ), 5.05 (s, $2 \mathrm{H}, \mathrm{PhCH}_{2} \mathrm{O}-$ ), 3.94-3.92 (m, 4 H, - $\mathrm{CH}_{2} \mathrm{OPh}$ ), 3.48-3.46 (t, $2 \mathrm{H}$, $\left.-\mathrm{CH}_{2} \mathrm{Br}\right), \quad 2.58-2.55 \quad\left(\mathrm{t}, 2 \mathrm{H}, \quad \mathrm{CH}_{2}\right), \quad 2.21-2.19 \quad\left(\mathrm{~m}, 2 \quad \mathrm{H}, \quad \mathrm{CH}_{2}\right), \quad 1.78-1.75 \quad(\mathrm{~m}, 4 \mathrm{H}$, $\mathrm{PhOCH}_{2} \mathrm{CH}_{2} \mathrm{CH}_{2}\left(\mathrm{CH}_{2}\right)_{7} \mathrm{CH}_{3}$ and $\left.\mathrm{PhOCH}_{2} \mathrm{CH}_{2} \mathrm{CH}_{2}\left(\mathrm{CH}_{2}\right)_{10} \mathrm{CH}_{3}\right), \quad 1.46-1.43 \quad(\mathrm{~m}, \quad 4 \quad \mathrm{H}$, $\mathrm{PhOCH}_{2} \mathrm{CH}_{2} \mathrm{CH}_{2}\left(\mathrm{CH}_{2}\right)_{7} \mathrm{CH}_{3}$ and $\left.\mathrm{PhOCH}_{2} \mathrm{CH}_{2} \mathrm{CH}_{2}\left(\mathrm{CH}_{2}\right)_{10} \mathrm{CH}_{3}\right)$, 1.36-1.27 (m, $34 \quad \mathrm{H}$, $\mathrm{PhOCH}_{2} \mathrm{CH}_{2} \mathrm{CH}_{2}\left(\mathrm{CH}_{2}\right)_{7} \mathrm{CH}_{3}$ and $\left.\mathrm{PhOCH}_{2} \mathrm{CH}_{2} \mathrm{CH}_{2}\left(\mathrm{CH}_{2}\right)_{10} \mathrm{CH}_{3}\right), 0.90-0.87$ (t, $6 \mathrm{H}, \mathrm{PhO}\left(\mathrm{CH}_{2}\right)_{10} \mathrm{CH}_{3}$ and $\left.\mathrm{PhO}\left(\mathrm{CH}_{2}\right)_{13} \mathrm{CH}_{3}\right) .{ }^{13} \mathrm{C} \mathrm{NMR}\left(126 \mathrm{MHz}, \mathrm{CDCl}_{3}\right) \delta 172.4,160.6,137.9,106.5,101.1,68.2,66.5,32.8,32.6$, $32.1,29.8,29.7,29.7,29.5,29.5,29.5,29.4,27.9,26.2,22.8,14.3$.

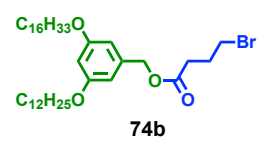

3-(Dodecyloxy)-5-(hexadecyloxy)benzyl 4-bromobutanoate (74b). Compound 74b was synthesized from compound 73b ( $0.30 \mathrm{~g}, 0.56 \mathrm{mmol}, 1.0$ equiv), 4-bromobutyric acid ( $94 \mathrm{mg}, 0.56 \mathrm{mmol}, 1.0$ equiv), DPTS (0.18 g, $0.62 \mathrm{mmol}, 1.1$ equiv) and DCC ( $0.23 \mathrm{~g}, 1.13 \mathrm{mmol}, 2.0$ equiv) following a procedure similar to that used for the synthesis of compound 74a. The title compound was obtained as a white solid (0.36 g, 94\%). ${ }^{1} \mathrm{H}$ NMR (400 MHz, $\left.\mathrm{CDCl}_{3}\right) \delta 6.49$ (d, $\left.2 \mathrm{H}, \mathrm{Ph} H\right), 6.43$ (t, $1 \mathrm{H}, \mathrm{Ph} H$ ), 5.07 (s, $2 \mathrm{H}, \mathrm{PhCH}_{2} \mathrm{O}-$ ), 3.95 (t, $4 \mathrm{H},-\mathrm{CH}_{2} \mathrm{OPh}$ ), 3.49 (t, $2 \mathrm{H},-\mathrm{OCOCH}_{2} \mathrm{CH}_{2} \mathrm{CH}_{2} \mathrm{Br}$ ), 2.59 (t, $2 \mathrm{H},-\mathrm{OCOCH}_{2} \mathrm{CH}_{2} \mathrm{CH}_{2} \mathrm{Br}$ ), 2.22 (m, $\left.2 \mathrm{H},-\mathrm{OCOCH}_{2} \mathrm{CH}_{2} \mathrm{CH}_{2} \mathrm{Br}\right), 1.79$ (m, $4 \mathrm{H}, \mathrm{PhOCH}_{2} \mathrm{CH}_{2}\left(\mathrm{CH}_{2}\right)_{9} \mathrm{CH}_{3}$ and $\mathrm{PhOCH}_{2} \mathrm{CH}_{2}\left(\mathrm{CH}_{2}\right)_{13} \mathrm{CH}_{3}$ ), 1.52-1.21 (m, $44 \mathrm{H}, \mathrm{PhOCH}_{2} \mathrm{CH}_{2}\left(\mathrm{CH}_{2}\right)_{9} \mathrm{CH}_{3}$ and $\left.\mathrm{PhOCH}_{2} \mathrm{CH}_{2}\left(\mathrm{CH}_{2}\right)_{13} \mathrm{CH}_{3}\right), 0.91\left(\mathrm{t}, 6 \mathrm{H}, \mathrm{PhO}\left(\mathrm{CH}_{2}\right)_{11} \mathrm{CH}_{3}\right.$ and $\left.\mathrm{PhO}\left(\mathrm{CH}_{2}\right){ }_{15} \mathrm{CH}_{3}\right) .{ }^{13} \mathrm{C} \mathrm{NMR}\left(101 \mathrm{MHz}, \mathrm{CDCl}_{3}\right) \delta 172.3,160.5,137.8,106.4,101.0,68.1,66.4,32.6$, $32.5,31.9,29.7,29.7,29.7,29.6,29.6,29.4,29.4,29.3,27.7,26.1,22.7,14.1 . \mathrm{Mp}=28{ }^{\circ} \mathrm{C}$. 


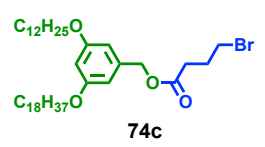

3-(Dodecyloxy)-5-(octadecyloxy)benzyl 4-bromobutanoate (74c). Compound 74c was synthesized from compound 73c ( $0.63 \mathrm{~g}, 1.12 \mathrm{mmol}, 1.0$ equiv), 4-bromobutyric acid ( $0.19 \mathrm{~g}, 1.12 \mathrm{mmol}, 1.0$ equiv), DPTS (0.33 g, $1.23 \mathrm{mmol}, 1.1$ equiv) and DCC (0.46 g, $2.24 \mathrm{mmol}, 2.0$ equiv) following a procedure similar to that used for the synthesis of compound 74a. The title compound was obtained as a colorless oil (0.66 g, 83\%). ${ }^{1} \mathrm{H}$ NMR (500 MHz, $\left.\mathrm{CDCl}_{3}\right) \delta 6.47(\mathrm{~d}, 2 \mathrm{H}, \mathrm{Ph} H), 6.41(\mathrm{t}, 1 \mathrm{H}, \mathrm{Ph} H), 5.05(\mathrm{~s}, 2 \mathrm{H}$, $\left.\mathrm{PhCH}_{2} \mathrm{O}-\right)$, 3.94-3.92 (m, $4 \mathrm{H},-\mathrm{CH}_{2} \mathrm{OPh}$ ), 3.48-3.46 (t, $2 \mathrm{H},-\mathrm{CH}_{2} \mathrm{Br}$ ), 2.58-2.56 (t, $\left.2 \mathrm{H}, \mathrm{CH}_{2}\right), 2.23-2.19$ (m, $2 \mathrm{H}, \mathrm{CH}$ ), 1.78-1.75 (m, $4 \mathrm{H}, \mathrm{PhOCH}_{2} \mathrm{CH}_{2} \mathrm{CH}_{2}\left(\mathrm{CH}_{2}\right)_{8} \mathrm{CH}_{3}$ and $\left.\mathrm{PhOCH}_{2} \mathrm{CH}_{2} \mathrm{CH}_{2}\left(\mathrm{CH}_{2}\right)_{14} \mathrm{CH}_{3}\right), 1.43$ $\left(\mathrm{m}, 4 \mathrm{H}, \quad \mathrm{PhOCH}_{2} \mathrm{CH}_{2} \mathrm{CH}_{2}\left(\mathrm{CH}_{2}\right)_{8} \mathrm{CH}_{3}\right.$ and $\left.\mathrm{PhOCH}_{2} \mathrm{CH}_{2} \mathrm{CH}_{2}\left(\mathrm{CH}_{2}\right)_{14} \mathrm{CH}_{3}\right), \quad 1.27 \quad(\mathrm{~m}, \quad 44 \mathrm{H}$, $\mathrm{PhOCH}_{2} \mathrm{CH}_{2} \mathrm{CH}_{2}\left(\mathrm{CH}_{2}\right)_{8} \mathrm{CH}_{3}$ and $\left.\mathrm{PhOCH}_{2} \mathrm{CH}_{2} \mathrm{CH}_{2}\left(\mathrm{CH}_{2}\right)_{14} \mathrm{CH}_{3}\right), 0.90-0.88$ (t, $6 \mathrm{H}, \mathrm{PhO}\left(\mathrm{CH}_{2}\right)_{11} \mathrm{CH}_{3}$ and $\left.\mathrm{PhO}\left(\mathrm{CH}_{2}\right)_{17} \mathrm{CH}_{3}\right) .{ }^{13} \mathrm{C} \mathrm{NMR}\left(126 \mathrm{MHz}, \mathrm{CDCl}_{3}\right) \delta 172.4,160.6,137.9,106.5,101.1,68.2,66.5,32.8,32.6$, $32.1,29.8,29.8,29.8,29.8,29.7,29.5,29.5,29.4,27.9,26.2,22.8,14.3$.

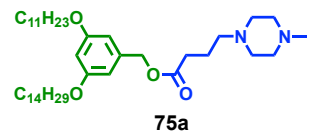

3-(Tetradecyloxy)-5-(undecyloxy)benzyl 4-(4-methylpiperazin-1-yl)butanoate (75a, IAJD105). Compound 74a ( $0.61 \mathrm{~g}, 0.95 \mathrm{mmol}, 1.0$ equiv), 1-methylpiperazine ( $0.11 \mathrm{~g}, 1.10 \mathrm{mmol}, 1.1 \mathrm{equiv}), \mathrm{K}_{2} \mathrm{CO}_{3}$ ( $0.20 \mathrm{~g}, 1.42 \mathrm{mmol}, 1.5$ equiv) were stirred in $\mathrm{MeCN}(20 \mathrm{~mL})$. The mixture was heated at reflux $\left(95^{\circ} \mathrm{C}\right)$ for $3 \mathrm{~h}$. The reaction mixture was cooled to $23^{\circ} \mathrm{C}$ and $\mathrm{MeCN}$ was removed under reduced pressure. Then water $(30 \mathrm{~mL})$ was added, and the mixture was extracted by DCM $(30 \mathrm{~mL} \times 3)$. The organic phase was collected, dried over anhydrous $\mathrm{MgSO}_{4}$, filtered and dried to give the crude product. The crude product was purified by column chromatography $\left(\mathrm{SiO}_{2}\right)$ with $\mathrm{DCM} / \mathrm{MeOH}=20 / 1$ as the eluent. Then the obtained product was dissolved in DCM $(20 \mathrm{~mL})$, which was washed by $\mathrm{NaHCO}_{3}$ solution $(2 \%, 20 \mathrm{~mL})$. The aqueous phase was extracted by DCM $(20 \mathrm{~mL})$ for another two times. The organic phase was combined and dried over anhydrous $\mathrm{MgSO}_{4}$. Filtration and evaporation of the solvent yielded the title compound as a light-yellow oil (0.56 g, 90\%). ${ }^{1} \mathrm{H}$ NMR (500 MHz, $\left.\mathrm{CDCl}_{3}\right) \delta 6.45(\mathrm{~d}, 2 \mathrm{H}, \mathrm{Ph} H), 6.38(\mathrm{t}, 1 \mathrm{H}, \mathrm{Ph} H)$, 5.01 (s, $\left.2 \mathrm{H}, \mathrm{PhCH}_{2} \mathrm{O}-\right), 3.92-3.90$ (m, 4 H, - $\left.\mathrm{CH}_{2} \mathrm{OPh}\right), 2.45$ (br, $\left.8 \mathrm{H},-\mathrm{N}\left(\mathrm{CH}_{2} \mathrm{CH}_{2}\right)_{2} \mathrm{~N}-\right), 2.40-2.36(\mathrm{~m}, 4$ $\mathrm{H},-\mathrm{NCH}_{2} \mathrm{CH}_{2} \mathrm{CH}_{2} \mathrm{COO}-$ ), 2.29 (s, $3 \mathrm{H}, \mathrm{NCH}_{3}$ ), 1.84-1.81 (m, $\left.2 \mathrm{H},-\mathrm{NCH}_{2} \mathrm{CH}_{2} \mathrm{CH}_{2} \mathrm{COO}-\right), 1.77-1.73$ (m, $4 \mathrm{H}, \quad \mathrm{PhOCH}_{2} \mathrm{CH}_{2} \mathrm{CH}_{2}\left(\mathrm{CH}_{2}\right)_{7} \mathrm{CH}_{3}$ and $\left.\mathrm{PhOCH}_{2} \mathrm{CH}_{2} \mathrm{CH}_{2}\left(\mathrm{CH}_{2}\right)_{10} \mathrm{CH}_{3}\right), \quad 1.43-1.41 \quad(\mathrm{~m}, \quad 4 \quad \mathrm{H}$, $\mathrm{PhOCH}_{2} \mathrm{CH}_{2} \mathrm{CH}_{2}\left(\mathrm{CH}_{2}\right)_{7} \mathrm{CH}_{3}$ and $\left.\mathrm{PhOCH}_{2} \mathrm{CH}_{2} \mathrm{CH}_{2}\left(\mathrm{CH}_{2}\right)_{10} \mathrm{CH}_{3}\right), \quad 1.25 \quad$ (m, $34 \quad \mathrm{H}$, $\mathrm{PhOCH}_{2} \mathrm{CH}_{2} \mathrm{CH}_{2}\left(\mathrm{CH}_{2}\right)_{7} \mathrm{CH}_{3}$ and $\left.\mathrm{PhOCH}_{2} \mathrm{CH}_{2} \mathrm{CH}_{2}\left(\mathrm{CH}_{2}\right){ }_{10} \mathrm{CH}_{3}\right), 0.88-0.85$ (t, $6 \mathrm{H}, \mathrm{PhO}\left(\mathrm{CH}_{2}\right)_{10} \mathrm{CH}_{3}$ and 
$\left.\mathrm{PhO}\left(\mathrm{CH}_{2}\right)_{13} \mathrm{CH}_{3}\right) .{ }^{13} \mathrm{C} \mathrm{NMR}\left(126 \mathrm{MHz}, \mathrm{CDCl}_{3}\right) \delta 173.4,160.5,138.2,106.5,101.0,68.2,66.2,57.6,55.1$, 52.9, 45.9, 32.3, 32.0, 29.8, 29.7, 29.7, 29.5, 29.5, 29.4, 29.4, 26.2, 22.8, 22.2, 14.2. Purity by HPLC: 99+\%. MALDI-TOF MS $m / z$ of $[\mathrm{M}+\mathrm{H}]^{+}$calculated for $\mathrm{C}_{41} \mathrm{H}_{74} \mathrm{~N}_{2} \mathrm{O}_{4}$ : 658.6; Found: 658.6.

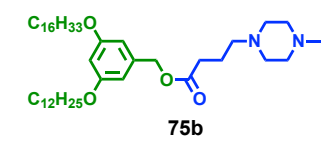

3-(Dodecyloxy)-5-(hexadecyloxy)benzyl 4-(4-methylpiperazin-1-yl)butanoate (75b, IAJD106). Compound 75b was synthesized from compound $74 \mathbf{b}(0.36 \mathrm{~g}, 0.53 \mathrm{mmol}, 1.0$ equiv), 1-methylpiperazine (79 mg, $0.79 \mathrm{mmol}, 1.5$ equiv) and $\mathrm{K}_{2} \mathrm{CO}_{3}(0.11 \mathrm{~g}, 0.79 \mathrm{mmol}, 1.5$ equiv) following a procedure similar to that used for the synthesis of compound 75a. The title compound was obtained as a light-yellow oil (0.36 g, 97\%). ${ }^{1} \mathrm{H}$ NMR (400 MHz, $\left.\mathrm{CDCl}_{3}\right) \delta 6.49$ (d, $\left.2 \mathrm{H}, \mathrm{PhH}\right), 6.42$ (t, $\left.1 \mathrm{H}, \mathrm{PhH}\right), 5.05$ (s, 2 H, PhCH $\mathrm{H}_{2} \mathrm{O}$ ), 3.94 (t, $4 \mathrm{H},-\mathrm{CH}_{2} \mathrm{OPh}$ ), 2.49 (br, $\left.8 \mathrm{H},-\mathrm{N}\left(\mathrm{CH}_{2} \mathrm{CH}_{2}\right)_{2} \mathrm{~N}-\right), 2.41-2.35$ (m, $\left.4 \mathrm{H},-\mathrm{NCH}_{2} \mathrm{CH}_{2} \mathrm{CH}_{2} \mathrm{COO}-\right), 2.28$ $\left(\mathrm{s}, 3 \mathrm{H}, \mathrm{NCH}_{3}\right), 1.87\left(\mathrm{~m}, 2 \mathrm{H},-\mathrm{NCH}_{2} \mathrm{CH}_{2} \mathrm{CH}_{2} \mathrm{COO}-\right), 1.78\left(\mathrm{~m}, 4 \mathrm{H}, \mathrm{PhOCH}_{2} \mathrm{CH}_{2}\left(\mathrm{CH}_{2}\right)_{9} \mathrm{CH}_{3}\right.$ and $\left.\mathrm{PhOCH}_{2} \mathrm{CH}_{2}\left(\mathrm{CH}_{2}\right)_{13} \mathrm{CH}_{3}\right), 1.28\left(\mathrm{~m}, 44 \mathrm{H}, \mathrm{PhOCH}_{2} \mathrm{CH}_{2}\left(\mathrm{CH}_{2}\right)_{9} \mathrm{CH}_{3}\right.$ and $\left.\mathrm{PhOCH}_{2} \mathrm{CH}_{2}\left(\mathrm{CH}_{2}\right)_{13} \mathrm{CH}_{3}\right), 0.90(\mathrm{t}$, $6 \mathrm{H}, \mathrm{PhO}\left(\mathrm{CH}_{2}\right)_{11} \mathrm{CH}_{3}$ and $\left.\mathrm{PhO}\left(\mathrm{CH}_{2}\right)_{15} \mathrm{CH}_{3}\right) .{ }^{13} \mathrm{C} \mathrm{NMR}\left(101 \mathrm{MHz}, \mathrm{CDCl}_{3}\right) \delta 173.3,160.5,138.1,106.4$, 100.9, 68.1, 66.2, 57.5, 55.0, 52.7, 45.8, 32.2, 31.9, 29.7, 29.7, 29.6, 29.6, 29.4, 29.4, 29.3, 26.1, 22.7, 22.1, 14.1. Purity by HPLC: $99+\%$. MALDI-TOF MS $m / z$ of $[\mathrm{M}+\mathrm{H}]^{+}$calculated for $\mathrm{C}_{44} \mathrm{H}_{80} \mathrm{~N}_{2} \mathrm{O}_{4}$ : 701.6; Found: 700.8 .

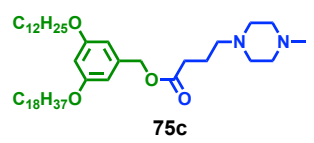

\section{3-(Dodecyloxy)-5-(octadecyloxy)benzyl 4-(4-methylpiperazin-1-yl)butanoate (75c, IAJD107).}

Compound 75c was synthesized from compound 74c ( $0.64 \mathrm{~g}, 0.90 \mathrm{mmol}, 1.0$ equiv), 1-methylpiperazine (99 mg, $0.99 \mathrm{mmol}, 1.1$ equiv) and $\mathrm{K}_{2} \mathrm{CO}_{3}(0.15 \mathrm{~g}, 1.10 \mathrm{mmol}, 1.2$ equiv) following a procedure similar to that used for the synthesis of compound 75a. The title compound was obtained as a light-yellow oil (0.54 g, 82\%). ${ }^{1} \mathrm{H}$ NMR (500 MHz, $\left.\mathrm{CDCl}_{3}\right) \delta 6.45(\mathrm{~d}, 2 \mathrm{H}, \mathrm{Ph} H), 6.38(\mathrm{t}, 1 \mathrm{H}, \mathrm{Ph} H), 5.01\left(\mathrm{~s}, 2 \mathrm{H}, \mathrm{PhCH} \mathrm{H}_{2}\right.$ ), 3.91-3.89 (m, $\left.4 \mathrm{H},-\mathrm{CH}_{2} \mathrm{OPh}\right), 2.48$ (br, $\left.8 \mathrm{H},-\mathrm{N}\left(\mathrm{CH}_{2} \mathrm{CH}_{2}\right)_{2} \mathrm{~N}-\right), 2.40-2.35$ (m, $4 \mathrm{H},-\mathrm{NCH}_{2} \mathrm{CH}_{2} \mathrm{CH}_{2} \mathrm{COO}-$ ), $2.29\left(\mathrm{~s}, 3 \mathrm{H}, \mathrm{NCH}_{3}\right), 1.84-1.81$ (m, $\left.2 \mathrm{H},-\mathrm{NCH}_{2} \mathrm{CH}_{2} \mathrm{CH}_{2} \mathrm{COO}-\right), 1.76-1.73$ (m, $4 \mathrm{H}$, $\mathrm{PhOCH}_{2} \mathrm{CH}_{2} \mathrm{CH}_{2}\left(\mathrm{CH}_{2}\right)_{8} \mathrm{CH}_{3}$ and $\left.\mathrm{PhOCH}_{2} \mathrm{CH}_{2} \mathrm{CH}_{2}\left(\mathrm{CH}_{2}\right)_{14} \mathrm{CH}_{3}\right), \quad 1.45-1.39 \quad(\mathrm{~m}, \quad 4 \quad \mathrm{H}$,

$\mathrm{PhOCH}_{2} \mathrm{CH}_{2} \mathrm{CH}_{2}\left(\mathrm{CH}_{2}\right)_{8} \mathrm{CH}_{3}$ and $\left.\mathrm{PhOCH}_{2} \mathrm{CH}_{2} \mathrm{CH}_{2}\left(\mathrm{CH}_{2}\right)_{14} \mathrm{CH}_{3}\right), \quad 1.30-1.24 \quad(\mathrm{~m}, \quad 44 \quad \mathrm{H}$,

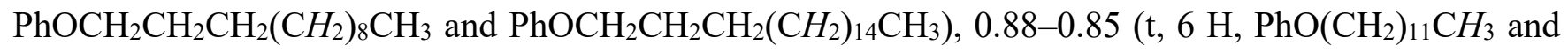
$\left.\mathrm{PhO}\left(\mathrm{CH}_{2}\right){ }_{17} \mathrm{CH}_{3}\right) .{ }^{13} \mathrm{C} \mathrm{NMR}\left(126 \mathrm{MHz}, \mathrm{CDCl}_{3}\right) \delta 173.4,160.5,138.2,106.5,100.9,68.2,66.2,57.6,55.1$, 
$52.9,46.0,32.3,32.0,29.8,29.8,29.7,29.7,29.7,29.5,29.5,29.4,26.2,22.8,22.2,14.2$. Purity by HPLC: 99+\%. MALDI-TOF MS $m / z$ of $[\mathrm{M}+\mathrm{H}]^{+}$calculated for $\mathrm{C}_{46} \mathrm{H}_{85} \mathrm{~N}_{2} \mathrm{O}_{4}$ : 729.6; Found: 729.2.

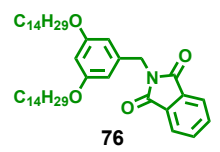

2-(3,5-Bis(tetradecyloxy)benzyl)isoindoline-1,3-dione (76). To a DCM solution (20 mL) of compound 5 (4.14 g, $7.77 \mathrm{mmol}, 1.0$ equiv) was added 2 drops of DMF, followed by the dropwise addition of $\mathrm{SOCl}_{2}$ (1.12 g, $9.37 \mathrm{mmol}, 1.2$ equiv). The reaction mixture was stirred at $23^{\circ} \mathrm{C}$ for $0.5 \mathrm{~h}$. Then DCM and excess $\mathrm{SOCl}_{2}$ was removed under reduced pressure. The obtained intermediate product was dissolved in dry DMF $(40 \mathrm{~mL})$ and potassium phthalimide $(1.73 \mathrm{~g}, 9.32 \mathrm{mmol}, 1.2$ equiv) was added. The mixture was stirred at $80{ }^{\circ} \mathrm{C}$ under $\mathrm{N}_{2}$ atmosphere for $1 \mathrm{~h}$. The reaction mixture was cooled to $23{ }^{\circ} \mathrm{C}$ and DMF was removed under reduced pressure. Then water $(30 \mathrm{~mL})$ was added, and the mixture was extracted by DCM $(30 \mathrm{~mL}$ $\times 3$ ). The organic phase was dried over anhydrous $\mathrm{MgSO}_{4}$ and filtered. The filtrate was concentrated and purified by column chromatography $\left(\mathrm{SiO}_{2}\right)$ with hexane/EtOAc $=20 / 1$ as the eluent to give the title compound as a white solid (3.48 g, 68\%). ${ }^{1} \mathrm{H}$ NMR $\left(500 \mathrm{MHz}, \mathrm{CDCl}_{3}\right) \delta 7.82(\mathrm{~m}, 2 \mathrm{H}, \mathrm{Ph} H), 7.72(\mathrm{~m}, 2$ H, $\mathrm{Ph} H$ ), 6.55 (s, $2 \mathrm{H}, \mathrm{Ph} H$ ), 6.34 (s, $1 \mathrm{H}, \mathrm{Ph} H$ ), 4.76 (d, 2 H, PhCH $\mathrm{PH}_{2}$-), 3.90 (t, $\left.4 \mathrm{H},-\mathrm{CH}_{2} \mathrm{OPh}\right), 1.72$ (m, $\left.4 \mathrm{H}, \mathrm{PhOCH}_{2} \mathrm{CH}_{2}\left(\mathrm{CH}_{2}\right)_{11} \mathrm{CH}_{3}\right), 1.42\left(\mathrm{~m}, 4 \mathrm{H}, \mathrm{PhOCH}_{2} \mathrm{CH}_{2} \mathrm{CH}_{2}\left(\mathrm{CH}_{2}\right)_{10} \mathrm{CH}_{3}\right), 1.26$ (br, $40 \mathrm{H}$, $\left.\mathrm{PhOCH}_{2} \mathrm{CH}_{2} \mathrm{CH}_{2}\left(\mathrm{CH}_{2}\right)_{10} \mathrm{CH}_{3}\right), 0.89$ (m, $\left.6 \mathrm{H}, \mathrm{PhO}\left(\mathrm{CH}_{2}\right)_{13} \mathrm{CH}_{3}\right) .{ }^{13} \mathrm{C} \mathrm{NMR}\left(126 \mathrm{MHz}, \mathrm{CDCl}_{3}\right) \delta 168.1$, 160.6, 138.4, 134.0, 132.3, 123.4, 107.0, 100.7, 68.1, 41.8, 32.1, 29.8, 29.7, 29.7, 29.5, 29.5, 29.4, 26.2, 22.8, 14.2. $\mathrm{Mp}=57^{\circ} \mathrm{C}$.

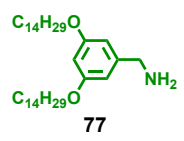

(3,5-Bis(tetradecyloxy)phenyl)methanamine (77). Compound 76 (1.00 g, $1.50 \mathrm{mmol}, 1$ equiv) and hydrazine monohydrate $\left(\mathrm{NH}_{2} \mathrm{NH}_{2} \bullet \mathrm{H}_{2} \mathrm{O}, 0.75 \mathrm{~g}, 15.0 \mathrm{mmol}, 10\right.$ equiv) were dissolved in EtOH $(20 \mathrm{~mL})$. The mixture was heated at reflux for $2 \mathrm{~h}$. The reaction mixture was cooled to $23^{\circ} \mathrm{C}$ and $\mathrm{EtOH}$ was removed under reduced pressure. Then water $(10 \mathrm{~mL})$ was added, and the mixture was extracted by DCM $(10 \mathrm{~mL}$ $\times 3$ ). The organic phase was dried over anhydrous $\mathrm{MgSO}_{4}$ and filtered. Filtration and evaporation of the solvent yielded the title compound as a white solid ( $0.85 \mathrm{~g}, 99 \%) .{ }^{1} \mathrm{H}$ NMR $\left(400 \mathrm{MHz}, \mathrm{CDCl}_{3}\right) \delta 6.44$ (d, $2 \mathrm{H}, \mathrm{Ph} H$ ), 6.34 (t, $1 \mathrm{H}, \mathrm{Ph} H$ ), 3.93 (t, $4 \mathrm{H},-\mathrm{CH}_{2} \mathrm{OPh}$ ), 3.78 (s, $2 \mathrm{H}, \mathrm{PhCH}_{2} \mathrm{NH}_{2}$ ), 3.49 (s, $2 \mathrm{H}, \mathrm{PhCH}_{2} \mathrm{NH}_{2}$ ), $1.72\left(\mathrm{~m}, 4 \mathrm{H}, \mathrm{PhOCH}_{2} \mathrm{CH}_{2}\left(\mathrm{CH}_{2}\right)_{11} \mathrm{CH}_{3}\right), 1.42\left(\mathrm{~m}, 4 \mathrm{H}, \mathrm{PhOCH}_{2} \mathrm{CH}_{2} \mathrm{CH}_{2}\left(\mathrm{CH}_{2}\right)_{10} \mathrm{CH}_{3}\right), 1.26$ (br, $40 \mathrm{H}$, $\left.\mathrm{PhOCH}_{2} \mathrm{CH}_{2} \mathrm{CH}_{2}\left(\mathrm{CH}_{2}\right)_{10} \mathrm{CH}_{3}\right), 0.89\left(\mathrm{~m}, 6 \mathrm{H}, \mathrm{PhO}\left(\mathrm{CH}_{2}\right)_{13} \mathrm{CH}_{3}\right) .{ }^{13} \mathrm{C}_{\mathrm{NMR}}\left(101 \mathrm{MHz}, \mathrm{CDCl}_{3}\right) \delta 160.6$, $145.8,105.4,99.7,68.1,46.8,32.0,29.8,29.8,29.7,29.7,29.5,29.5,29.4,26.2,22.8,14.2 . \mathrm{Mp}=42^{\circ} \mathrm{C}$. 


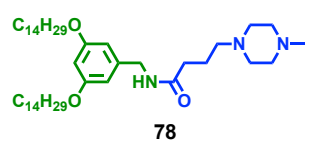

$N$-(3,5-bis(tetradecyloxy)benzyl)-4-(4-methylpiperazin-1-yl)butanamide (78, IAJD108). Compound 77 (0.25 g, 0.47 mmol, 1 equiv) and 4-(4-methylpiperazin-1-yl)butanoic acid hydrochloride (24b, $0.10 \mathrm{~g}$, $0.47 \mathrm{mmol}, 1$ equiv) were dissolved in $6 \mathrm{~mL}$ dry DCM. NEt 3 (3 drops) was added. DCC (0.19 g, 0.94 mmol, 2 equiv) was added in one portion into the above mixture. The reaction was allowed to stir at 23 ${ }^{\circ} \mathrm{C}$ for $12 \mathrm{~h}$. Afterwards, urea was removed by filtration, and washed with DCM carefully. The filtrate was concentrated and purified by column chromatography $\left(\mathrm{SiO}_{2}\right)$ with $\mathrm{DCM} / \mathrm{MeOH}=30 / 1,10 / 1,8 / 1$ and 8/1 with $0.1 \%$ TEA as the eluent. Then the product was dissolved in DCM $(20 \mathrm{~mL})$, which was washed by $\mathrm{NaHCO}_{3}$ solution $(2 \%, 20 \mathrm{~mL})$. The aqueous phase was extracted by DCM $(20 \mathrm{~mL})$ for another two times. The organic phase was combined and dried over anhydrous $\mathrm{MgSO}_{4}$. Filtration and evaporation of the solvent yielded the title compound as a white solid $(0.27 \mathrm{~g}, 82 \%) .{ }^{1} \mathrm{H} \mathrm{NMR}\left(400 \mathrm{MHz}, \mathrm{CDCl}_{3}\right) \delta 6.93(\mathrm{t}$, $1 \mathrm{H},-\mathrm{CO}-\mathrm{NH}$-), 6.38 (d, $2 \mathrm{H}, \mathrm{PhH}), 6.32$ (t, $1 \mathrm{H}, \mathrm{PhH}), 4.31$ (d, $\left.2 \mathrm{H},-\mathrm{CH}_{2} \mathrm{Ph}\right), 3.88$ (t, $4 \mathrm{H},-\mathrm{CH} \mathrm{H}_{2} \mathrm{OPh}$ ), 2.62-2.05 (m, $15 \mathrm{H},-\mathrm{N}\left(\mathrm{CH}_{2} \mathrm{CH}_{2}\right)_{2} \mathrm{~N}-,-\mathrm{OCOCH}_{2} \mathrm{CH}_{2} \mathrm{CH}_{2}$ - and $\left.-\mathrm{NCH}_{3}\right), 1.80\left(\mathrm{~m}, 2 \mathrm{H},-\mathrm{OCOCH}_{2} \mathrm{CH}_{2} \mathrm{CH}_{2}-\right.$ ), $1.73\left(\mathrm{~m}, 4 \mathrm{H}, \mathrm{PhOCH}_{2} \mathrm{CH}_{2}\left(\mathrm{CH}_{2}\right)_{11} \mathrm{CH}_{3}\right), 1.41$ (m, $\left.4 \mathrm{H}, \mathrm{PhOCH}_{2} \mathrm{CH}_{2} \mathrm{CH}_{2}\left(\mathrm{CH}_{2}\right)_{10} \mathrm{CH}_{3}\right), 1.24$ (br, $40 \mathrm{H}$, $\left.\mathrm{PhOCH}_{2} \mathrm{CH}_{2} \mathrm{CH}_{2}\left(\mathrm{CH}_{2}\right)_{10} \mathrm{CH}_{3}\right), 0.86\left(\mathrm{t}, 6 \mathrm{H}, \mathrm{PhO}\left(\mathrm{CH}_{2}\right){ }_{13} \mathrm{CH}_{3}\right) .{ }^{13} \mathrm{C} \mathrm{NMR}\left(101 \mathrm{MHz}, \mathrm{CDCl}_{3}\right) \delta 172.8$, 160.7, 140.8, 106.4, 100.2, 68.1, 57.5, 55.1, 53.1, 46.0, 43.8, 35.1, 32.0, 29.8, 29.8, 29.8, 29.7, 29.7, 29.5, 29.5, 29.4, 26.2, 22.8, 22.4, 14.2. Purity by HPLC: 99+\%. MALDI-TOF MS $m / z$ of $[\mathrm{M}+\mathrm{H}]^{+}$calculated for $\mathrm{C}_{44} \mathrm{H}_{82} \mathrm{~N}_{3} \mathrm{O}_{3}$ : 700.6; Found: 700.8. $\mathrm{Mp}=68{ }^{\circ} \mathrm{C}$. 


\section{Dimensions of DNPs and Luminescence Expression In Vitro}

Table S1. Dimensions of DNPs Containing Luc-mRNA Obtained by Co-assembly of IAJDs with LucmRNA by Injection in Acetate Buffer (10 mM, pH 4.0) and Luminescence Expression in HEK293T Cells $(125 \mathrm{ng} / \mathrm{well}, n=3)$

\begin{tabular}{|c|c|c|c|c|c|c|c|}
\hline IAJD & $\begin{array}{c}\text { Buffer } \\
(10 \mathrm{mM})\end{array}$ & $\begin{array}{c}\text { CIAJD }_{\text {IA }} \\
(\mathrm{mg} / \mathrm{mL})\end{array}$ & $\begin{array}{l}\text { Cluc-mRNA }_{\text {Lut }} \\
(\mathrm{mg} / \mathrm{mL})\end{array}$ & $\begin{array}{c}\text { Size } \\
(\mathrm{d}, \mathrm{nm})\end{array}$ & PDI & Luminescence & $\begin{array}{l}\text { Standard } \\
\text { deviation }\end{array}$ \\
\hline 64 & Acetate $(\mathrm{pH} 4.0)$ & 4 & 0.10 & 135 & 0.271 & 125 & 7 \\
\hline 65 & Acetate $(\mathrm{pH} 4.0)$ & 4 & 0.10 & 241 & 0.249 & 18 & 2 \\
\hline 66 & Acetate $(\mathrm{pH} 4.0)$ & 4 & 0.10 & 165 & 0.320 & 234 & 43 \\
\hline 70 & Acetate $(\mathrm{pH} 4.0)$ & 4 & 0.10 & 205 & 0.438 & 455,361 & 66,604 \\
\hline 71 & Acetate $(\mathrm{pH} 4.0)$ & 4 & 0.10 & 237 & 0.451 & 473,548 & 123,589 \\
\hline 74 & Acetate $(\mathrm{pH} 4.0)$ & 4 & 0.10 & 180 & 0.317 & 3,926 & 1,559 \\
\hline 75 & Acetate $(\mathrm{pH} 4.0)$ & 4 & 0.10 & 235 & 0.328 & 68,572 & 6,794 \\
\hline 76 & Acetate $(\mathrm{pH} 4.0)$ & 4 & 0.10 & 78 & 0.287 & 17 & 3 \\
\hline 77 & Acetate $(\mathrm{pH} 4.0)$ & 4 & 0.10 & 110 & 0.267 & 129 & 6 \\
\hline 78 & Acetate $(\mathrm{pH} 4.0)$ & 4 & 0.10 & 629 & 1.000 & 8,688 & 1,914 \\
\hline 79 & Acetate $(\mathrm{pH} 4.0)$ & 4 & 0.10 & 352 & 0.763 & 27,615 & 6,704 \\
\hline 81 & Acetate $(\mathrm{pH} 4.0)$ & 4 & 0.10 & 111 & 0.287 & 206,161 & 21,200 \\
\hline 82 & Acetate $(\mathrm{pH} 4.0)$ & 4 & 0.10 & 162 & 0.144 & 17 & 2 \\
\hline 83 & Acetate $(\mathrm{pH} 4.0)$ & 4 & 0.10 & 143 & 0.430 & 68,691 & 2,498 \\
\hline 84 & Acetate $(\mathrm{pH} 4.0)$ & 4 & 0.10 & 171 & 0.303 & 205 & 152 \\
\hline 85 & Acetate $(\mathrm{pH} 4.0)$ & 4 & 0.10 & 102 & 0.250 & 47,369 & 18,262 \\
\hline 86 & Acetate $(\mathrm{pH} 4.0)$ & 4 & 0.10 & 91 & 0.234 & 47,066 & 21,163 \\
\hline 87 & Acetate $(\mathrm{pH} 4.0)$ & 4 & 0.10 & 146 & 0.486 & 33 & 7 \\
\hline 88 & Acetate $(\mathrm{pH} 4.0)$ & 4 & 0.10 & 100 & 0.342 & 17 & 2 \\
\hline 89 & Acetate $(\mathrm{pH} 4.0)$ & 4 & 0.10 & 149 & 0.467 & 55 & 12 \\
\hline 91 & Acetate $(\mathrm{pH} 4.0)$ & 4 & 0.10 & 188 & 0.498 & 65,255 & 5,573 \\
\hline 95 & Acetate $(\mathrm{pH} 4.0)$ & 4 & 0.10 & 105 & 0.352 & 153,564 & 25,782 \\
\hline 96 & Acetate $(\mathrm{pH} 4.0)$ & 4 & 0.10 & 139 & 0.402 & 22,799 & 4,244 \\
\hline 97 & Acetate $(\mathrm{pH} 4.0)$ & 4 & 0.10 & 204 & 0.482 & 342,016 & 70,616 \\
\hline 98 & Acetate $(\mathrm{pH} 4.0)$ & 4 & 0.10 & 187 & 0.221 & 22,209 & 10,213 \\
\hline 99 & Acetate (pH 4.0) & 4 & 0.10 & 277 & 0.571 & 87,433 & 7,107 \\
\hline 103 & Acetate (pH 4.0) & 4 & 0.10 & 88 & 0.275 & 19 & 8 \\
\hline 105 & Acetate $(\mathrm{pH} 4.0)$ & 4 & 0.10 & 94 & 0.294 & 85 & 21 \\
\hline 106 & Acetate $(\mathrm{pH} 4.0)$ & 4 & 0.10 & 105 & 0.275 & 309 & 116 \\
\hline 107 & Acetate (pH 4.0) & 4 & 0.10 & 146 & 0.279 & 93,745 & 12,116 \\
\hline 108 & Acetate $(\mathrm{pH} 4.0)$ & 4 & 0.10 & 214 & 0.334 & 136,424 & 3,167 \\
\hline $\begin{array}{l}\text { Negative Control } \\
\text { (untreated cells) }\end{array}$ & & & & & & 81 & 5 \\
\hline MC3-Luc-mRNA & & & & & & $1,320,533$ & 105,967 \\
\hline
\end{tabular}




\section{Luminescence Expression In Vivo}

Table S2. Quantification of Luminescence Expression In Vivo

\begin{tabular}{|c|c|c|c|c|c|c|c|c|c|}
\hline \multirow[b]{2}{*}{ IAJD } & \multirow{2}{*}{$\underset{(\mathrm{mg} / \mathrm{mL})}{\mathrm{C}_{\text {IAJD }}}$} & \multirow{2}{*}{$\begin{array}{l}\text { C }_{\text {Luc-mRNA }} \\
(\mathrm{mg} / \mathrm{mL})\end{array}$} & \multicolumn{2}{|c|}{ pH } & \multirow{2}{*}{$\begin{array}{c}\text { Size } \\
(\mathrm{d}, \mathbf{n m})\end{array}$} & \multirow[b]{2}{*}{ PDI } & \multirow{2}{*}{$\begin{array}{c}\mathbf{T} \\
(\mathbf{h})^{a}\end{array}$} & \multirow{2}{*}{$\begin{array}{c}\text { Total flux } \\
(\mathbf{p} / \mathbf{s})\end{array}$} & \multirow{2}{*}{$\begin{array}{c}\text { Organs } \\
\text { with luminescence }\end{array}$} \\
\hline & & & $\begin{array}{l}\text { Acetate } \\
\text { buffer }\end{array}$ & Sample & & & & & \\
\hline 64 & 4 & 0.10 & 4.0 & 4.53 & 135 & 0.271 & 4 & 0 & -- \\
\hline 65 & 4 & 0.10 & 4.0 & 4.22 & 241 & 0.249 & 4 & 0 & -- \\
\hline 66 & 4 & 0.10 & 4.0 & 4.50 & 165 & 0.320 & 4 & $2.58 \times 10^{7}$ & $\begin{array}{l}\text { Lung (weak), } \\
\text { liver (strong), } \\
\text { spleen (strong) }\end{array}$ \\
\hline 70 & 4 & 0.10 & 4.0 & 4.50 & 205 & 0.438 & 5 & $6.62 \times 10^{6}$ & $\begin{array}{l}\text { Lung (strong), } \\
\text { spleen (weak) }\end{array}$ \\
\hline 71 & 4 & 0.10 & 4.0 & 4.39 & 237 & 0.451 & 5 & $3.79 \times 10^{7}$ & $\begin{array}{l}\text { Lung (weak), } \\
\text { liver (weak), } \\
\text { spleen (strong) }\end{array}$ \\
\hline 74 & 4 & 0.10 & 4.0 & 4.46 & 180 & 0.317 & 5 & $1.71 \times 10^{7}$ & $\begin{array}{l}\text { Lung (weak), } \\
\text { liver (weak), } \\
\text { spleen (strong) }\end{array}$ \\
\hline 75 & 4 & 0.10 & 4.0 & 4.62 & 235 & 0.328 & 5 & $3.37 \times 10^{7}$ & $\begin{array}{l}\text { Lung (weak), } \\
\text { liver (weak), } \\
\text { spleen (strong) }\end{array}$ \\
\hline 76 & 4 & 0.10 & 4.0 & 4.47 & 78 & 0.287 & 5 & $7.81 \times 10^{7}$ & $\begin{array}{l}\text { Lung (weak), } \\
\text { liver (weak), } \\
\text { spleen (strong) }\end{array}$ \\
\hline 77 & 4 & 0.10 & 4.0 & 4.50 & 110 & 0.267 & 5 & $2.44 \times 10^{6}$ & $\begin{array}{l}\text { Lung (weak), } \\
\text { liver (weak), } \\
\text { spleen (strong) }\end{array}$ \\
\hline 78 & 4 & 0.10 & 4.0 & 4.46 & 629 & 1.000 & 5 & $1.12 \times 10^{5}$ & $\begin{array}{l}\text { Lung (strong), } \\
\text { spleen (weak) }\end{array}$ \\
\hline 79 & 4 & 0.10 & 4.0 & 4.43 & 352 & 0.763 & 6 & $1.34 \times 10^{7}$ & $\begin{array}{l}\text { Lung (weak), } \\
\text { liver (weak), } \\
\text { spleen (strong) }\end{array}$ \\
\hline 81 & 4 & 0.10 & 4.0 & 4.38 & 111 & 0.287 & 6 & $2.32 \times 10^{7}$ & $\begin{array}{l}\text { Lung (weak), } \\
\text { liver (strong), } \\
\text { spleen (weak) }\end{array}$ \\
\hline 82 & 4 & 0.10 & 4.0 & 4.26 & 162 & 0.144 & 5 & $1.62 \times 10^{6}$ & Spleen (strong) \\
\hline 83 & 4 & 0.10 & 4.0 & 4.31 & 143 & 0.430 & 5 & $7.11 \times 10^{7}$ & $\begin{array}{l}\text { Lung (weak), } \\
\text { liver (weak), } \\
\text { spleen (strong) }\end{array}$ \\
\hline 84 & 4 & 0.10 & 4.0 & 4.44 & 171 & 0.303 & 5 & $6.89 \times 10^{5}$ & $\begin{array}{l}\text { Lung (weak), } \\
\text { liver (weak), } \\
\text { spleen (strong) }\end{array}$ \\
\hline 85 & 4 & 0.10 & 4.0 & 4.44 & 102 & 0.250 & 5 & $2.87 \times 10^{6}$ & $\begin{array}{l}\text { Lung (weak), } \\
\text { liver (weak), } \\
\text { spleen (strong) }\end{array}$ \\
\hline 86 & 4 & 0.10 & 4.0 & 4.39 & 91 & 0.234 & 5 & $4.73 \times 10^{7}$ & $\begin{array}{l}\text { Lung (weak), } \\
\text { liver (strong), } \\
\text { spleen (weak) }\end{array}$ \\
\hline 87 & 4 & 0.10 & 4.0 & 4.47 & 146 & 0.486 & 6 & $3.24 \times 10^{7}$ & $\begin{array}{l}\text { Lung (weak), } \\
\text { liver (weak), } \\
\text { spleen (strong) }\end{array}$ \\
\hline 88 & 4 & 0.10 & 4.0 & 4.55 & 100 & 0.342 & 6 & $2.34 \times 10^{6}$ & $\begin{array}{l}\text { Lung (weak), } \\
\text { liver (weak), }\end{array}$ \\
\hline
\end{tabular}




\begin{tabular}{|c|c|c|c|c|c|c|c|c|c|}
\hline & & & & & & & & & spleen (strong) \\
\hline 89 & 4 & 0.10 & 4.0 & 4.45 & 149 & 0.467 & 6 & $5.92 \times 10^{7}$ & $\begin{array}{l}\text { Lung (weak), } \\
\text { liver (weak), } \\
\text { spleen (strong) }\end{array}$ \\
\hline 91 & 4 & 0.10 & 4.0 & 4.44 & 188 & 0.498 & 6 & $9.94 \times 10^{6}$ & $\begin{array}{l}\text { Lung (weak), } \\
\text { liver (weak), } \\
\text { spleen (strong) }\end{array}$ \\
\hline 95 & 4 & 0.10 & 4.0 & 4.38 & 105 & 0.352 & 6 & $6.61 \times 10^{7}$ & $\begin{array}{l}\text { Lung (weak), } \\
\text { liver (weak), } \\
\text { spleen (strong) }\end{array}$ \\
\hline 96 & 4 & 0.10 & 4.0 & 4.52 & 139 & 0.402 & 5 & $4.79 \times 10^{7}$ & $\begin{array}{l}\text { Lung (weak), } \\
\text { liver (weak), } \\
\text { spleen (strong) }\end{array}$ \\
\hline 97 & 4 & 0.10 & 4.0 & 4.42 & 204 & 0.482 & 5 & $5.89 \times 10^{7}$ & $\begin{array}{l}\text { Lung (weak), } \\
\text { liver (weak), } \\
\text { spleen (strong) }\end{array}$ \\
\hline 98 & 4 & 0.10 & 4.0 & 4.35 & 187 & 0.221 & 6 & $2.06 \times 10^{6}$ & $\begin{array}{l}\text { Lung (weak), } \\
\text { liver (weak), } \\
\text { spleen (strong) }\end{array}$ \\
\hline 99 & 4 & 0.10 & 4.0 & 4.32 & 277 & 0.571 & 6 & $4.49 \times 10^{6}$ & $\begin{array}{l}\text { Lung (weak), } \\
\text { liver (weak), } \\
\text { spleen (strong) }\end{array}$ \\
\hline 103 & 4 & 0.10 & 4.0 & 4.58 & 88 & 0.275 & 6 & $1.70 \times 10^{6}$ & $\begin{array}{l}\text { Lung (strong), } \\
\text { spleen (weak) }\end{array}$ \\
\hline 105 & 4 & 0.10 & 4.0 & 4.42 & 94 & 0.294 & 6 & $4.74 \times 10^{7}$ & $\begin{array}{l}\text { Lung (weak), } \\
\text { liver (strong), } \\
\text { spleen (weak) }\end{array}$ \\
\hline 106 & 4 & 0.10 & 4.0 & 4.41 & 105 & 0.275 & 6 & $3.48 \times 10^{7}$ & $\begin{array}{l}\text { Lung (weak), } \\
\text { liver (weak), } \\
\text { spleen (strong) }\end{array}$ \\
\hline 107 & 4 & 0.10 & 4.0 & 4.42 & 146 & 0.279 & 6 & $2.19 \times 10^{7}$ & $\begin{array}{l}\text { Lung (weak), } \\
\text { liver (weak), } \\
\text { spleen (strong) }\end{array}$ \\
\hline 108 & 4 & 0.10 & 4.0 & 4.54 & 214 & 0.334 & 6 & $9.66 \times 10^{6}$ & $\begin{array}{l}\text { Lung (strong), } \\
\text { spleen (weak) }\end{array}$ \\
\hline
\end{tabular}

a. Time from Luc-mRNA-IAJD injection to the imaging of mice on the IVIS imaging system.

b. Organs showing luminescence indicated the expression of luciferase protein in the corresponding organs. Strong meant the luminescence intensity was relatively high in that organ, compared to other organs. Weak meant the luminescence intensity was relatively low in that organ, compared to other organs. 


\section{DLS Data of DNPs Assembled from IAJDs and Luc-mRNA}

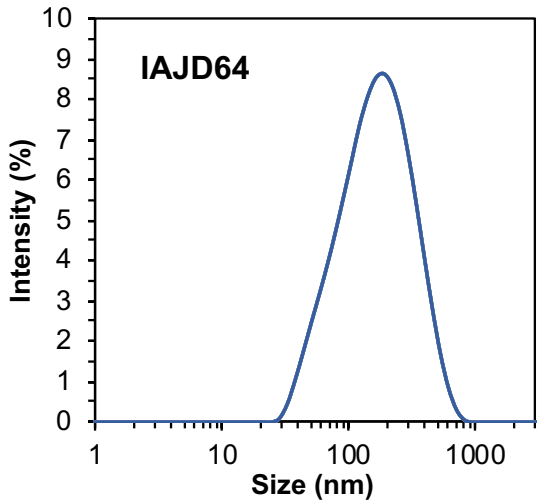

IAJD64 (4.0 mg/mL) + Luc-mRNA (0.10 mg/mL) in acetate buffer $(\mathrm{pH}=4.0)$

Size $(D)=135 \mathrm{~nm}, \mathrm{PDI}=0.271$

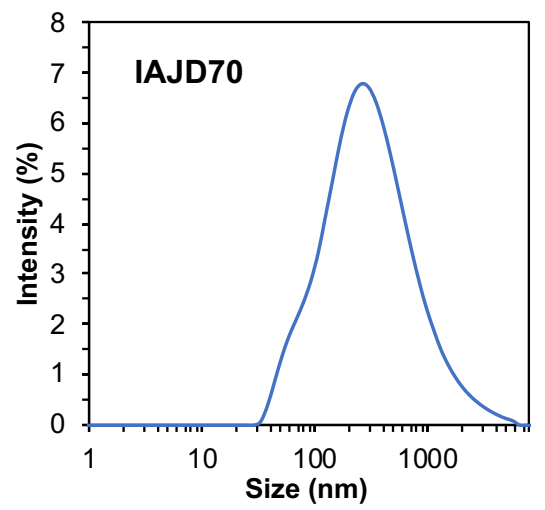

IAJD70 (4.0 mg/mL) + Luc-mRNA $(0.10 \mathrm{mg} / \mathrm{mL})$ in acetate buffer $(\mathrm{pH}=4.0)$

Size $(D)=205 \mathrm{~nm}, \mathrm{PDI}=\mathbf{0 . 4 3 8}$

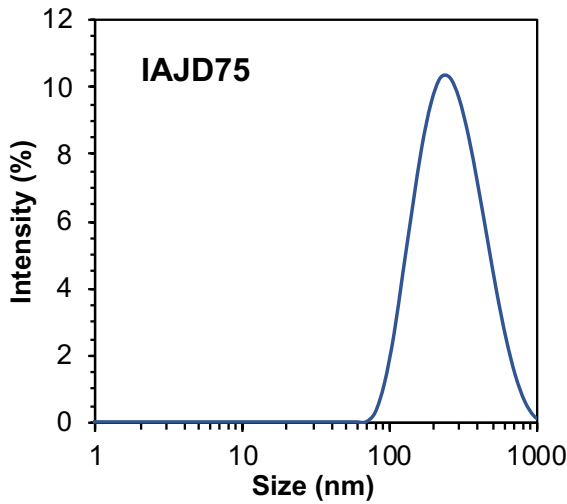

IAJD75 (4.0 mg/mL) + Luc-mRNA (0.10 mg/mL) in acetate buffer $(\mathrm{pH}=4.0)$

Size $(D)=235 \mathrm{~nm}, \mathrm{PDI}=0.328$

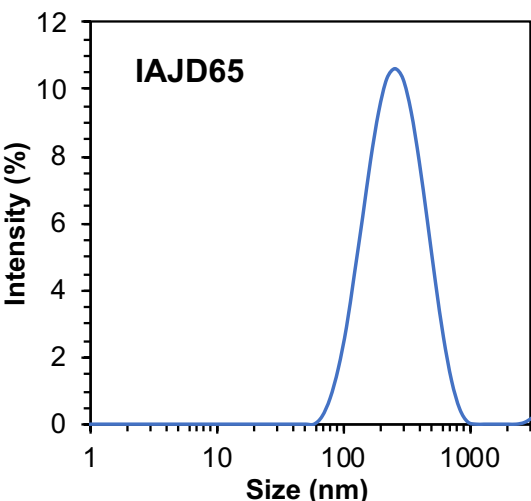

IAJD65 (4.0 mg/mL) + Luc-mRNA (0.10 mg/mL) in acetate buffer $(\mathrm{pH}=4.0)$

Size $(D)=241 \mathrm{~nm}, \mathrm{PDI}=0.249$

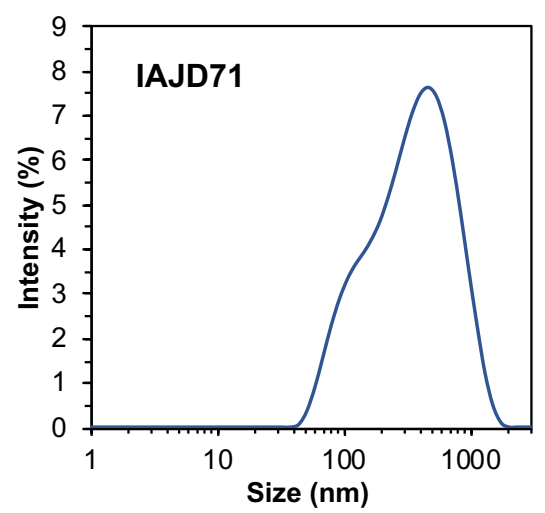

IAJD71 (4.0 mg/mL) + Luc-mRNA (0.10 mg/mL) in acetate buffer $(\mathrm{pH}=4.0)$

Size (D) $=237 \mathrm{~nm}, \mathrm{PDI}=0.451$

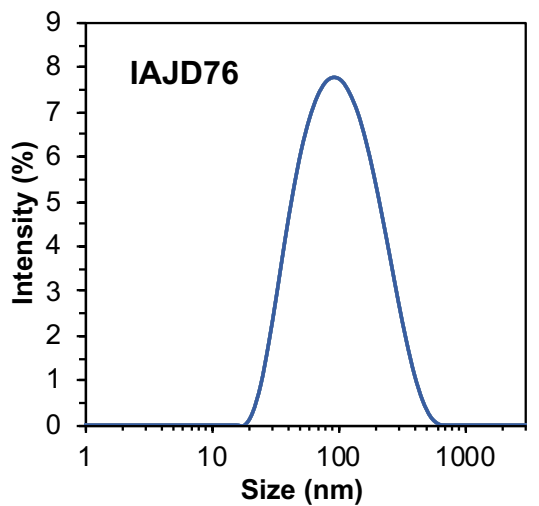

IAJD76 (4.0 mg/mL) + Luc-mRNA (0.10 mg/mL) in acetate buffer $(\mathrm{pH}=4.0)$

Size $(D)=78 \mathrm{~nm}, \mathrm{PDI}=0.287$

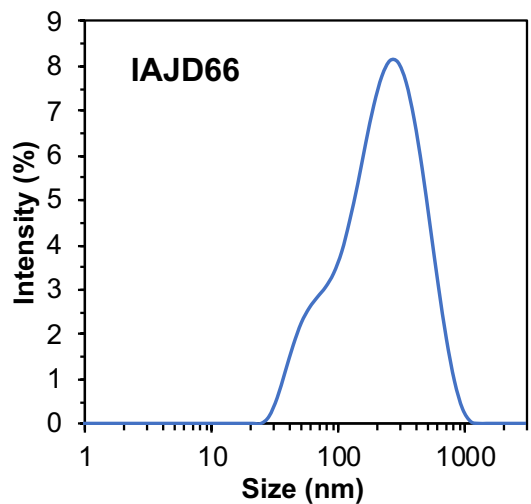

IAJD66 (4.0 mg/mL) + Luc-mRNA (0.10 mg/mL) in acetate buffer $(\mathrm{pH}=4.0)$ Size $(D)=165 \mathrm{~nm}, \mathrm{PDI}=0.320$

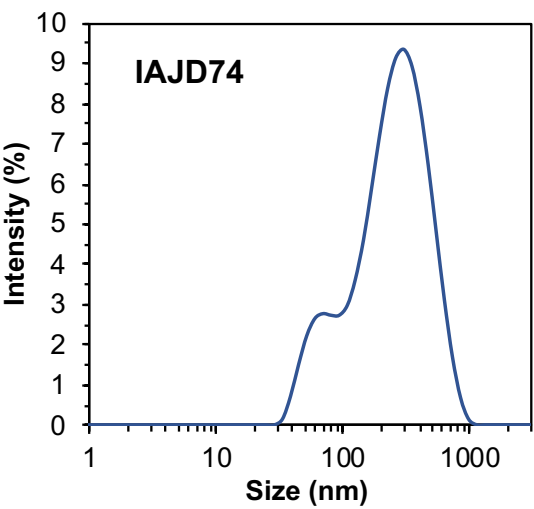

IAJD74 (4.0 mg/mL) + Luc-mRNA $(0.10 \mathrm{mg} / \mathrm{mL})$ in acetate buffer $(\mathrm{pH}=4.0)$

Size (D) = $180 \mathrm{~nm}, \mathrm{PDI}=0.317$

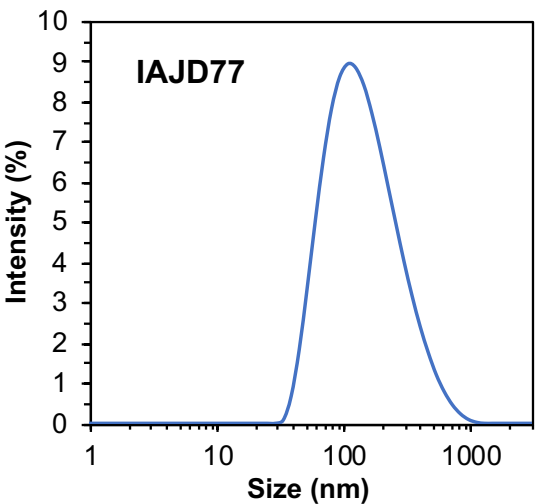

IAJD77 (4.0 mg/mL) + Luc-mRNA (0.10 mg/mL) in acetate buffer $(\mathrm{pH}=4.0)$ Size $(D)=110 \mathrm{~nm}, \mathrm{PDI}=0.249$

Figure S2. DLS data of DNPs assembled from IAJD64-66, 70, 71 and 74-77. 


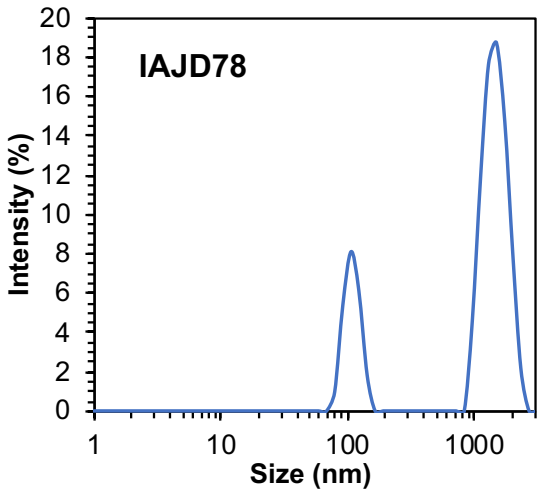

IAJD78 (4.0 mg/mL) + Luc-mRNA (0.10 mg/mL) in acetate buffer $(\mathrm{pH}=4.0)$

Size $(D)=629 \mathrm{~nm}, \mathrm{PDI}=1.000$

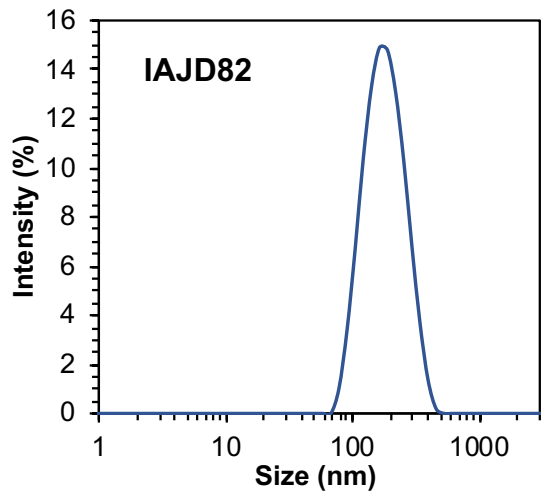

IAJD82 $(4.0 \mathrm{mg} / \mathrm{mL})+$ Luc-mRNA $(0.10 \mathrm{mg} / \mathrm{mL})$ in acetate buffer $(\mathrm{pH}=4.0)$

Size $(D)=162 \mathrm{~nm}, \mathrm{PDI}=0.144$

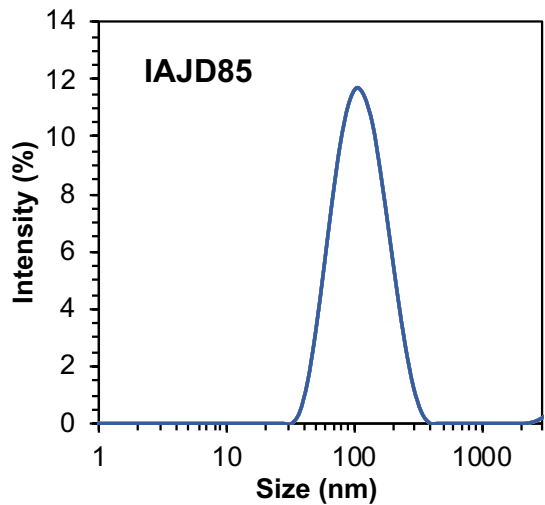

IAJD85 $(4.0 \mathrm{mg} / \mathrm{mL})+$ Luc-mRNA $(0.10 \mathrm{mg} / \mathrm{mL})$ in acetate buffer $(\mathrm{pH}=4.0)$ Size $(D)=102 \mathrm{~nm}, \mathrm{PDI}=0.250$

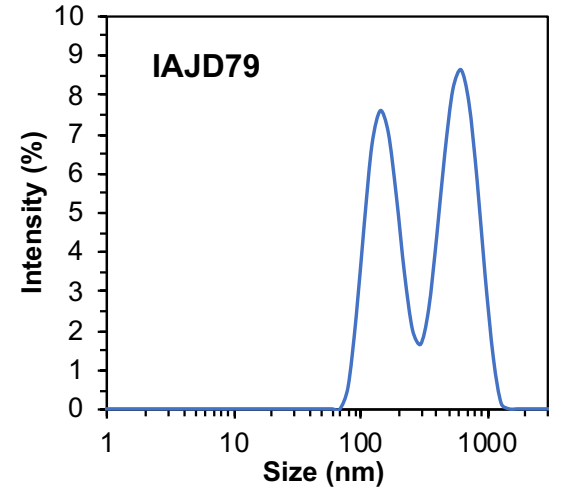

IAJD79 $(4.0 \mathrm{mg} / \mathrm{mL})+$ Luc-mRNA $(0.10 \mathrm{mg} / \mathrm{mL})$ in acetate buffer $(\mathrm{pH}=4.0)$

Size $(D)=352 \mathrm{~nm}, \mathrm{PDI}=0.736$

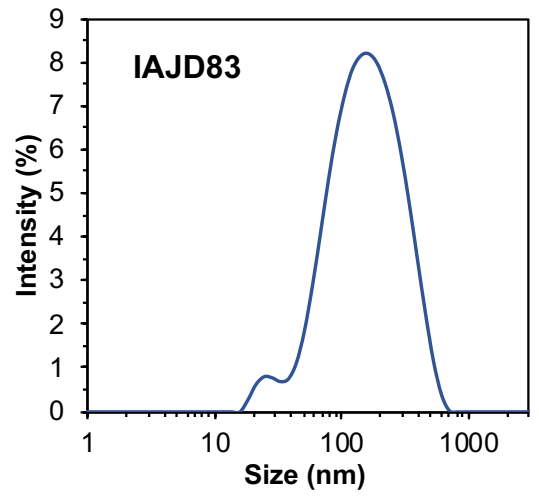

IAJD83 $(4.0 \mathrm{mg} / \mathrm{mL})+$ Luc-mRNA $(0.10 \mathrm{mg} / \mathrm{mL})$ in acetate buffer $(\mathrm{pH}=4.0)$

Size $(D)=143 \mathrm{~nm}, \mathrm{PDI}=0.430$

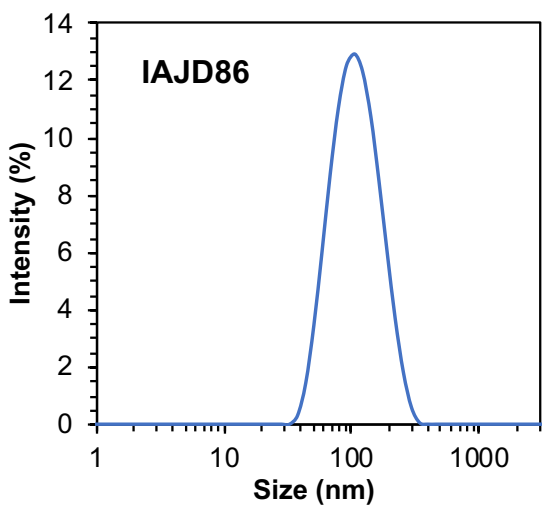

IAJD86 $(4.0 \mathrm{mg} / \mathrm{mL})+$ Luc-mRNA $(0.10 \mathrm{mg} / \mathrm{mL})$ in acetate buffer $(\mathrm{pH}=4.0)$

Size $(D)=91 \mathrm{~nm}, \mathrm{PDI}=0.234$

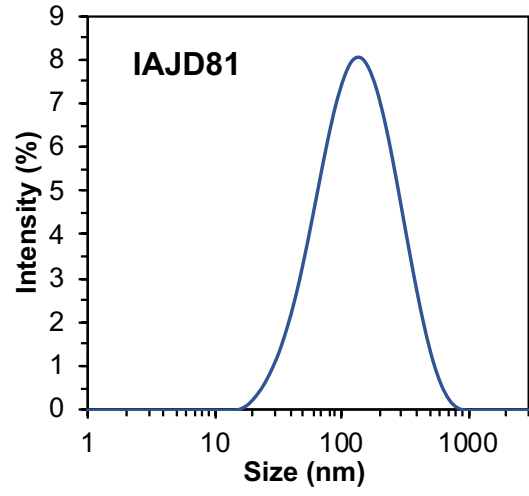

IAJD81 $(4.0 \mathrm{mg} / \mathrm{mL})+$ Luc-mRNA $(0.10 \mathrm{mg} / \mathrm{mL})$ in acetate buffer $(\mathrm{pH}=4.0)$

Size $(D)=111 \mathrm{~nm}, \mathrm{PDI}=0.287$

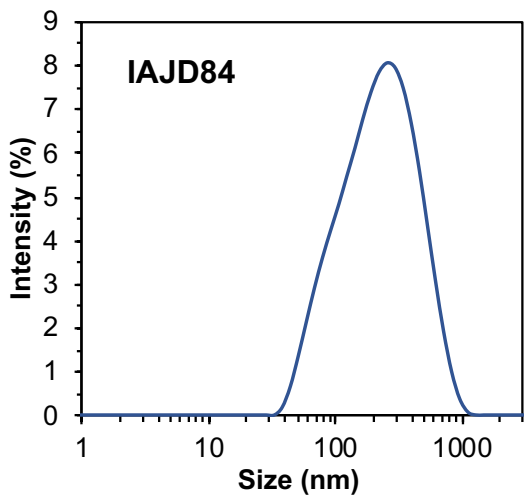

IAJD84 $(4.0 \mathrm{mg} / \mathrm{mL})+$ Luc-mRNA $(0.10 \mathrm{mg} / \mathrm{mL})$ in acetate buffer $(\mathrm{pH}=4.0)$

Size $(D)=171 \mathrm{~nm}, \mathrm{PDI}=0.303$

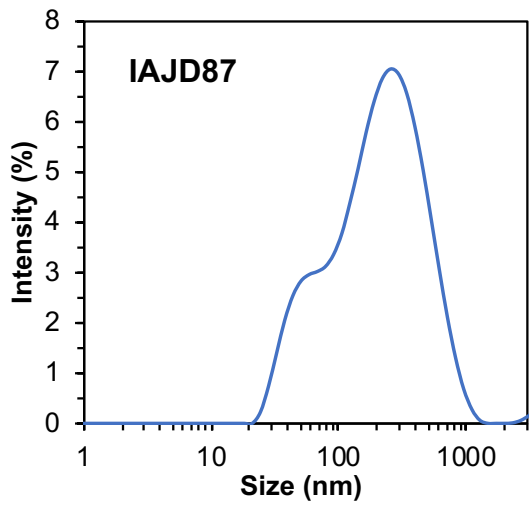

IAJD87 $(4.0 \mathrm{mg} / \mathrm{mL})+$ Luc-mRNA $(0.10 \mathrm{mg} / \mathrm{mL})$ in acetate buffer $(\mathrm{pH}=4.0)$

Size $(D)=146 \mathrm{~nm}, \mathrm{PDI}=0.486$

Figure S3. DLS data of DNPs assembled from IAJD78, 79 and 81-87. 


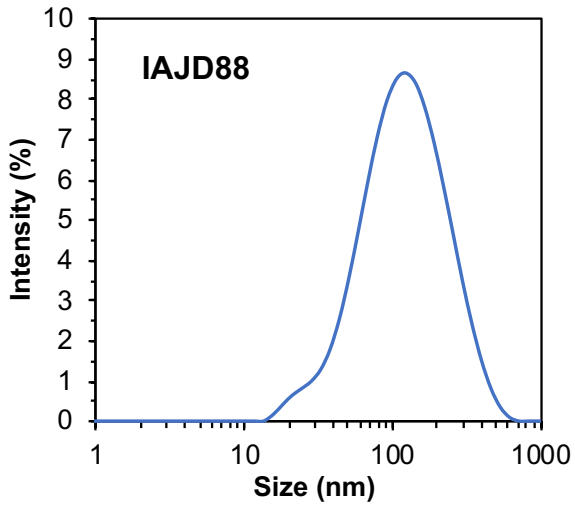

IAJD88 (4.0 mg/mL) + Luc-mRNA (0.10 mg/mL) in acetate buffer $(\mathrm{pH}=4.0)$

Size $(D)=100 \mathrm{~nm}, \mathrm{PDI}=0.342$

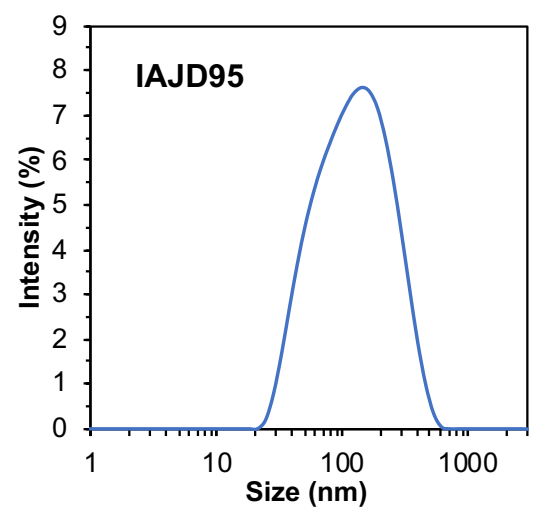

IAJD95 $(4.0 \mathrm{mg} / \mathrm{mL})+$ Luc-mRNA $(0.10 \mathrm{mg} / \mathrm{mL})$ in acetate buffer $(\mathrm{pH}=4.0)$

Size $(D)=105 \mathrm{~nm}, \mathrm{PDI}=0.352$

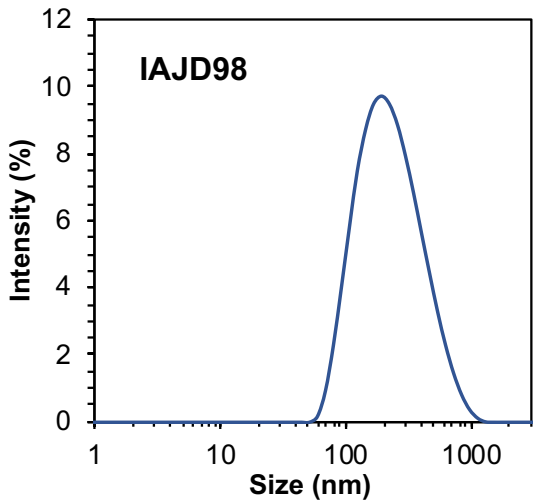

IAJD98 (4.0 mg/mL) + Luc-mRNA (0.10 mg/mL) in acetate buffer $(\mathrm{pH}=4.0)$

Size $(D)=187 \mathrm{~nm}, \mathrm{PDI}=0.221$

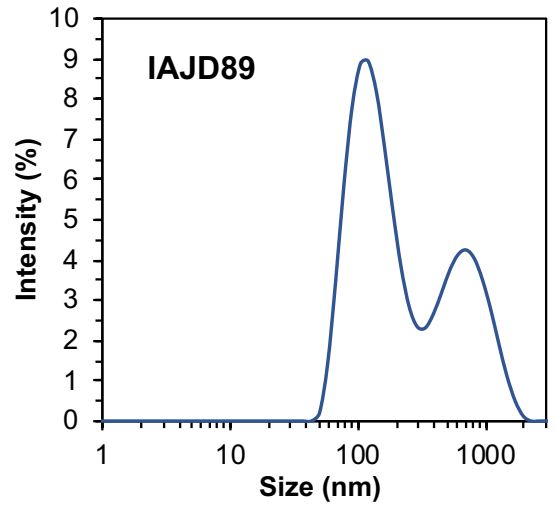

IAJD89 (4.0 mg/mL) + Luc-mRNA (0.10 mg/mL) in acetate buffer $(\mathrm{pH}=4.0)$

Size (D) = $149 \mathrm{~nm}, \mathrm{PDI}=0.467$

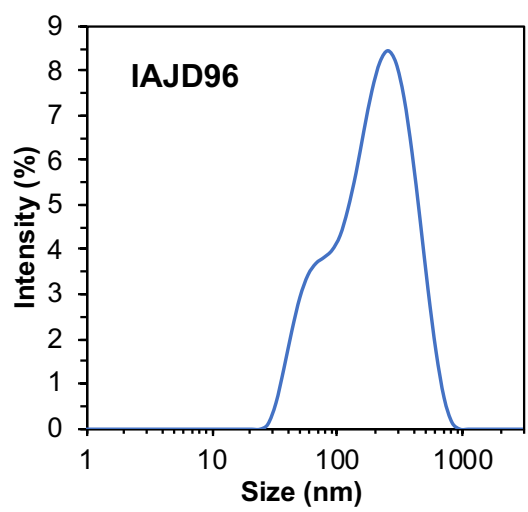

IAJD96 (4.0 mg/mL) + Luc-mRNA (0.10 mg/mL) in acetate buffer $(\mathrm{pH}=4.0)$

Size (D) = $139 \mathrm{~nm}$, PDI = 0.402

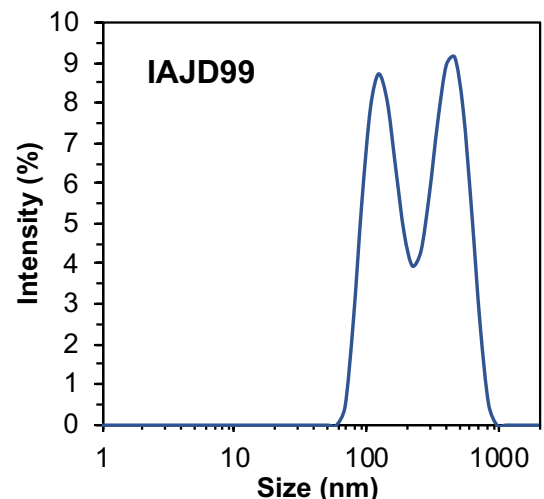

IAJD99 (4.0 mg/mL) + Luc-mRNA $(0.10 \mathrm{mg} / \mathrm{mL})$ in acetate buffer $(\mathrm{pH}=4.0)$

Size (D) = $277 \mathrm{~nm}$, PDI = 0.571

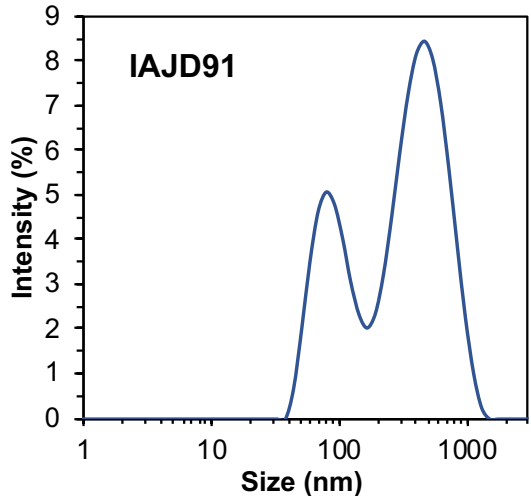

IAJD91 (4.0 mg/mL) + Luc-mRNA (0.10 mg/mL) in acetate buffer $(\mathrm{pH}=4.0)$

Size $(D)=188 \mathrm{~nm}, \mathrm{PDI}=0.498$

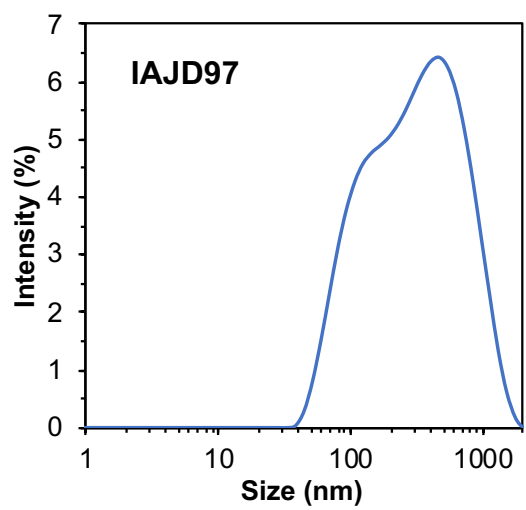

IAJD97 (4.0 mg/mL) + Luc-mRNA (0.10 mg/mL) in acetate buffer $(\mathrm{pH}=4.0)$

Size $(D)=204 \mathrm{~nm}, \mathrm{PDI}=0.482$

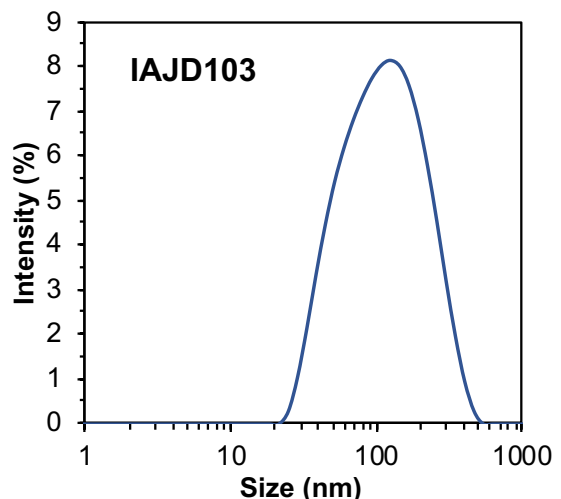

IAJD103 $(4.0 \mathrm{mg} / \mathrm{mL})$ + Luc-mRNA $(0.10 \mathrm{mg} / \mathrm{mL})$ in acetate buffer $(\mathrm{pH}=4.0)$

Size $(\mathrm{D})=\mathbf{8 8} \mathrm{nm}, \mathrm{PDI}=\mathbf{0 . 2 7 5}$

Figure S4. DLS data of DNPs assembled from IAJD88, 89, 91, 95-99 and 103. 


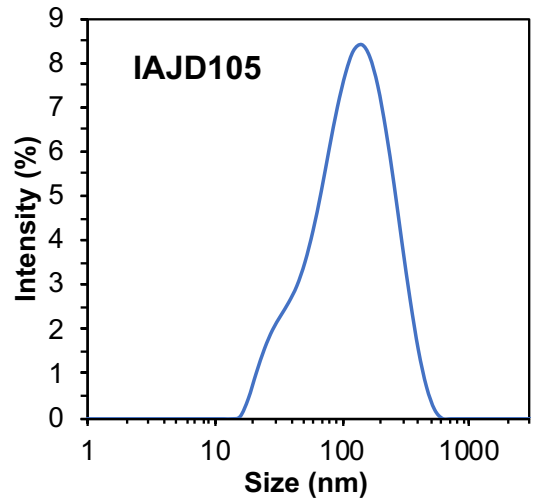

IAJD105 $(4.0 \mathrm{mg} / \mathrm{mL})+$ Luc-mRNA $(0.10 \mathrm{mg} / \mathrm{mL}$ in acetate buffer $(\mathrm{pH}=4.0)$

Size $(D)=94 \mathrm{~nm}, \mathrm{PDI}=0.294$

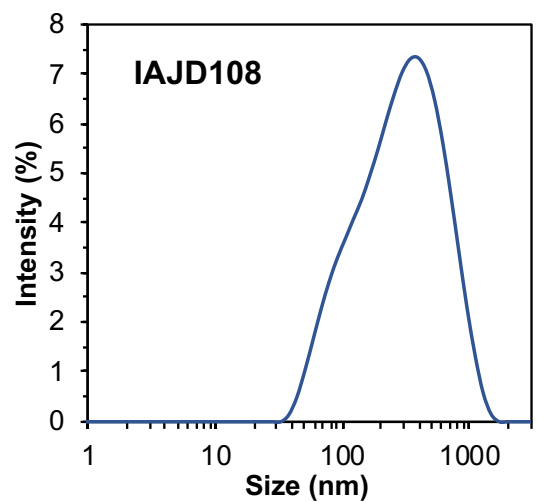

IAJD108 $(4.0 \mathrm{mg} / \mathrm{mL})+$ Luc-mRNA $(0.10 \mathrm{mg} / \mathrm{mL}$ in acetate buffer $(\mathrm{pH}=4.0)$

Size $(D)=214 \mathrm{~nm}, \mathrm{PDI}=0.334$

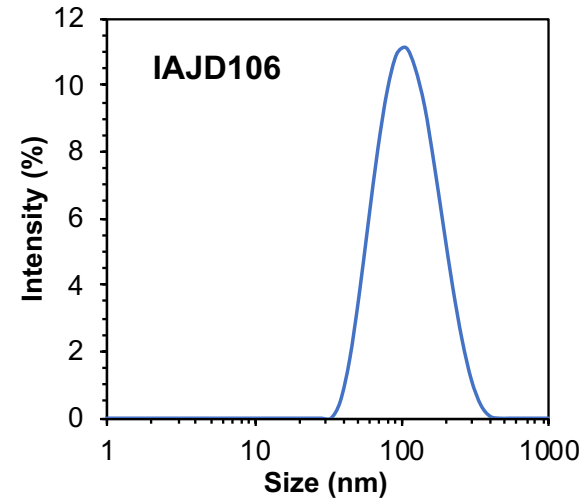

IAJD106 $(4.0 \mathrm{mg} / \mathrm{mL})+$ Luc-mRNA $(0.10 \mathrm{mg} / \mathrm{mL}$ in acetate buffer $(\mathrm{pH}=4.0)$

Size $(D)=105 \mathrm{~nm}, \mathrm{PDI}=\mathbf{0 . 2 7 5}$

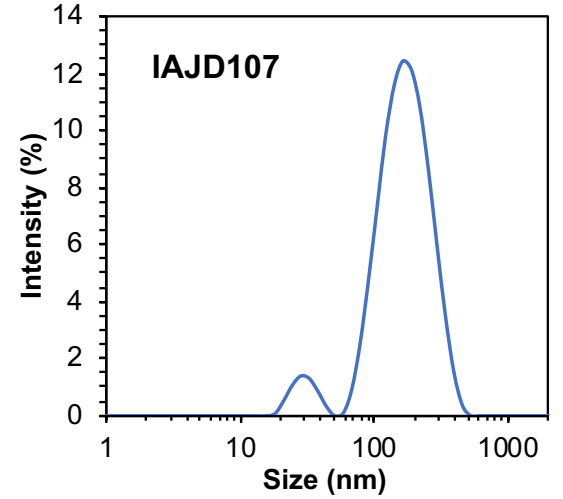

IAJD107 $(4.0 \mathrm{mg} / \mathrm{mL})+$ Luc-mRNA $(0.10 \mathrm{mg} / \mathrm{mL}$ in acetate buffer $(\mathrm{pH}=4.0)$

Size $(D)=146 \mathrm{~nm}, \mathrm{PDI}=0.279$

Figure S5. DLS data of DNPs assembled from IAJD105-108. 


\section{Stability of DNPs by DLS}

Table S3. Stability of DNPs Determined by DLS ${ }^{a}$ at $5{ }^{\circ} \mathrm{C}$ After Different Periods of Time

\begin{tabular}{|c|c|c|c|c|c|c|c|c|c|}
\hline \multirow{2}{*}{$\begin{array}{c}\text { IAJD } \\
\text { (storage time) }\end{array}$} & \multirow{2}{*}{$\underset{(\mathrm{mg} / \mathrm{mL})}{\mathrm{C}_{\mathrm{IAJD}}}$} & \multirow{2}{*}{$\begin{array}{l}\text { CLuc-mRNA } \\
(\mathrm{mg} / \mathrm{mL})\end{array}$} & \multicolumn{2}{|c|}{ pH } & \multirow{2}{*}{$\begin{array}{c}\text { Original } \\
\text { size } \\
(\mathrm{d}, \mathrm{nm})\end{array}$} & \multirow[b]{2}{*}{ PDI } & \multirow{2}{*}{$\begin{array}{c}\text { Size } \\
(\mathbf{d}, \mathbf{n m})\end{array}$} & \multirow[b]{2}{*}{ PDI } & \multirow{2}{*}{$\begin{array}{c}\text { Ranking } \\
\text { of } \\
\text { stability }^{c}\end{array}$} \\
\hline & & & $\begin{array}{l}\text { Acetate } \\
\text { buffer }\end{array}$ & Sample & & & & & \\
\hline 64 (48 days) & 4.0 & 0.1 & 4.00 & 4.53 & $135(\mathrm{U})^{b}$ & 0.271 & $184(\mathrm{U})$ & 0.195 & Excellent \\
\hline 65 (48 days) & 4.0 & 0.1 & 4.00 & 4.22 & 241(U) & 0.249 & 322 (B) & 0.257 & Good \\
\hline 66 (48 days) & 4.0 & 0.1 & 4.00 & 4.50 & $165(\mathrm{U})$ & 0.320 & $192(\mathrm{U})$ & 0.239 & Excellent \\
\hline 70 (34 days) & 4.0 & 0.1 & 4.00 & 4.50 & $205(\mathrm{U})$ & 0.438 & $237(\mathrm{U})$ & 0.400 & Excellent \\
\hline 71 (47 days) & 4.0 & 0.1 & 4.00 & 4.39 & 237 (B) & 0.451 & 253 (B) & 0.311 & Excellent \\
\hline 74 (34 days) & 4.0 & 0.1 & 4.00 & 4.46 & 180 (B) & 0.317 & 204 (U) & 0.242 & Excellent \\
\hline 75 (47 days) & 4.0 & 0.1 & 4.00 & 4.62 & $235(\mathrm{U})$ & 0.328 & $253(\mathrm{U})$ & 0.295 & Excellent \\
\hline 76 (28 days) & 4.0 & 0.1 & 4.00 & 4.47 & $78(\mathrm{U})$ & 0.287 & $95(\mathrm{U})$ & 0.320 & Excellent \\
\hline 77 (41 days) & 4.0 & 0.1 & 4.00 & 4.50 & $110(\mathrm{U})$ & 0.267 & $117(\mathrm{U})$ & 0.303 & Excellent \\
\hline 78 (41 days) & 4.0 & 0.1 & 4.00 & 4.46 & $629(\mathrm{~B})$ & 1.000 & 343 (B) & 0.581 & Not Stable \\
\hline 79 (41 days) & 4.0 & 0.1 & 4.00 & 4.43 & $352(\mathrm{M})$ & 0.763 & $328(\mathrm{M})$ & 0.658 & Good \\
\hline 81 (41 days) & 4.0 & 0.1 & 4.00 & 4.38 & $111(\mathrm{U})$ & 0.287 & $121(\mathrm{U})$ & 0.258 & Excellent \\
\hline 82 (14 days) & 4.0 & 0.1 & 4.00 & 4.26 & $162(\mathrm{U})$ & 0.144 & $212(\mathrm{U})$ & 0.192 & Excellent \\
\hline 83 (14 days) & 4.0 & 0.1 & 4.00 & 4.31 & 143 (B) & 0.430 & 144 (B) & 0.328 & Excellent \\
\hline 84 (14 days) & 4.0 & 0.1 & 4.00 & 4.44 & $171(\mathrm{U})$ & 0.303 & $192(\mathrm{U})$ & 0.226 & Excellent \\
\hline 85 (14 days) & 4.0 & 0.1 & 4.00 & 4.44 & $102(\mathrm{U})$ & 0.250 & $119(\mathrm{U})$ & 0.247 & Excellent \\
\hline 86 (14 days) & 4.0 & 0.1 & 4.00 & 4.39 & $91(\mathrm{U})$ & 0.234 & $104(\mathrm{U})$ & 0.267 & Excellent \\
\hline 87 (14 days) & 4.0 & 0.1 & 4.00 & 4.47 & 146 (B) & 0.486 & 168 (B) & 0.465 & Excellent \\
\hline 88 (14 days) & 4.0 & 0.1 & 4.00 & 4.55 & $100(\mathrm{U})$ & 0.342 & $124(\mathrm{U})$ & 0.210 & Excellent \\
\hline 89 (14 days) & 4.0 & 0.1 & 4.00 & 4.45 & 149 (B) & 0.467 & 174 (B) & 0.434 & Excellent \\
\hline 91 (14 days) & 4.0 & 0.1 & 4.00 & 4.44 & 188 (B) & 0.498 & 221 (B) & 0.486 & Excellent \\
\hline 95 (14 days) & 4.0 & 0.1 & 4.00 & 4.38 & 105 (B) & 0.352 & 130 (B) & 0.304 & Excellent \\
\hline 96 (14 days) & 4.0 & 0.1 & 4.00 & 4.52 & 139 (B) & 0.402 & 140 (B) & 0.355 & Excellent \\
\hline 97 (14 days) & 4.0 & 0.1 & 4.00 & 4.42 & 204 (B) & 0.482 & 213 (B) & 0.336 & Excellent \\
\hline 98 (14 days) & 4.0 & 0.1 & 4.00 & 4.35 & $187(\mathrm{U})$ & 0.221 & 185 (U) & 0.248 & Excellent \\
\hline 99 (14 days) & 4.0 & 0.1 & 4.00 & 4.32 & 277 (B) & 0.571 & $221(\mathrm{U})$ & 0.320 & Excellent \\
\hline 103 (14 days) & 4.0 & 0.1 & 4.00 & 4.58 & $88(\mathrm{U})$ & 0.275 & $92(\mathrm{U})$ & 0.283 & Excellent \\
\hline 105 (7 days) & 4.0 & 0.1 & 4.00 & 4.42 & $94(\mathrm{U})$ & 0.294 & $99(\mathrm{U})$ & 0.287 & Excellent \\
\hline 106 (7 days) & 4.0 & 0.1 & 4.00 & 4.41 & $105(\mathrm{U})$ & 0.275 & $103(\mathrm{U})$ & 0.300 & Excellent \\
\hline 107 (7 days) & 4.0 & 0.1 & 4.00 & 4.42 & 146 (B) & 0.279 & 146 (B) & 0.271 & Excellent \\
\hline 108 (7 days) & 4.0 & 0.1 & 4.00 & 4.54 & 214 (B) & 0.334 & 217 (B) & 0.376 & Excellent \\
\hline
\end{tabular}

$\boldsymbol{a}$. All the samples are prepared in acetate buffer. $\boldsymbol{b}$. U: Unimodal size distribution of DLS curve; B: Bimodal size distribution of DLS curve; M: Multimodal size distribution of DLS curve. $c$. Ranking of stability: Excellent (in green color) - the original sizes and distribution remained almost the same after storage; Good - the original sizes and distribution changed slightly (size difference was less than $100 \mathrm{~nm}$ ) after storage or the original size remained almost the same but with multimodal distributions after storage; Not stable - the original sizes and distribution changed obviously (size difference was more than $100 \mathrm{~nm}$ and distribution type of DLS curve changed) after storage. 


\section{9. $\mathbf{p K}_{\mathrm{a}}$ Measurements of Individual IAJD Molecules}

Table S4. $\mathrm{pK}_{\mathrm{a}}$ of Individual IAJD Molecules

\begin{tabular}{cc}
\hline IAJD No. & $\mathbf{p K}_{\mathbf{a}}$ \\
\hline IAJD 64 & 7.06 \\
IAJD 65 & 7.40 \\
IAJD 66 & 6.37 \\
IAJD 70 & 6.44 \\
IAJD 71 & 6.38 \\
IAJD 74 & 6.32 \\
IAJD 75 & 6.22 \\
IAJD 76 & 6.28 \\
IAJD 77 & 6.40 \\
IAJD 78 & 6.46 \\
IAJD 79 & 6.25 \\
IAJD 81 & 6.19 \\
IAJD 82 & 6.18 \\
IAJD 83 & 6.30 \\
IAJD 84 & 6.19 \\
IAJD 85 & 6.21 \\
IAJD 86 & 6.24 \\
IAJD 87 & 6.49 \\
IAJD 88 & 6.28 \\
IAJD 89 & 6.45 \\
IAJD 91 & 6.48 \\
IAJD 95 & 6.33 \\
IAJD 96 & 6.32 \\
IAJD 97 & 6.46 \\
IAJD 98 & 6.25 \\
IAJD 99 & 6.31 \\
IAJD 103 & 6.23 \\
IAJD 105 & 6.50 \\
IAJD 106 & 6.38 \\
IAJD 107 & 6.42 \\
IAJD 108 & 6.59 \\
\hline
\end{tabular}



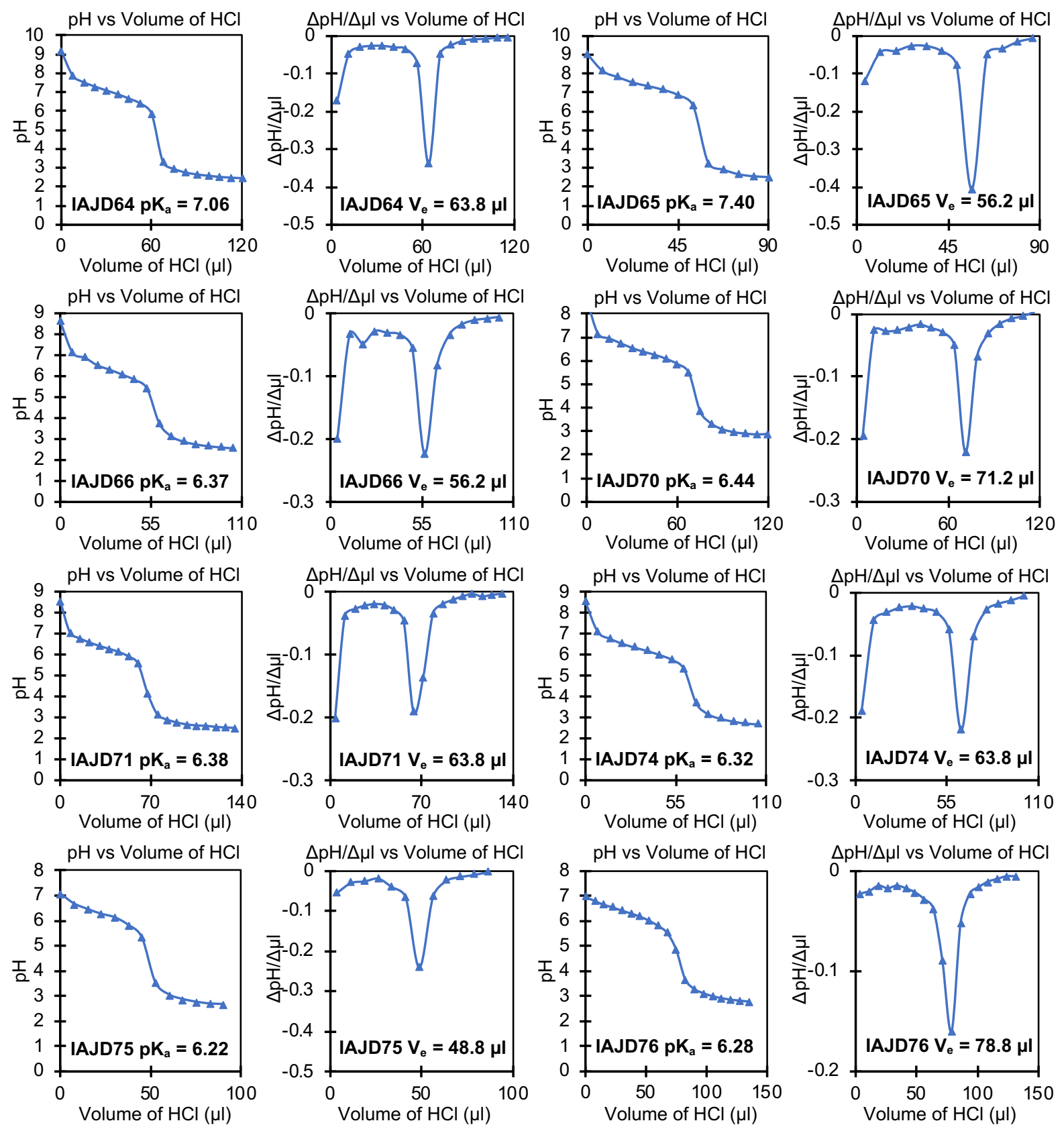

Figure S6. Titration curves showing changes in solution $\mathrm{pH}$ in response to addition of a strong acid for IAJD molecules. 

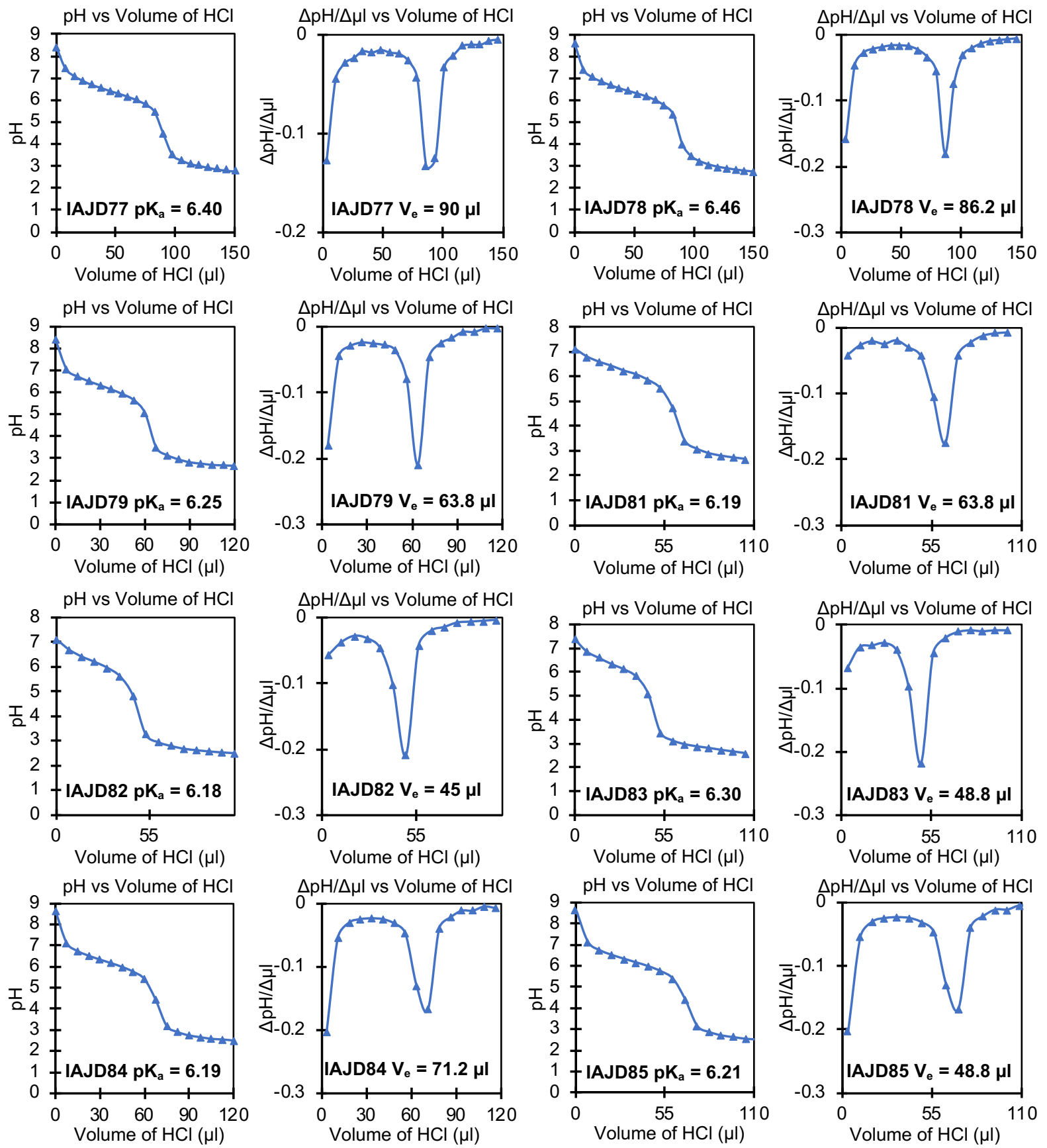

Figure S7. Titration curves showing changes in solution $\mathrm{pH}$ in response to addition of a strong acid for IAJD molecules. 

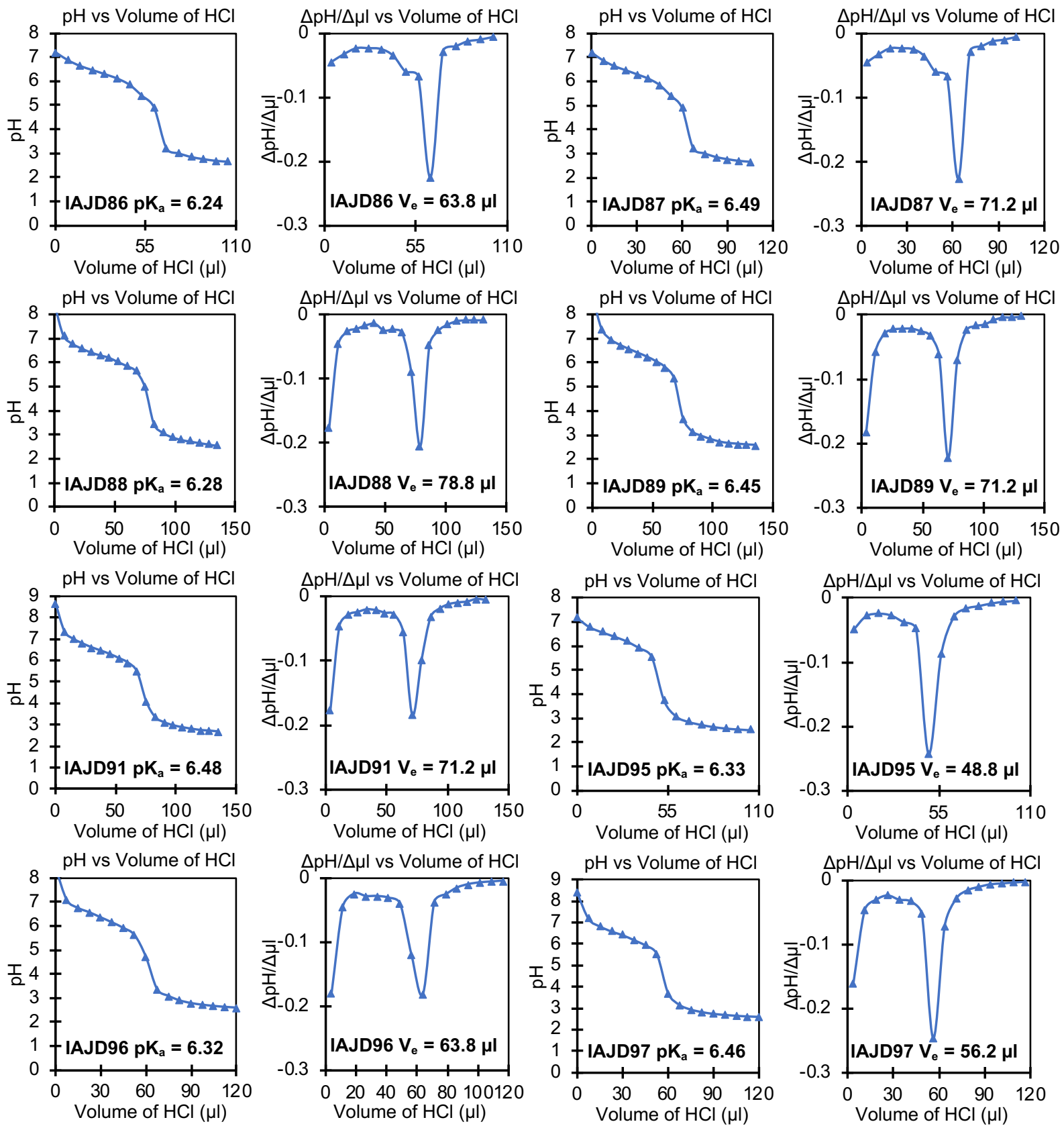

Figure S8. Titration curves showing changes in solution $\mathrm{pH}$ in response to addition of a strong acid for IAJD molecules. 

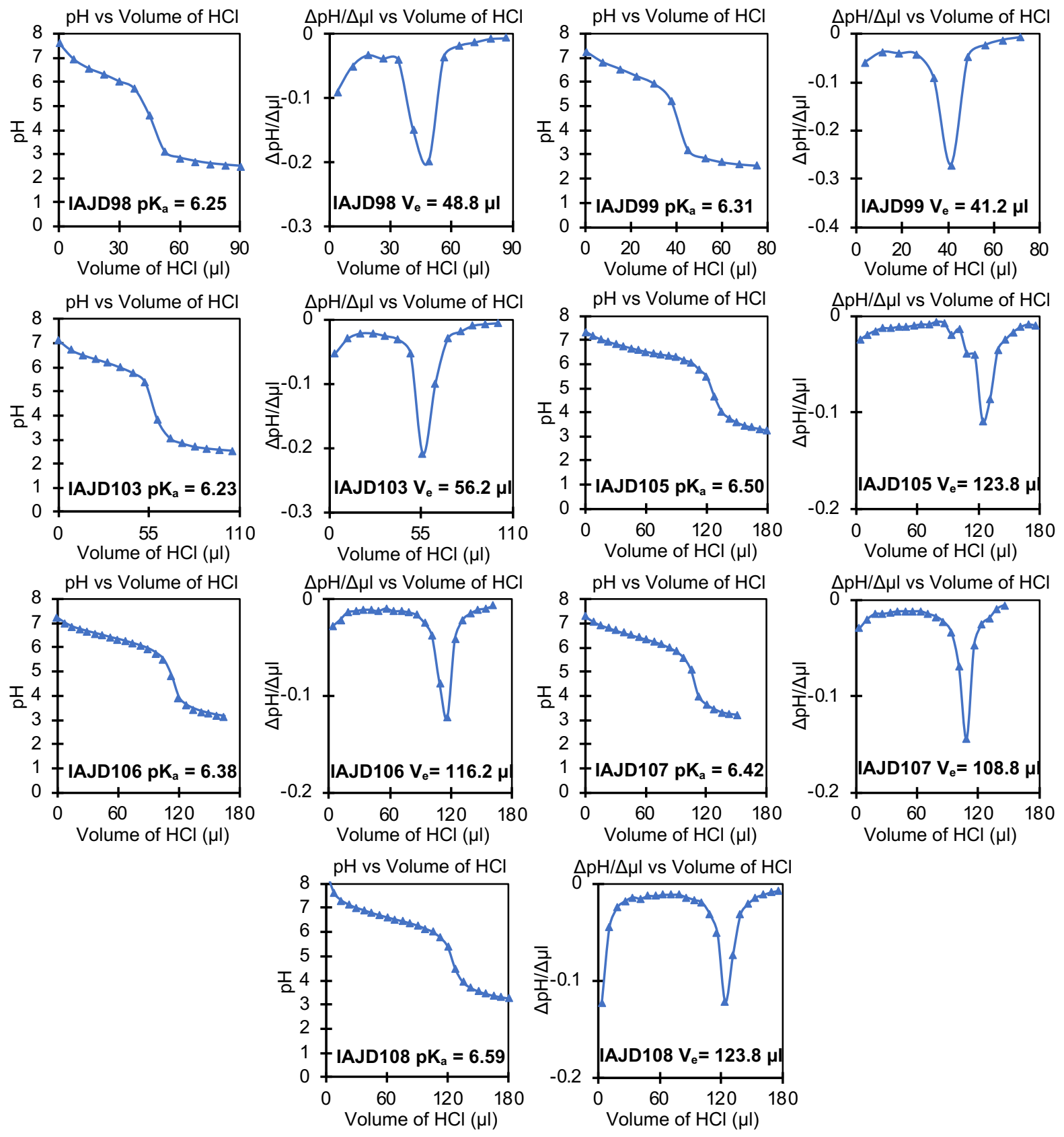

Figure S9. Titration curves showing changes in solution $\mathrm{pH}$ in response to addition of a strong acid for IAJD molecules. 


\section{In Vitro vs In Vivo Efficacy}
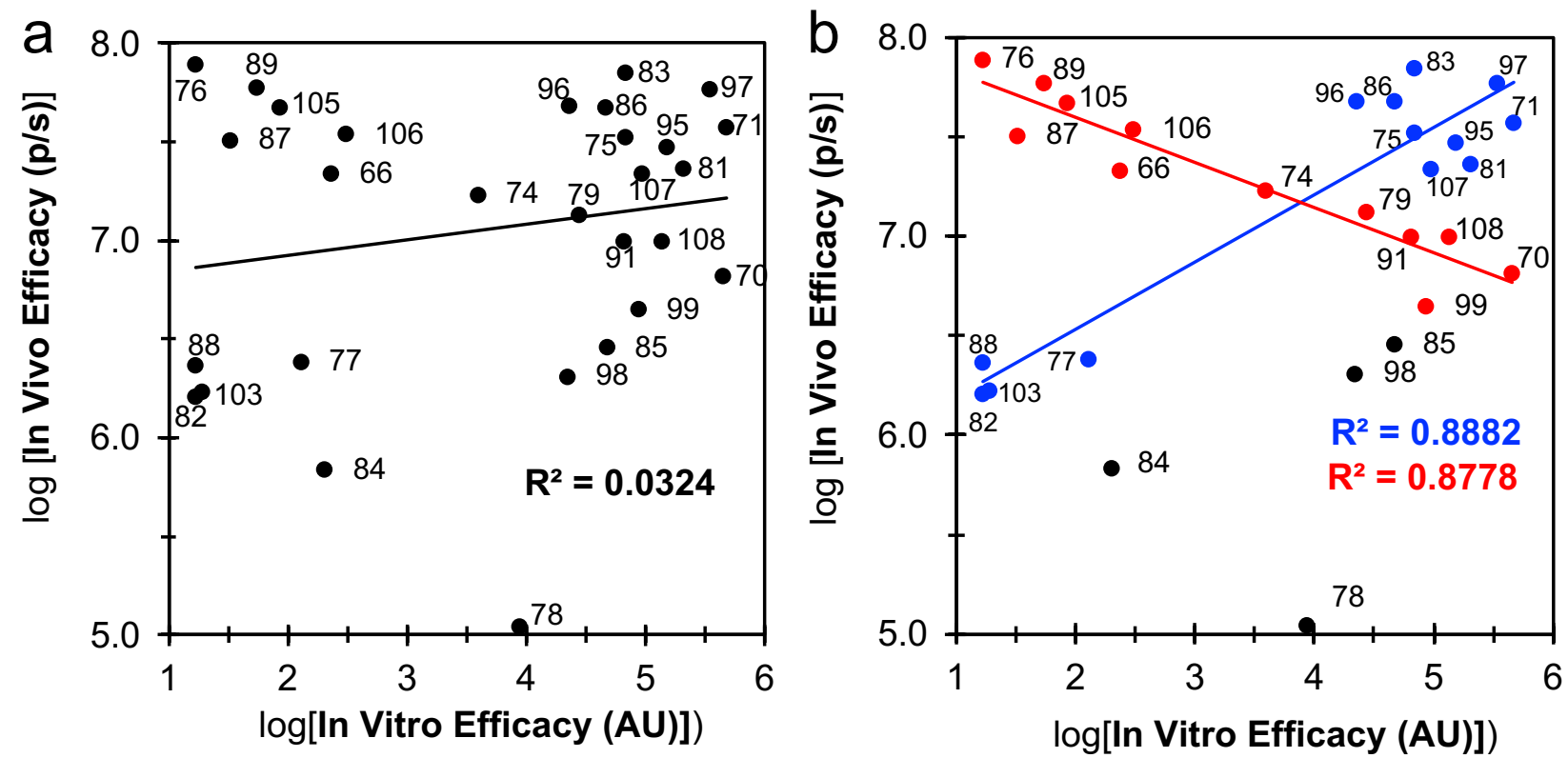

Figure S10. Comparison of in vitro efficacy and in vivo efficacy of DNPs co-assembled from IAJDs and Luc-mRNA. (a) No correlations were found between in vitro and in vivo activities when all data points were considered; (b) positive and negative correlations between in vitro and in vivo activities were found for two different groups of bias selective data points marked in red and in blue respectively (the selection of data points has no scientific base). 


\section{Supporting References}

(1) Moore, J. S.; Stupp, S. I. Room Temperature Polyesterification. Macromolecules 1990, 23, 65-70.

(2) Pardi, N.; Muramatsu, H.; Weissman, D.; Kariko, K. In Vitro Transcription of Long RNA Containing Modified Nucleosides. Methods Mol. Biol. 2013, 969, 29-42.

(3) Buzzacchera, I.; Xiao, Q.; Han, H.; Rahimi, K.; Li, S.; Kostina, N. Y.; Toebes, B. J.; Wilner, S. E.; Möller, M.; Rodriguez-Emmenegger, C.; Baumgart, T.; Wilson, D. A.; Wilson, C. J.; Klein, M. L.; Percec, V. Screening Libraries of Amphiphilic Janus Dendrimers Based on Natural Phenolic Acids to Discover Monodisperse Unilamellar Dendrimersomes. Biomacromolecules 2019, 20, 712-727.

(4) Wang, L.; Partridge, B. E.; Huang, N.; Olsen, J. T.; Sahoo, D.; Zeng, X.; Ungar, G.; Graf, R.; Spiess, H. W.; Percec, V. Extraordinary Acceleration of Cogwheel Helical Self-Organization of Dendronized Perylene Bisimides by the Dendron Sequence Encoding Their Tertiary Structure. J. Am. Chem. Soc. 2020, $142,9525-9536$.

(5) Percec, V.; Wilson, D. A.; Leowanawat, P.; Wilson, C. J.; Hughes, A. D.; Kaucher, M. S.; Hammer, D. A.; Levine, D. H.; Kim, A. J.; Bates, F. S.; Davis, K. P.; Lodge, T. P.; Klein, M. L.; DeVane, R. H.; Aqad, E.; Rosen, B. M.; Argintaru, A. O.; Sienkowska, M. J.; Rissanen, K.; Nummelin, S.; Ropponen, J. Self-Assembly of Janus Dendrimers into Uniform Dendrimersomes and Other Complex Architectures. Science 2010, 328, 1009-1014.

(6) Zhang, D.; Atochina-Vasserman, E. N.; Maurya, D. S.; Huang, N.; Xiao, Q.; Ona, N.; Liu, M.; Shahnawaz, H.; Ni, H.; Kim, K.; Billingsley, M. M.; Pochan, D. J.; Mitchell, M. J.; Weissman, D.; Percec, V. One-Component Multifunctional Sequence-Defined Ionizable Amphiphilic Janus Dendrimer Delivery Systems for mRNA. J. Am. Chem. Soc. 2021, 143, 12315-12327.

(7) Zhang, S.; Sun, H.-J.; Hughes, A. D.; Draghici, B.; Lejnieks, J.; Leowanawat, P.; Bertin, A.; Otero De Leon, L.; Kulikov, O. V.; Chen, Y.; Pochan, D. J.; Heiney, P. A.; Percec, V. “Single-Single” Amphiphilic Janus Dendrimers Self-Assemble into Uniform Dendrimersomes with Predictable Size. ACS Nano 2014, $8,1554-1565$.

(8) Thompson, S.; Hamilton, A. D. Amphiphilic $\alpha$-Helix Mimetics Based on a Benzoylurea Scaffold. Org. Biomol. Chem. 2012, 10, 5780-5782.

(9) Kanth, J. V. B.; Periasamy, M. Selective Reduction of Carboxylic Acids into Alcohols Using Sodium Borohydride and Iodine. J. Org. Chem. 1991, 56, 5964-5965. 